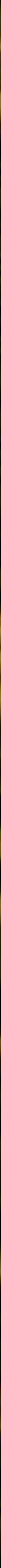





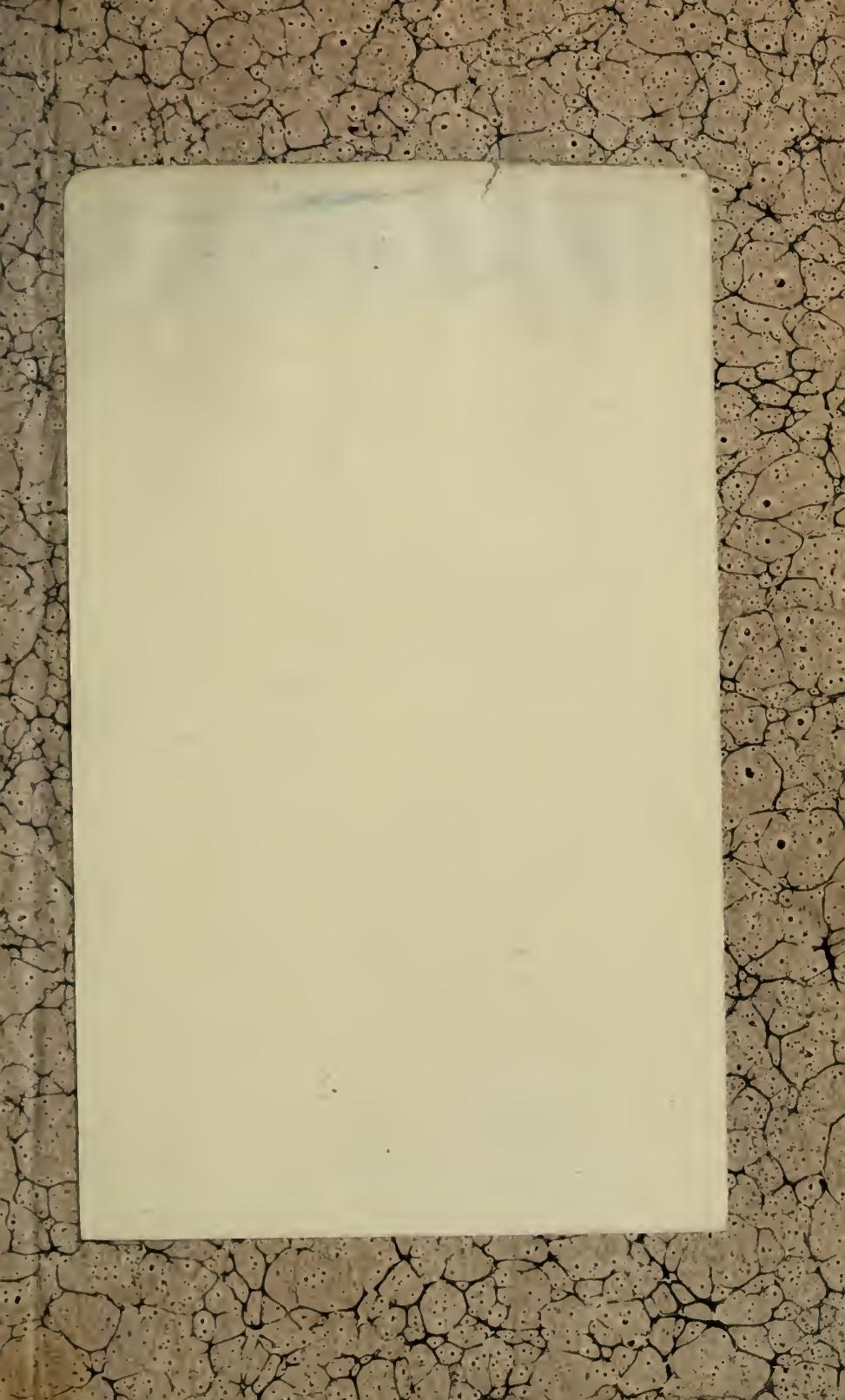


Digitized by the Internet Archive in 2010 with funding from University of Illinois Urbana-Champaign 



\section{SINGULORUM}

\section{GENERUM CURCULIONIIUU}

UNAM ALTERAMVE SPECIEM

ADDITIS ICONIBUS

\section{$\boldsymbol{\Lambda}$ \\ DAVID LABRAM}

A I) NATUIA M DELINEATIS

ILLUSTRAVIT

L. IMIIOFF, Med. Dr.

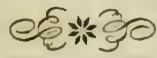

Dic

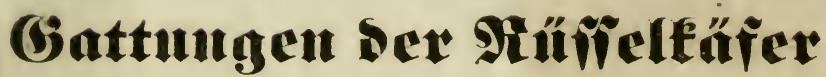

erläutert

durch bildliche Darftellung sinzelner Arten von

Davis $2 a b r a m$.

llach Anlcitung und mit Beffhreibunģen

von

Dr. ?. Imboff.

Bnfel, 1838.

Edmeighaufer'ide Budbanclung. 
Entomologis benevolis fasciculum primum operis offerimus, in quo familiam illam Coleopterorum, maxima et forme et coloris diversitate oculis gratissimam, Curculionides seilicet, tractaturi sumus; idque eo consilio, ut ad horum studium et alios, difficultate huc usque deterritos, via quantum per nos fieri potest munita, invitemus. Constat quidem, ista insecta accuratissime descripta esse in opere: Genera et Species Curculionidum, cum Synonymia hujus familice; a C. J. Schönherr. Iste vero liber quum iconibus plane eareat, et alii ad quos remittit autor vel nimio pretio venales exstent vel iconibus minus perfectis instructi sint, non inutilem nos operam facere existimamus, si, duce illo opere, Curculionidum genera singula depictis una alterave specie latina et germanica lingua illustranda suscipimus. Quæ res ut facilius efficiatur nonnulli Entomologix cultores editorem varia ratione ita adjuverunt, ut fasciculum hunc mox secundus, itemque brevi temporis spatio reliqui justo ordine sint subsecuturi.

Fasciculus unusquisque 8 tabulas icones referentes continebit, quarum explicatio totidem plagulis subsequetur. 
Das etwaz̉ fduvierige Studium einer febr anjicben: Een Funtlie Der Räfer ju erleidhtern uno ju förbern,

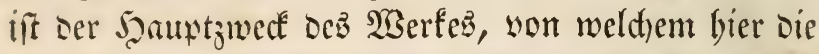
erife sieferung vorliegt. Die Entomologen finden

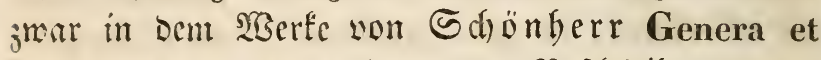
Species Curc. dec. jebr genaue Befdreibungen Der

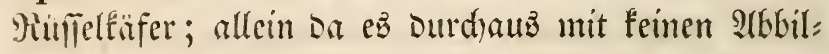
sumgen beyleitet if und in Den, theilo fefr foftbaren Werfen, wornuf ç binweizt, dieje felbift nur zerifreut und jum Theil unvolltommen gegeben find, fo wiro

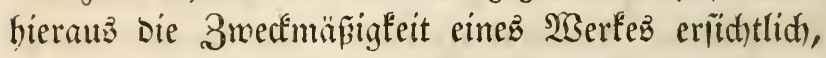
worin foldhe mit möglid)fer Sollfändigfeit und Treue uni in fyftematijdem 3 ufanmenbange geliefert wür: Dent. Dicie Bollfindigteit in Beziebung auf (j)attun: aen foll surd Dab gegenwärtige Unternebmen erreidht wersen, beffen Slufgabe eš fein wird, won jeber (jattung sime soer einige ?(rten getreu nad) Der Siatur afzu= biloen, uno ourdi Befdyreibung in lateinifder uno

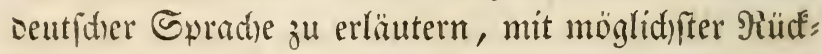
lid)t auf Bas Edionberrid) 23 ert.

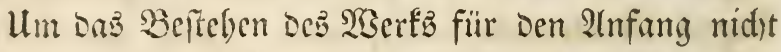
allein won äufern Umftïnoen, alfo aud von Der 3 abl

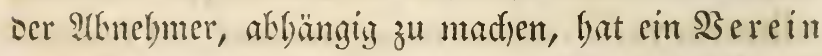
won Freunden Der Entomologie, Den Jeraus: yeler mit den nörbigen Mitteln zu unterftüzen be: fals lofien, fo saf nach Dem erfen bald Dab zucite 5eft und nad) diejen eben fo die folgenden in furzer Seit eridseinen werden.

Gn jeoem Seft weroen auf 8 Blättern Die ?akil: sungen uno auf eben fo vielen bic Bejdreibungen apreben meroen. 


\section{SINGULORUM}

\section{GENERUM CURCULIONIDUM}

UNAM ALTERAMVE SPECIEM

ADDITIS ICONIBUS

A

$D A V I D$ LABRAM

AD NATURAM DELINEATIS

ILLUSTRAVIT

L. IMHOFF, Med. Dr.

PARS 1.

Fascic. $1-10$.

Die

\section{Gattungen Der Mütielfürer}

erläutert

Durch Gildiche Darferlung einzelner arten

(1) 11

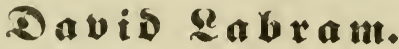

Rach Pfuleitung und mit Befdreifungen

1) 0 !

Dr. 3mborf.

Erpter Sheil.

S.eit $1=10$.

$$
\mathfrak{B} \text { a } \mathfrak{i} \mathfrak{i} \text {, }
$$

Jin Berlag ser Chueighaufer'idien Buकhandung.

1842. 




\section{INDEX PARTIS PRIME (Fascic. 1-10.)}

Antliarhinns Zamiae.

$$
\text { Dregei. }
$$

Ptatymerus Germari.

Arrhenodes dispar.

$$
\text { corniger var. }
$$

(Hormocerus) coronatus.

(Trachelizus) pygmaeus. adustus clavicornis.

(Nemorhinus) duplieatus.

Belopherus militaris.

Belorhynchus curvidens.

Ceocephalus reticulatus.

Riisii.

Cephalobarus macroceplialus.

Brenthus (Ischyromerus) madagasca= riensis.

Eutrachelus Temminckii.

Claeoderes radulirostris.

Brenthus Anchorago.

vulneratus.

lineicollis.

(Nemocephalus) laevis.

Ischnomerus erythroderes.

Taphroderes striolatus.

Ulocerus tetraurus.

Episus aculeatus.

Cylas turcipennis \& angustatus.

Oxyrhynchus discors.

Bruchus luteicornis.

(Caryoborus) nucleorum.

Spermophagus cistelinus \& cardui.

trodon suturalis

Deuterocrates nebulofus.

Allacerastes lepidus.

Decataphanes gracilis. pictus.

Xenocerus saperdoides var.

Mecocerus Gazella. disparipes
Phloeotragus Heros.

Ptychoderes elongatus.

$\mathrm{X} y$ linades atricornis

Meconemus tuberculatus.

Chirotenon adustus.

Systaltocerus platyrhinus.

Acorynus sulcirostris.

Anthribus albinus

Dama \& retufus.

Evicorynus crassicornis.

Polycorynus pantherinus compressicornis.

Discotenes coèlebs.

Nemotrichus indistinctus.

Lagopezus tenuicornis.

Stenocerus fulvitarfis.

Uterosomus verrucofus.

Platyrhinus latirostris.

Aroeocerus Coffeae.

Cratoparis lunatus.

Tapirus.

Tophoderes frenatus.

Analotes discoideus.

Gymnognathus Ancora.

Phaenithon costatus. albosparsus.

Tropideres albirostris. niveirostris.

Blaberus fallax.

Eugonus subcylindricus.

Brachytarfus scabrofus.

Camarotus marginalis. coccinelloides.

Pterocolus ovatus.

Cybebus rufipennis.

Attelabus bispinofus.

melancoryphus rar.

variabilis. scutellaris.

Apoderus languidus $\&$ hy ftrix. Camelus.

Rhynchites grandis 


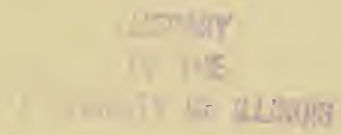



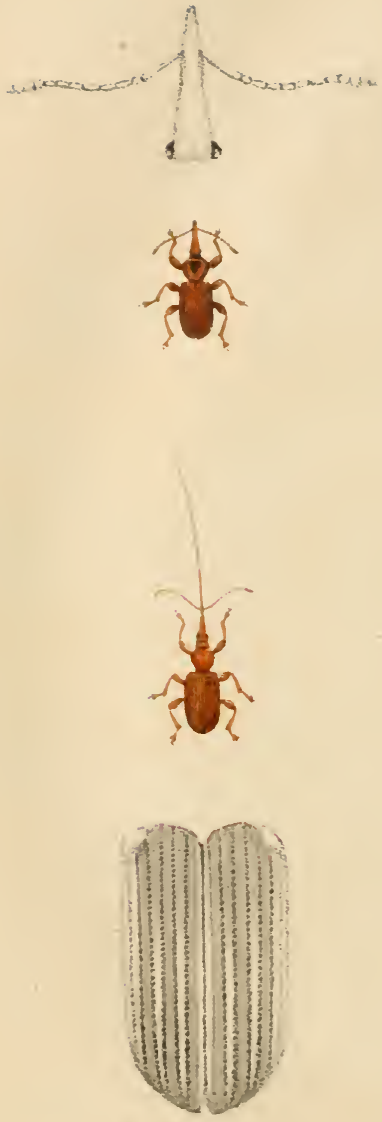

Antlimelesueses Zaveire 


\section{Fam. ANTLIARHINIDES.}

\section{A N T L I A R H I N US Z A M I A}

(Schönh, Gen. \& $\mathrm{s}_{\mathrm{p}}$. Curc. T. III. P. 2. p. 824.)

Longitudine varians, in depietis mas lineas circides 3 longus, femina pollicaris et ultra. Subdepressus, punctulatus, testaceus, mas aliquantum obscurior, ad eastaneum fere vergens, ore, antennarum apice, oculis et interdum in mare macula thoracis media niggricantibus. Caput et rostrum sexu diversa, in mare supra canaliculata, in femina requata, maris caput collo aque latum, femince co angustius, rostrum in mare thoracem longitudine parum superans, latitudine capitis, antrorsum angustius, in femina triplicem thoracis et elytrorum Iongitudinem aquans, eylindrieum, capillare, basi sola crassiore; parte postica in utroque sexu thoracis longitudine; parte antica in mare trientem

श! fünge verict)icocn, bei ben abgebildecten baz̉

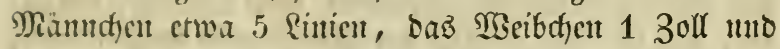
barïber lang. Biemlid) flachgebrïctt, gebüpfclt, zic=

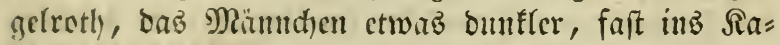
itanicuteramte übergeheno, Muno, Fühleripibe, stugen

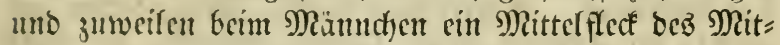

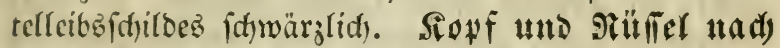
sem (bejh)

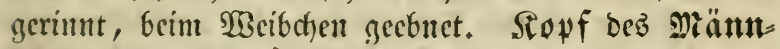

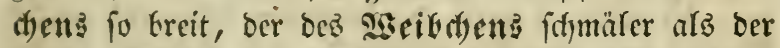
Fुarz. xritlfer beim Männdyen wenig länger alz oer Mittelfeibşdyild, von our Breite bez Ropfez, nads

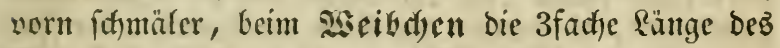
Mittelleibeffhildes uno ber frlïgeldecten erreidyent, malzig, haarbünn, mur bic Matrzel etwas bicfer; ber hintere Theil bei beiben (Sefdyledtern von ber fänge

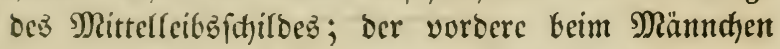
mur cincu Dritthcil bes gauzen Ritffer betrageno, 
totius rostri modo constituente, in femina partis postica longitudinem decies superante. Antennce in mare vix thoracis basin attingentes, in femina graciliores, elytrorum basin fere superantes, 12 articulate, articulo primo elongato, clavato, 7 sequentibus sub-obconicis, 4 ultimis clavam elongatam constituentibus. Thorax sub-orbiculatus. Scutellem triangulare. Elytra sulcata, sulcis transversim striatis, interstitiis planis, alternis fere a medio ad apicem, margineque laterali convexis. Pedes elytris aliquantum brevioribus, antici parum, medii magis, postici maxime basi distantes, femore medio incrassato, tibia subcurvata, anticorum interne a medio ad apicem dense ciliata, posteriorum apice hirsuta, tarsus tibia parum brevior, articulis primo, secundo, tertioque bifido subtus spongiosis, quarto precedentem parum excedente.

beim $\mathfrak{B e i b d j e n ~ b i e ~ 1 0 f a d j e ~ \& a ̈ n g e ~ b e z ̇ ~ h i n t e r n ~ T h e i l e z ~}$ übertreffent. Fith) (ev beim Männdhen faum bie Murzel

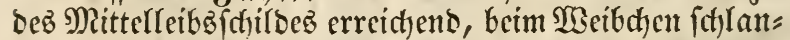
fer, faft über bie SMurzel ber Frägeldecten wegreichend; 12gliebig, bas 1ite Sslico langgeftrectt, feulenförmig, bie 7 folgendent faft verfehrt fegelfürmig, bie 4 lekten eine langgeitreate Rente bildond. Mitterreigaidird

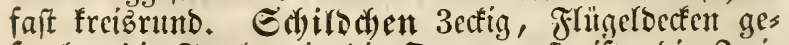
furdt, bie Frtrchent in bie Dutcere geitreift, bie 3 wis idjenräume flach, abmedficlno etwa yon ber Mitte an biz zur Exize uno am Seitentrande crhaben. Šine etwaz fïrzer alz bic Fflïgeldecten, bie vorberíten twe= nig, bie nittlerst mefhr, bie hinteriten bebentento an ber Misurgel you cinander abitehend, ber Edjentel in ber Mitte verbidft, bie Edjiene fdjwadh gebogent, an ben

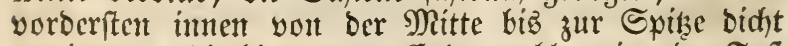
gewimpert, bie hintern am Ende ranlhhanrig, ber Fup

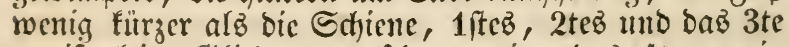
zwocipaltige Gslico untent fđjwammig, baz 4te wenig über bas 3te hinaußragend. 


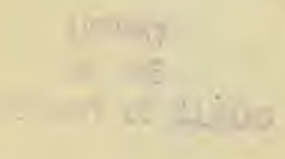



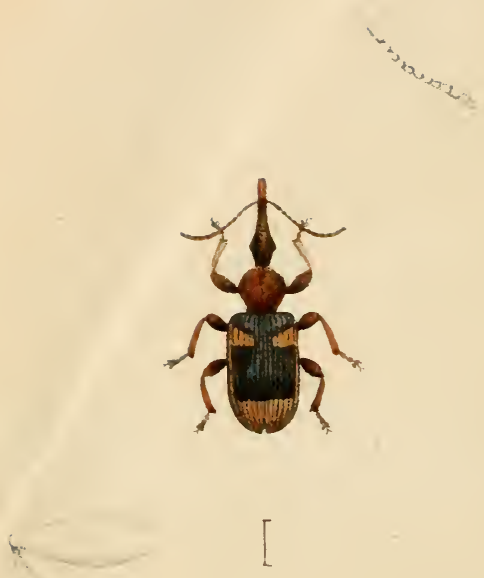

$=1$

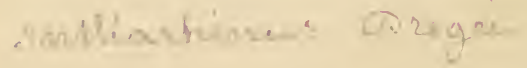
Plotymenes locumere 


\section{Fam. ANTLIARIINIDES.}

\section{PLA T Y M ER US G ERMARI.}

(Schönh. Gen. At Sp. Curc. T. III. P. 2. p. 830.)

Lineas 2 longus. Depressus, punctulatus, nitidus, niger, rostri apice, antennis, thoracis lateribus, pedibus posterioribus anticorumque femore rufo-piceis, elytrorum maculis, pedumque anticorum tibia tarsoque fulvescentibus. Caput latitudine aliquantum longius, postice in collum constrictum. Rostrum sexu diversum: in mare capitis duplicem longitudinem xequans, subtus deplanatum, antrorsum nonnihil angustatum, parte postica subquadrilatera, femince rostrum longitudine capitis et thoracis, capite angustius, cylindricum. Antenna elytrorum basin attingentes, 12 -articulatx, articulo primo elongato, clavato, 7 sequentibus obconicis, brevibus, 4 ultimis incrassatis. Thorax antice posticeque truncatus, ad angulos anticos rotunda-

3wei \&inien lang. Fladgedrïft, gedizpfelt, glän= zento, fd)warz, Exize bes Rülfels, Fühler, Eciten ১ez Mittelleibzfdyilbez, hintere Beine uno Sdjentel ber vorberftent röthlids=ped)braut, Frlitgeldectentlectent, uno Ed)iene uno fấ ber vorberiften Beine braungelb= (id). Siopf etwas länger alb breit, hinten in einent

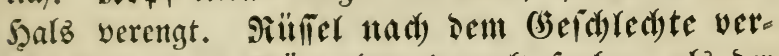
fdieben: beim : Männd)en boppelt fo lang alz ber Ropf, unten abgeflad,t, nad) vorn etwaz verjamä= lert, feit hinterer Theil beinahe 4 feitig, ber Siutlfel

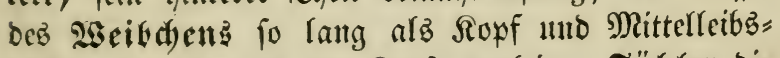

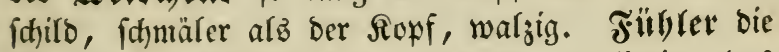
Murzel ber Frlitgeloectent erreicheno, 12gliebig, baß 1/te Glico langgeftreft, feulenförmig, bie 7 folgentent verfehrt riförmig, furz, dic 4 leķten verbicft. Mit terleigaidib vorn uno hinten abgeftutst, an ben ge= 
tos latior, basin versus sensim angustatus. Seutellum triangulare. Elytra sulcata, maculis duabus, una antica prope suturam abrupta, altera apicali, commmi, lineaque laterali illas jungente, fulvescentibus. Pedes elỵtris breviores, antici parum, medii magis, postici maxime inter se basi distantes, femore compresso, prasertim anticorum utrinque angulato-dilatato, tibia subcurvata, posteriorum apice hirsuta, tarsi articulis primo, secundo, tertioque bifido subtus spongiosis, quarto precedentem parum excedente.

runbeten Sorbereffen breiter, nady ber $\mathfrak{B u t r z e l}$ hit

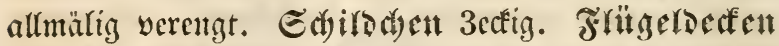
gefurdyt, 2 Fledfen, ein vorberer nahe an ber Nath abgebrodyenter, ein antorer gemeinfidaftlidyer ant Enbe, uno einte biefe frectent verbindentbe Scitenlinie braut= gelblich. Sente fürzer alz bie Frügeldecten, bie vor= beriten wenig, bie mittlern mehr, bie hinteriten beden= tento ant ber Sigurgel vout cinatioer abjeflento, ber Edyent= fel zufammengecrideft, befonder an ben vorberiten Beinen beibericitz wintflig erweitert, bie Ecthicne ctma gefrimmt, bie ber hintern ant Ëtoe rauthlyarig, 1fics,

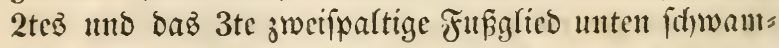
mig, das 4te wenig itber oas 3te heransangent. 


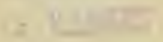





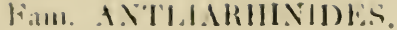

\author{
PIATMERLS Germari. \\ rsclih. Ciell. is sp. Curc. T. 111. P. $\leq$ p. ssi.) \\ Patria: Caffiria.
}

Descriptio in sequentibus proposita secundum spe. cimen femineum a $\mathrm{Germario}$ nobiscum communica. sum, quod vir clarissimus ab illustrissimo $\mathrm{S}$ c hö n h e r $r$ in ipso accepisse nos docuit.

Depressus, nitidus, nigro-piceus, rostri apice, anten. nis, thoracis lateribus, pedibusque rufo-piceis, elytrorum maculis, una magna basali communi, altera minore fere apicali testaceis. Caput pone oculos elongatum, postice tumidum. Rostrum capite plus duplo longius, $\epsilon_{0}$ dimidio angustius, cylindricum, perparum arcuatum. Antennce rostro longitudine xquales, versus hujus hasin insertæ, 12-articu. latx, clavatx, clava tertiam totius antennæ partem xquanie, ovali, 4-articulata. Thorcix fere orbicularis, antice posticeque truncatus. Scutellum triangulare. Pedes, maxime postici, basi inter se remoti, robusti, breves, femore mutico, compresso, posteriorum tibia versus apicem dilatata ad angulum exteriorem spinuloso-ciliata, tarso tibix æque longo, articulo penu. timo bilsbo. Elytra oblongo-subquadrata.

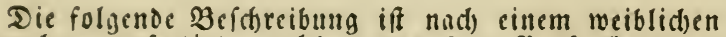
Excmplare verfertigt, melches uns Serr Brof. (S) in ar mittbeilte, Det es felbif mieder von Serrn $\mathbb{S}$ d) ön ber er. balten fu baben uns verifiderte.

Flachgedrüđt, glängeno, đd)warz=ped)braun, Ende Des Rürlels, Frähler, Eeiten Des Mittelleibsífildes uno Beine röthlid()-yed)brnun, Flügeldedtenfledten, cin grofier gemeinfhaftlidier an ber $\mathfrak{B u r g e l}$ und ein fleinerer nnbe nm Enoe giegelfarben. Sopf binter ben Augen verlinn: gert, binten angefdrollen. Ritifel mebr als Doppelt fo lang als ber Ropf, balb fo fdmal als oiefer, malzig, febr fdimach gebogen. Fïbler fo lang als ber Rüfel

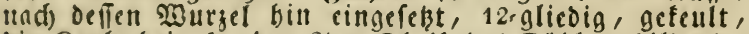
die Reule beillabe den 3ten Theil Des Fúblers bildend, oval, 4gliedig. Mrittelleibafhild faft freigrund, vorn und hinten abgeftubt. Edhilochen oreicatig. Beine, vors

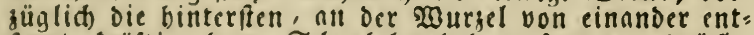
fernt, fröftig, furg, Gdienfel wefbrlos sufammengedrü dt' Ediene der hintern aegen bas Ende hin ermeitert, $\mathrm{nm}$

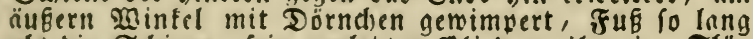
als die Edirne, feill vorleß̨tes Elico zweilappig. Fłlü: gelocefen lïnglich vieredtig. 



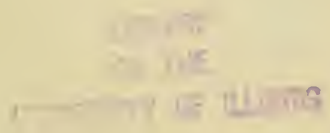

. 


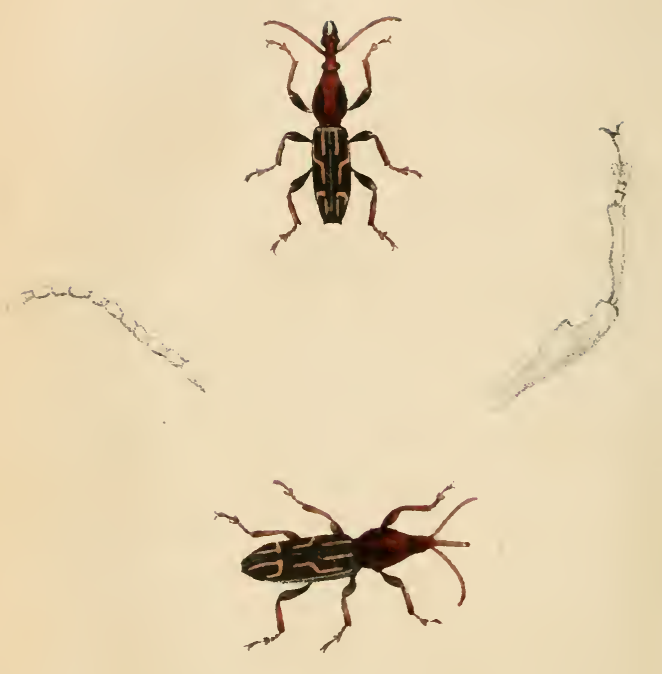

Alerlenendes dispar 


\section{Fam. BRENTHIDES.}

\section{A R R H E N O I ES I IS P A R.}

(Schönh. Gen. * sp. Curc. T. I. P. 1. p. 553.)

Lineas 9 ad 10 longus. Opacus, rostro nitido, castaneus, elytris ferrugineo-notatis, thoracisque plaga laterali, interdum et corpore subtus ad latera femoribusque olsscurioribus. Capul transversum. Rostrum sexu diversum; in mare capite parmu angustius, xeque altum ac latum, medio constrictum, supra excavatum, latere marginatum; parte postica longitudine capitis, quadrilatera: parte antica postica longitudine equali, cordata: mandibula porrecta, elongata, dimidiam rostri longitudinem xquantes, apice rotundatx, dextera sub apice dente clongato rotundato ancta; in femina rostri postica parte dimidiam capitis fongitudinem vix superante, antrorsum angustata, supra subtus foveolis utrinque in lineam curvatam locatis,

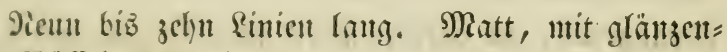

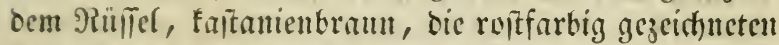

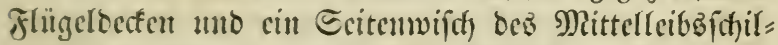
bes, zuweilen and) ber Rörper unten feitwärts unto bie Beine sunfler. Siopf quecr. Pritliel mady Sem (iscid)led)te verid)iesen; Geim Mäund)en wenig id)mäler alz ber $\Omega$ opf, ebent fo hod) alz breit, itt ber Mitte eingefdumt, sbent ausgehöhlt mit ciner Seiten= leite, fein linterer Theil fo lanty alzz ber Sopf, 4 jei= rig; ber vorbere Theil fo lang als ber hintere, hers= formig; bie Derfiefer vorgeitrect, ranggejogen, fo lang als ber halbe Ritffer, alt ber Epize germmbet, ber redfte unter ber Epiłe mit einem verlängerten,

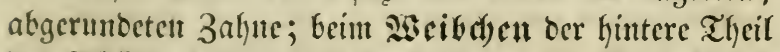

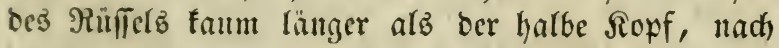

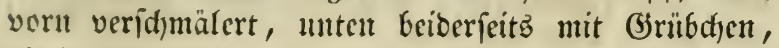
bie in eine gefrümmte Sinie gereift fino, oben mit cinter 
supra fovea longitudinali impressa: parte anticas triplicem capitis longुitudinem et trientem latitudinis aquante, cylindrica: mandibula subocculta, subquadrate, apice fere tridentate. Antennce filiformes, articulis priorilus obeonicis, sequentibus subcylindricis, ultimo elongato, mediis vix latitudine longioribus. Thorax subovatus. Elytra ad apicem truncatum utrinque unidentata, convexa, foveolis in series longitudinales dispositis et ad suturam deplanatam sulco vix punctulato impressa. striis elevatis ferrugineis ornata, longitudinalibus $\mathbf{A}$, transversis 2, his interdum interruptis, una ante medium obliqua, longitudinales duas, humeralem scilicet et mediam jungente altera pone medium, curvata. Pedes dimidimn corporis pane longुi, antici aliquantum elongati, omnium femore dente armato, tibia subflexuosa, tarsi articulis primo, secundo, tertioque bifido subtus spongiosis, quarto his æque longo.

fängägrube, ber vordere Theil 3ntal fo lang und cinen Drittheil fo breit als ber Sopf, waljig, mit halbuer= ftecften, faft vicrectigen, aut Ende mingefehr 3 zahtuigen

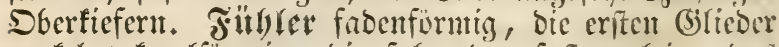
verfehrt fegelfürmig, bie folgenton fait waljig, bas Iç̧te geitrecft, bie mittlern faum läntger al: brcit. Mittelfeigzidsirs faft ciförmig. Frätgerserfen ant abgeftuksten (Enbe beiocrfeits einjahnig, gewolbt, mit

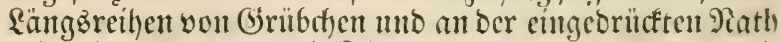
mit ciner faum geditpfelten Furthe bur(t) zogen, mit crhabuten rolffarbunen Etrichen gejiert, 4 länglidaen, 2 queeren, sicis juncilen unterbrotyen, einter, yor bor

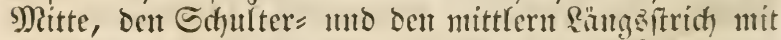
einatioer verbintento, ber alloere linter ber s) Mitte, ge= frïmntt. Sicinte von halber Siüperlänge, die vors Deriftent etwas verlängert, an allent Der Edicnfel mit

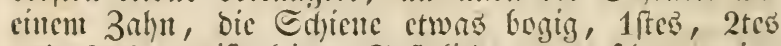

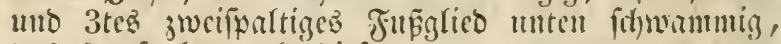
ons the fin latty alö biefe. 



$$
\text { r }
$$




\section{ARRHENOIES CORNIGER Varietas.}

\section{Palria: Brasilia.}

Mai. Castaneus elytris ferrugineo notatis obscurioribus vittaque sinuata thoracis utringue nigra. Capue subquadratum, subtus processu corniformi instrucImin, versus pectus flexo, cylindrico, apsce acumi11 ato, interstitium pedum anticorum paene attingente. Rostrum capite triplo longius, postica parte aeque fere longa atque antica, versus apicem sensin paulo attenusta, antica apice dilatata, mandibulus satis validas cxerente. Antennac longitudine rostri, filiformes, articulis prioribus obconicis, sequentibus sub-cylindricis, ultimo elongato attenuato. $T$ T $/ O=$ I $a \cdot x$ sub-rotundatıs, basi constrictus. I'cdes, fraecipue antici, longiusculi, femore unidendato, libia subflexuosa, tarsi articulis primo, secundo tertioque bilobo subtus spongiosis, quarto hiv aeque longo. Lilytice elongata, seriebus longitudin alibus foveolarum impressa, apice truncata.

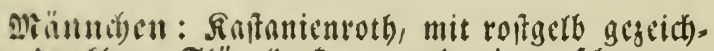
neten Dunflern Flügeldecten, und eiller fdwargen buctigen Räng binde beiderieits auf Dem Mittelleibs. itbilds. Sisut falt vieredig, unten mit einem in Beltalt cines Sorns , gegen die Bruft gebogenen, waljigen, am Ende zugépisten, den Mittelraum Der worderiten Beine beinabe erreichenden Fortiake. Riti fel 3 mal länger als der fopf, fein binterer Theil ungefebr fo lang als der vordere, gegen dos Ende ein weni! verdünnt, feill vorderer am Endee erweitert, die jiemlich fräftigen sterfiefer vorftrectend. Fith

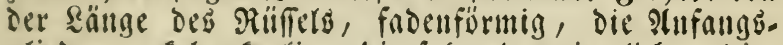
glieder verfebrt feglig, bie folgenden jiemlich lalgig,

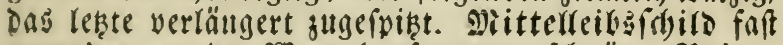
gerundet, an der $\mathfrak{B}$ urzel zufammengefdnürt. Beine, Norjüglich bie vorberiten, länglid, mit cingahnigem St)enfel, etwas gebogener Sthiene und Des Futes lites, 2tes, 3tes zlocilappiges Shlied unten fdowam.

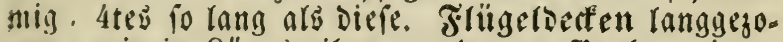
gen, mit in sängüreiben georoneten Brnben eingeoriitift; nm Ende nogeptubt. 



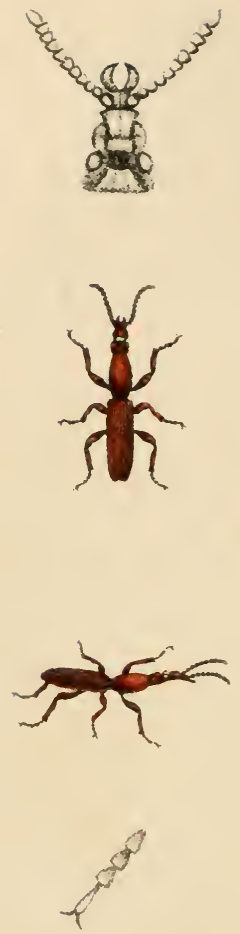

dreshen. (Hermoceress) innnaties 


\section{Fam. BRENTHIDES.}

\section{ARRIENODES (HORMOCERUS) CORONATUS.}

(Schünh. Gen. de Sp. Curc. T. I. P. 1. p. 550.)

Semipollicaris. Castaneus, rostri apice, antennis, basi et apice femorum tibiarmmque tarsisque nigricantibus. Rostrum cum copile longitudine thoracis. Caput longitudine dimidium rostri fere repuns, transversiom, subfus convexum, supra fovea utrinque juxta oculum cum antica profundiore connexa, impressum. Rostrum a capite incisura laterali discretum; parte postica fere longitudine capitis, et eo parum angustius : postice fovea media cum illa eapitis confluente excavata: antice subito ad superficiem elevata, canali a margine fovex laterali sejunctam, canalicula media longitudinali impressam, margine postico angustato supra fovean modo descriptam aliquantum producto flavociliato, apice aliquantum demissam dilatatam et utrimpe anriculatam; parte antica sexu diversa:

Eincu halfen Boll rant\}. Saftanicubraun, Fithler, Siarjel mo Exitic ber Edhenfer mo Edticnen mo

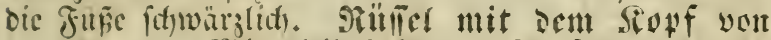

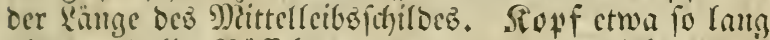

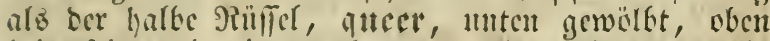
beibericits mit cinter neben bem ?hage liegentoen, in cime vorbere, tiefere vom Sioff Durd) cinen feitlidjen Einfduntt abgegrengt; fein hinterer Theil mugefehr fo (ang mo wenig fithmäler als ber Sorf, linten mit cinter mittlern, in bie bes

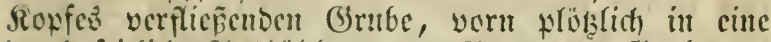

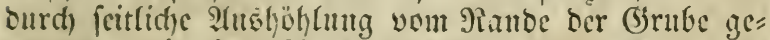

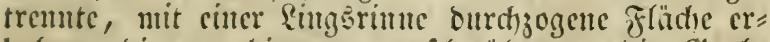
hoben, bic am hinteren verid)mälerten, die Grntbe ctwaz

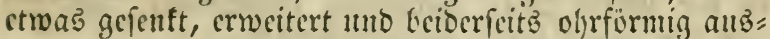

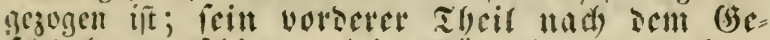

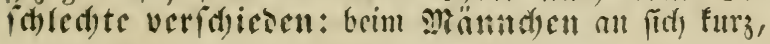


in mare ipsa brevi at cum mandibulis capiti eque longa, processu supero bifudo, Iohisque duobis inferis instructa; mandibulx his insertx, acuminate, dextera modice-, sinistra angulato-curvata: in femina parte antica lonģitudine postica, hujusque dimidiam latitudinem vix equante, jam inter antennas incipiente, demissa, eylindrica, apice subascendente; mandibulis suboccultis, parallelo grammicis, apice obliquis, emarginatis. Antennce rostro cum capite paulo longiores, moniliformes, apice acuminata. Thorax conicus basi angustatus. Elytra apice truncata et angulo exteriore rotundata, sulcis longitudinalibus, rectangulis, in fundo striis transversis impressis exarata. Pedes longitudine dimidium corporis pane equantes, medii reliquis paulo breviores, omnium femore mutico, tibia subflexuosa, posticorum in mare incurva, tarso cylindrico, articulis primo, secundo, tertio conformibus, obconicis, subtus medio glabris utrinque spongiosis, quarto longitudine duorum precedentium.

aber mit bent Dberfiefern von Der Ränge bez Ropfez, mit einem obern zmeipaltigen fortias uno 2 untern fappen; bie Sberfiefer bicfen eingefingt, jugcipist, ber rectite mäpsig, ber liufe winflig gefritmmt; becut Sicibden ber verbere Theil fo lang uno faum halb fo breit als oer hintere, fidon zwifhen bent Fühlern begimnent, gefentt, walzig, am Gnoc etwaz aufwäts fteigeno, mit jiemlich verborguen, lättglict)tectigen,

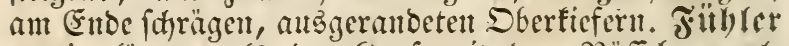
wentig ränger als ber Siopf ntit bent Rilliel, fert= idnurförmig, am Enbe jugeinist. Mitterreib:

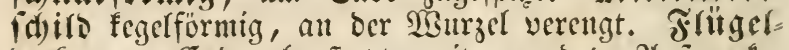
Decfen am Enbe abgeîtult, mit germbeter shusencefe, von red)twinfligen, auf Dem Girmbe mit Duecritridyen cingebriuctent fintgifurchen ourd)ogen. Sicint fait von halber Rörperlänge, bie mittlern tum STSenige fürzer alz bie antorn, ant allent ber Edyentel jahntos, bie Edjiente ctwaz bogig, an ben hinteriten beint Män=

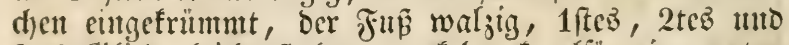
3tes Ģlied gleidigeitaltet, verfehrt fegelfürmig, unten in ber Mitte fahl, beibericitz fofwammig, bas the von ber finge ber 2 vorhergehenden. 


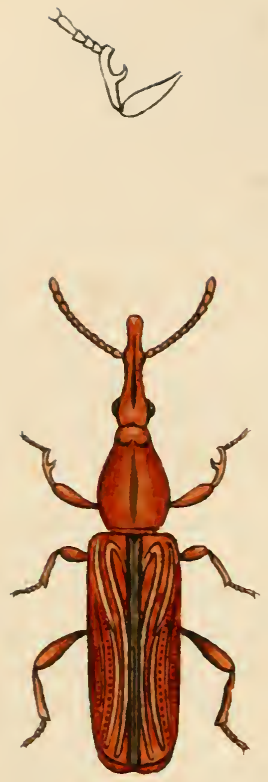

㐘

Vurherrodes(Truchelizus) pygmacew 


\section{Fam. BRENTHIDES.}

\section{ARRIENODES (TRACIELIZUS) PY GM EUS.}

(Schönh. Gen. \& $\mathrm{S}_{\mathrm{p}}$. Curc. T. I. P. 1. p. 535.)

Palria: Mexico.

Mas. Lineas 2-2 $1 / 2$ longus, ad basin elytrorum lineam $1 / 2$ latus. Nitidus, castancus, elytrorum sutura, gentbusque nigricantibus. Caput transversum, rostro dimidio brevius, supra convexum, antice fovea, in rostri casalem abente impressum. Rostrum capite alifuantum angustius, elongatoquadratum, subeurvatum, medio utrincue ad insertionem antennarum lobatum; postica parte antice aque longa, supra canali longitudinali, in partem intermediam etiam extensa, exarafa, parte antica refuata, sensin versus apicem subdilatata. Thorax elytris angustior, conicus, apice et basi constrictus, supra canali longitudinali, profunda impressus. Antenuce longitudine capitis et thora-

Mïmnthen. In ber \&änge von 2-21/2 Ŕnien, an

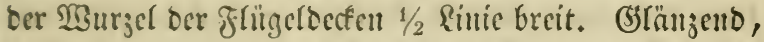
faftanienbratm, bie Piaht ber Frlügeldecten unt bic Sinice

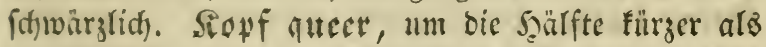
ber Rillfer, oben gewölbt, yorn mit cinter in cine

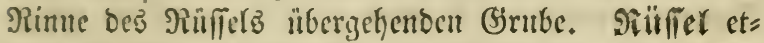

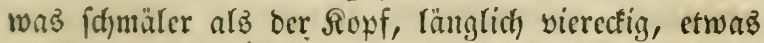
gefrümmt, in ber Mitte beiberfeitz an ber Einfüguntgas= ftelle ber Fillyler gelappt; fein hinterer Theil fo lang alb ber vorbere, boen mit einer, fich aud, allf ben mittlern Theil criftrecfenton \&änģ̉rime, fein vorberer Theil eben, allmälig gegen bas Frmbe crweitert. Mittel=

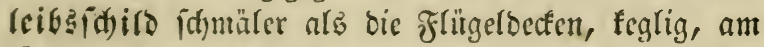
Ënoe und an Infang eingefdumt, oben mit einer

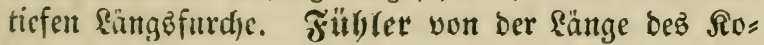


cis, crassiuscula, moniliformes, articulis tribus ultimis majoribus. Elytra convexa, ${ }^{\circ}$ ad suturam impressa et costa ante medium sutura incipiente ad basin assurgente hic reflexa et apicem usque flexuose ducta, instructa, reliquo spatio ad marginem usque punctorum serichus impressa, prima a costa suturali alteraque minus curvata inclusa; apice marginata, marggine rotundato. Pedes validi, femore mutico, posticorum subtus rigide ciliato, tibia anticorum interne processu medio versus apicem directo, hamato acuto instructa, tarso omnium tibia aque longo, articulis primo, secundo tertioque bifido subtus setosis, quarto his fere aque longo.

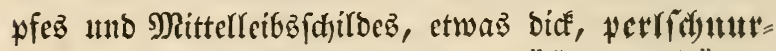
förmig, Die 3 Enogriescr vergrö̈rert. Frïgel=

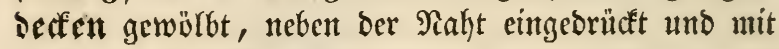
ciner yor Der Mitte ber $\mathfrak{R a h t}$ beginnenden, gegen bie $\mathfrak{B u r}$ el aufíteigenden, hier umgefrimmten unb bo: gig biz an bie Exike hingejogenen Seifte verfehent,

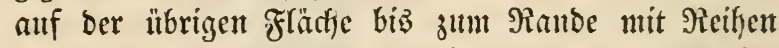

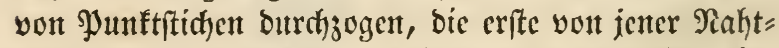
reifte unt einer jweitent weniger gebognent feifte citt= geidjloffen; am Enbe geranbet, ber Rand rundich. Beine fräftig, ber Edjenfel unbewehrt, ant ben hint terften unten fteif gewimpert, an ben vorberitent bie Schiene innmärtb̉ mit einem mittlern, nad) ber Spitice geridfteten, hadfenartigen, zugefpikten Fortfałe, ant

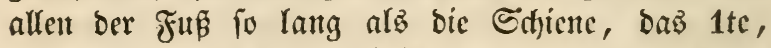
2te und zmeifpartige 3te Gilico untell beritig, bab 4te biefen gleid, lang. 



\section{I'RAC:HELIZLS ADUSTUS Schh.

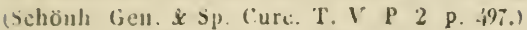

Patria: Brasilia. Mlus. IE. F. Germari, Halensis. Id ip. sum exemplar, guod primum Schönherrio trans mis. sum vir clarissimus postea nobiscum communicavit.)

Mas. Rufc_ferrugineus, elytrorum macula prope suturam pone medium pigra. Caput postice in eullum bulbiforme incrussatum. Rostrum capite pxne triplo longius subåcuatum sul, filiforme, apice $\mathcal{S}$ inedio palulum incrassaıum. Antennce rostro longitudine æeguales moniliformes, articulis iribus ultimis parum majorihus. Thorax oblongus canaliculo longitudinali insculpus. Pedes mediocres femore inermi, tarso subtus setuloso. Filytra punctis plurimis seriatim dispositis, \& sulco suturali impressa, elongata, apice coujunctim rotundata.

Stäuther. Siofroth, eill Fled Der Flügeldecten an Der

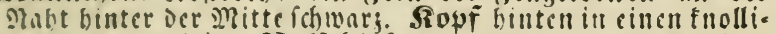
gen sols verdittt. Riiliel falt 3 mal länger als ber Sopf ets mas gebogen, jicmlich) fadenförmig, nm (Enoe uno in oer

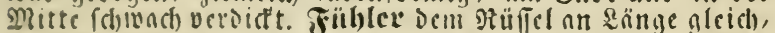
perlichnuriömis, Die 3 Enoglieber Wenig grö̈er. Qhit: telleibsichilo länglid, von eilter sängstrinne cingegrabeu. Scine mittelgrofi, mit unbervebrtem Edenfel, uno unten

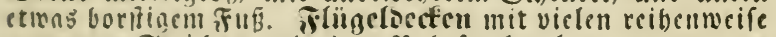
georncten Etrichen uno einer Prabtfurdbe, Ianggejojen, num Ende semeinfdonftlict) gerundet.

\section{trachelizes clavicores Schil. (5rhönh. Gell. \& Sp Curc. T'. I" P. 2. p.492) Patria: Brasilia.}

Femina: Rufocastaneus, rostro cum antennis, pedum geniculis elytrorumque macula prope suturam pone inedium nigricantibus. Caput postice in collum bulbiforme incrassatum. Rostrum capite plus duplo longius, antica parte filiformi. Antennae moniliformes, ultimis tribus articulis majoribus. Thor ax oblongus, canaliculo longitudindi insculptus. Pedes medioeres, femore inermi, tarso sublus spongioso. Elyerce suhlavia, sulco suturali impressa, ante apicem constricta, apice ipso conjunctim rotundata.

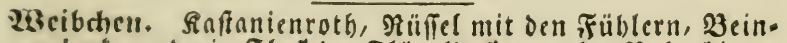

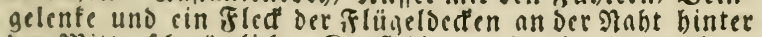
ber plitte fomirglich sopf binten in cinen fnolligen sals verdidt. Hinifiel mebr als Dopuelt fo lang als ber Ropf, fein $\mathfrak{B}$ orocrtbeil fadenförmig. Fühler perffdinur= formig, die 3 lebten Blicoer gröfer. Mrittelleibointilo länglict) mit einer sengstrinne Scine mittelgrob. mit unberefrtem $\subseteq$ (b) geloecten beinabe glatt, mit einer $\mathfrak{n}$ atfurde, vor bem Ende cingefdnürt, am Ende felbit gemeinfdinftids gerundet. 



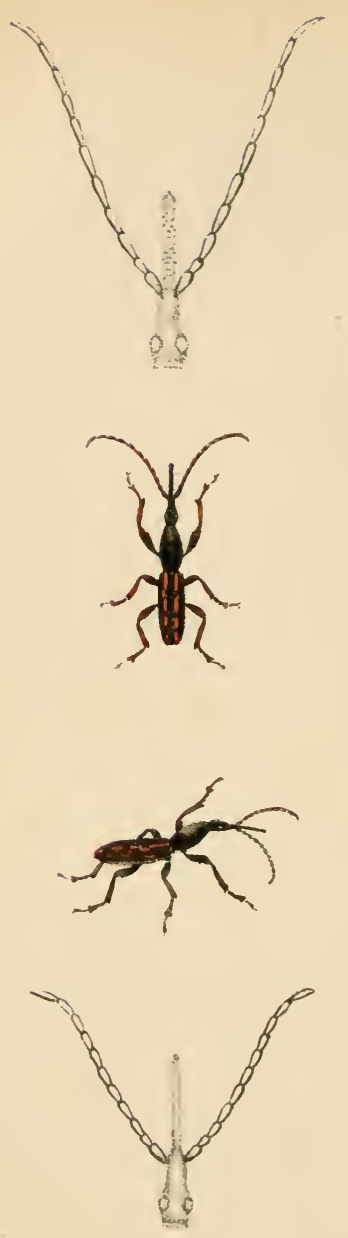

durhen. (Inemorhisnus)dugplicatur 


\section{Fam. BRENTHIDES.}

\section{IRRIIENOES（NEMORHINUS） DU - PLICA T US.}

\section{ARRIF. (NEMORH.) DUPLICATUS ET A RRH. (NEMORH.) INDICATUS.}

(Schoinh. Gen. \& Sp. Curc. T. I. P. 1 p. 529 \& 550.$)$

Longitudine $7 \frac{1}{2}$ linearum in depietis, in aliis, ut asseritur, vel majore (in femina) vel ei minore (in mare). Aeneo-niger, antennis, corpore subtus pedibusque in mare dilute-, his et rostro in femina obscure-, fere nigro-castaneis, elytris flavo-notatis. Caput latitudine non lonģius. Rostri antica pars et antennce sexu diversa. Illa postica partis Iongitudinem fere triplicem et latitudinis dimidimm aquante, in femina eylindrica, lavissima, mandibulis subquaIratis, apice trilentatis, in mare subtus convexa, supra canaliculata et tuberculata, mandibulis oblongis, apice bidentatis. Autenne filiformes, in

Ränge bei ocn abgetilocten Etïcfen 71/2 Rinien, bei anbern, wie angegeben wirb, bebententor (im weib=

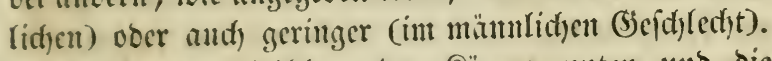
Bronjeldwar, Fühler, ber Rürper unten unt bie Beine bein Miünndyen hell=, bieje unt ber Milffel beim

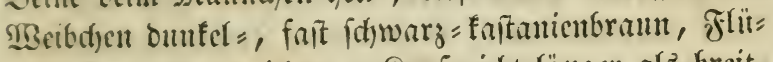

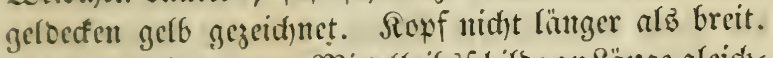

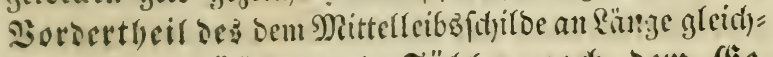
fommenton viliffers แns Filbret แad) Bem (be

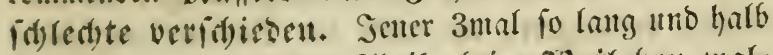
fo breit als ber hiutere Theil, beim siseifed)en mal= zig, ganj glatt, mit fait 4ectigen, ant (5noe 3 jahnigen Sberfiefern, beim miantuchen unten gewölbt, oben

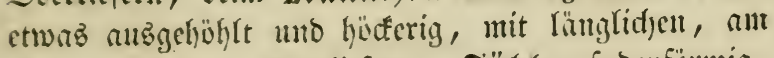
Ende 2jahmingen Dferfiefern. S̈̈̈t)ler fabenförmig, 
femina longitudine elytrorum, in mare horum et thoracis longitudine, articulis baseos obconicis, reliquis cylindricis, his in mare latitudine triplo in femina duplo longioribus. Thor ax ante basin constrictam conicus. Elytra apice truncata et utrinque unidentata, sulcis longitudinalibus aliis ad suturam, aliis ad marginem exteriorem, apice foveolatis, inter hos et illos seriebus tribus punctorum rersus apicem in sulcos transeuntibus exarata, stria ter interrupta in interstitio sulcorum tertio a sutura, striola una alterave adjacente et stria laterali infra humerum flavis ornata. Pedes dimidium corporis longi, antici elongati, omnium femore dente armato, tibia subflexuosa, tarsi articulis primo, secundo, tertioque bilobo subtus spongiosis, quarto antecedentibus fere aque longo.

beim $\mathfrak{s e i b d ) e n ~ f o ~ l a n g ~ a l s ~ b i e ~ F r i n g e l d e c t e n , ~ b e i m ~}$

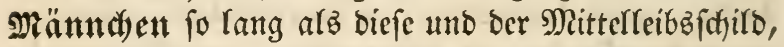
bie $\mathfrak{W u r}$ jelglieder verfehrt ciförmig, bie itbrigent wal= zig uto beim Männchen 3 mal, beim Mseibchen boppelt fo lang alz breit. Mitterfeitgidiro yor ber cinge= id) mürten $\mathfrak{B}$ urgel fegelfürmig. Frïgeroeaten abge= ftukt uno beibericits cinzahnig, mit am Enoc grubi=

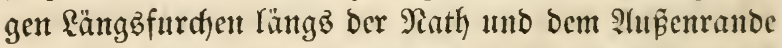
unt zwifhen bicfen unt jenten 3 am Enbe in Furdyen übergehenben Jumftreihen burdsogen; gelb fint ein 3 mal unterbrodhener, in bem 3ten 3wifhenraume von ber Nath verlaufender Stridh, 1 vber 2 biefem anlie: gento Stridjeldyen unt ein feitlidjez unter ber Edyulter liegentoez. Beinte von halber Rörperlänge, die vor= berifent verlängert, an allen ber Sthentel mit eintent

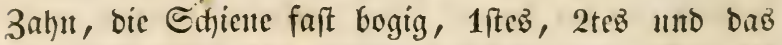
3te zmeifpaltige Fupghlicd unten f(t)wammig, daz 4te fait fo lang alz biefe. 


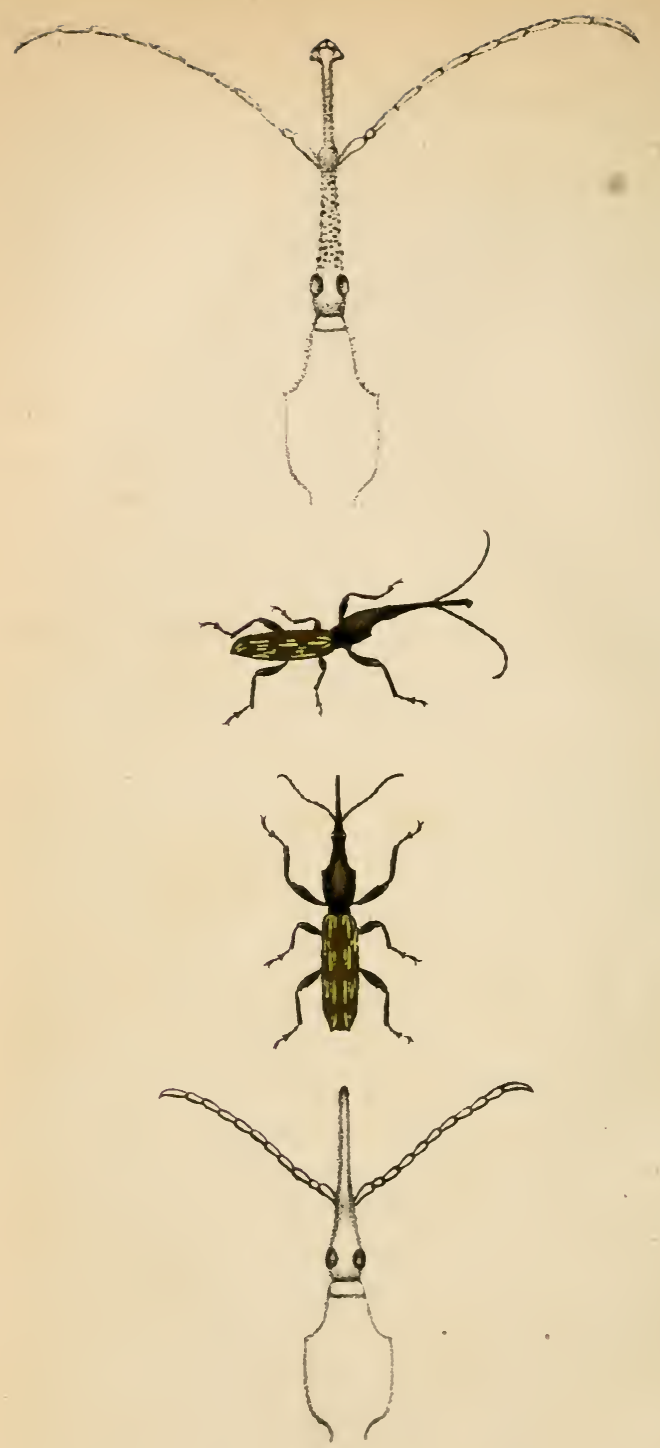

Belopherus militoris 


\section{Fam. BRENTHIDES.}

\section{B EL L O II ER US MI LIT A IR IS. \\ (schönh. Gen, et $S_{p}$. Curc. T. I. P 1, p. 556.)}

Lineas 9 ad 10 longus. Nitidus, fusco-reneus, elvtris orichaleeo-notatis dilutioribus, parte antica rostri, antennis tarsisque nigris, in femina corpore subtus rufescente. Caput oblongum, Rostrum, antenne et thorax sexu diversa. Rostrum maris trientem corporis aequans, tuberculis acutis scabrum; parte postica tereti, quam antica parumper longiore; parte antica tenuiore, quadrilatera, apice saggillato-dilatata, mandibulis oblongis, apice oblique truncatis. Femince rostrum quadrante corporis fere brevius; parte postica vix dimidiam anticx partis longitudinem acquante, subeylindrica, subtus utrinque punctis latiuseulis circiter $\mathbf{8}$ in lineam locatis, ad latera 6 impressa, caterum lavi; parte antica postiex dimidiam latitudinem xquante, cylindrica, lavissima, mandibulis suboccultis, subquadratis,

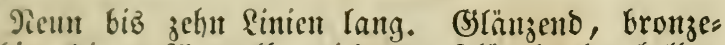
farbig, bie mefíntiggelbgezeid)neten frügeloedfent helfer,

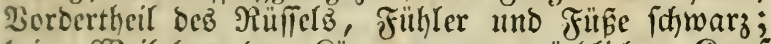
beim Meibdjen ber Rürper unten rüthlid). Ropf

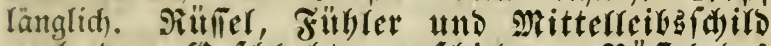

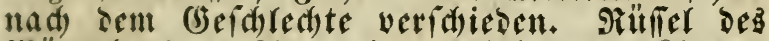
Miänt()ens an \&änge einen Drittheil bez Rörperz betragent, burd) fipise Syöderd)en rauh; fein hinterer Theil brehrunt, um Bentiges länger als ber vorbere; ciejer büner, 4 jeitig, am Enbe pfeilförmig erweitert,

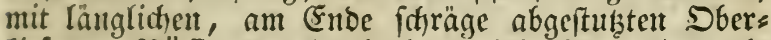

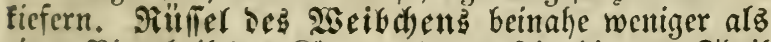
einen Sierttheil еฮ̉ Rörperz lang; fein hinterer Theil faum to lang als ber vorbere, faft walzig, unten

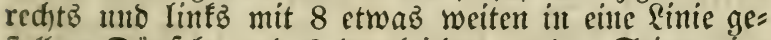
ftellten Düpfeln unb 6 bergleidjent an ben Seiten cin= gebrüct, übrigens glatt; fein vorberer Theil halb fo breit als ber hintere, walzig, fehr glatt, mit ziemlid) veritecten, beinahe 4ectigen, am Enoe 3zahnigen Sber= 
apice tridentatis. Antenure filiformes, in femina rostri et capitis longitudine, in mare graciles, thoracis duplicem longitudinem fere superantes. Thovax latitudine longior, antice et basi angustatus, in mare gracilior, subtus et ad latera tubereulis acutis asperatus, antice utrinque tamquam incisus, incisura tuberculo majore utrinque terminata, in femina levissimus, antice leviter sinuatus, sinu tuberculo parum conspicuo utrinque terminato. Elytra apice truncata et utrinque unidentata, lineis punctorum longitudinalibus, et sulco suturali impressa, instertitia linearum striolis orichalceis cirea 20 his longioribus illis brevioribus ornata. Pedes sat graciles, antici precipue in mare elongati, omnium femore dente acuto armato, tibia subrecta, anticorum subflexuosa, tarsi articulis subtus spongiosis, execpto quarto; tertio bifido, quarto longitudine preedentium.

fiefert. Fithler fabenförmig, beim sicibden fo

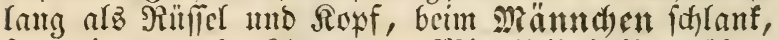

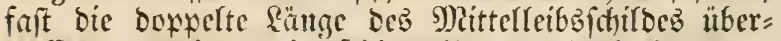
treffent. Mitterreibsid)irs länger als breit, vorn uno hinten verf(c)mälert, beint Mäannd)en idhlanfer,

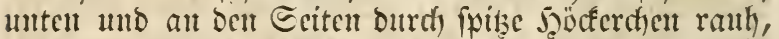
vorn beiber feitz gleichfan cingeldhnitten, ber Eimjunitt an jedem Enbe mit cinem ftärfern 5öberchen, beim Wcibchen völfig glatt, vorn an ben Seiten leicht ants: gebuchtet, bie Butht ntit einem faum beutlichent Jä̈cter=

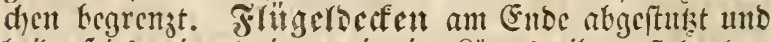

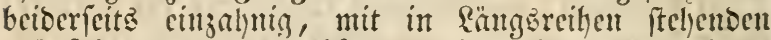
Ditpfelut unb cincr Piathfurche, bie 3wifhenräntme jencr

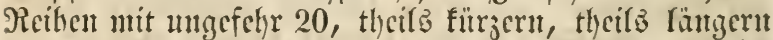

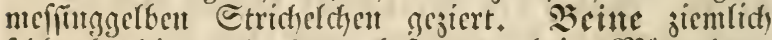
(d) lanté, bie vorberîten, Gejonber beim Männdhen, verlängert, ant allent ber Edhenfel mit cincm foibent 3ahn, bie Edjiene beinahe gerabe, an ben vorberiten

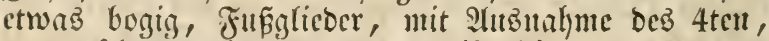
unten f(t)wammig, baร 3te zweipaltig, baร 4 te von orr Sënge ser vorhergehenden. 


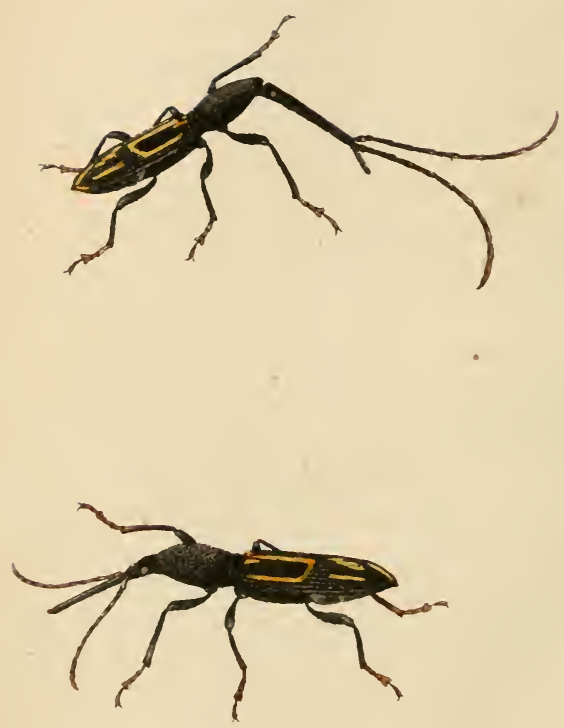

Belorhynchus curvidenes 


\section{Fam. BRENTHIDES.}

\section{BELORIIYNCIUS CURVIDENS.}

(Schönh. Gen. s sp. Curc. T. I. P, 1. p, 5/1.)

Lineas eirciter 15 longus. Niger, antennis tarsisque eastancis, elytris flavo-notatis. Caput in mare nutans, in femina porrectum, pone oculos constrictum, et in collum aliquantum co latius abiens. Rostrum et antenne sexu diversa. Rostrum in femina trientem totius corporis aquans, in mare eo aliquantum longius; postica parte in mare capiti omnino contigua et conformi, grannlata, quadrangulari, lateribus oblique compressa, facie supera angusta, antica partis triplicem longitudinem xequante, in femina contra illa punctulata, subcylindrica ab hac quater longitudine superata; parte antica dimidio quam postica humiliore, lavissima cylindrica, in femina vix, in mare abruptius deflexa; mandibula in utroque sexu parve, subquarlrate, apice tridentate. Antennce fili-

Ungefelyr 15 Rinien lann. Sdymarz, Finthler unto Finke taftantenbraun, Frügelocfen gelbgezcidhnet. Der

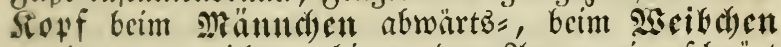
gerabe vor gerichtet, hinter ben ?llugen cinge(d)ürt

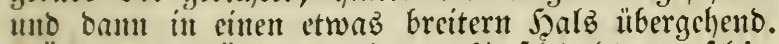

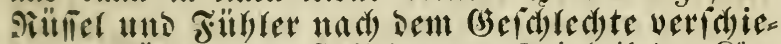

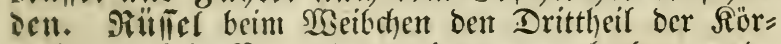
perlänge, beim Mäund)en nod, etwab mehr betrageno; fein hinterer Theil beim Männden mit bem Ropf burd)=

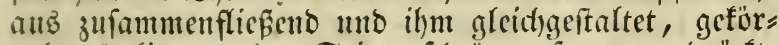
nelt, 4ectig, an ben Eeiten fouräg zufammengeorictet, bie obere Esite fdymal, orcimal fo lang alz ber vor" bere Theil, beim $\mathfrak{B c i b d y e n}$ gedupfelt, fait walgig, bagegen von vorbern Theil unt Das Bierfache an fänge übertroffen; bicfer um bie J̧älfte niebriger alz Der hintere, fehr glatt, walzig, beim $\mathfrak{B g}^{2}$ ibden faum, beim Mämnd)en ftarf abwärtb gerid)tet; Dberfiefer in beiben Geidjledtern flein, fait 4edig, am Enbe 3 ah =

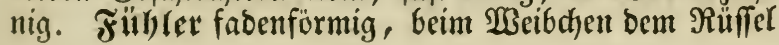


formes in femina rostri et capitis, in mare horum et adhue thoracis longitudine. Thorax elongatus, supra setulis griseis granulisque scaber, linea longitulinali lavi. Elytra apice truncata et utrinque uni-dentata, foreolis in series longitudinales digestis impressa, striis elevatis flavis ornata, plurimis crenulatis anticis duabus longioribus in medio stria obliqua junctis, cxteris, disjunctis, brevioribus aut brevissimis, illarum una laterali ante apicem, altera suture propiore ad ipsum dentem apicalem de currente, harum tres pone medium serie obliqua a sutura versus posticum locata, et tandem dua basales. Pedes elytrorum longitudine, antici elongati, in mare adhne longiores quam in femina, omnium femore mutico, tibia subrecta, anticorum in mare subflexuosa, tarsi articulis, excepto quarto, subtus spongiosis, tertio bifido, quarto hujus et antecedentis longitudine.

und Ropf, beim Mäundhen biefen und nod) bem Mit=

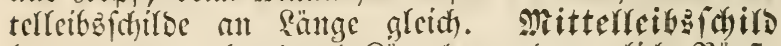
lantggezogen, obent burch Rörnclent unt grantiche Börit: then raulh, mit glatter eängšlinie. Frlügeldecfen am

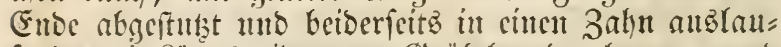
fent, mit Rängäreihen von Gritbchen burthzogen, unt gelben, erhabenen Etrichen gefthmüct', bie meiten ges ferbt, 2 vorbere längere, in ber Mitte surch einen farägen Duceritrid) verbutben, bie anbern getrennt, theits fitrzer, theil'b fehr furz, won jenten ber eine feitlidh yor ber Exitze, bor andere näher ant ber Nath, biz zum Enojahn verlanfent, von bicfen 3 in faträger

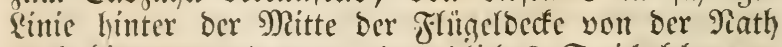
nad) hinten georonet, unb cublich 2 Etricheldcut an

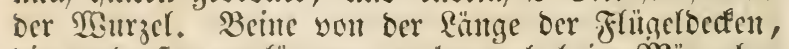
die vorberifen verlängert, ntchr noch beim Männdyent

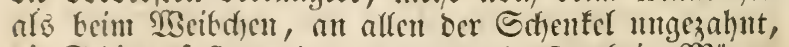
die Edhiente faft gernoe, an ben vorberiten beim Männ=

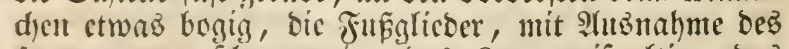
ften, unten idjwanmig, Daz 3te jweifpaltig, onz 4te fo rang alo biefes und bas vorhergehende. 


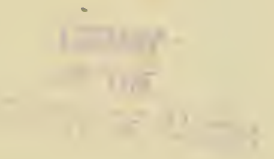



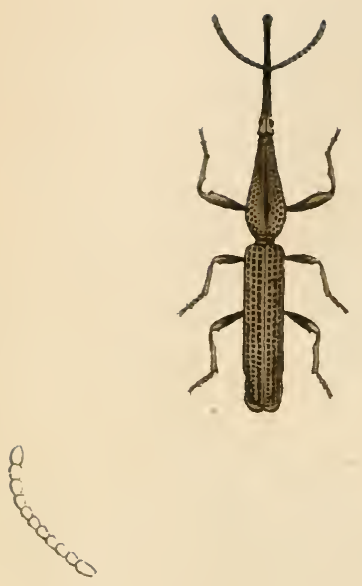<smiles>c1ccccc1</smiles>

Proceptiselus reticulatus 


\section{Fam. BRENTHIDES.}

\section{E O C E P II A L US R E T I C UL A T US.}

(Schönh. Gen. \& $\mathrm{S}_{\mathrm{p}}$. Curc. T. I. P. 1. p. 560.)

Patria: Sumatra, Jara.

Lineas 9 al $17 \frac{1}{2}$ longus. Picens vel nigricans, luto aggglutinato hic illic tectus. Caput fere latius ac longum, griseo-tomentosum, postice in marginem acutum, bilobum productum. Rostrum, thorax, pedes et elylra sexu diversa. Rostrum maris thoraci acjue longum, sultetragonum; postica parte parum crassiore, pubescente, antica paene aque longa; hac apice aliquantum dilatata; rostrum femince thorace, et quidem lujus quarta parte brevius; postica parte quartam thoracis partem, antica cjus dimidiam acuante, illa conica, pubescente, hac tenuiore, cylindrica, glabra. $\boldsymbol{A} n$ tennce rostri antice parti xque longe, pubescentes, submoniliformes, articulis tribus ultimis quam reliqui paulo majoribus. Thorax in femina ovatus, in mare elongatus, ab apice ad hasin parumper

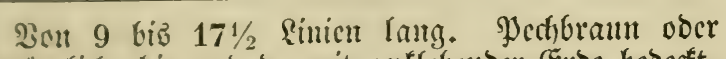
[d,warglid), hie unt ba mit anflebenter Eroe bebeft. Solf bcinahe breiter alz lang, graufilgig, hinten in

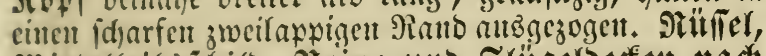

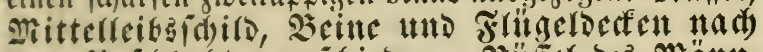

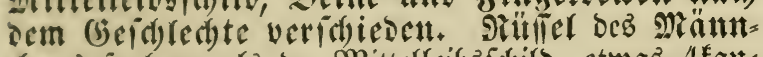
đ) tig; fein hinterer aheil wentg biffer, flaumflaarig, beinahe fo lang als ber vorbere; bićer am Enbe ct:

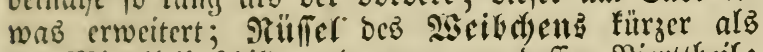

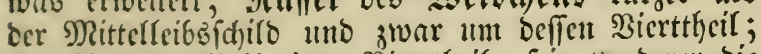
fein hinterer Theil cintu 2 ierttheil, feit yorberer bic

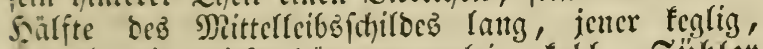
flammhaarig, bicier bümer, walzig, fahlf. Fiibler

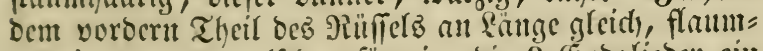
haarig, etwas perlfduutrforntig, bic 3 Enoglieber citt

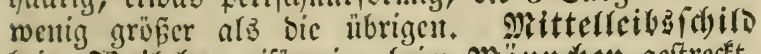
beim siscibden ciformig, beim Männden geftreft, 
dilatatus, basi ipsa angustatus, supra subdepressus, sulco longitudinali profundo incisus, utrinque punctis majoribus, sulbtus minoribus impressus. Elytra thorace ejusque dimidio parum longiora, basi pro individuis lineam $1 \frac{1}{4}$ ad $13 / 4$ lata; foveolis transversis per series longitudinales dispositis impressa; dorso subdepressa; apice in mare deplanato producta, extus et ad angulum suturalem subacutum rotundato-margimata, in femina simpliciter rotundata. Pedes pubescentes, inter se subaquales, medii reliquis parum breviores, omnimm femore in femina mutico, in mare unidentato, anticorum dente parum conspicuo; tilia densius pnbeseente, fere tomentosa, compressa, anticorum in mare intus angyulata; tarso tibia fere aque longo, articulis primo et secundo transversis tertioque bilobo tomentosis, quarto his aeque longo. Abdominis primum segmentum subtus variolosum, in mare late et fere per totam longitudinem excavatum.

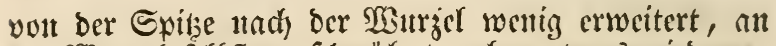

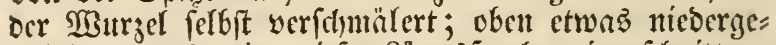
orüdt, Durd) cine ticfe sångg̈furd)e cintgefd)nittent, beiberfeitş nuit gröferen, untent mit flcitern Dupfen cingeftodhen. Frtitgeloeffen menig länger alz ber

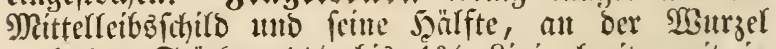
itad) Dent Stücfent $1 \frac{1 / 4}{4}$ biz $13 / 4$ fintic breit, mit in \&änģrcihen georoneten queeren (Sritbdjent cingeftod)en,

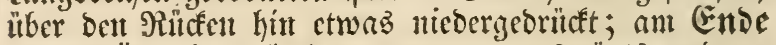

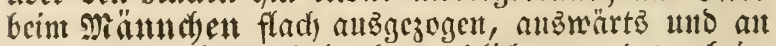

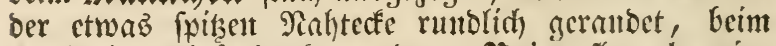
Socibeden cinfad, abgertutoct. Secine flummthaarig, unter einanber fajt gleid), bie mittlern monig fiir= zer als bie übrigen, ant allent ber Echenfel beint

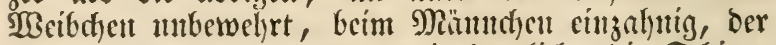
Zalyt an bent vorberifent wentig bentlid); bie Edjiene bidjter flaumbarriz, bcinahe firzig, julammtengcoritct, bie ber vorderfíten beim Minumdent inten ecfig vor=

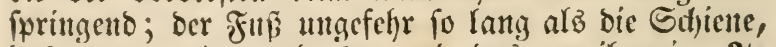

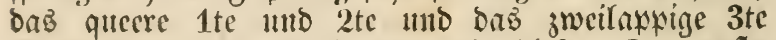
Ejlico firzin, baz 4te fo laning alz bicfe. Der erite Sinterfeibsabidnitt muten blatternarbig gedupft,

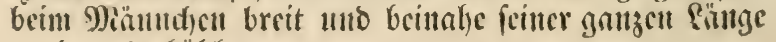
nad) altzgeljühlt. 


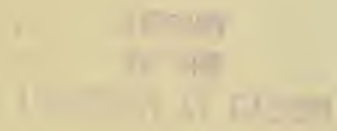




$$
\underline{1}
$$




\section{CEOCEPHAI.US RIISII. \\ Patria: Aquapim Guincae.}

Elongatus, rufo testaccus, antennis, lhoracis margine antico pedum geniculis tarsisque excepto ungut nigricantilus. Capul pone oculos elongatum, sub-quatiratum, postice margine bilobo. Rostrum. capite angustius pro sexu parum diversum, in mare capite triplo longius, sub-filiforme, apice nonnihil dilatatum, in fermina crpute duplo paululo longiu., lostica parte conica, antica filiformi. Antemme rostro vix longiores sub-moniliformes, articulis tribus ultimis majoribus. Thorax duplo longin quam latior, medio latere paulum dilatatus, sulco Inngitudinali exaratus, punctis creberrinis distinctus. Pede's breviusculi, femore inermi. turso sub-cylindrico articulis primo secundoyue sub-globosis tertinque submis sponpiosis. quarto lis ar que longro; Elylla valde elongata, sulcata, su'cis punctatis ante apicen desinentibus, duobus suluralibus profundoribus vix punctatis, al apicem usque decurentibus, apice attentuato-rotundato producta, marginata.

Enmigeitreft, jiegelrotb, Fübler, vorderer Rand

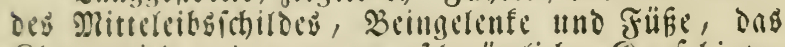
flauenglied augigenommen, fid)wätglich. Sioff binter Den Alugen verlänģert, Keinate vierefig, binten mit

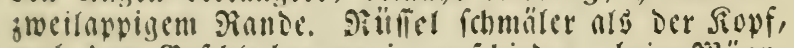
nach Dem (3efd)led)te wenig veridbieden, beim Jisint. () en 3 mal läm!er als det fiopf, ziemlich fadenfürmig, am Ende etwas erweitert, beim soeibeden wentg als ooppelt länger als ber fopf, fein binterer abcil feglig, ficin vorderer fadentömig. Fiibler faum län!er als

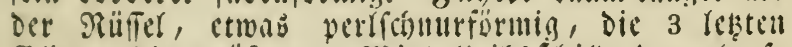

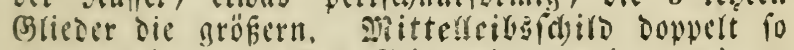
lang al's breit, an der Seitentmitte wenig criveitert, der sänge nach. Won einer farche ausgeböblt, fibr vielifichig, vorne glntt. Beine jiculich furg mit un=

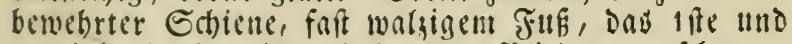
te beinabe fugelig und das 3 te (slied unten fitwan. mig, das 4 te diefen gleing [anis. Filiggerseffen lauis. gigogen, gefurdt, bie Furchen ftichig, vor Der Evize allibörend, Die 2 an Der Nabt tiefer, falln ftid)ig, his aur Epize verlaufend; mit verfamälert แnt geruil. Det ansigogener, gernndeter Swike. 



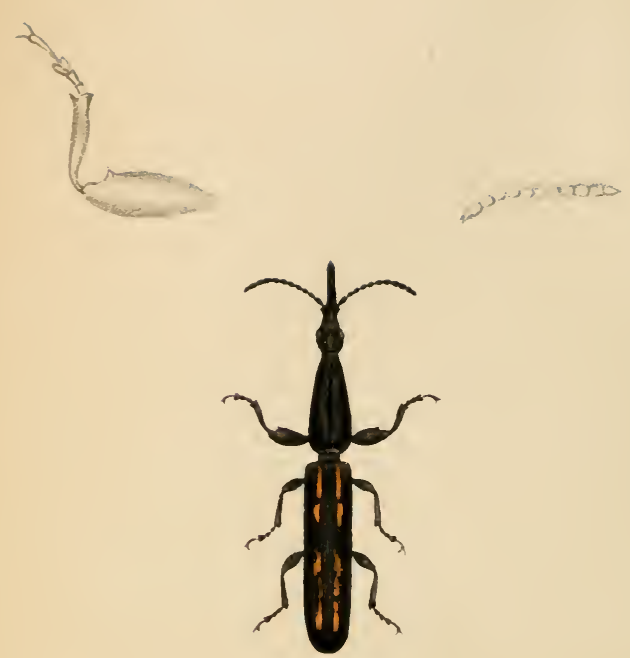

Cepholobarens macrosephatess 


\section{Fim. RRENTHIDIS.}

\section{CEPHALORARIS MACHOCEPHAICS Schönh}

(scliüh t;en. f. Sp (inre. T. V. P. 2. p. 519 )

Patria: Columbia.

ICharacteres secumdum feminam a Cl. Germar nobis trattsmisiam in sequentibus exhibiti.)

Ninidus, niger elytris flavo-notatis. Capul pone ocu. los elongaimm, crassum quadratum, postice profundius constrictum. basi ipsa collum bulbiforme for mante. Rostrum capite vix ter longiore, inter antennas sulcatum, postica parte superne quam caput depressiorc, antica partc tenuiore, cylindrica. $\boldsymbol{A} \boldsymbol{n}=$ tennce rostro vix longiores pilosæ, versus apicem vix incrassatæ, articulis inferioribus obconicis, exterioribus turbinatis, ultimo conico. Thorax elongatus ante basin coustrictam conicus, supra sulco longiundinali profundo insculptus. Pedes antici mediocres validi, posteriores breviusculi, femore compresso subus demte armato, tibia nonnibil flexuosa, tarso tibiz fere aeque longo, articulo penultimo biloho subtus spongioso. Flytra thorace duplo longiora, sul. depressa, sulcata, sulcis exterioribus punctatis, interstitis fere planis, tertin yuartoque a sutura interrupte-Ravo_tinctis.

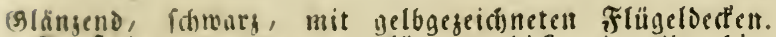
Sovf binter ien slugen verlängert, Did, vieredtig, bin. ten tief cimiefdnitrt, die $\mathfrak{B u r g e l}$ felbit einen fullen.

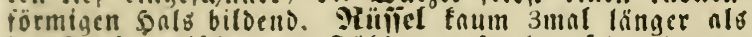
der fopf, ginifoen Den frühlern gefurdbt, fein binterer Theil oben mebr niedergedrüt nls Der Gopf, fein vor. Derer Theil bünner, walzig. Füblex fnum linger als Der Rüliel, bnarig, gesen ons Ende fllum verdid"t, die untern (Blieder verfechrtenlin, die obern freifelförmig, das lekte feglig. 9yittelleibsichlio lnnggegogen, vor ber zufammengef(hnürten $\mathfrak{B} u r g e l$ feglig. oben mit einer tiefen en̈ugs̆fur(t)e. 2orderfte Beine mittellnna, froiftig,

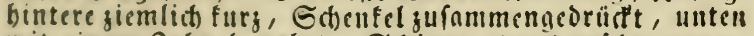
mit cinem 3nbn bewehrt, Gd)iene etwns geidsinungen, Fैu ungefibr fo lang nls die Schiene, fein vorlektes Blied zrocilnprig, unten fdirnmmig. Flügcloceten sovs velt fo lang als oer mittelleibsfdilo, ziemlich findare. orüdt, gefurdt, Die düfern Furden punftitidig, ore Stoifctenräume beinnbe eben, der 3te und the von der Nabt an ulterbrochen gelbgefärbt. 




\section{Fam. BRENTHIDES.}

\section{BRENTHUS (ISCHYROMERUS) MA. D A G I S CA R I ENS IS.}

(Brenthi nove species dure Mus. Escher-Zollikofer Tigurensis.)

Patria: Madagasear.

Lincas 11 longus. Nitidus, nigger. Mas anguslus, femina latior, valielior. Capuet el rostrme sexu diversu. Caput muris pone oculos elongatum, thoracis dimidiam partem longitudine snperans, evlindrieum, paulo pone oculos ad hasin usque plieulis transversis rugnolosum, capul/emine vix sextam thoracis partem longum, transversum, lave, postice medio impressum. Rostrom maris thoraci arque longum subtetragonum; parts postica antiea aque longa, illa basi, hac apiec aliquantum dilatata, rostrum femince thorace, et quidem hujus terlia parte, brevius; parte postica capiti fere aque longa, supra canali longitulinali impressa; parte autica postice simul cum capite aque longa, subeylindrica, subdepressa. Antenne thoracis dimidio paulo Iongriores, moniliformes articulis tribus ultimis majoribus. Thorax supra depressus lavissimus suleo profundo longitudinali insculptus,

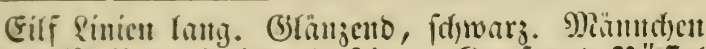

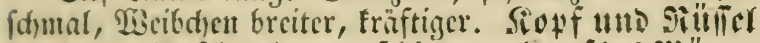

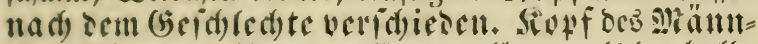
d)en hinter bent ?lugett verlängert, länger al: ber halbe

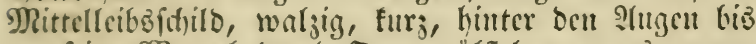

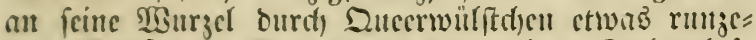

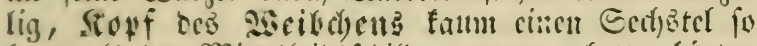
lang als ocr Mittelleibsift)ilo, quecr, glatt, hinten in oer Mitte cingebrilut. จilifier bes Mrännt)en?

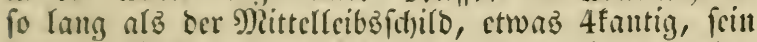
hinterer Theil fo lang. alz fein vorberer, jener ant ber

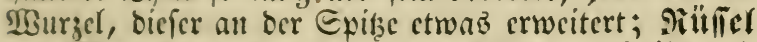

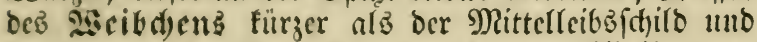
joar um beflen Drittheil; fein hinterer Theil uttge= fehr fo laug als ber Sopf, oben burd) cine fintgä= rime cintgeoritet; fein vorberer Theil fo lantg afb ocr hintere fammt bem Siopfe, beinahe waljig, ctwab

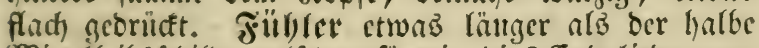

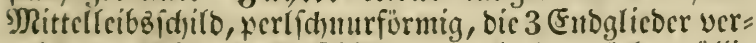

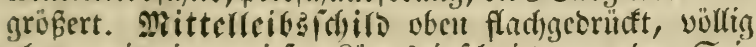

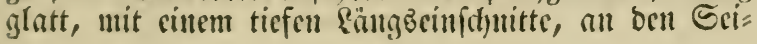


ad latera punctis crebris impressus; in mare elongatus, ab apice ad basin parum dilatatus; in femina Iongior latiorque, ovatus, basi ipsa in utroque anginstatus. Elytra ad hasin 1 1/8 lineam in mare, $13 \frac{4}{4}$ lineam in lemina lata, dorso depressa, ad suturam suleo lato, basi et apice, carina illic longiore, hic breviore in duos diviso, reliquo spatio punctorum seriebus postice et externe in sulcos transeuntibus impressa, punctis interioribus et basalibus minoribus, exterioribus et apicalibus majoribus, subtransversis; apice rotundata, margyinata. Pedes inter se longituline fere aquales, femore valido, precipue in femina compresso, medio incrassato dilatito, supra macula tomentosa, grisea tecto, anticorum intus ante basin dente acuto armato, apice ipso in femina incurvo, tibia compressa versus apicen griseo tomentosa, tarso tibia fere aque longo, articulis primo, secundoque obtrigonis supra margine apicali tomentosis et tertio bilobo subtus spongiosis, quarto his aque longo.

ten mit sidjten Dupfot beitodjen; beint Männtyen

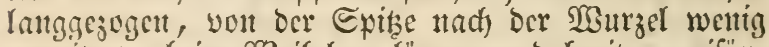
crwectert, bcint Meibdent länger unb breiter, eiför:

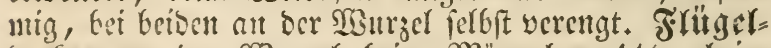

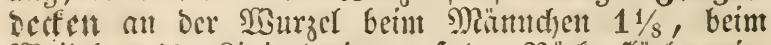

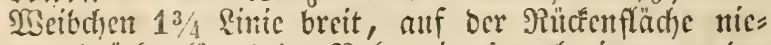
ocrgeoritcft, länge ber Piaht mit cinter breitett, at ber Minurgel mo Epise butid) cinten, bort längernt, hier fürjern Sicl, $2=$ getheilten Futrche, auf ber übrigent

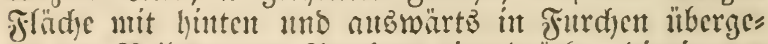

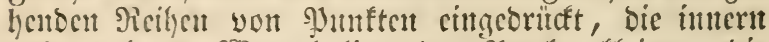

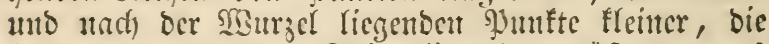

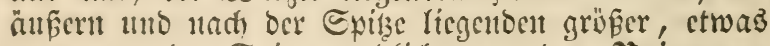
queer; an ocr Epişe rumblidy, geranbet. Beinte un= ter fid) an Rünge ungefehr gleid; ber Sctjenfel fräfs

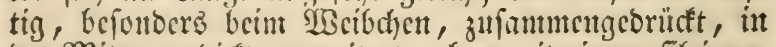
ber Mitte verbicft, erweitert, obent mit cinem filzigen, grauen flect befleioet, ber ber vorberftent intwentig

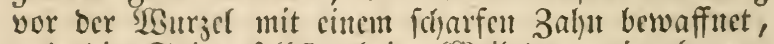

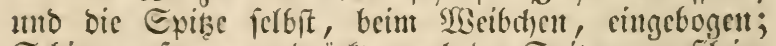

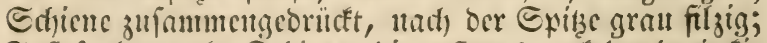

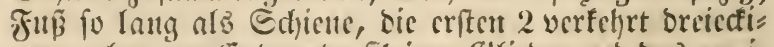
gett, oben am Entrante filzigen Ǵlieder unt bas zwei= lappige 3te unten fogwantmig, oas 4te fo lantg alo fie. 


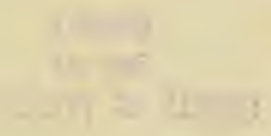



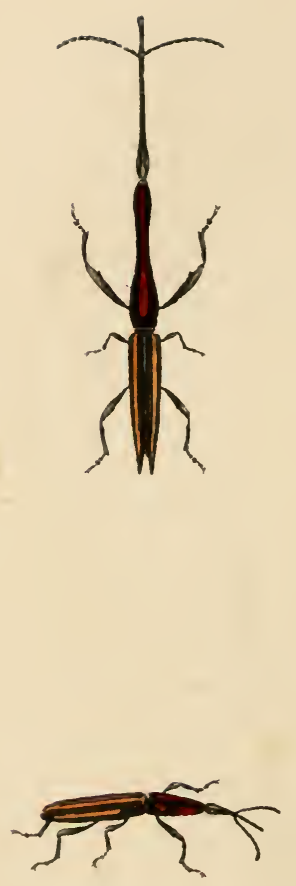

Burethees remtioraye 


\section{Fam. BRENTHIDES.}

\section{BRENTIUS I NGHOIA GO.}

(Sichönh. Gien.et sp. Curc. T. 1. P 1. p.5/5.)

l'atria: Ameriea meridionalis.

Longitudine fuam plurime varians secundum sexum et individua; nas lineas $6 \frac{1}{2}$ inter et 21 longus; femina $8 \frac{1}{2}$ ad $10 \frac{1}{2}$ lineas longa. Elytris flavorel fulvescenti-striatis, nitidus niger, sapius thoracis vilta media abdominisque et thoracis infera facie maxima parte castancis. Cruput, roslrum, thorax ac elytra sexu diversis. Caput maris obconicum, elongatum, femince aeque latum ac lonfium, postice parum angustatum. Rostrum maris elytris ayue longum, subtetragonum; postica parte quam antica ter longiore, basi capiti fere aeque lata, versus apieem sensim sensimpue angustius; antica parte apice alipuantum dilatata; rostrum fomince enm capite elytrorum dimidian longitudinem vix superans; parte postica conica capitiague Ionga parte antica hoc dnplo longiore, temu, eylindrica, decurva. Anlenue femori et tibis anticorum pelum acpue longa, apice parum incrassata, puhrscentes, articulis prioribus maris olsconicis,

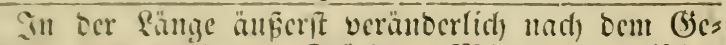

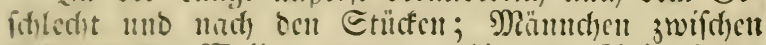

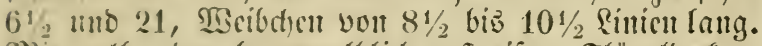

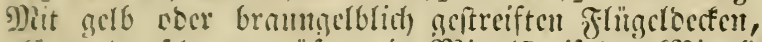

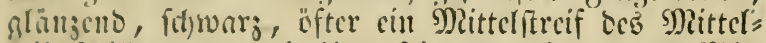

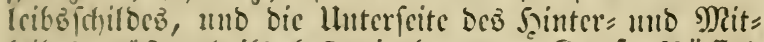

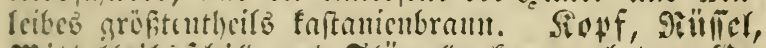

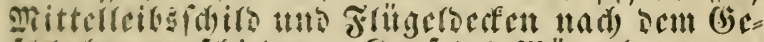
id)(ed)te verid)icsen. Siopf ocs Mäund)

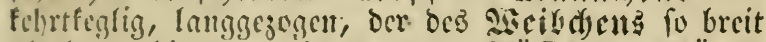

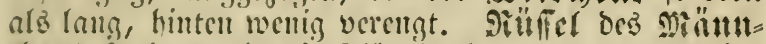

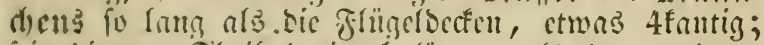
fein binterer Ilycil orcimal lünger als oer vorbere, all ber sfisurgel fait fo breit als ocr Ropf, und, ber Exibe hin allmilling sumner; frin vorberer Theil an

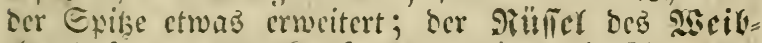
(d)

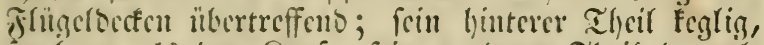

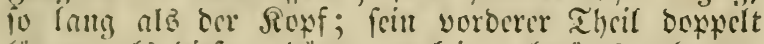

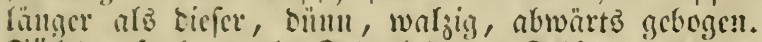

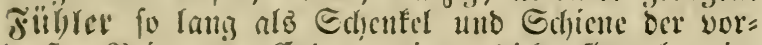

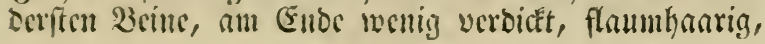


femina subghlobosis. Thorax postice sulco longitullinali profundo impressus, in mave valule clongatus, clytris aque longus, conum medio angusustatum referens, in femina conicus, convexior, elytris horumgue quilem tertia parte brevior. Elytra sulcis, uno proxime ad suturan jacente, lato, profundo, lavi aliisque tum hune aljacentibus, tum marginalibus, pro parte foveolatis, interque hos et illos punctorum seriebus $\vec{b}$ impressa, striis flavis sen fubescentibus, una interiore a basi usque fere ail apicem ducta et hic striola apicali sutura propiori occurrente, altera exteríore, nec basin nee apicem attingente, ornata; apice in mare ultra abdomen allenuato-elongata, in femina abdomen haul superantia, obtuse rotundata. Pedes longitudine inter se diversi, antici clongati, pracipue in mare, medii minimi, anticorum femore unidentato, posteriorum mutico, omnium tarso tibia fere aque longo, articulis primo, secundo tertioque bilobo subtus spongiosis, quarto his rque longo.

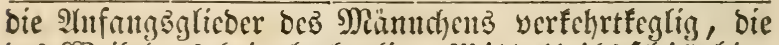

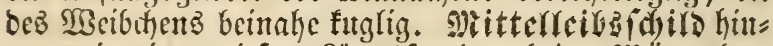

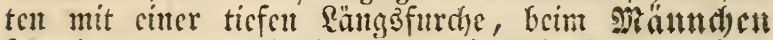

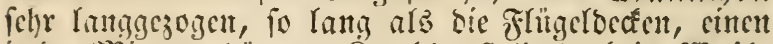
in ber s) Ritte verbïnnten Regel baritelleno, beim sicib=

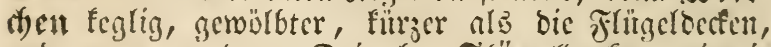
und zmar unt Deren Drittel. Frtïgerbedent mit é

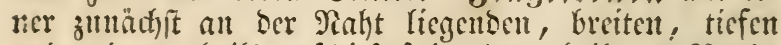
unt anbern, theils auf biefe forgenten, theilz ant Ranto vertanfenten, theilweife mit (jritbethen verfehenen Futr= d)en unto jwifdyen bicfen unto jencn mit 5 Ditnftrcifent ourdifjogen; mit gelben ober brautigelflidyen Strid)en

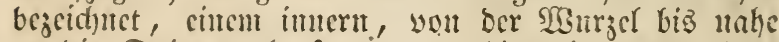
alt bie Exibe verlanfentent nino hier einent ber Paht nod) Mähern Enbifridycldyen begegnemben, unb cinem

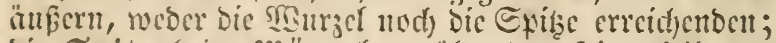

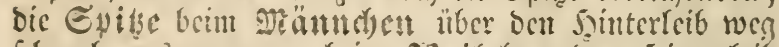

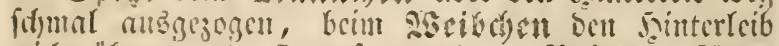

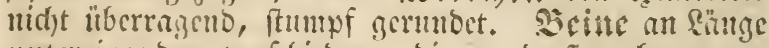
untercinanter verfdjicoun; bic vorberften langgezo=

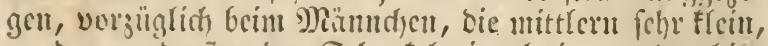

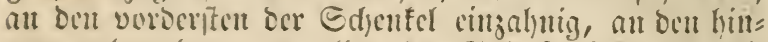

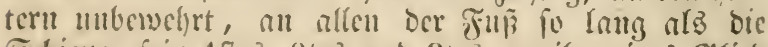

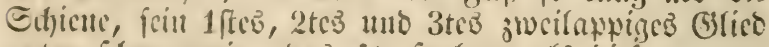

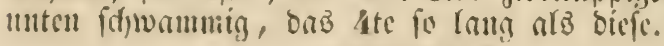




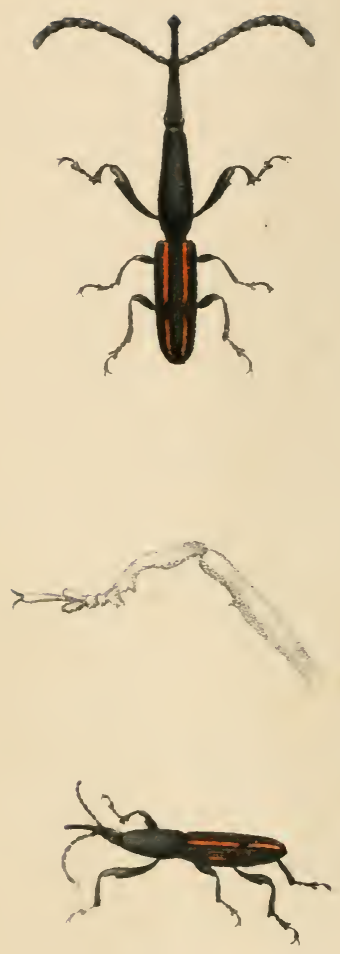

Clecoderess radulinostres 
Fam. BRENTHIDES.

\section{CLAEODERES RADULIROSTRIS.}

(Clacoderes radulirostris \& planirostris.)

(Schüul. Gen. \& Sp. Curc. T. J. P. 1 p. 363 \& 365.)

Patria: Brasilia.

Mas 15 lineas longus, ad basin elytrorum 15/6 lineam latus, femina brevior, 10 lineas longa. Nitidus, niger, subtus castaneus, elytris fulvescenti-striatis. Capul transversum, supra convexum \& in lobum posticum rotundatuin magine attenuatum productum. Rostrum, antennce \& thorax sexu diversa. Ro= strum in mare thorace vix brevius; postica parte quam antica aliquantulum longiore, conica, suprid canalicula tenui impressa, parte antica quam postica tenuiore, subtetragona, supra scabriuscula, apicc subito amplia:a; in femina dimidio thorace parum longius; postica parte capite ipso breviore, antica tenui, filiformi. Antennce versus apicem dilatata, in mare validiores, thoracem ac simul caput longitudine aquantes, in femina thoraci vix aque longar; articulis prioribus obconicis, freliquis subquadratis, ultimo elongato, hoc \& 4 antecédentibus pubescentibus, opacis, in mare la-

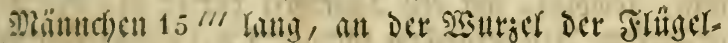

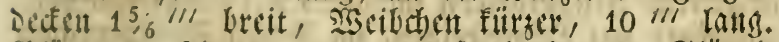

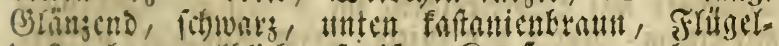
recen braungerbida gefreift. Sionf quect, oben ge.

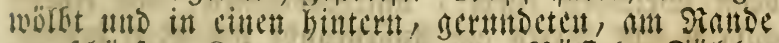

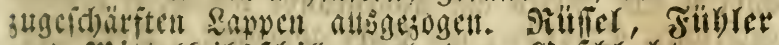

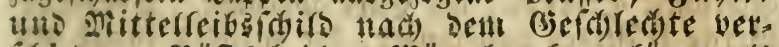

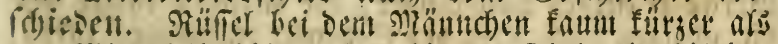
oct stittencibsithils; bet bintere sheil cilt bischent liäger nls der vordere, feglig; der wordere abeil cünnct als Der biutere, fait 4 fantio, oben ctwos raub, ant Ende plotslich crweitert; bein 23 cibenen

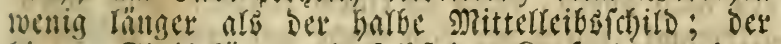
hintere Theil füract als felbet Der Sopf, Det wordere cünn, fasenformig. Fïhlet gegeu das cude erweitert, heim sllüm

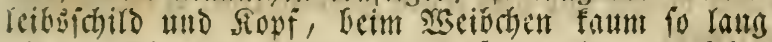

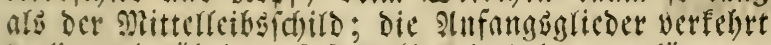

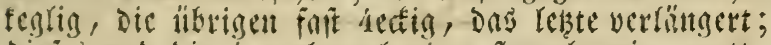

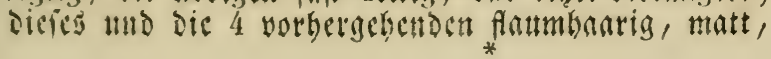


- tere versus thoracem spectante fimbriatæ. Thorax in mare elongatus, ad apicem parumper angustatus, elytris pane aque longus, subdepressus, canalicula tenussima impressus, in femina ovatus, convexus, elytris tertia parte brevior. Elytra interne sulcis, externe punctorum seriebus longitudinalibus impressa, in interstitio tertio stria, pone medium in mare latius, in femina augustius interrupta, alteraque brevissima ad marginem exteriorem fulvescentibus notata; apice truncata. Pedes antici reliquis validiores, longiores, medii breviores, omnium femore unidentato, tarsi articulis $1 \mathrm{mo}, 2$ do, tertioque bilobo subtus spongrosis, 4 to his rque longo, anticorum tibia biarcuata , primum arcu majore extus, tunc arcu minore intus curvata, subtus ante apicem dente valido, apice extus dente altero, intus unco bidentulo armata, inter hunc \& dentem primum in emarginatura fimbriata.

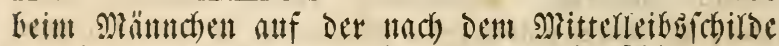
gerichteten Eeite geframît. Mitterfeibajediro beim

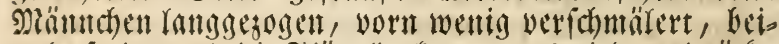

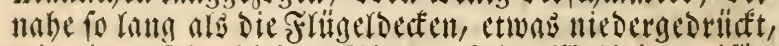

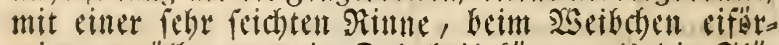

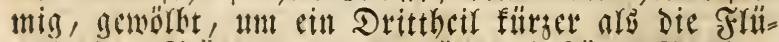

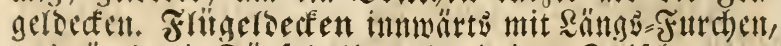

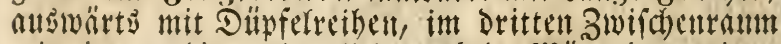

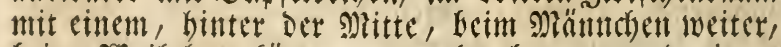

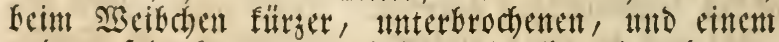
andern fegre furtsen am shafenrande riegenden Grauts gertsichen Etreifen; am Ende abgeitutst. Bsorerite

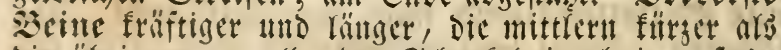
Die itbrigen; att allen Der Echenfer cingahnig, 1 ftes,

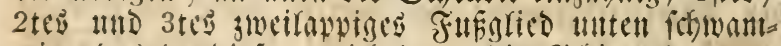

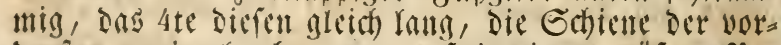

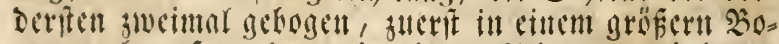

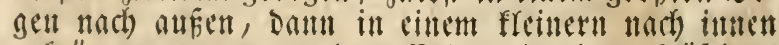
gefriimme, tenten vor bem Ende mit cinem fräftigen 3aht, ant Ende nutswäts mit cintem andern 3abu,

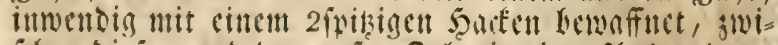

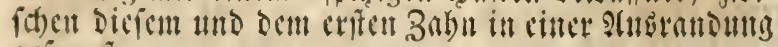
gefranit. 


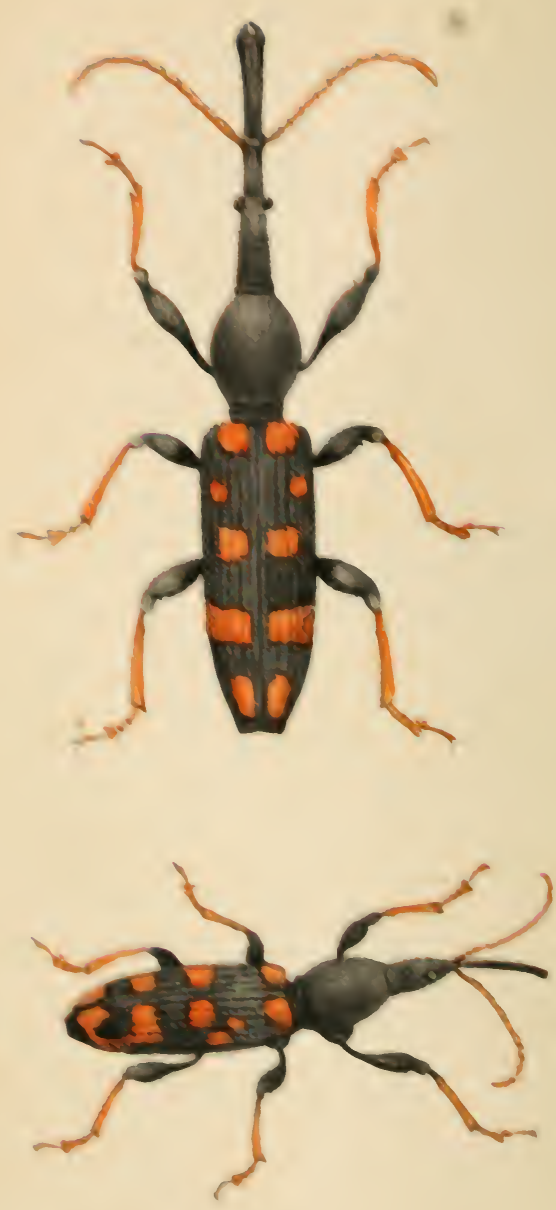

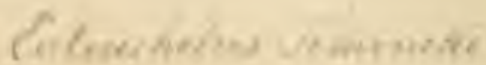




\section{Fam. BRENTHIIUES.}

\section{IUTA ACHELCS TEMMINCRI.}

(Gehomb lien. is S Cure $\mathrm{T}, \mathrm{P}$ 1. p. J58.)

Longritudine varians, usque ad 52 lineas longy"s, sed etian vix pollicem superans. Nitidus, nigger, antennis, striis sen maculis elytrorum, tibiis tar-isque anrantiacis. Caput pone oculos elongatum et rostrum subcurvatum sexu diversa. Maris caput longritudine fere thoracis, cvlindricum, pliculis transversis granulisque exasperatum; rostrun carinulis grannlisque scahrum: parte postica Inngyitudine dimidium cappitis squante: parte antica capitis longitudine, quadrilatera, apice dilatata, mandibulis exsertis, fere oblongis, apice dexteræ tri-sini-tre bidentato. Femince caput thoracis dimidimm Iongum, versus basin sensim dilatatum, pliculis granulisyue pancioribus, supra antice posticergue deficientibus; rostrum parcius grranulatum,

In ber Rünge rochielno, bis 32 sinien, aber aud faum mehr als 1 3oll lang. Glanzent, idjrarz, F̧üler, F̧lügeldecten= Etriche oder flecten, Edjienen unt fitse pemeranjengelb. Der hinter sen Tugen verlängerte Stow uno etwas ge=

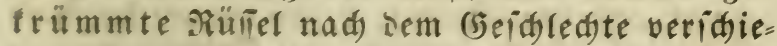
ien. Beim Männd)en ber Sefi faît yon ber Ränge

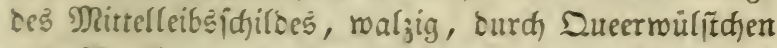
uno Sernchen rauh; ber Rulliel mit feinen Rielen uno fiondyen; iein hinterer Theil halb fo lang als ber Repf; lein vorberer von Ropflange, tieitig, am Ente erroeitert, cie Decerfiefer vorliegent, etrả länglich, Las Ente bes redten 3 = bes linfen 2jahnig. Beim Siseibden ber Repf halb fo lang als ber Mittelleibs= ichilo, nad) ber Wurzel hin allmälig erweitert, mit menigen uno sben nadf yorn uno hinten fehlenten

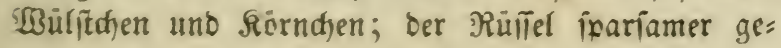


supra fere lave: parte postica longitudine trientem capitis vix superante : parte antica capitis duplicem longitudinem at modo trientem latitudinis requante, cylindricum, mandibulis suboccultis, utraque apice dilatata, tridentata. Antennce filiformes. Thorex subovatus antice constrictus. Elytra ad apicem truncatum utrinque angulo obtuso prominula, convexa, sulcis longitudinalibus, duabus suturalibus angustis, reliquis latioribus foveolatis exarata, maculis aurantiacis ornata ex striolis subelevatis longitudinalibus, compositis, his in certis individuis, nee vero in depictis, rarioribus, disjunctis, ut affertur. Pedes dimidium corporis longi, antici elongati, omuium femore denticulo armato, tibia compressa, subrecta, tarsi articulis primo, secundo, tertioque bifido subtus spongiosis, quarto his reque longo.

förnt, wben beinahe glatt: fein hinterer Theil faum ränger alz ein Drittheil beßz Ropfez: feit vorberer ooppelt fo lang uno einen Drittheil fo breit alb ber Ropf, walzig, bie Dberfiefer zientlich veritectt, beibe

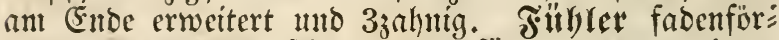
mig. Mitterleigaldirs faft eiförnig, vorn cinges idnitrt. Frïtgeroeffen am abgeitukten Enbe beiber= feitz in cutem ftumufen Sinfel etwas voripringend, gewoulbt, mit fänģ̧furchen, 2 fothalen an ber Nath uno hieranf andern, breitern, mit (Srubd)en verfehe: nen, Durtfoggen, utto mit pomeranjengelben, aub

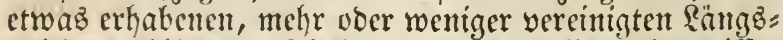
firid)en gebildeten, Flecten, auth angeblict bei gemifien Stitcfen, nimmermehr aber bei Den abgebildeten, tutr mit foldyen einjelnen, wenigen Strichen gefd)mildt. Beine von halber Rörperlänge, bie vorberiften ver= längert, alt allett ber Edhenfel mit cintem Dähndhen,

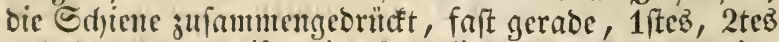
แแto ono the fo lang alo biefe. 



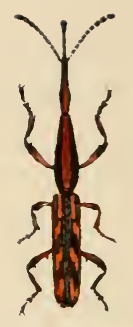<smiles>[C]=C</smiles><smiles>C=C=CC</smiles><smiles>CCC1(CC)OC(=O)C1(CC)CC</smiles>

Srenthes virlnevedes 


\section{Fam. BIRENTHIDES.}

\section{IR E N T II US VUL NER A TUS.}

(Schôuh. Gen. de S Sp. Curc. T. 1.P. 1. p. 5ris.)

Patria: Brasilia \& Cayenna.

Longitudine varians sectundum sexum et individua; mas $10 \frac{1}{2}$ ad $12 \frac{1}{2}$ lineas longus, femina $81 / 2$ ad 10 lineas longa, latitudine $1 \frac{1}{3}$ linea ad basin elytrorum. Antennis nigris, subtus castaneus, rostri abdominisque apice et meso-metasternique latere nigris, supra nigger vitta media thoracis, capitis et postice rostri partis castanea, elytrorum striis maculisque ferrugineis, pedibus nigris femorum basi tibiisque pro parte castaneis. Rostrum pedesque postici sexue diversa. Caput obconicum, postice inter tubereula duo impressum. Rostrum maris subtetragonum, longitudine thoracis; postica parte antica arque longan, crassiuscula, capiti scilicet fere reque lata, subus versus caput griblo; parte antica aliquantum decurva, temiore, apice parum dilatata, rostrum femine dimidia thoracis parte vix longins; postica parte subtetragona,

Sit oer fïnge wed) fetno nad) Dem (Sefdrledte mo

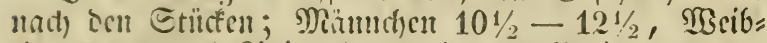

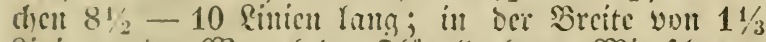
finic an ocr Murjel ber Fltigcldecten. Mit fowar=

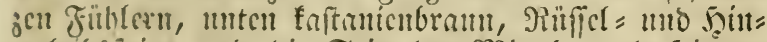

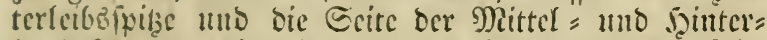

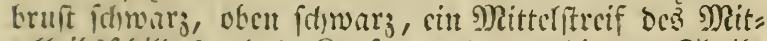

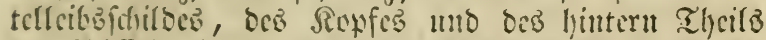
bes Siliffels fnffanicubram, Stritye unto Ffecte ber

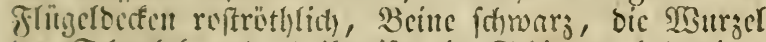
ocr Eshentel mo theifmeife bie Echienen foftanicu=

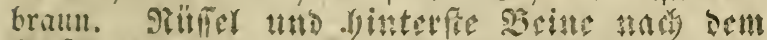

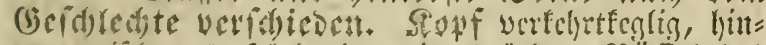

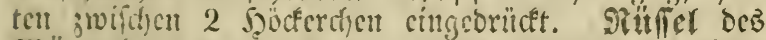

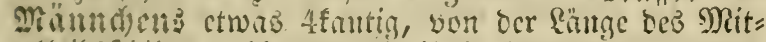
telleibaffitlocs; hinterer ahcil fo lang alb ber vor=

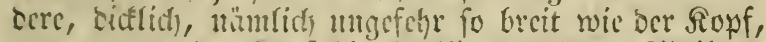
unten gegen ben Siopf hin bueftiy; voroerer Theil ct= waro abruatt

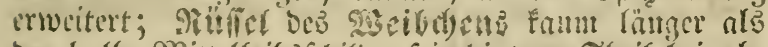

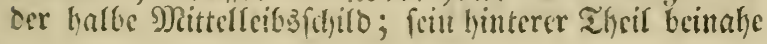


crassinscula, autice parum angustata, eapite ipso lere breviore; parte antica decurva, capitis duplicem longitudinem aguante, cylindrica. Antennce thorace breviores, apice incrassate, articulis plurimis arfue latis ac longis, pubescentibus. Thorax elongato-conicus, basi constrictus, supra subtusque eanali longitudinali impressns. Elylra thorace sesquilongiora, piceo-nigra, strie longiludinalibns, una basali, duabus apicalibus, ma interiore, altera exteriore fasciisque obliquis duabus in disco ferrugineis notata, sulcisque longitudinalibus pro parte foveolatis, aliis ad suturam aliis ad marginem, et inler hos et illos punctorum seriebus yuinque impressa. Pedes antici elongati, postici mediocres, medii minores, omnium femore unidentato, posticorum in mare aliquantum elongato, curvatoque, et prope basin dente curvato aucto, tibia compressa, posticorum in mare flexuosa, dilatata, tarso tibia acfue longo, articulis primo secundo tertioque bilobo subtus spongiosis, quarto his aeque longo.

4fintig, bidflid), nad) worn ctwas verengt, fïrger alB ber Ropf; feil vorderer Thcil abwärtz getrummt, bowpelt fo lang alb ber Ropf, walzig. Fithlet fïr=

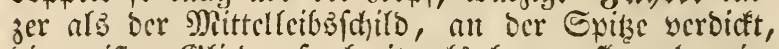
bic meiften Gificoer fo brcit alb lantg, flatmlyaarig.

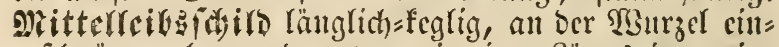
gefdumit, obent nno unten mit cuncr \&üngsinute cints georidet. Fritgeldedfen antorthalontal fo lantg als

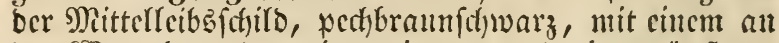

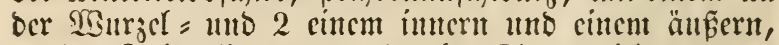

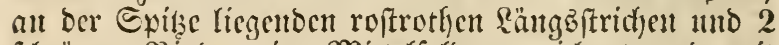
fdrägen 2 indent im Mittelfeloe gezcid)net und mit

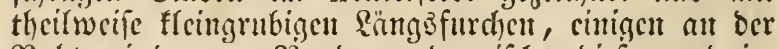

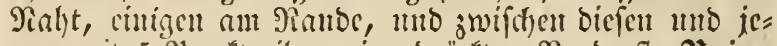

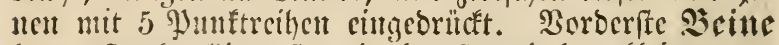
langgeftreft, binterite mittelgrof, mittlere fleiner, an allent ocr Ed)cuffer cinzahnig, ocr ber binterften beim

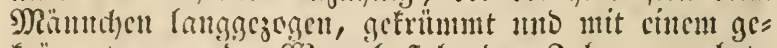

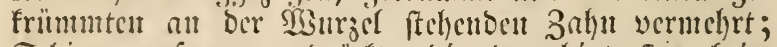
Edicne jufanmengebritcft, bic ber hinterfien beint

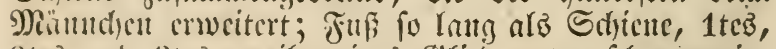

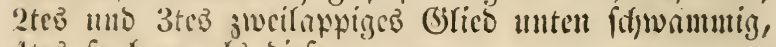
trez fo laniz als dicf́. 


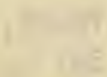

e

- 

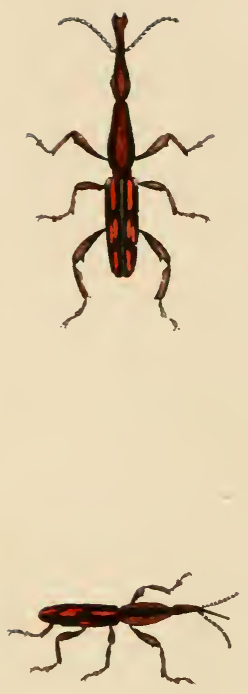

chenthers livecuollis 


\section{Nam. IBRENTIIIDES.}

BRENTHUS LINERCOLLIS.

(Schönh, Gen. \& Sp. Curc. T. I. 1. 1. p. 5/7.)

Patria: Brasilia.

Longitudine varians secundum sexum; mas lineas $11 \frac{1}{2}$ Inongus, femina 8 longa; latitudine $11 / 3$ lince al basin clytrorum. Elytris ferugineo-notatis, castaneus, rostri antica parte antennisque obscurioribus, vittis duabus superis thoracis capilisque pedumque basi et geniculo nigris. Caput, rostrum pedesque postici sexu diversa. Caput obconicum, in mare elongatum, in femina vix longius quam latum. Rostrum maris thoraci aque longum, parte postica quam antica vix longiore, hasi capiti acpuc lata, parte antica Jecurva, subtus plana supra usque arl medium oblique compressa et canaliculata, apice deplanata, basi dimidiam capitis latitudinem afuante, apice dilatata, mandiloulas exseręnte clongatas, apice obliçue tuncatas emarginatas, interne dentibus duobus, nno ex angulo inferiore apicis altero majore tuberculo lateris interioris medio formatis armatas. Rostrum femince thorace tertia lujus parte brevins, parte postica thoracis quar-

Ju ber fintge wedjiclno nach bent (Sefdyledte,

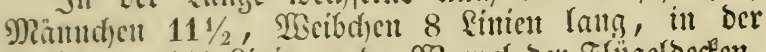
Breite vol $1 \frac{1}{3}$ finte an oor Murzel ber flïgeldeden.

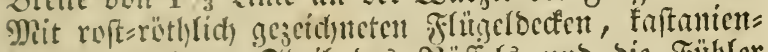
braul, vorberer Theil bes भïffers und bie Fühler

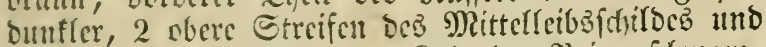

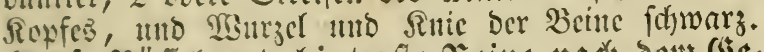

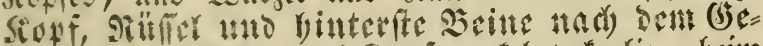

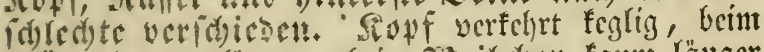
Mäund)en verlängert, bcim siociboben faum länger

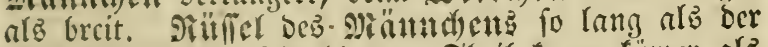

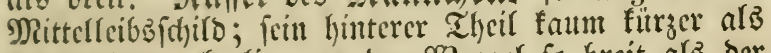
oer vorbere, feglig, aut Der SMurzel fo Greit als ber Sopf, abmürţื gebogen, unten flach, oben bỉ zur Mitte fiticf zufaumtengebrüdt und gerinnt, am Enoc

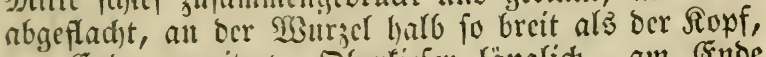
ant Enbe erweitert, Dberficfer ränglich, ain Ende fdriag geifust, aubgerandet, itmocnoig mit 2 כälynent bewaifinet, cinent von ber mutern Ecfe Der Spiłze, und

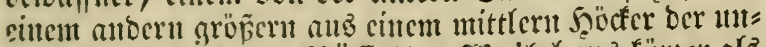

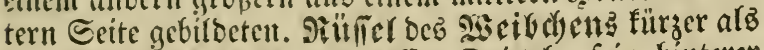
ber Mittelleibzidjilo mo beflen Drittel; fein hinterer 
tam partem vix acpuante, conica, parte antica curvata, thoracis tertiam partem longitudine parum superante, tenui, cylindrica, mandibulis suboccultis. Antemne crassiuscula, thoraci pane aepue longa, arliculis plurimis aeque longis ac latis. Thorax conicus, basi constrictus. Elytra thoracem ejusque dimidium longitudine aquantia apice truncata, al suturam et marginem exteriorem sulcis, reliquo spatio punctorum sericbus quinque impressa; striolis late ferrugineis ornata, una marginali, reliquis suture propioribus, harum prima longiore cum adjacente alia punctiformi, secunda et tertia mediis, juxta positis, quarta apicali. Pedes antici et postici inter se subacque longi, medii is breviores, omnium femore unidentato, posticorum mari quam femina longiore, anticorum tibia intus denticulo medio instructa, posticornm in mare apice incrassata et intus paulo ante basin ultra medium us(jue membranaceo dilatata; tarso tibia fere aque longo, articulis primo, secundo, tertioque bilobo subtus spongiosis, quarto his aeque longo.

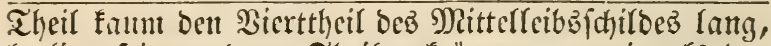
feglig, fein voroerer Theil gefrïmmt, wenig alb belt

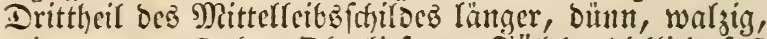
mit etwas verfitedten Dberfiefern. J̈ith)(er bicflid), fait fo lang als ber Mittelleibüfdillo, bic meijten SSlieber fo

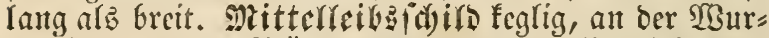
zel cingeidnütt. Frlïgelseffen antorthalbmal fo lantg als ber Mittellcibsfotill, ant Enoe abgeltubt, an ber

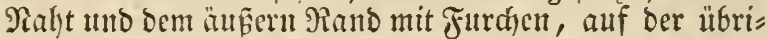
gen Fläd)e mit 5 Juntreiben cingebritat; mit hell roît

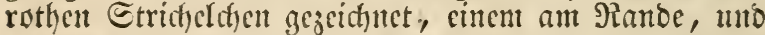
andern näher ant Der Naht, von biefen onb erje zientlidy Iang mit cinem baneben لiegenden putntförmigen Stris

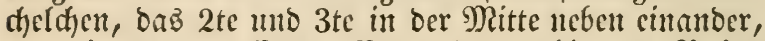
uno cin 4 tes am Endoc. Sorberfite und hinteríte 3 cine einanber an \&änge fait gleidy, bie mittlern fïrger alb fie; aut allen ber Sibenfel einzahnig, ber ber finteriten länger bcim Männdyen alb beim Mcibdyen, an bent vor" beriten vie Edjiene innen mit cinen mittlern Bälundyen veriehen, an bent hinterifen beim Männd)en ant Enbe verbicft und inten fur; vor ocr Murjel bis vitber bie Mitte

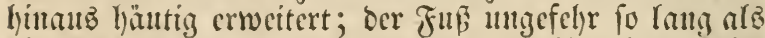

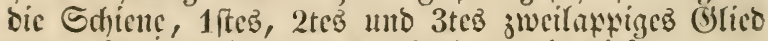
unten fdnonmmig, ong the fo lang als bicke. 


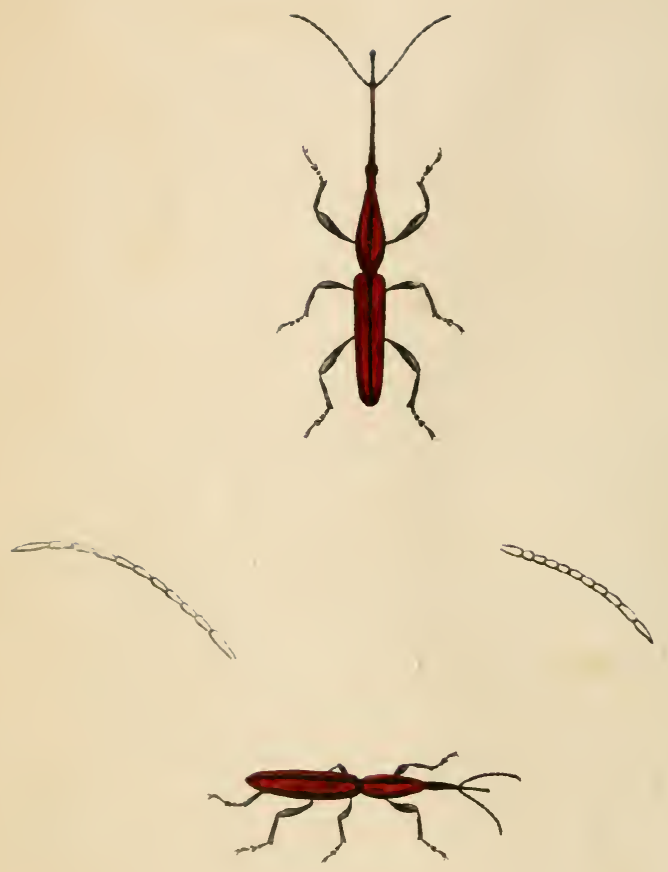

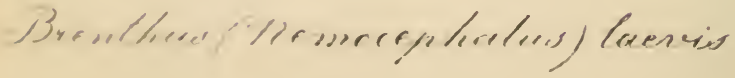




\section{Fam. BRENTIIDES.}

\section{BRENTIIUS (NEMOCEPHALUS) LAVIS.}

(Schünh. Cien. d sp. Cure. T. I. r. 1. p, 5is.)

I'atria: Brasilia.

Longrituline diversus secundum sexum, mas 13 lineas longus, femina 11 longa; latitudine $1 \frac{1}{2}$ linea ad basin elytrorum. Castaneus elytris abdomineque nitidis, rostri apice, antenuis, thoracis vitta media, sutura margineque elytrorum, pedibusigue nigris. Capul, rostrum et antenne filiformes sexu diversa. Capul maris pone oculos elonfatum, fere dimidiam thoracis partem longitudine aеquans, cylindricum, copme femince aque longum ac latum, vix quintam thoracis partem longitudine aefuans. Rostrum maris subtetragronm, longitudine capitis thoracisyue, capite parmm angnstius; postica parte thoraci acyue longa, supra canalicula, al basin parum conspicua, impressa; antica parte eaput longitudine adpunte, decurva, supra

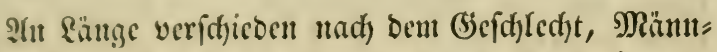
d)en 15, Meibd)en 11 sinien lant ; in ber Breite von $1 \frac{1}{2}$ Sintie an tor $\mathfrak{B u r g e l}$ ber frlitgeldecfen. Rafta= nicutraun, Flügeldedfen unb Şinterleib glänzend, Rüf

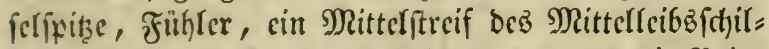

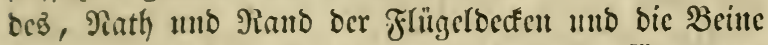
farwarg. Sopf, silifier und sie faicuförmigen

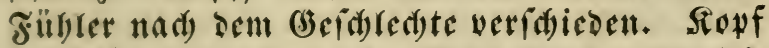

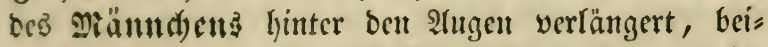
nahe halb fo lang als ber Mittelleibsifdild, walzig,

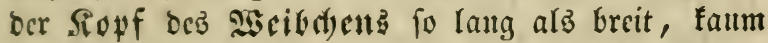

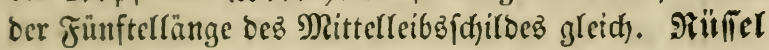
bes Miänudicntz faft 4fantig, yon ber eänge beş. תopfes unt Mittelfeibşfdildez, wenig fdymaler als ber Sopf; fein hinterer Theil fo lang alछ ber Mittel= reibşfdilo, oben mit einer, an ber $\mathfrak{B}$ urzel faum bes 
caniculata, apice aliquantum dilatata, rostrum fiemince thorace brevins, parte postica capiti vix acpue longa, subtetragona, supra canaliculata, parte antica porrecta, tenuiore, cylinklrica, thoracis dimidiam longुitudinem requante. Antennce in mare thorace cum capite aliçuantum longiores, in femina illi solummodo aque lonģae. Thorax conicus, basi constrictus, supra sulco longitudinali impressus. Elytra thorace pane duplo lonģiora, fere levia, ad suturam bisulcata, sulco interiore latiore, exteriore angustiori basin non attingente; ad humeros in tuberculum protracta; postice anguste marginata. Pedes sat elongati, antici reliquis aliquantum longiores, omnium femore nutico, tibia recta, tarsi articulis primo elongato, secundo tertiogue bilobo subtus spongiosis, quarto duobus antecedentibus aque longo.

merfbarent, Minne Durdyjogen; fein vorberer Theil

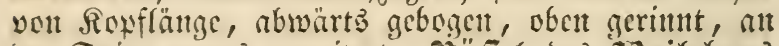

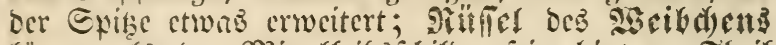

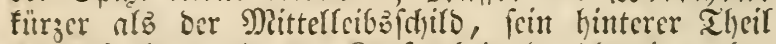

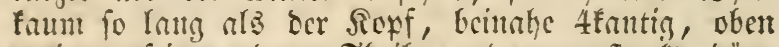
gerimt, fein vorberer Theil gerabe vorgefteceft, bün=

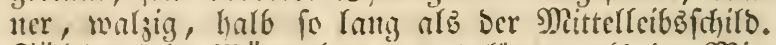

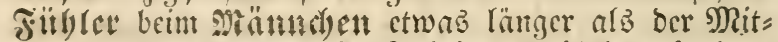
tellcibefchilo mit ben Ropf, beim siscibd)en fo Iang

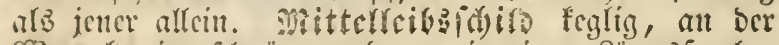

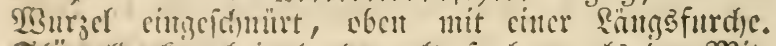

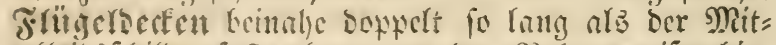

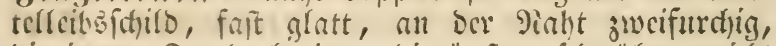
bic iunere furd) breiter, bie änsere folmäler, nid)t

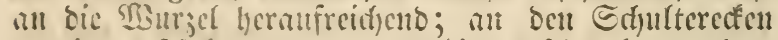
ju ciuten Syéfer vorgezogen; linten fühmal geranbet. Bicinte jienlich lang gezegen, bic vorberftent ctwa

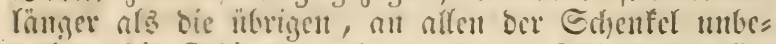
welirt, bie Echicute girnse; nıt bent Tuß bnä crfte, verlingerte Gilics, bas 2te mis zweilatipige 3te unten

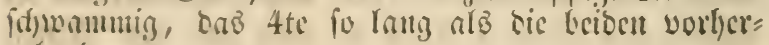
zetrenten. 


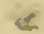

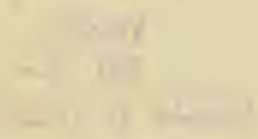




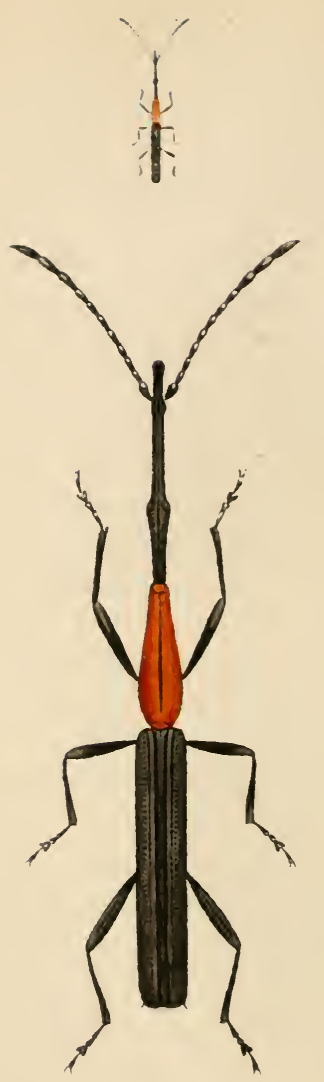

Suthnomerens raytlinoderes 


\section{Fam. BRENTHIDES.}

\section{ISCHYOMERUS ERYTIRODERES.}

(Ischnomerus eryeluroderes Chevrolat. Mus. Sillermaun Argenturatensis.)

Palria: Manilla.

Mas. Lineas $\mathbf{\zeta}^{3 / 4}$ longus; lineam $1 / 2$ al basin elytrorum latus, inde gracillimus. Opacus, piceoniger, thorace rufo testaceo. Caput thoracis dimidia parte lonģius, pone oculos elonģatum, cylindricum, apice parum latius, supra scabrum et sulculo lonģitudinali ab apice al nedium ducto impressum. Rostrum thorace; et yuidem hujus quarta parte, longius; parte postica ter ac antica longa, semicylindriea, supra plana, juxla carinam longitudinalem median utrincpue suleata, subtus convexa; parte antica nitida, apice subdepressa, aliquantum dilatata, hasi supra sulcata. Antenne rostro eum eapite arque longae, filiformes, apice parum inerassatx, articulis tribns ultimis elongatis, pubes-

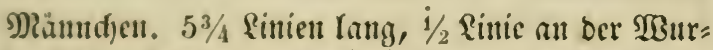
jel ber Fliigclocefen breit, fomit fehr foylant. Matt,

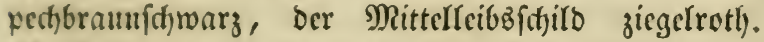

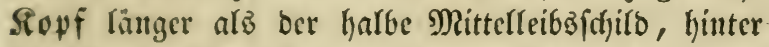

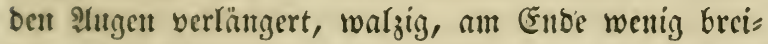
ter, oben rauth uno mit ciner feinen vout bem Enbe nad) ber Mitte hin gejogenen Furd)e cintgebrüctt.

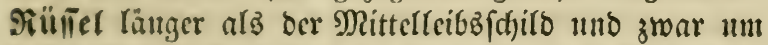
beffen \$iertthcil, halbwarzig; fein hinterer Zheil brcis mal fo lang als ber vorbere, oben flad), neben cinem mittlern \&ünģૈficl beiberfeit gefurdyt, unten gewölbt; fein vorberer Theil glänzeno, an ber Epike etwaz nicoergeorildeft uno crweitert, an ber $\mathfrak{S u r g e l}$ oben ges furd)t. Fïlyler fo lang als Rïffel uno Sopf, fa=

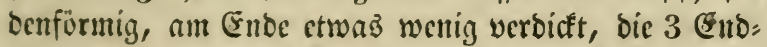
glieber ranggeftreft, flammlyaarig, bic vorkergehenben 
centibus, antecedentibus obconicis. Thorux conicus, basi constrictus, supra suleo lonģitudinali impressus. Elytra thoracem cum capite et rostro longituline acguantia, spina apicis aeuta prope marginem extcriorem armata, punctorum seriebus 6 et sulcis, uno marginali, duobus suturalibus, horum interiore latiore, profundiore, rectangulo, lavi, exteriore angustiore, punctis instructo impressa. Pedes graciles, dimidlium corpus longi, medii reliquis paulo breviores, omnium femore tib:aque compressis, illo mutico, utrinque per longitulinem sulcato, hac vix flexuosa, tarso tibia aque lougo, articulis primo, secundo, tertioque subtus sponģiosis, primo elongato, tertio bilobo, quarto duobus precedentibus eque longo. Abdominis primum seģmentum subtus et metasternum utringue serie punctorum minimorum instructum.

verfehrt feglig. Mitterfeigaldirs feglig, an ber

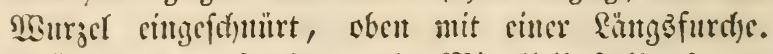
Sritgersedfen fo rang ala Mittelfcibafdjirs fammut

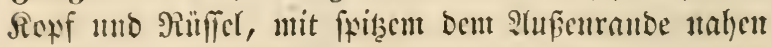

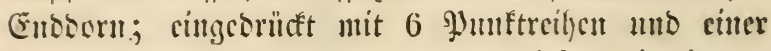
Siant = unb 2 Sinhtfurd)en, you biefen bie inture brciter, ticfer, rect)twinfelig, glatt, sic "̈แB̈ere enger,

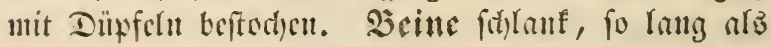
oer halbe Sötwer, bie mittlern etwas fitroer atz bie ilbrigen, an allen ber Edyenfir mo bie Edjiene zu= fammengeorindt, jencr unbewehrt, bciberfeitä ber \&äntge

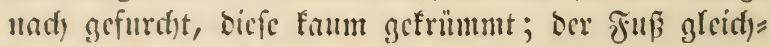

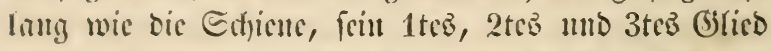
unten f(t)manmig, bas 1te langgcitrect, bas 3te z'mcilntyig, bus 4te fo lang als bie beiben vorlyers

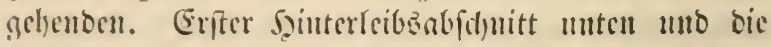

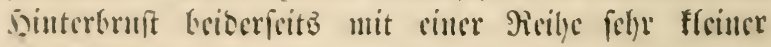
Jumftitidic. 



$$
\text { I }
$$




\section{TAPHROIERES S'TRIOI.A'TUS.}

('I'aphroderes n. sp. Germar Mlus. Patria: Brasilia.)

Nigricans thorace ac ventre castaneo-rulis, olytris ferrugineo-notatis. (iput quadratim, postice in collum bulbilorue incrassalum. $h^{\prime}(1, y / 20 m$ deflexum, arcuatum, capite duplo. longius, postica parte conica, ancico filiformu. filtemllace medion rostro insertae, rostro aeque longac, submoniliformes, articulis tribus ulcimis majoribus sub-compressis, clavae speciem constituentibus. T'hurnx valde elongatus, dimidio antico quam postico duplo angustiore, lateribus latius excavilis. Perler compressi, breves, tibia quam tarso dimidio \& amplius breviore, tarso subums setuloso, posteriorum primo articulo asticulis secundo \& tertio simul sumtis aeque longo lilytı a sub-rugulosa, sericlus punctorum longitudinalibus impressa, apice lacvia, juxta suluranu sulco exarata, valile elongala, linearia, apice aecque lata ac basi, truncata, ante appicem oblique impressa macula apicis, striolisque tribus, una ante medium, duabus pone medium, harum cxtemore breviore fungincis notata. I'mler lateribus apuceyue excavalus.

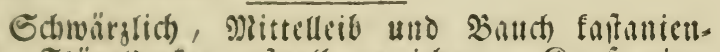
rotb, Flügeldeden roligelb gejeidunct. Sinpt vier,

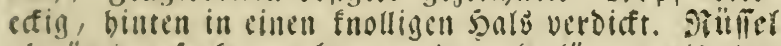
abmärty gelente, gebogen, doppelt länger alo der sept, fein binterer Theil fenlig, der vordere faden.

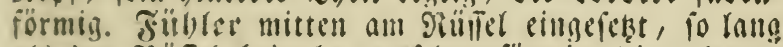
als ber Sil̈liel, beimabe perlid)murförmig, die 3 letsteil Slieder grïber, etwas zufammengedridat, cille $\mathcal{A r t}$

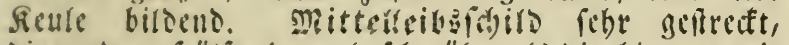
die vordere sälfte soppelt fomäler aly dic biutere, mit weit auggeböblten Sciten. Scine zufanmengedrifat, furg, Gdictle um die Sälfte uno mebr fürger als der

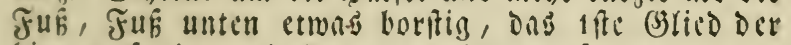
bintern io lang als dns 2 te und 3 te zufammen!enom.

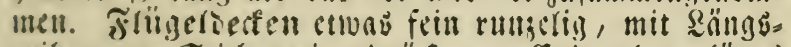
reiben von Stiden eingedrüift, am Enbe glatt, läng der Sabt mit cincr Jurche cingegraben, fibr lang. gejogen, linear, am Ende fo brit aly an der SBar. jel, vor dem Ende fitrïg cingeorüct, cin Endfect und 3 Stricheldbell, cills vor, 2 binter ier Mitte, Davon das äufere fürget, roltack. Siand all dell

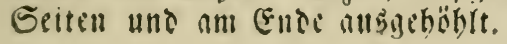





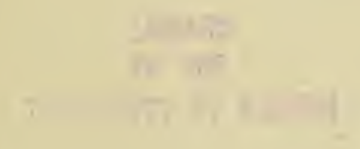




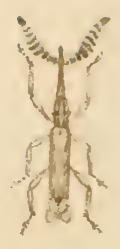

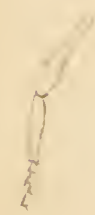

Illorems Cetranrens 
FaIM. ULUCERIDES.

\section{ULOCERUS TLTRAURUS.}

(Ulocerus nova species. Mus. Werthemanu Basileensis.)

Patria: Buenos-Ayres.

Lineas 8 longus, ad basin elytrorum $1 \frac{1}{4}$ lin. latus, inde sat gracilis; compresso-cylindricus; griseosquamosus, subtus \& in elytrorum dorso fusco-striolato exalbidus, rostri antica parte in femina nuda, nigra. Caput thorace triplo brevius, pone oculos elongatum, aliquantum longius ac latum, postice abscissum, supra sulco longitudinali $\&$ in rostri posticam partem extenso impressum, oculis lateralibus, rotundatis, prominentibus. Rostrum capite plus duplo longius, parte postica capiti subæque lata, in mare co pæene sesquilongiore, in femina ei xque longa; parte antica in mare capiti vix xque longa, quartum antennarum articulum non attingente, scalorum, mandibulis solis glabris, nitidis, nigris; in femina quam caput pane sesquilongiore, quartum antennarum articulum pæne excedente, cylindricum, glabrum, subadscendente. Antennce rostro paulo longiores imbricato-squamosæ, 12-articulatæ, arti-

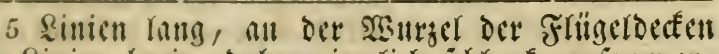
$1 \frac{1 / 4}{4}$ Sinien breit, baber jiemlich fd)lanf; julammen.

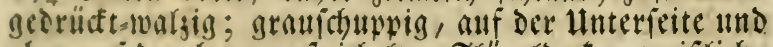
ohen nuf Den braungeîtrichelten Flïgerdeden weiślich,

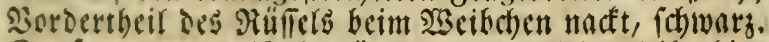

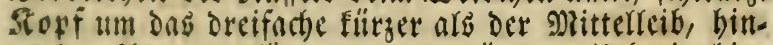
ter ren sugen verfängert, etwag länger als breit, bitt: ten afgefdonittell, obell mit eitter auch auf den Sinter-

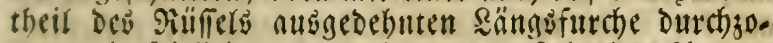
gen, mit feitlichen, germbeten, voritebenden Sugen. giiinel mebr als boppelt fo lang als ber fopf, det bintere ibeil beinabe- io breit, beim Mianneben fajt

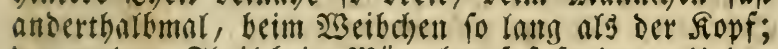
rer vorbere Theil beim Mlännchen fait fo lang als ber Sopf, dns 4 te F́tihlerglied nidst erreichend, rauth, nut die sberficier fabl, glängend, fhwarz; beim Şeibchen beinabe andertbalkmal fo lang als ber Jopf, über das 4te Fühlerglied beinnte wegreichend, walgig, fahl, etwas anfiteigend. Fiilster wenig länger als Der Fopf, jiegelartig beichuppt, 12 gliedig, die mitt. 
culis mediis depresso-dilatatis, reliquis obconicis, quatuor ultimis arctissime connexis, agre discernendis, articulum tamquam unicum constituentibus . octavo aque magnum, conicum, acuminatum, squamis destitutum, nigricantem. Thorax elongatus, carınis $\{$ longradinalibus, tuberculisque 6 transversim per medium positis instructus, apice angustior, pone lunc constrictus, basi bisinuatus. Elytl a thoraci. capiti \& rostro simul sumtis aque longa, primo parum latiora, elongato-quadrata, punctorum seriebus \& costa suturali longitudina!ibus notata, postice ad suturam syuamarum fasciculo instructa, tunc declivia, apice explanato-producta, anguloque exteriore fumbriato-squamosa. Pedes circiter dimidium corpus longi, femore mutico, tibia compressa, elongato quadrata, versus apicem angustata, apice inerma, tarsi articulis primo, secundo, tertioque bipartito subtus spongiosis, quarto duobus precedentibus aque longo, unguiculıs parvis.

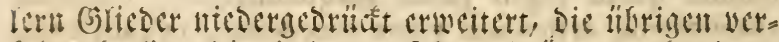

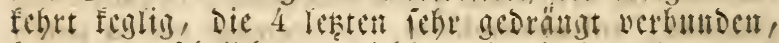

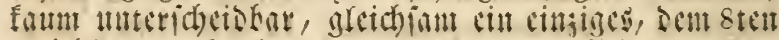

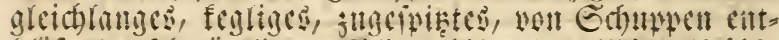

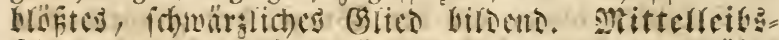
fálo geitreat, mit 4 sängsfielen, tmo 6 sttect itfer

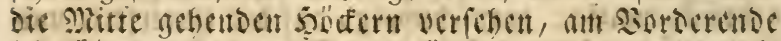

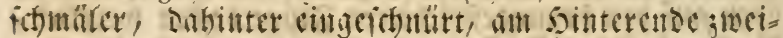

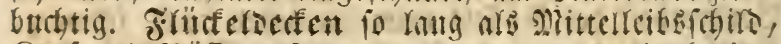
Ropr und Ruffer jufammen gettommen, wetig breiter ald ter crite; gettredt bieredig, mit utht ser sänge

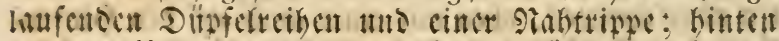

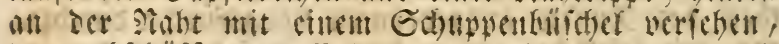

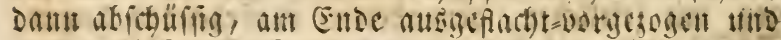

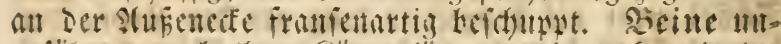

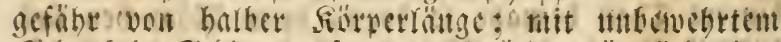

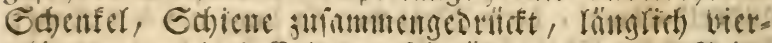
ectig, gegen das Enoc veridamullett, an ser Gpitse

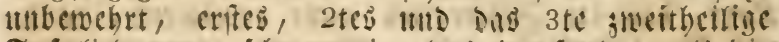
Fufiglico unten fowammig, tas 4 te fo lang als tic

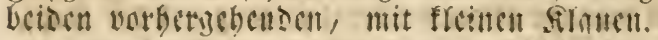




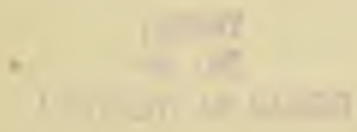

.

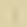



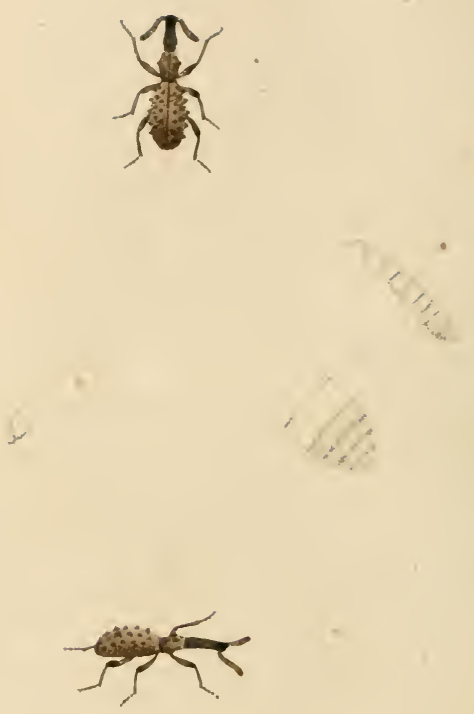

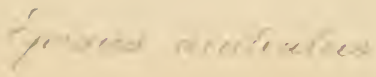




\section{Ham. ULOCERIDES.}

\section{EPISUS ACULEATUS.}

(Exisus aculeatus Schönh. Mus Silbermamn Argentoratensis.)

Patria: Promontorium Bonæ Spei Africæ.

l.ineas 6 longus, trans medium elytrorum $1 \frac{1}{2}$ lineam latus. Opacus, ater, grisco squamosus, antennis pedibusque etiam parcius nigro-setosis, capite rostroque nudis. Caput \& rostrum thorace parum angustiora, eoque sesqui longiora, puncta, cylindrica, supra sulco medio longitudinali alteroque inter oculos transverso impressa; caput rostro paulo brevius, aque longum ac latum, pone oculos elongatum; rostrum medio parum angustatum, apice utrinque lobo acuto \& tuberculo liuic suprajacente, posteriore instructum. Antennce lobum inter \& tuberculum inserta, thoraci aque longa, crassæ, 12-articulata; articulis 5 ultimis arctissime conjunctis, inde indestinctis, articulum tanquam unicum, conicum, acutum, septimo vix longiorem, pauloque la-

6 Senion lang, liber dic slitte der Frïgeldedent

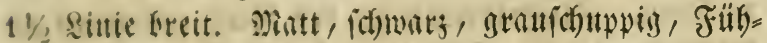

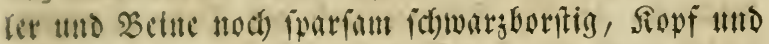

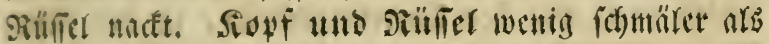

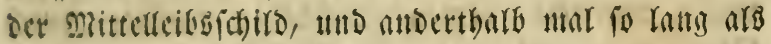
siefer, gediupilt, waljig, oben mit einct mittlert

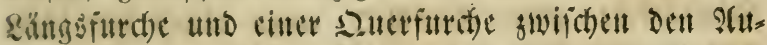

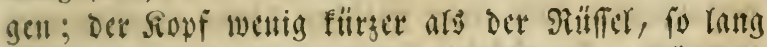

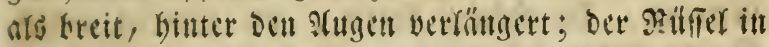
der פatte wenig berengt, nut Ende beiderfeitz mit cincu jpisen sappen und cincm Daribbet nub Dabinter

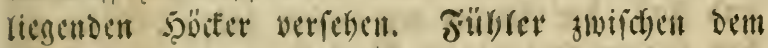
sappen und Söber cingeringt, fo rang als ber Mlits telleibgidfild, diff, 12 gliedig; dic 5 reisten (s) rieder auFi: gedringtefte mit cinander verbunden, Daber ununterfoieden, gleichfam cin eingiged, fegliges, iptises, faum rängereb und mentg breiteres stico als 
tiorem, constituentibus; articulis antecedentibus 7 inter se subaqualibus, prioribus fere æque longis ac latis, reliquis brevioribus, transversis. Thorax elongatus, cylindricus, supra juxta sulcum longitudinalem medium utrinque tuberculorum seriebus duabus \& tuberculo laterali instructum. Elytra sutura connata, basi apiceque truncata, thoraci æque Jata, medio modice dilatata, postice declivia; convexa, foveolato-rugosa, in dorso tuberculorum triplice serie, una laterali, altera suturali, tertiaque interjacente instructa, tuberculis conicis, posticis majoribus. Pedes interse æquales, dimidium corpus longi, femore parum incrassato, tibia \& tarso cylindricis, hujus articulis integris, quarto cum unguiculis æque ac duo præcedentes longo.

Das 7te birsend; bie workergehenden 7 (S)Ieder unter fich fait gleich, Die crifen beinnbe fo lang als breit,

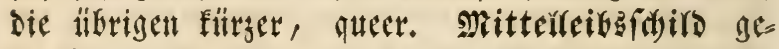
ftrect, wargig, oben meben Der sängsmittelfurche

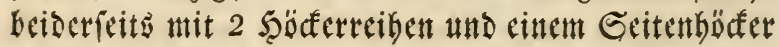
verfehen. Frïgerbefen an Der Pabt zufammen ges madbien, an Der şargel und am Ende abgetutht, gleich) breit wic Der stittelleifsichird, in Der Mitte mäpig erweitert, binten abichüfitg; gewölst, Durch

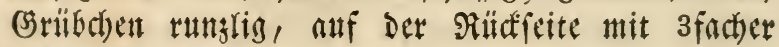
Şöcferreibe; einter feitlichen, eincr längg Der Daht verlaufenden und eitter zwifhen diefer inneliegenden veriehen, die söfer feglig, Die bintern gröper. Beine unter fid gleidh, volt balfer fiörperln̈nge, mit wentig verdictem Ed)enfer, wargiger Schiene und Fuf, die Şlieder von diefem gams, das 4te mit ben Flauen fo ling als bie beiden worbergebenden. 


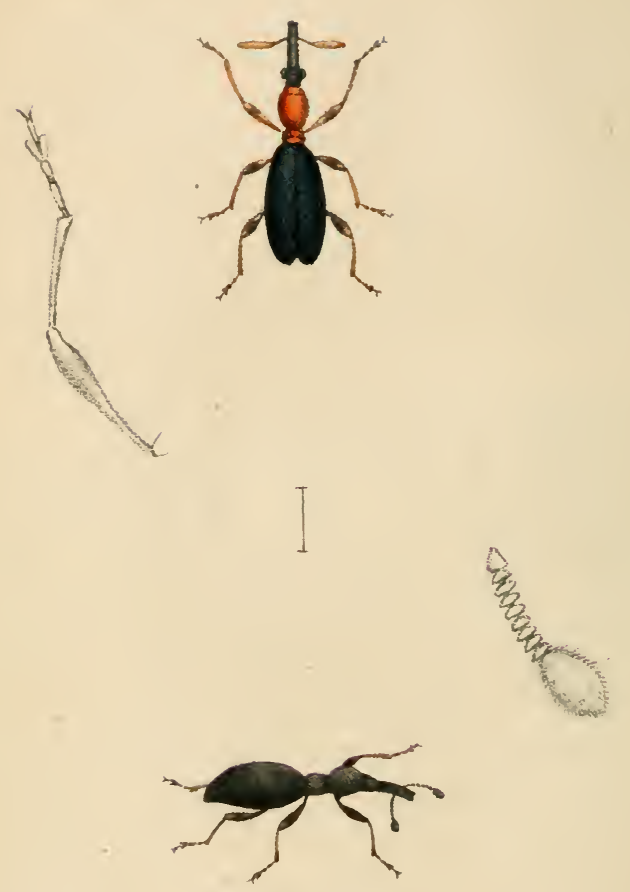

Cylow Lurcijeñers \& angustaters 


\section{Fau. CYLADES.}

\section{CYLAS Latr.}

Caput postice elongatum, basi in modum bulbi incrassatum; oculis semiglobosis, prominentibus.

Rostrum vix arcuatum, teres, validum.

Antennce medio rostro inserta, valida, 10-articulatæ, articulo primo æque longo ac lato, articulis 2-9 brevissimis, transversis, coarctatis, simul sumtis rostro dimidio æque longis, ultimo his duplo latiore, clavam constituente, sexu diversam Thorax elongatus, binodis, nodo anteriore quam posterior duplo majore.

Elytra oblongo-ovata, fornicata.

Pedes dimidium corpus æque longi, antici aliquantum longiores; omnium femore clavato, mutico, tibia tereti, tarso huic æque longo, articulis interse subrque longis, primo, secundo tertioque bilobo subtus spongiosis.

Solf binten vertängert, an Der Sastrgel fnollenför. mig verdictt; mit balkfugligen, vorragenden âtuen. Piiliel faum gefogen, orebrund, fröftig.

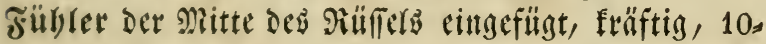
gliedig, 1 ftes Grict fo lants als breit, 2 bis 9 s fehr furs, querr, atcinandergedrängt zufammen genommen fo lang als der balbe stüfer; Das retste Doppelt fo breit alis dicke, cine, nadi) dem (be, (d) Ied) verfidiedente reule, bildend.

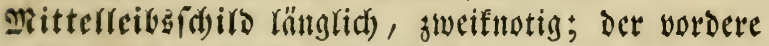
Finoten Doppelt fo grofi als der bintere.

Friitgersecten ränglich ciförmig, bod)genölbt. Secitte von balber Siörperlänge, vorderfite ctwas rän. ger; an allen ber Edbenfer feulenförmig, unbe= wehrt, Die Gabiene Drehrund, Der Fuf fo lang als bicie, feine Slieder wnter fich ungefähr gleidh lang, 1 ffé, 2tę und zwcilappiges 3tes unten famammig. 
CYLAS TERCIPENNIS.

(Scliünl. Gen. Si Sp. Curc. T. 1. P. 1. p. 369.)

Patria: Ile de France.

Mas: Antennarum clava cylindrica, pilosa, articulis precedentibus simul sumtis duplo longiore.

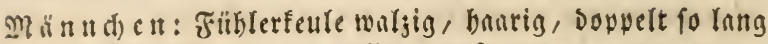
als dic vorbergebenden Glieber jufammengenommen.

\section{CYLAS ANGESTATCS.}

(Dejean Catalogue \&c. 3e Edit. p. 267.)

Patrir: Senegal.

Femina: Antennarum clava ovata, obtuse acuminata, articulorum præcedentium simul sumtorum dimidiam longitudinem æquante.

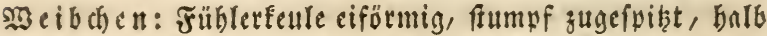
fo lang als dic vorbergebenden Glieder zufammengenom= metr. 


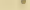

作

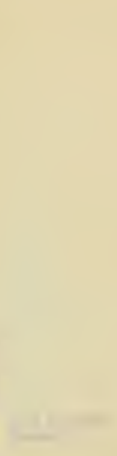




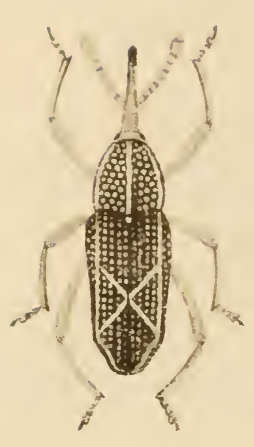

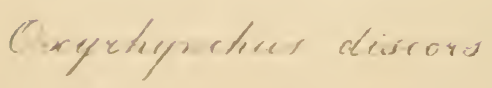


Fam. OXYRHYNCHIJES.

OXYRHYNCHUS Schönh.

Caput transversum, thoraci intrusum, oculis immersis, inferis, fere confluentibus, transversim oblongis, ad latus assurgentibus.

Rostrum elongatum, sub filiforme, arcuatum; postica parte capiti aque longa; antica quam postica triplo longiore, in mare sensim attenuata, usque fere ad apicem scabra, in femina filiformi, cylindrica, levi. Antennce rostri apicem paulo excedentes, 9-articulata, articulis obconicis, plurimis aque latis ac lonlongis, articulo actavo paulo elongato, antecedentibus parumper crassiore, cum nono, ei intruso, mimimo, spongioso tamquam clavam constituente.

Thorax oblongo-ovatus, basi bisinuatus. Scutcllum elongatum.

Sopf queer, in Den Mlittefleib cingefdoben, THgen cingejenft, unten regend, beinabe zufanmentiefend, in bie suecre langgejogen, bis zut Eeite nufifteigend. siilliel ranggejogen, beinabe fadenförmig, getogen; feit binterer abeil von Sepflänge; feit vorderer 3 mal lämyer als ber biutere, beim Mä̈nnd) all mälig verdünnt, bis beintabe jur Epize raub, beim sacibdicn fadouförmiz, walgig, glatt.

Fïgler wenig die Sillfelipibe überngend, 9gliedig, die (Slieder verfehet feglig; dic meifen fo breit als lattg, Das ste Blied wentg verlängert, ein wenig bifer als die vorbergehenden, mit dem meunten, ibm eill= geichobenen, fegr fleinen fifwammigen (s)liede gleith). fam eitte feule birdent.

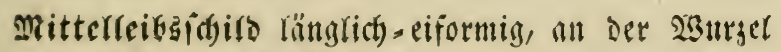
incifuctig. Edriraben langgegogen. 
Elytra oblongo-ovata, convexa, versus apicem callosa.

Pedes corpore parum breviores, femore mutico, basi attenuato, tibia compressa, angulata, apice incurva, $\&$ dente curvato, acuto, valido terminata, tarso dimidia tibia parte vix longiore, articulis primo, secundo tertioque bilobo subtus spongiosis, quarto paulo quam pracedens longiore, unguiculis minimis.

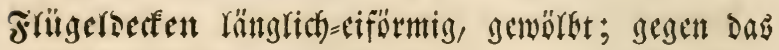
Ente fatwielig.

Beine ein wenig fürger als Der seib; Der Schenfer unbewehrt, an ber $\mathfrak{s}$ atrgel verdünt, Echiene zufams "mengedriaft, fantig, an der Epibe eingebogen, and mit cittem gefrïmmten, fharfen, fräftigen $3 \mathfrak{h} \mathfrak{n}$ endigend, Der Fun faum länger als die halbe Schies

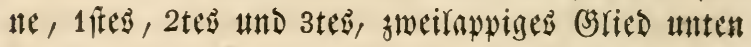

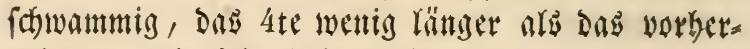
gebende, mit fehr fleinen sifuten.

OXYRHYNCHUS DISCORS.

(Schönl. Gen. \& Sp. Curc. T. I. P. 1. p. 379.)

Patria: Java, Sumatra. 


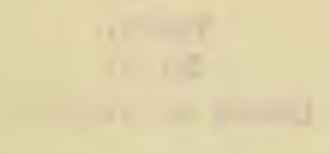

\section{•}



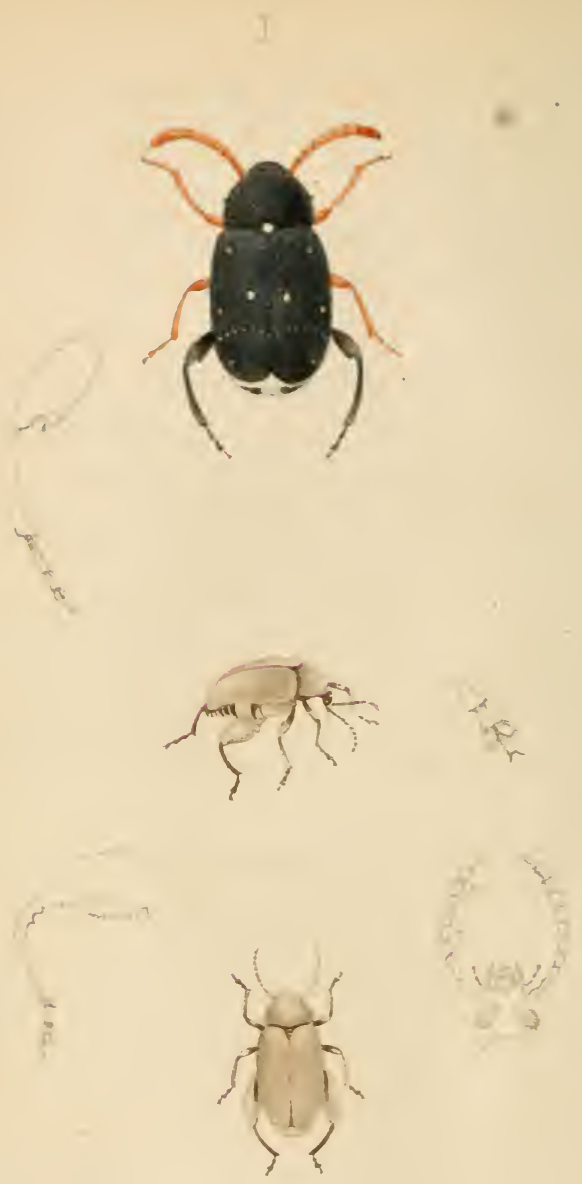

Diverhees lutercounes

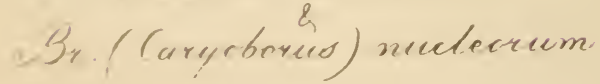




\section{Fam. BRUCHIDES.}

\section{BRUCHUS Schönherr.}

Caput brevius rostratum, pone oculos in collum elongatum, oculis antice emarginatis.

Rostrum circiter aque longum ac latum.

Antennce thoracem \& caput simul sumta longitudine saltem rquantes, validæ, basi attenuatæ.

Elytra supra parum convexa.

Pedes postici anterioribus longiores, femore incrassato, tibia apice spina fixa instructa.

Solf in cinten furgen Rillfer vorgegogen, binter den stugen balsartig verlängert, mit vorn aughgersttoeten Prugen.

siilled ungefebr fo lang als breit.

Fübler wenigitens fo lang als Siopf und Mittelleibg.

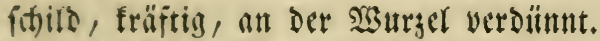

Sinterfte Beine länger als bie vorbern, ihe Gaths

fel verbiaft, und ibre Gatene am Ende mit cinet fetrizenden Dornfpise verfeben.

\section{BRECIISS LUTEICORNIS.}

(Schönh. Gen. \& Sp. Curc. T. I. P. 1. p. 65.)

Patria: Germania, Gallia, Tauria, Helvetia.

Oculi transversi, reniformes.

Antennce utrinque subserratæ.

Pedum posticorum femur versus apicem unidentatum, tarsi articulus primus reliquis xque longus, aliquantum curvatus, tertius subtus spongiosus.

It ugen queer, nicrenförmig.

F

In ben binterifen Beinen ber Schenfel gegen bie Epize cingnhnig, bas er fie funglied fo lang als bie iibrigen, etrons gefrümmt, bas britte unten f(t) nummig. 
BRUCHUS (CARYOBORUS) NLCLEORTM.

(Shönh. Gen. \& Sp. Curc. T. 1. P. 1. p. 92.)

Patria: America meridionalis.

Oculi capitis latera latius ambientes, æque longi ac. lati, granulati.

-Antenne intus serratx.

Pedum posicorum femur validissimum, valde incras. satum, compressum, fere lenticulare, prope basin unidentato, inde a dente usque, fere ad apicem serratum, tibia incurva; ommizm tarsns articulis primo, secundo tertioque depressis, subtus spongiosis, primo quam secundus, hoc quam tertius aliquantum longiore.

If $u g e \pi$ über bic Ropffeiten etwas weit weggreifend, fo lang als breit, geförnelt.

F্̈

SIn Den biuter fien $\mathfrak{B}$ einell ber Schenfel febr friftig, febr verbiatt, zufammengebriät, beinabe rinfenförmig,

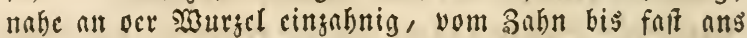
Ende fägejübnig, dic Eibiene cingeftümmt; nu nllen Beinen bns crite, ste und 3te Frufglieb niebergebrüct, unten forwammig, bas erife Glicb etıns weniges länger als Das 2 te, Diefes als dns 3tc. 


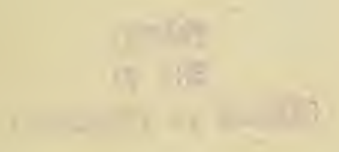



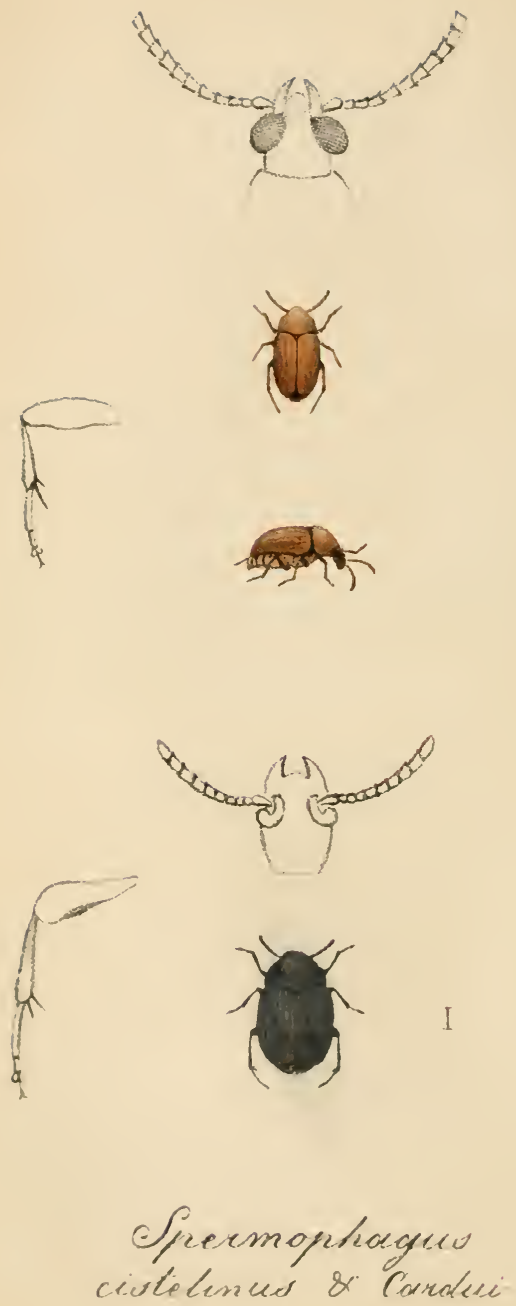


\section{Fam. BRUCHIDES.}

\section{SPERMOPHAGUS. Steven.}

Cipul vix rostratum, oculis subdepressis, antice ad antennarum insertionem emarginatis.

Antchne dimidium corpus circiter longa, compressa, intus subserrate, basi attenuatx.

Elytra supra modice convexa.

l'edes postici reliquis longiores, antici \& medii inter se aque longi, posticorum femore paulo incrassato, nutico, subtus canaliculato, tibia spinis duabus anicalibus mobilibus instructa, tarso tenui: articulo primo reliquis saltem reque longo, modice arcuato, tertio bilobn, ninimo.

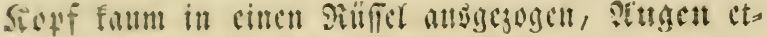
wa misergestütet, born an ber Einfïgmtis der Fïblit amgeramot.

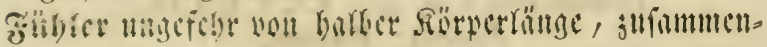

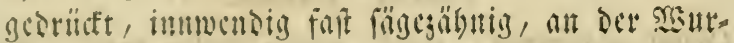
jel wersilumt.

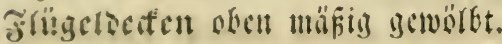

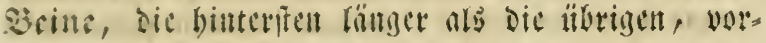

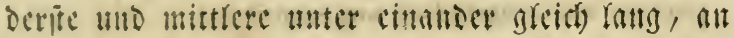
Den binterita der Gothenfel ein wentig verdidt, Imbewebrt, unten berinnt, Dic Gethent mit 2 bes meglichen Endoornen verfeben, der Juf ditnt,

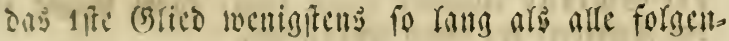
ren, leitht getogen, bas 3te jweilnppige febr flein. 
(Schönh. Gen. \& Sp. Curc. T. I. P. 1. p. 103.)

Patria: Brasilia.

Caput ab oculis ad os usque fere trigonum, pone oculos angustatum, oculis latera capitis latius am. plectentibus.

Pedum posticorum tibia spina exteriore quam in. terior ter longiore, ultra medium articuli primi tarsi extensa.

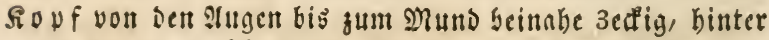
ben SIugen verfd)mälert, bie $\mathfrak{A}$ ugen über bie Ropffei= ten weit meggreifent.

It Denbinterfen Beinen Der n̈ufere Dorn ber Gchienc 3mal länger als ber innere, Des criten Fufgliedes binaustagent.

\section{STERMOPHAGUS CARDUI.}

(Schönh. Gen. \& Sp. Curc. T. I. P. 1. p. 108.)

$$
\text { Patria: Europa. }
$$

Caput oblongum, oculis capite multo brevioribus, transversis, reniformibus.

Pedum posticorum tibice spinis duabus apicalibus xque inter se longis, tertiam articuli primi tarsi partem vix longitudine superantibus.

Sơf länglid), bie a ugen viel fürger nIs ber Ropf, queer, nierenförmig.

In Den binterfen Beincn Dic be iden EnDbornen ber $G$ chiene cinander gleid) lang, faum länger als Der Drittheil Des erfeten FuEgliedes. 


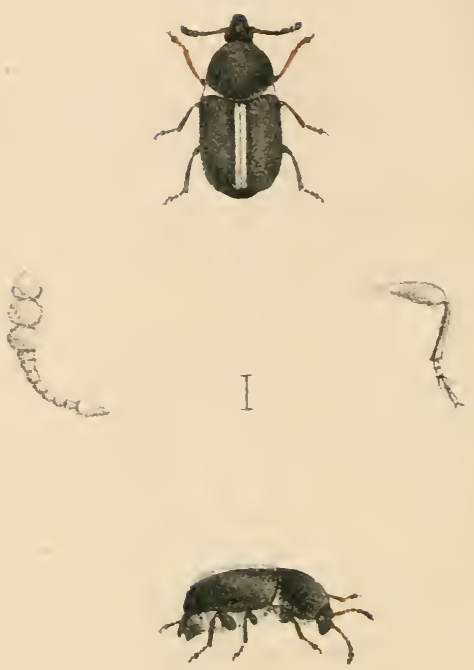

troden suteralis 


\section{Fam. BRUCHIDES.}

\section{URODON Schönh.}

Caput brevius rostratum, ad oculos usque thoraci intrusum, oculis subovatis, antice emarginatis.

Rostrum versus apicem parumper angustatum.'

Antennce capite \& rostro simul sumtis parum longiores, clavatæ, clava elongata, sub-perfoliata, 3 articulata, articulo ultimo ovato acuminato, pracedentibus duobus subglobosis.

Thorax elytris parum brevior, antice posticeque productus.

Elytral supra convexa.

Pedes inter se subrque longi, femore mutico, tibia apice inermi, tarso tibia aque longo, articulis primo, secundo, tertioque brevibus inter se aque longis, quarto precedentibus duobus aque longo.

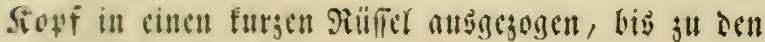

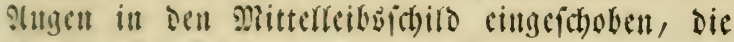
sugen foit eiformig, vorn ansigerandet.

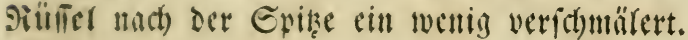
Jiibler wenig länger alg fiopf und Rilliel, gefoult, sic Sienle langgejogen, beinabe Durchblättert, 3glic. sig, bag lescte Bglied ciförmig, zugejpist, Die 2 vor. berbebenden beinabe fuglig. slittelleibgid)irs wenig lämger als die Frägeldecfen, mach vorn und bittent altsgezogen. Frïgelesten oben gewölst. Beine unter fich falt gleid) lang, der Gdonfer unbewehrt, dic Grbiente am Ënde unbewaffinet, Det

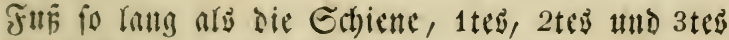
(Slied fur;, wnter fich gleich lang, das 4te fo lang als sie beiden vorbergebenden. 
Abdomen apice pro sexu diversum, in femina rotundatum, in mare emarginatum, segmento ultimo ventrali utrinque in processum acutum elongato,

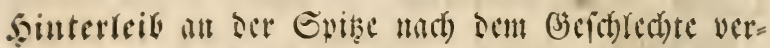
fetiesen; beim siscibdent abgermoct, feim shänn=

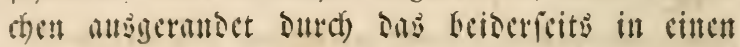

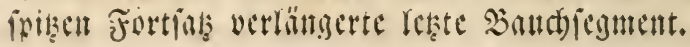

ERODON SUTTLRALIS.

(Schönh. Gen. \& Sp. Curc. T. I. P. 1. p. 114.)

Patria: Gallia, Helvetia, Ausria, 'l'auria, Persia.

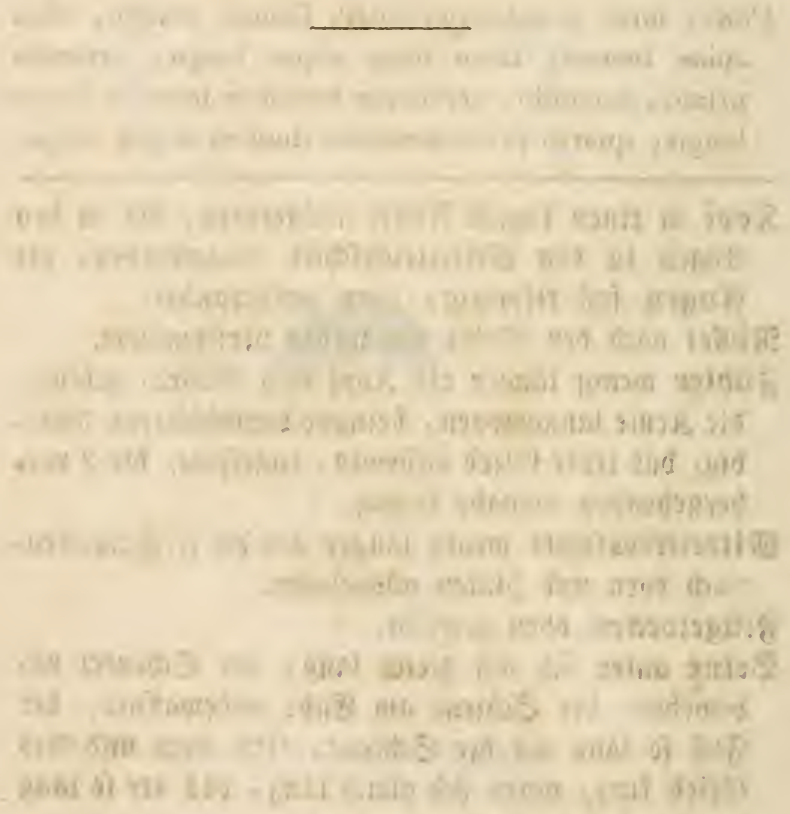




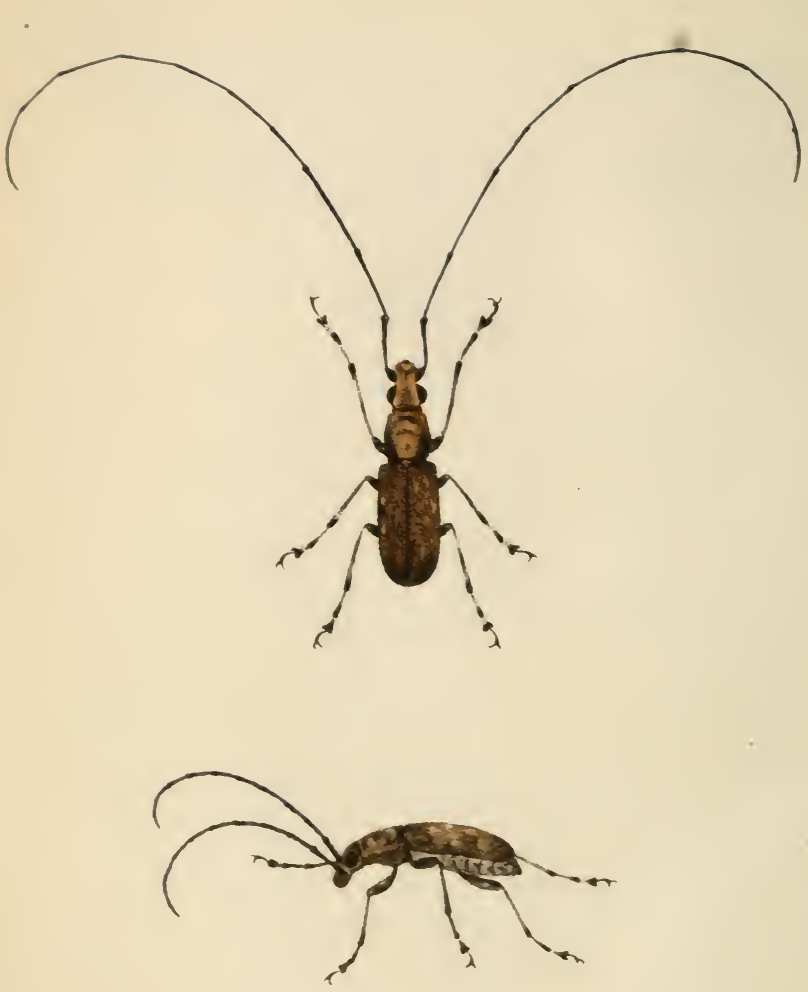

Deuterosentes nebulosus 


\section{Fam. ANTHIRIBIDES.}

DEUTEROCRATES.

Coput aque longum ac rostrum, oculis lateralibus, prominentibus, magnis, rotundatis.

liostrum breve, supra inaquale, apice emarginatum. Antemnce filiformes, in mare corpore triplo longiores, in femina corpus longitudine aquantes, articulis primo excepto elongatis, secundo quam primus aliquanto longiore, sequentibus paullo crassiove.

Thorax elongatus, inaqualis, antice constrictus. Elytra elongata.

Pedes elongati, tibia quam femur longiore, tarsi articulo primo quam secundus longiore.

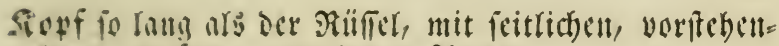

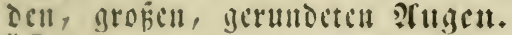
Riillel furj, ofen uncken, am Eube nusgerandet.

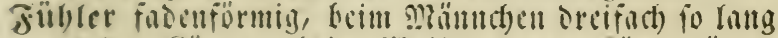

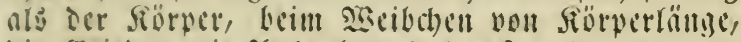

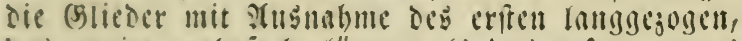

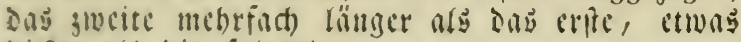
diefer alb dic folgentor.

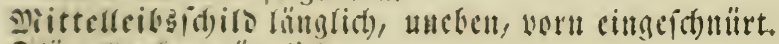
F્liigeloeden läm!llid).

Sicime lämglich), Ethienc länger als ier Gebenfel,

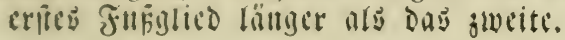

UEETEROCRATES NEBULOSES.

(Mus, publ. Basilliense.)

Niger, supra tomento ochraceo, fusco-nebuloso, subtus cinereo, tectus; antennis pedibusque in femina rufo-piceis, in mare nigris cincreo-, illis in hoc olsoletius-variegatis.

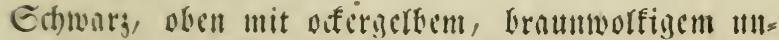

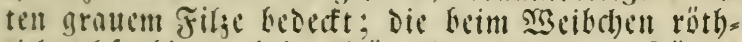

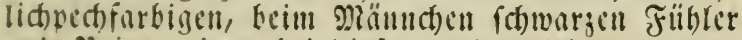
und ßine, jine bei dicfem undeutlicter, grange. ithedt.

Patria: Aquapin Guinex. 



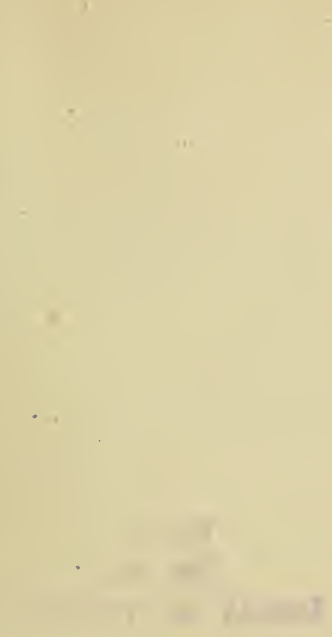




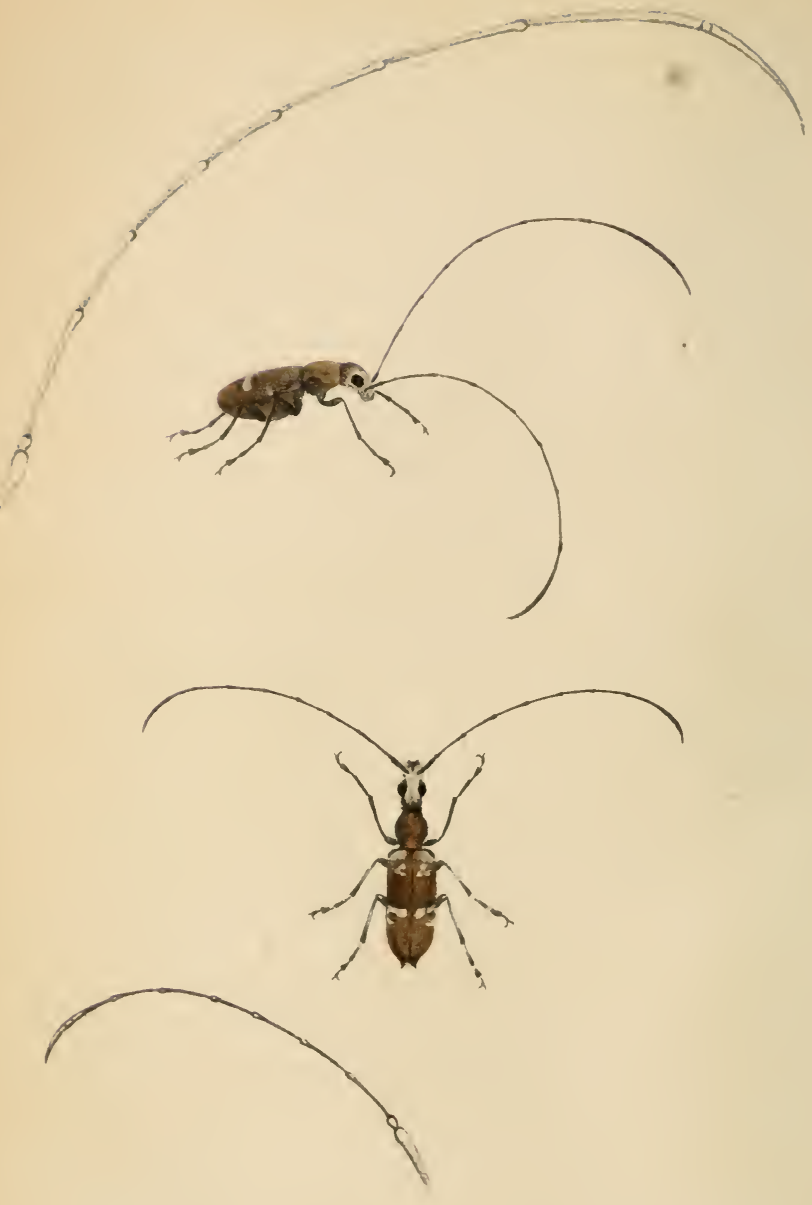

Anarenostar lepieders 
Ham. AN'THRIBIDES.

ANACERAS'TES.

Cipul aque longum ac rostrum, pone oculos tumidum, elongatum, oculis lateralibus, magnis, prominentibus, rotundatis.

Rostrum longiusculum, antice paulo dilatatum.

Antennce in fovea rostri superiore, propius os insertar, tenues, subfiliformes, in mare corpore plus duplo longiores, in femina corpus longitudine æquantes, articulis tertio \& sequentibus, decimo excepto, elongatis, nono, decimo minimo \& undecimo clavam compressam, angustissimam, elongatofusiformem formantibus.

Thol:ax paulo longior quam latior, antice constrictus, lateribus postice latius excavatis.

Pedes elongati, tibia yuam femore, tarso quam tibia longiore, articulo secundo tarsi quam primo dimidis breviore.

Elytir elongata.

Siopf io lang als der Rifide, binter den ?agen auf, gequollen, verlängert, stugen feitlich, grof́, vor. itebend, gerundet.

จiullel jemlich Lany, wora etwas erweitert.

Fiibler ill ciner obern (5ruphe des Rüfely, nabe am Mlunde cingefügt, dïnn, beinabe fadenförmig, beim Männd)en mebr als doppelt fo lang als der fiör= per, beim siscifden von Siörperlänge; 3tey und folgende bsticier, sas lote nusgenommen, lant? geftreft, dab gte, bay fibr fleint lote und dab

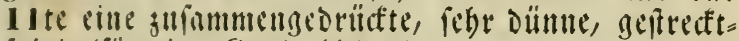
ipendelformige seale bildend.

mittefleibsid)ilo wenig länger als breit, born gujam=

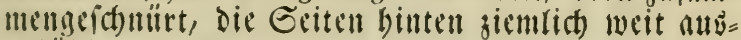
geboublt.

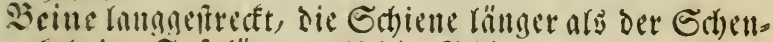
fil, der Fuf länger aly die Schielle, day 2 te slite des Fufey lim die sölfte fürget ald das lite.

stïgerdeffen langgegogen.

\section{ANACERASTLS LEPIDES}

Niger, pube subtiliore fuscescente tectus, rostro su. perne, elytrorum maculis, antennarumque annulo apicali albicantibus.

Patria: Aquapim Guinex. 

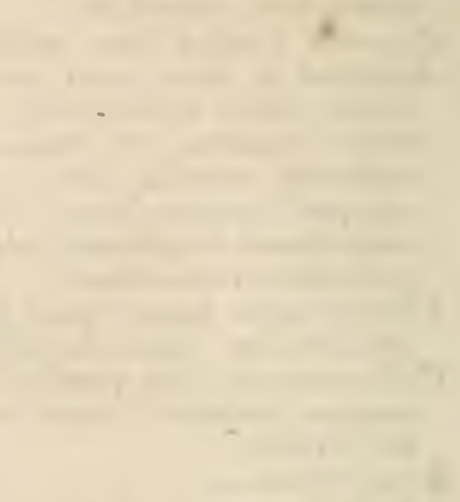
(3)

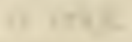

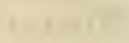




\section{FaII. ANTHRIBIISES.}

\section{I)ECATAPHANES.}

Ciput eque longum ac rostrum, oculis atcralibus, magnis, prominentibus, subrotundatis.

Rosilum paulo longius quam latius, basi impressmum. - Allemele in forea rostri laterali profunda insertae, in mare longissima, tenues subfiliformes, ad summum apicem modice incrassatir, scilicet articuli Qni aprice. $10^{\circ} \& 11^{\circ}$ clavan tenuissimam, acuminatam formantibus; in femina seu longae, \& sicut in mare subliliformes, seu mediocres, modice clavita, clavir tblonga ex articulis $9^{\circ}, 10^{\circ} \&$ $11^{\circ}$ arclissime connexis formata; articulo $10^{\circ}$ in utroque sexu ininimo, vix discreto.

' / hor ax paulo longior quam latior, antrorsum parum angustatus, dorso depresso-inequalis.

Pedes seu elongati seu mediocres. Lilylict elongata, thorace paulo latiora.

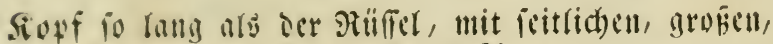
woritebenden, falt germbeten scugen.

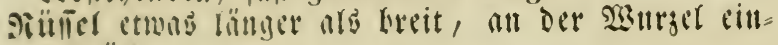
gercriict.

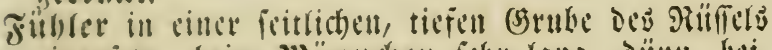

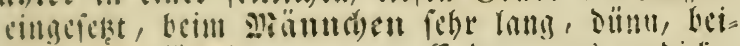
mabe fadenförmig, gally am Ende etwas verdict,

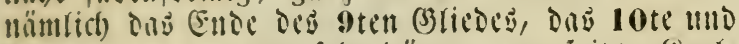

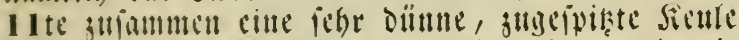
bilbend, beim socibat) entweder lang beim Niämndbell foft fodenförmig, oder mittellums,

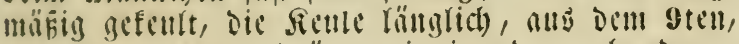
loten mt 11 ten gedrängt mit cinnuder verbutmoenen (5)ticdern gerbildet; das lote (s)lied ill heiden Bse= iblect)tern fibr flein, faum beutlict).

mittefleigsidsiro ein wenig linger als breit, math vorn wenig veremst, obennuf eingedriift mo mebent. Brine elltwedr langgeitreift oder mittellang.

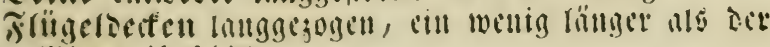
mittellitisthils.

Patria: Aquapim Guincie. 


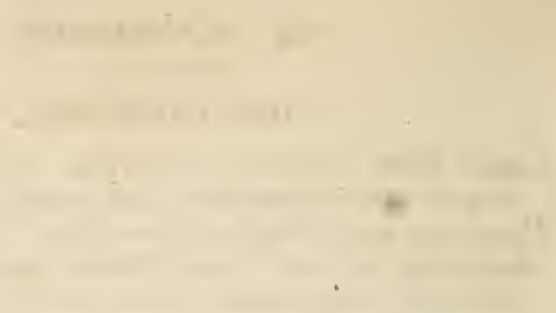




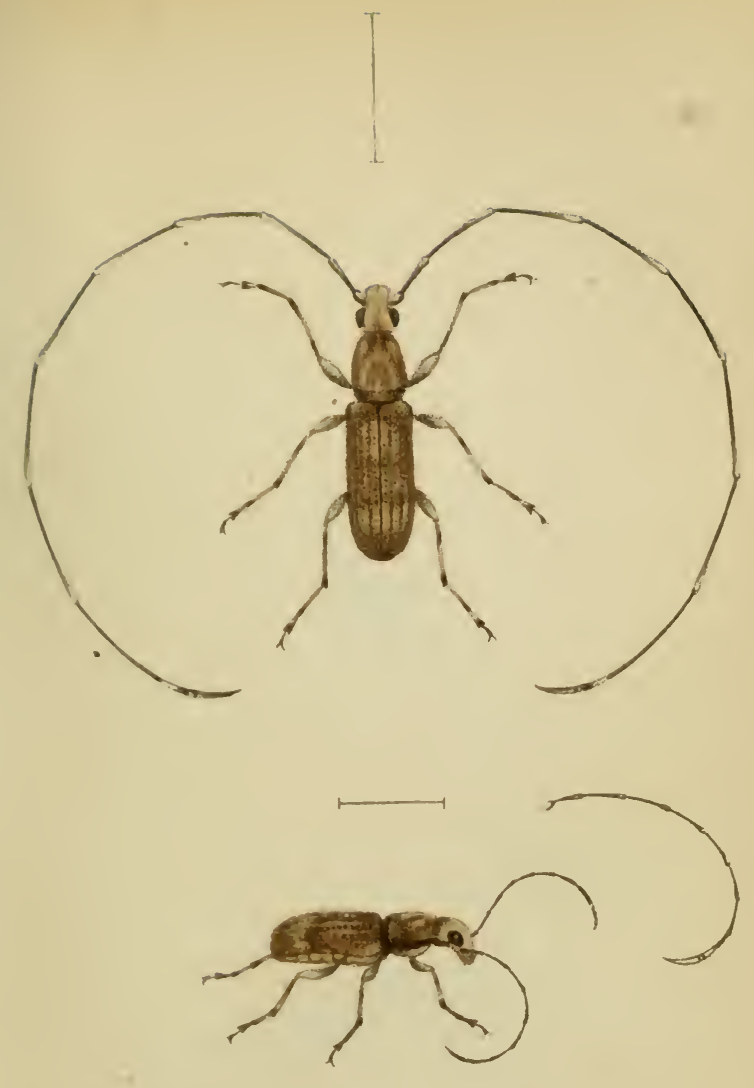

Dernetaphanes gracilies 


$$
\begin{aligned}
& 1-+7 \\
& \text { 1. nis }
\end{aligned}
$$

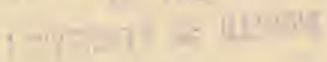




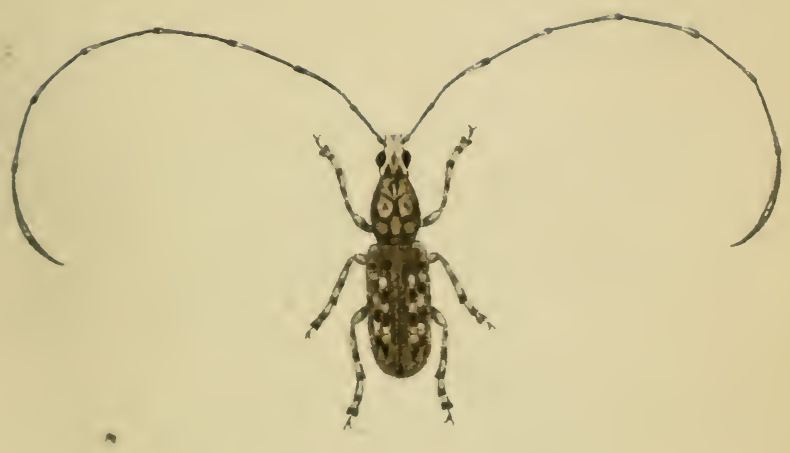

$I$
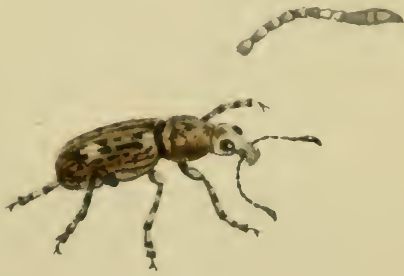

Derataphanes pictir. 



\section{FanI. ANTHRIBIDES.}

\section{DECATAPHANES.}

\section{S'TIRPS 1.}

Antennce in mare corpore triplo longiores, in femina corporis longitudinem paulo excedentes, subfiliformes; articulis a secundo ad nonum usque elongatis, in mare altcro post alterum sensim longiore, in femina longitudine inter se aqualibus.

I'coles elongati.

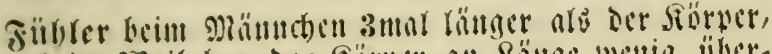

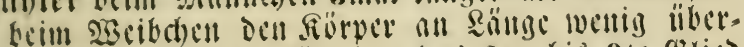

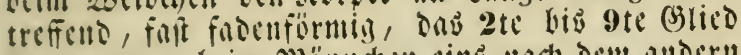

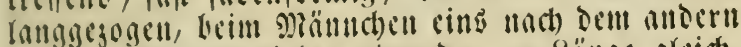
länger, beim şeibthen cinnuder an sänje gleidh. Brine langgejogen.

\section{WECATAPHANES GRACIIAS.}

Iomento ochraceo variegatim olsscuriore tectus, piceus, vitta laterali capitis thoracisque nigricante; tarsis antennisque cinere-variegatis.

S'TIRIS 11.

Anlennce maris corpore plus duplo longiores, subfiliformes, articulis a secundo usque elongatis, inter se subaeque longis; femince dimidum corpus longac, inodice clavatio, articulis clavam antecedeniibus obconicis.

Pecles mediocres.

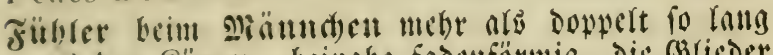
alb der fiörper, beimabe fadenförmig, die bsticder vom 2 ten an langgeftredt, unter cinnuder falt gleid)= lan!; Leim sicibden von balber sörperlänge, mäfin gefeult; die (s)licoer wor Der fienle werfebrt teglig.

Beine mittellnug.

DECATAPHANES PICTLS.

Viger, tomento ochraceo seu griseo tectus, thoracis maculis varie, lineisque elytrorum tessellatimallicantibus fuscusque. pedibus antennisque cinereonstiegatis. 


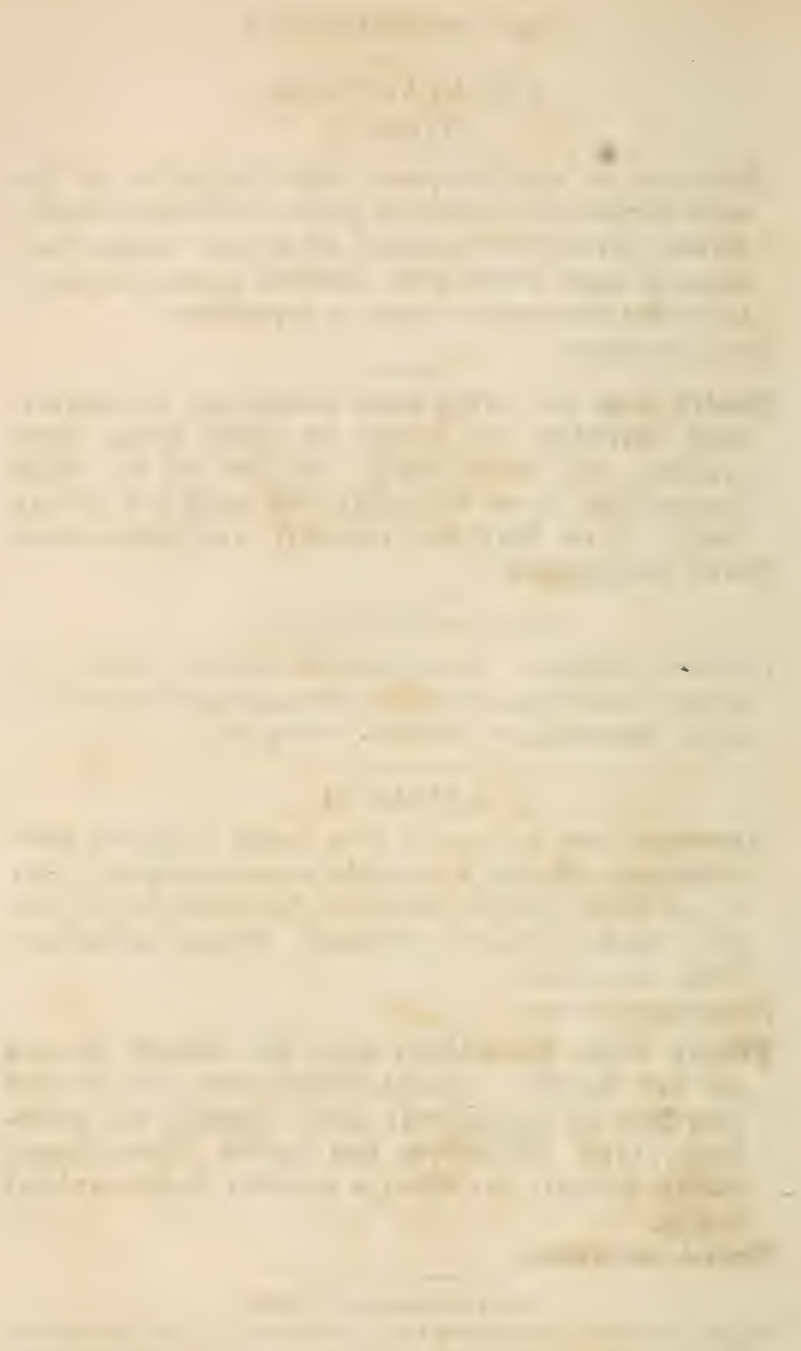




\section{Fam. ANTHRIBIDES.}

\section{XENOCERUS Germar.}

Caput sub-transversum, oculis lateralibus, transversis, emarginatis.

Rostruln breve, latum.

Antcrnec in fovea profunda haud procul ab oculis insertx, subfiliformes, sexu diversæ; in marc corpore ferc triplo longiores, tenues, articulis alternis longioribus, secundo subserpentino, dilatato, quartoque pralongis simul cum tertio compressis, ultimo depresso-subdilatato apice acuminato; in femina corpore dimidio parum longiores, pilis adpressis vestitx, crassiusculæ, basi aliquantum attenuatæ, articulis plurimis obconicis, prioribus brevioribus, ultimo ovato acuminato ac intermediis subelongatis. T/101 ax elongatus, lateribus perparum rotundatus,

Stopf etwas it die sueere nuggebreitet mit feitlichen, queergeitellen ausgerandeten sugen.

Riitiel furg, breit.

Fübler nictst weit vor ben 2 (ugen in ciner tiefen (srube eingefotet, beinabe fabenförmig, mach dem (Beidhlect)te verichieden; teim Männd)en etwa 3 mal fo lang als der förper, Dïn, von Den Slie. dern ie ras andre länger, das 2 te, etwa gefchlän. gelte, erweiterte und 4te vorgüglich lang tulo zugleid mit bem 3ten jufammengedrïft, dns leşte nieder. gedrüt und etwag erweitert, am Ende zugefpist; beim sseibden wenig länger ald der balbe Sö̈r. ner, mit anliegenden Sanren befleider, didflidh, an Der sisurgel ein wenig verbünut, die meiften Glieder verfebrt fegelförmig, die erften fïrzer, bad lek̨te, eiförmige, zugchintąte und die mittlern ziem= (id) langgegogen.

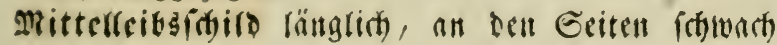


ante basin carinula transversa cum laterali conjuncta instructus.

Elytra elongata, lateribus parallela, posterius parum angustata.

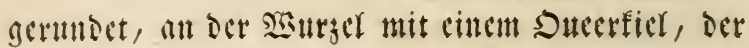
mit cincm fitliden verbunden ift.

Frügeroefen langgegogen, mit gleichlaufenden Seiten. rändern bis sum etwas fid verfamiallernden (Ende.

XEXOCERUS SAPERDOIDES.

(Schönh. Gen. \& Sp. Curc. T. I. P. 1. p. 1S.)

Patria: Insula Java:

Yarietas: Elytris fascia communi pone medium, maculisque una scutellari, altera pone humerum tertiaque inter has \& fasciam interjacente, in femina \& puncto versus apicem elytrorum, albo-tomentosis.

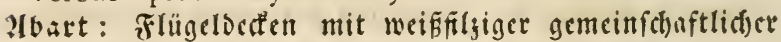
D. uecrbinde binter Der Mitte! uno cintem am Echillochen, cinem binter. Dem Schulterminfel uno cinem zmifhen Diefen und Der 3 inde mitteninneliegenden Flede, nuch) nod) beim $\mathfrak{B}$ cibchen cincm Punfte gegen Dns Ende Dex Flïgeloed"en bin. 


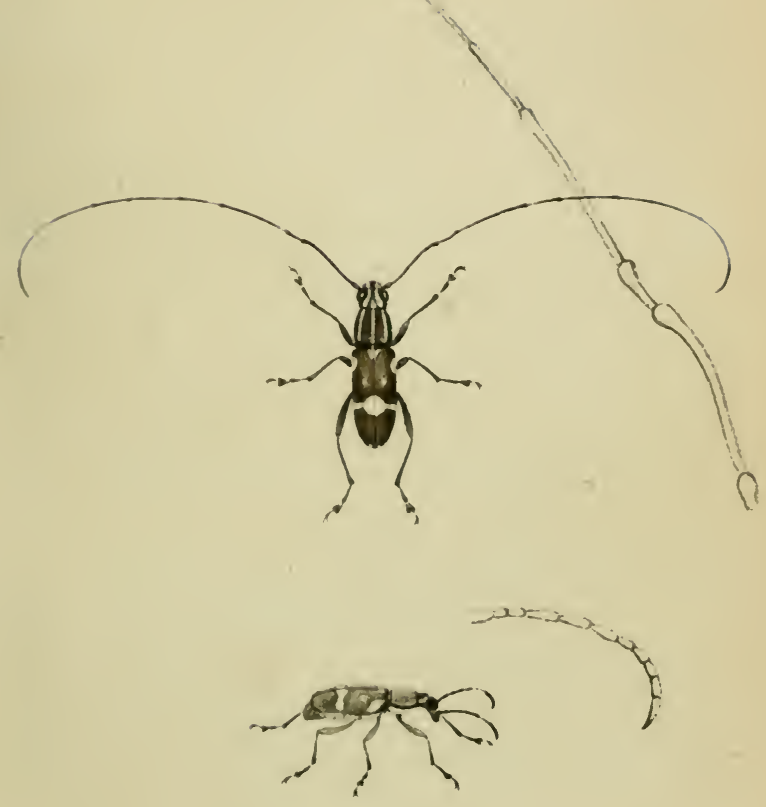

Yenocerus saperdoides war. 



\section{Fam. ANTHRIBIDES.}

\section{MECOCERUS Schönh.}

Caput æque latum ac longum, oculis rotundatis, antrorsum convergentibus.

Rostrum elongatum, apice ampliatum, mandibulis in femina majoribus, acuminatis, in dorsi fovea seta articulata, porrecta, in mare ibidem pilorum penicillo inserto instructis.

Antennce versus apicem rostri in fovea oblonga insertæ, subfiliformes, sexu diversæ; in mare corpore plus duplo longiores, tenues, ante apicem vix dilatatæ, compressæ, articulo primo validiori, elongato, clavato, secundo obconico, minuto, tertio \& sequentibus usque ad octavum elongatis, apice crassioribus, prioribus sub-arcuatis, noni apice, decimo \& basi undecimi aliquantulum com-

Stopf io breit als lang, mit gerundeten, fich vorn gegeneinamber meigenden $\mathfrak{P} u g e n$.

Riiliel langgegogen, an Ende anghebreitet, die sber-

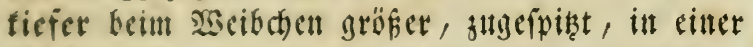
Riüengrube feim sseifden mit einer gegliederten vorgeitreften Borite, beim Miännchen mit einem Sonarpinfer verfeben.

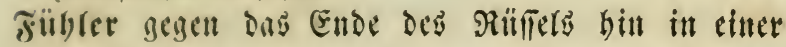
länglichen Brube cingejanft, beinabe fadenförmig, nach mebr als soppelt fo lang als ber אörper, bünn, vor sem Ermbe faum erweitert, jufammengebrüat, Das crite Elied fräftig, geftreft, feulenförmig, das 2te verfebrt feglig, flein, das 3te und bic folgenden bis zum sten langgegogen, am Ende bifter, die eritern etwas gebogen, das 9 te an ber

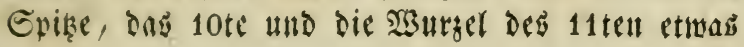


presso-dilatatis, undecimo apice acuminato cum precedente simul sumto longitudinem noni aquante; in femina dimidium corpus longi; articulis tribus ultimis quam pracedentes crassioribus.

Thorax oblongus, anterius a medio sensim attenuatus, carina pone medium transversim ducta \& utrinque ad medium latus antrorsum curvata instructus, pectorc in mare utrinque ante pedes anticos spina armato.

Elytra convexa, oblongo - subovata.

Pcdes antici elongati, eorumque primo tarsi articulo quam reliquorum duplo longiore.

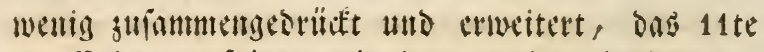

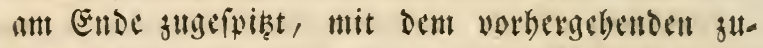
fanmen fo lang als bas 9 te; beim siscibenen won balber Siörperlänge, die 3 Endylieder difer nly Die worbergebentoct.

Mitterfeivglofirs ränglich, born wou Der Mritte an aldmälig veridyuälert, mit eitem siel, ber queer

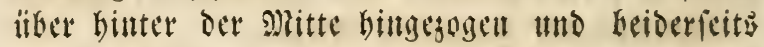

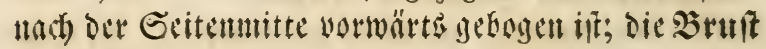

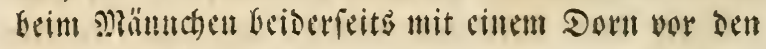
vorberiten Bitlit.

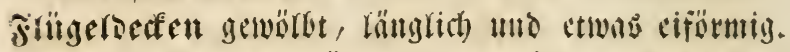

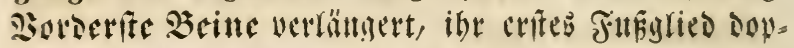

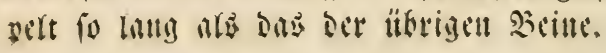

MECOCERUS GAZELL.I.

(S.höuh. Gen. \& Sp. Curc. T. I. p. 116.)

Patria: Iusula Java. 



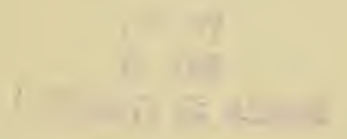



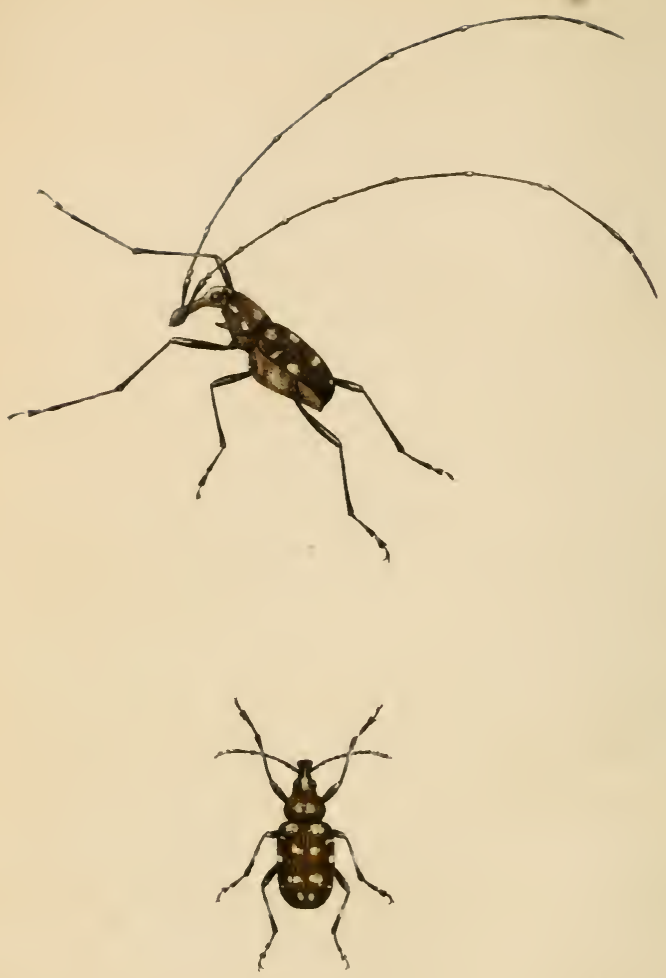

Mnererenes diesponerpes 


\section{Fan. ANTHRIBII)ES}

MECOCERUS Schinh.

\section{COHORS I.}

Pedes in utroque sexu aut longi aut mediocres.

\section{Erite Schar.}

Beine in beiden (3efdeledtern lattg oder mittelgrof.

MECOCERUS GAZELLA.

\section{COHORS II.}

Pedess in mare longissimi, in femina longiusculi.

\section{3meite Schar.}

Beine beim Männden febr lang, beim $\mathfrak{B}$ eibden ziemrict) lang.

\section{MECOCERUS DISPARIPES.}

(Mus. publ. Basiliense.)

Niger, dense brunneo-sericeus, vitta capitis, maculis. que thoracis \& elytrorum pallide flavis, antennarum medio, tibiis tarsisque in mare distinctius, in femina obsoletius cinereo_variegatis.

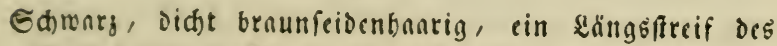
Ropfes und Fleden bes Dhittelleibsfdildes und Der Flüs geloed゙'

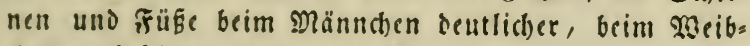
then berlofdener grall.gefdedt. 



\section{Jinm. ANTHRIBIIUES}

PHI.OEO'TRAGUS Schönh.

Caput latius ar longum, oculis lateralibus, rotundatis.

Rostrum elongatum, apice ad foveam antennarum constituendam utrinque lobatum.

Antennce ad apicem rostri insertæ, in mare corpus aliquantum longitudine superantes, in femina vix aquantes; subfiliformes, articulis tribus ultimis clavam elongatam, angustam, depressam constituentibus, reliquis cylindricis, apice nodosis.

Thorax: oblongo-subovatus, ante basin carina semicirculari, utrinque antrorsum adscendente instructiIs.

Seff breiter als lang, mit feitlicten, abgerundeten Tiugen.

Piilier langgigogen, am Enoc jur Biroung oer Fïb. fergrube beideritits gefappt.

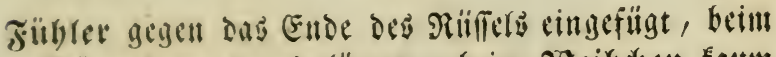
shïund)en etwas länger, beim stocibd)en faum fo lang als der fiörper; fadenfürmig, die 3 Endo glicoer eitue geitrefte, fhmale, niedergedrücte fente bildent bie thbrigen Blieder walgig, am Ende ftrotig.

Mitterfeibsforiro länglich und falt eiförmig, vor

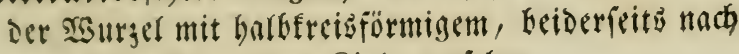
vorn binanteigendem siele verfeben. 
Elytra elongata.

Pedes mediocres.

Fritgerseffen langgejogen.

Bsine mittellang.

PHLOEOTRAGUS HEROS.

(Schönh. Gen. \& Sp. Curc. T. I. P. 1. p. 120.)

Patria: Guinea. 

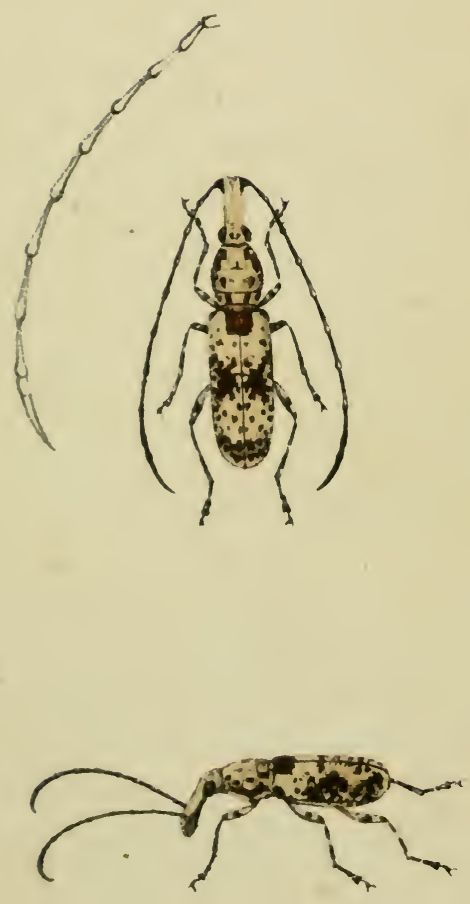

Esstreotiongue Heros 



\section{Fam. ANTHRIBIDES.}

PTYCHODERES Schonh.

Caput vix longins ac latum, oculis lateralibus, rotundatis.

Rostrum vix elongatum.

Antennce in fovea versus apicem rostri insertx, subfiliformes, in marc corporis circiter longitudinem aquantes, in femina ejus dimidio breviores; articulis tribus ultimis incrassatis, discretis; antecedentibus in femina tenuioribus, obconicis, in mare elongatis, apice magis incrassatis; articulo primo in utroque sexu brevi, obconico.

Thorax oblongo-subovatus, medio depressus, carina ante basin transversa, medio interrupta, cum laterali juncta instructus. Scutellum transversum.

Solf faum länger als breit, mit feitlict)en, afgirunosten Pugen.

Rillïel faum langgejogen.

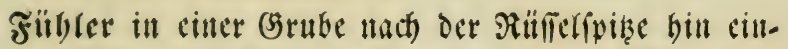
gefügt, beinabe fadenförmig; becm Niännd)en

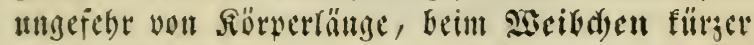
als ber balke Siörper; die 3 Entoglieder verbift, von einander abgegrent; die vorbergebenden keim

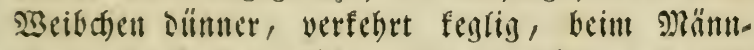
d)en geitreit, an Eithe mebr verbictt; ons arite (S)ied bei beiden (Sefithed)tern furz, verfebrt feglig.

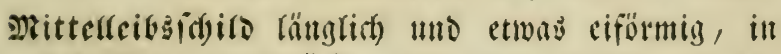
ber Mitte cingebrïatt, mit cintm queren, in ber

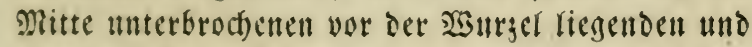
einem ifm vereinigten fettlidan Riele verfeben. Ed)isden quetr. 
Elytra elongata, medio depressa.

Pedes breviusculi, robusti.

Frïgelsecten langgejogen, in der Dlitte niedergedrütt. Beine etwas furg, fräftig.

PTYCHODERES EI.ONGATLS.

(Schönh. Gell. \& Sp. Curc. T. I. P. 1. p. 122.)

Patria: Brasilia, Cayenna. 

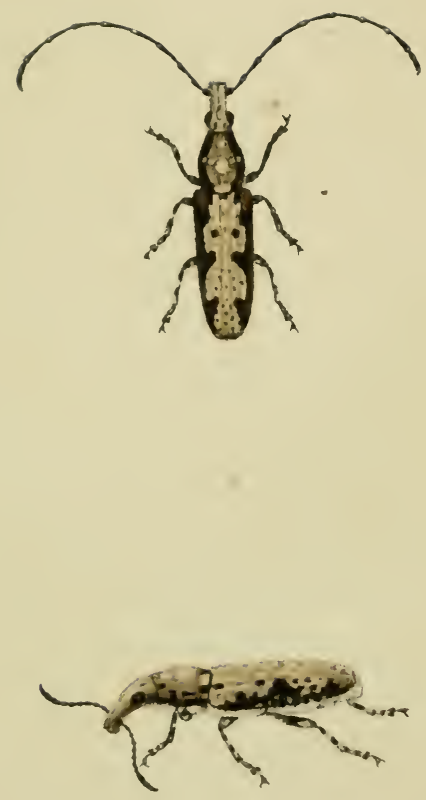

Sybrtioderes clengretus 



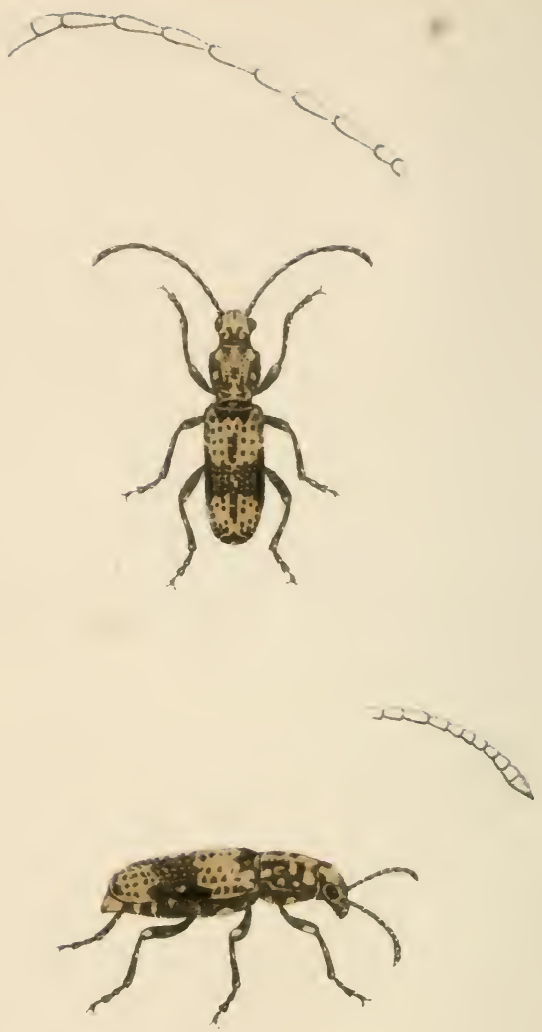

Yyónades ntrieornes 


\section{Fam ANTHRIBIIES}

\section{XYI.INADES Latreille.}

Caput postice tumidulum. oculis lateralibus, prominentibus, rotundatis, emarginatis.

Rostrum capite haud longius, reque altum ac latum, apice emarginatum.

Antennce in fovea rotunda rostri inserta, validre, apice aliquantum incrassatæ, pro sexu diverse longa; in mare circiter dimidium corpus, in femina modo tertiam quartamve ejus partem aquantes; nodosæ; articulis aut brevius aut longius obovatis, aut subglobosis, ultimo \& penultimo vel et antepenultimo arctius conjunctis.

Thor $a \cdot i$ oblongus.

Pedes inedocres, satis robusti, tibin angulata.

Sopf binten etwas aufgentorlen, mit feitrichen, vor. ragenden runblicben angigendoten Pugen.

ritile nicht lïnger aly der siopf, fo boch als breit, ant Borberende ausgerandet.

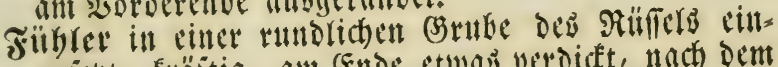
gejęt, fräftig, ain Ende etway verdidet, nact dent

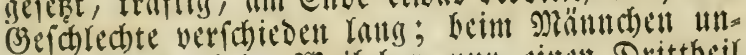

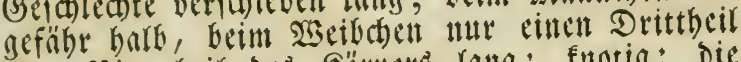
oder Sierttbeil des fïrpers lang; fmotig; die (s) liecer entweder fürger odet lätger verfebtt feg. lig, oder fait fuglig, ong leste und worlezte, oder auch Das näd) porturleste feiter miteinander verbunden. Mittercibgid)ilo länglich.

Brine mittelgrof́, stemlid, fräftig, mit winfliger Edicute.

XYLINADES ATRICORNIS.

(Schiml. (ien. \& Sp. Curc. T.I. P.1. p 180 \& T. V P. 1. p. 23'́)

Patria: Guinea. 


\section{Fam. ANTHRIBIDES.}

\section{MECONEMUS.}

Caput aque latum ac longum, oculis lateralibus, oblongis.

Rostrum sub-elongatum, mandibulis seta articulata, porrecta fovea dorsali inserta, instructis.

Antenne corpori aeque longa clavate; clava compressa, triarticulata; ante clavam filiformes, tenuissima, articulo primo incrassato, obovato, reliquis inter se subreque longis, elongatis, apice incrassatis, mediis sub-arcuatis, horum uno clavie aque longo.

Thorax subovatus, utrinque pone medium in angulum obtusum productus, carina instructus transversim ante basin decurrente \& inde versus angulum thoracis flexa:

Elytra oblonga.

Rowf fo breit als long, mit feitlingen, länglidgen Itugen.

Ritilel etmag langgejogen, die Sbetfiefer mit cinct gegliederten, vorgeftreften in einer obern Bsube eingefïgten Borite verfiben.

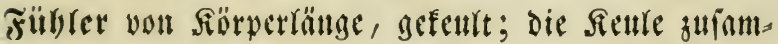
mettgedrïft, Dreigliedrig; vor det Sieule fadens förmig, febr Dünn; Das erite Blicb verdict, tum. gefebrteiförmig, die librigen ungefähr gleich lang unter cimander, geftreft, am Ende verdict, die mittlern etwas gebogen, eins derferfen fo lang als sic Nitule.

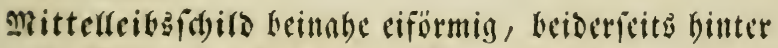
der Mlitte in eille ftumpfe Edfe vorgegogen, mit cinem queer vor ber $\mathfrak{3}$ urzel und dann nath den Geiten. edeut bin werlanfenden fiel veriehen.

şrïgerserfen länglict). 
MLCONEMUS TUBERCLLATUS.

Tropideres nov. sp. Mus. Escher=Zollikofer Turicensis.) Patrire: Mexico.

Niger, cinereo-pubescens, capite cum rostro subtus subnudo, thorace utrinque, elytrorumque maculis, fasciculisque nigro-fuscis, hisin carinis duabus longitudinalibus insertis; pedibus fusco-annulatis antennisque excepta basi \& clava piceo-rufis.

Gdimarg, grau=flaumbanrig, Der Ropf fammt Dem Rüflel unten faft natt, Der Mittelleibsichild beiberfeits, uno auf Den Flïgeldeden Fledten und Șanrbüfdel formarg: braun, biefe nuf 2 sängsficlen fiebend; die Dunfel ge= ringelten Beine uno Die Fühler, nusgenommen $\mathfrak{B}$ urgel uno Riule, pectbraun=rötblich. 


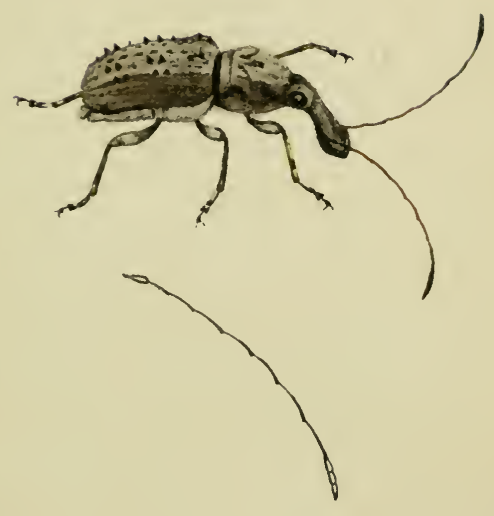

meconemus tuberculatur 


<smiles>CC1CC1C</smiles>
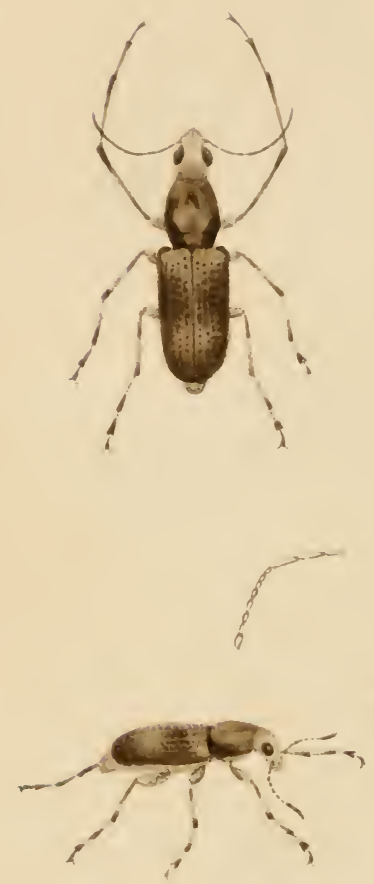

Siierlenen aderelees 


\section{FaII. A.NTHRIBITES. CHIROTEN'ON.}

Cirput aepue longum ac latum, oculis magnis, a latere in trontem assurgentibus, antice convergentubus. fostrum breve, latum.

Antennce in forea rostri laterali inserte, in femince tertian corporis partem longitudine ieyuantes, clavatx; clava angusta, elongata, dimidiam antenuam constiluente, 3 articulata; articulis clave inter se aque longis, sub-elongato-cuadratis, reliquis obconis: in mare dimdium corpus longa, filıformes, articu'is a tertio usque elongatis, tribus ultimis quam pracedentibus parum longioribus, vixque latsoribus. 'Thora. conicus, basi constrictus, supra depressus. Prelés elongati, tibia quam femore, tarso quam tibia longiore; in mare antici pralongi, articulis primo secumloque tarsi longissimis.

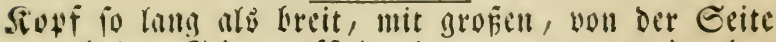
math der Ettrn aufiteigenden, vorn gegeneinamber (ich) ncigemden Tugen.

จitifel furg, breit.

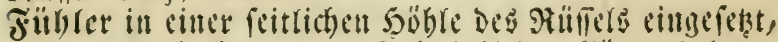

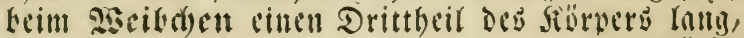
gefeult, die fente famal, langgejogen, die jälfte

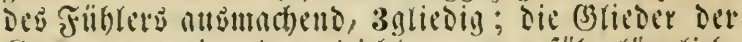

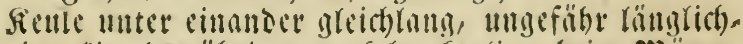
vierectig, de ilbrigen verfefrt=feglin; Leim Me and = (f) Glieber vom 3ten ant langgejogen, die 3 lefiten wenig länger mo fanm breiter als bie vorberge = bende!t.

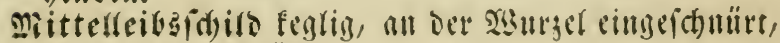
obeil nicoergedriftt.

Beine langgejogen, dic Schine länger nly der Schen=

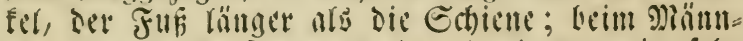
den die vorderiten ansuchmend lanis, mit febr langem liten und 2ten Fufiglicde.

CIIROTENoN AIUSTUS.

Xiger, tomento dilute ochraceo tectus, elytrorum apice ¿ plaga laterali triangulariter ad suturam extensa inter se conjunctis, thoracisque macula posticat angulari infinsatis, pedibus cinereo-variegatis.

Patria: Aquapim Guinex. 


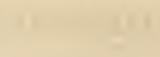

4

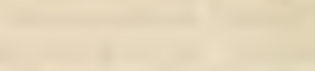

n

-

$+2$

(1)

th 


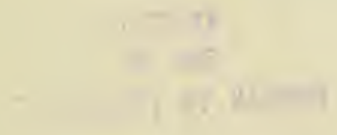

$$
\text { - }
$$



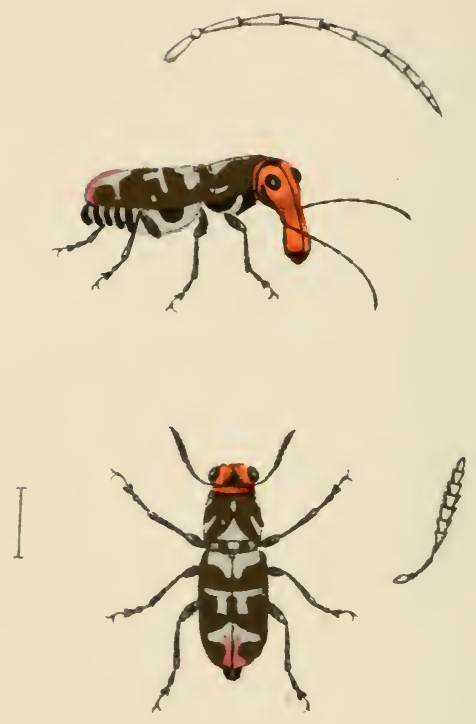

Systaltocerus platyrhinus 


\section{Fim, ANTHRIBIDES.}

\section{SYSTALTOCERUS.}

('c) ut reque latum ae thorax, oculis prominentibus. Rostrum ad perpendiculum deflexum, depressum, complanatum, lamine instar, capite saltem dupho longius, in mare a basi ad medium usque utrinque rotundato-dilatatum.

Antennce compressa; in mare corporis fere Iongitudine, articulis plurinis elongatis, tribus ultimis quam pracedentes brevioribus; in femina vix dimidium corpus aquantes, articulis tertio et quarto tenuibus, sequentubus aque latis ac longis, inter se longitudine xqualibus.

Pedcs mediocres, articulo primo tarsi elongato.

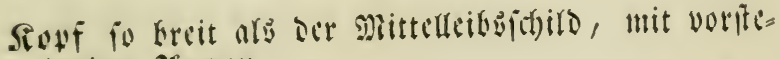
belldill Prugen.

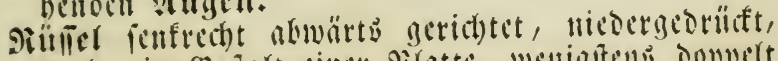

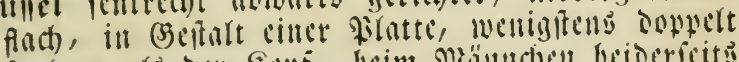
fo lanty als ber fiopf, beim Miänndben beiderfits

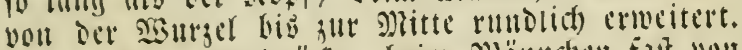

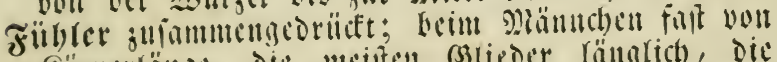
fiörperlänge, oie meiten (3lieder länglich), die 3 lekten für;er als dic vorbergebendent beim sistb.

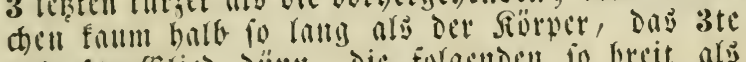
und ate (sticd Ditnth, Dic forgenten fo breit als lang, untercinnulder an Sänge gleit).

Beine mittellang, mit verlängertem eriten Fupgliede.

SISTALTOCERES PLATYRUINCS.

(Systellocerus Platvrhinus I)ej. Cat d. Colcopt. 3 me édition. p. 255.)

Patria: Cayennil.

Niger, supra brunneo-sericeo-pubescens; corporis lateribus, thorace, elytris pygididioque cintreo-notatis, sutura elytrorum postice sanguineo-, thracis margine antico, capite et rostro superne miniaceo-rubris.

Edhars, oben bramfcioenbariy; Ecitell Deb \&eibes,

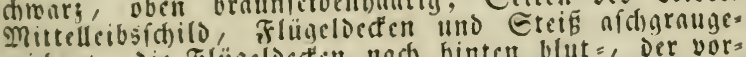
iecid)net, oie Ffliigeloecten nach binten blut $=$, Der yors Dere Rano des Mittelleibsifhildes, Der fiopf und Rilifel obennuf mennig = rotb. 


\section{FAII. ANTHRIBIDES.}

\section{ACORYNLS Sehh.}

Caput aque latum ac longum, oculis magnis, thoracem fere atlingentibus, rotundatis superioribus, antice approximatis.

Rostrum sub elongatum, antice truncatum, versus apicem utringue ad antennarum foveam formandam lobatum.

Antennce fere medio rostri lateri inserta, dimidium corpus circiter longa, tenues, filiformes, a medio ad apicem usque compressa; articulis tribus ultimis quorum intermedius brevissimus, arctius inter se junctis, clavam valde angustam formantibus; articulis reliquis inter se subrque longis, obconicis.

Thorax subeonicus, carina ante basin transversa, utrinque antrorsum flexa, instructus.

Sopf io breit als lany, die scugen grof, beimabe bis an Den Plittelleibsichild reichend, abgerundet, sben fiebeno, worn cintuder genthert.

ritillel etwas langgegogen, vorn gernde abgejdnittel, geasen dab Ende bin beiderjetis jur Biloung Der F̆̈ihlergrube gelappt.

Fiib)er ungefebr mitten ju den Ecitin des Rillifle singefect, etwa von balber fö̈perlänge, bïnn,

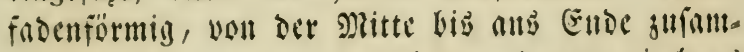
mengedriidt; Dic 3 Endglicder, deren mittleres fehr fur; ift, enger mit eimnoder verfunder, eitte

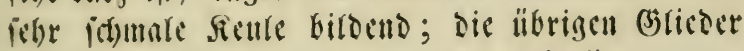
unter fich falt gleith lanty, verfehrt feglig.

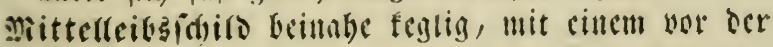

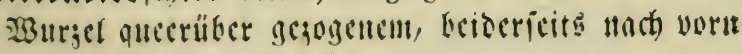
actogenem siele verieben. 
Elytra oblonga, a basi ad apicem modice angustata. Frïgeroeffen ränglich, von ber şutrgel mad) Der Spike bin mäpig verengt.

\section{ACORYNUS SULCIROSTRIS.}

(Schümh. Gen. \& Sp. Curc. T. I. P. 1. p. 124.)

Patria: Insula Java. 


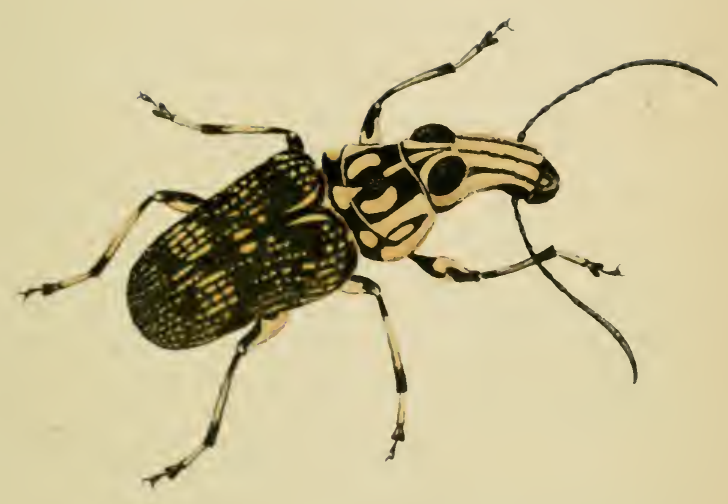

Acoryness serlerecstris 


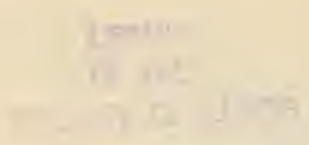




\section{FaII. ANTHIRIBIDES.}

AN'THRIBUS Schh.

Caput aque longum ac rostrum, oculis seu subrotundatis, minutis, lateralibus, seu reniformibus, magnis, a latere ad frontem assurgentibus, antice convergentibus.

Rostrum seu longiusculm, sen breve.

Antennce in fovea laterali rostri profunda insertæ, pro sexu diverse, in femina corporis dimidium tertiamve partem longae, clavatæ, clava triarticulata; in male corpus longitudine aquantes vel superantes, aut clava fere evanescente subfilıforınes ant omnino deficiente subsetaceæ; articulo ultimo acuminato.

Thorcex antrorsum angustatus.

Peules mediocres.

Elytia oblonga, supra convexa.

Sepf io lang als der rilfiel, entweder mit beinabe runden, fleinen, feitlident oder nierenförmigen, grofen, won der Geite mad) Der Grim binnufitei. genden, vorn fich gegeneinander neigenden satugen. orilliel entweder länglich ober furz.

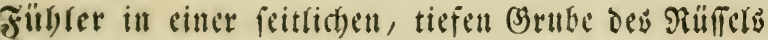

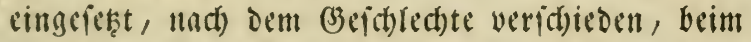
SBeibden die Sälfte oder den Drittbeil des Siör. perรื lang, gefeult, die feule 3gliedig; feim Mänu. d) den dem förper an sänge gleich oder ifn über. ragend, entmeder loegen falt verfarduindender seule beinabe fadenförmig, oder wegen gänjlid feblender Reule beinnbe borlenförmig; Das leste (s)lic ju. gefpizt.

Drittefleibiafild nach born verengt.

Decine mittellang.

Frligertecfen länglid), oben gemölbt. 


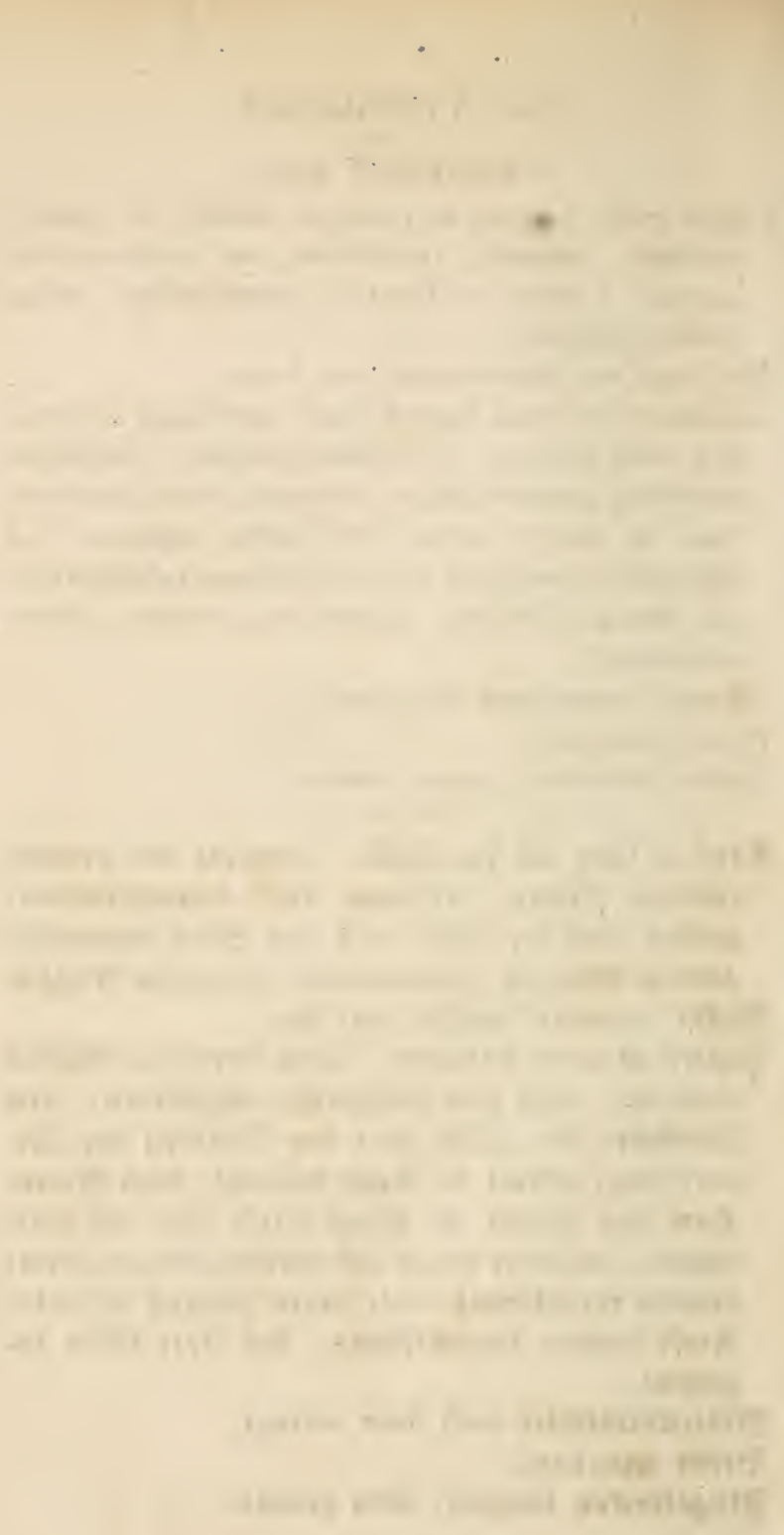




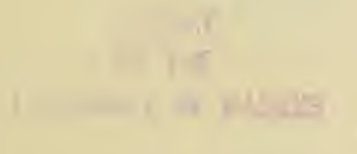




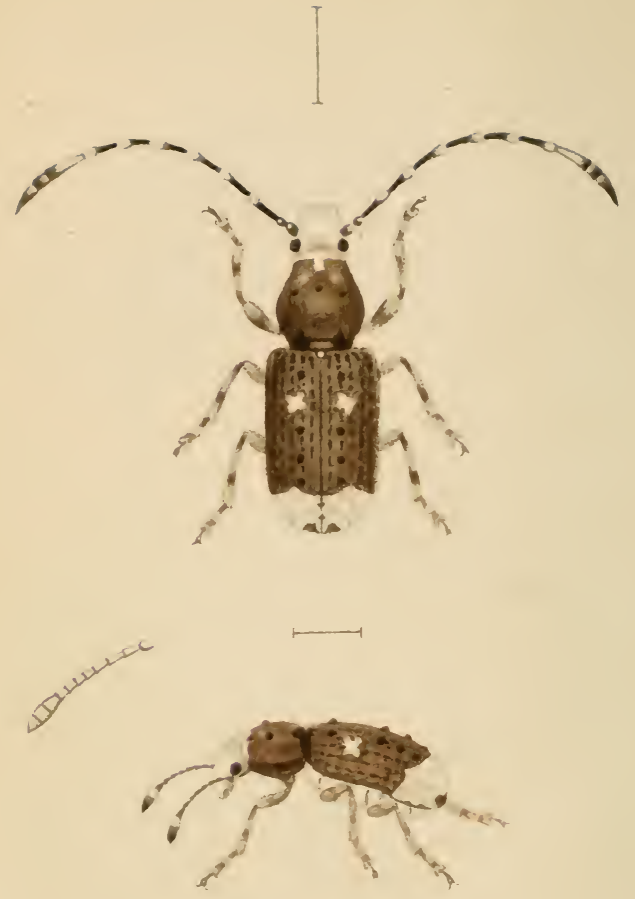

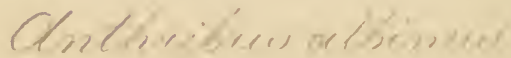




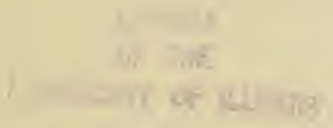

I

1 

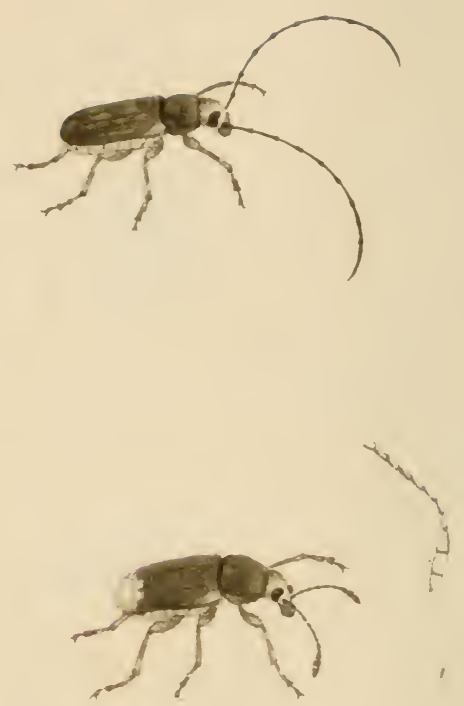

dnthribues Dama \& retursen 


\section{Fan. I.NTHRIBIDICS.}

\section{A.NTHRIBIS Schh.}

\section{S'TIRPS 1.}

Oculi laterales, minuti, antice vix comarginati. Rostrum saltem eque longum ac latum. Antennce maris subfiliformes, articulis 3 ultimis clavam tenuem subfusiformem conjunctim formantibus; femince in clavam sensim incrassate; clava obconica, articulo apicali brevi.

\section{ANTIRIBCS ALBINLS L.}

(Schïnh. Gell. $\&$ Sp. Curc. T. I. p. 131 \& T. V. P. 1. p. 2.ti.)

Patria: Luropa borealis $\&$ intermediat.

\section{S'TIRPS 11.}

Oculi a latere ad frontem assurgentes, magni, reniformes, in fronte convergente's.

Roslrum brevissimum, medio latere angulato-dilatatum.

Antemce maris subsetacer, articulis tribus ultimis discretis, paululuin compresso-dilatatis, ultimo elongato-attenuato, fcmince subito clavata, clave compressa articulıs discretis, aque inter se longis.

\section{ANTIRIBUS DAMA.}

Mas: Niger, tomento dilute olivaceo tectus, elytris line atim allido-maculatis; antennis nitidis nigris medio cirereo-variegatis, apice pubescentibus, fuscis.

\section{A.TTHRIBUS RETUSES.}

Femina: Niger, olivaceo-sericeo-tomentosus, elytris postice rotundato - retusis, olivaceo-albicantibus arcuatimque tuberculatis; antennis medio cinereo. variegatis.

Patria: Aquapin Guinex. 

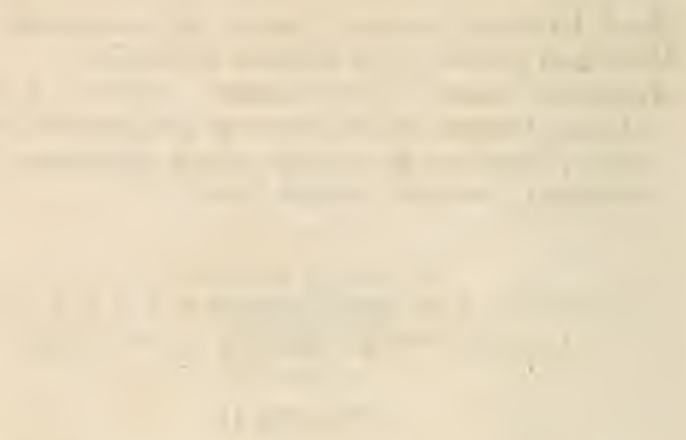

-

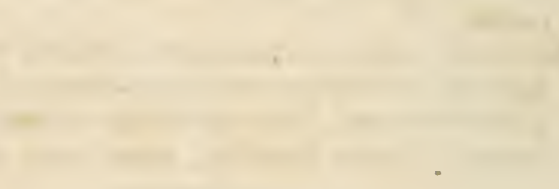




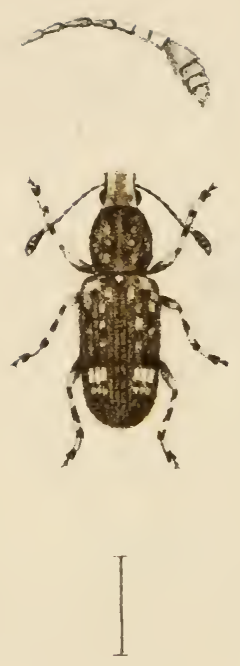

Aucorynue cradsicornis 


\section{Fam. ANTHRIBIDES.}

\section{EU゙CORYNUS Schönh.}

Caprut anise longum et latum ac rostrum, oculis lateralibus, rotundatis.

Rostrum breve.

Anteme medio rostri latere in fovea profunda insertæ, dimidium circiter corpus longitudine aquantes, clavatæ; clava elongata, depressa, 4-articulata, apice rotundata; articulis clavam antecedentibus, 1-4obconis, 5-7turbinatis.

Thorax parum longior quam latior, convexiusculus. Elytra elongata, thorace vix latiora, sub-cylindrica. apice conjunctim rotundata.

Pedes mediocres.

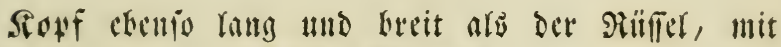
feitliden, gertndeten Prugen.

Piilliel furg.

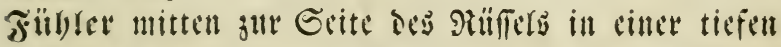
(5) rube cingefęt, ungefäbr von balber fiörperlänge, gefeult; Die sicule niedergedridt, länglid), vier. glicorig, an der Epize germndet; won Den Der ficule vorangebenden slicdern das Ite bis ate verfebrt feglig, das ste bis zte frecifelformig.

Mittefreibald)ild wenig länger als breit, etwas gelvöltet.

Frïgeroefen länglich), faum breiter ar: ber Mlit= telleibgidsilo, faft walgenförmig, an oer Spibec gemeinichaftlich gerundet.

aicine mittelgrofi.

ECCORYNUS CRASSICORNIS.

(Schü̈h. Gen. \& Sp. Curc. T. I. P. 1. p. 1S1. \& T. V. P. 1. p. 170.)

Patria: Sumatra, Java. 


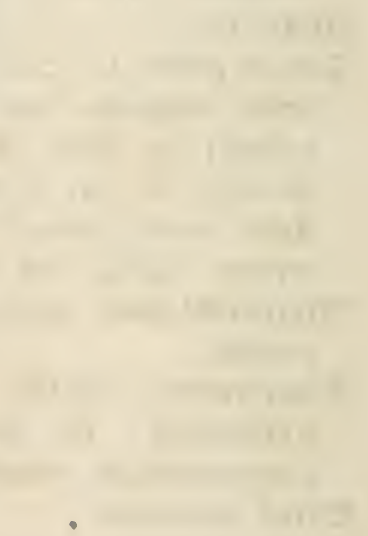

(1) 


\section{Fam. ANTHRIBIDES.}

\section{POI.YCORYNLS.}

Caput rostro paulo longius, oculis latcralibus transversis, antice sinuatis.

Rostrum brevissimum, crassum.

Antennce in fovea rostri profunda ante sinum oculorum insertæ, depresso-clavalæ; clava plus quam tri articulata, apice acuminata, subtus tota seu dimidia parte pilosa.

Thorax longior quam latior, antrorsum angustatus, dorso pone apicem \& ante basin depressus.

P'edes mediores, validiusculi, tarsi articulo sccundo quam primo paulo breviore.

Elytra elongata, apice truncata.

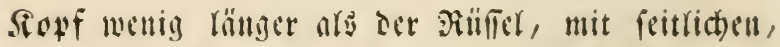
quectebenten, vorn augefucteten stugen.

siiller libr furg, biaf.

Fïbler in cinter tiefell (brube des Rüferg yor ber

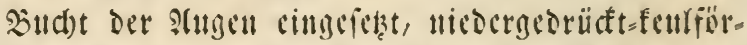
mig; Fente mebr als incigliedig, am Enoc zuges fpikt, unten gall; oder jur bälfte banrig.

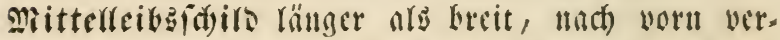
(d)mälert, obennuf binter bent Sordernatide mo bor Der şurgel nicocrgetrïtt.

Britte mittelgrof, jicmlich fräftig, das 2 te Funglico cill wenig fürger als bag lite.

Friigertecfen ranggegogen, am Ende afigeftust.

$$
\text { Patria: Aquapim Guinex. }
$$




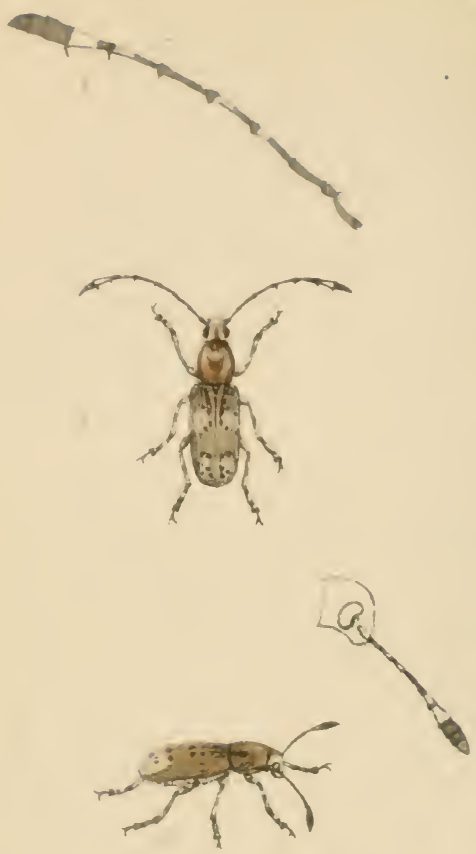

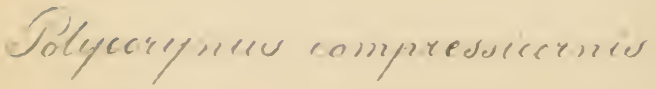




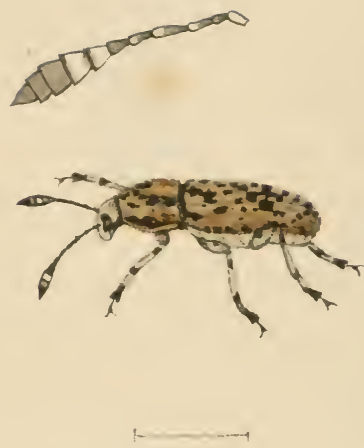

Polyceverees pantherenes 


\section{FaII. ANTHRIBIDES.}

\section{POLYCORYNUS.}

STIRPS 1.

- Anlcunce maris corpus longitudine aquantes, femince dimidio corpore breviores; clava 4-articulata.

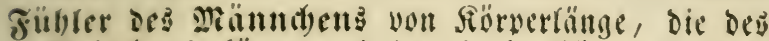

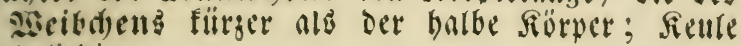
iglicoig.

POLYCORYNUS COMPRESSICORNIS.

(Mus. publ. Basiliense.)

Mas: Antennarum articulis clavam proxime pracedenlibus \& primo clava subtus apice utrinque pilorum lasciculo dentiformi instructis.

Mäund)en: : (n Den Füblern die (3)lieder zunäd) fo vor ber fienle mo das lite der feule unten am Ende beiderfeits mit rinem jabnförmigen Santpinfeldben verfiben.

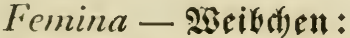

Polycorynus compressicornis Schönh.

(Scliönl. Gen. \& Sp. Curc. T. V. P. 1. p. 269.)

\section{STIRPS 11.}

Mas: Alllemene corpore dimidio paulo longiores; clava elongata 5 -articulata.

Männd)n: Fïbler cin wenig länger als der balbe fiörpir; fienle langgizogen, sglicdig.

\section{POLYCORYXUS PAXTHERINES.}

Niger, supra tomento helvolo, subtus albicante tectus, capite, thorace, pedibus elytrisque nigro-maculatis, antenuis cinereo-variegatis.

Echmari, oben mit fablgelbem, untell mit weiflichem Filze bededt, fopf, Mittelleibsfatilo, Beille und F⿱ (d) warg=gentedt, Fübler afd)grau=gefidedt . 



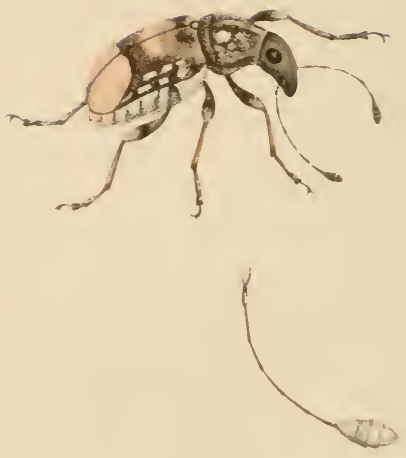

D) Derteneo separcalebs 


\section{Fam. ANTHRIBII)ES}

\section{I)ISCOTENES.}

('ipul latius yuam longins, oculi.; rotundatis. liostrum capite paulo longius, sub-elongato-1juadratum.

Antennat in rostri fuvea laterali insertæ, dimidio corpore nonuihil longiores, tenues, clavata, articulis tertio \& sequentibus ad septimum usque elongatis, fere aque inter se Inngis; clava 4 arliculata, compressa, lata, oblonga, articulis arctius connexis, secundo \& tertio transversis.

Thorax convexus, oblongus, literibus rotundatus. Prdes longiusculi

Elylia elongata.

Sionf brciter als lang, mit gerundeten sagen. Siiilel cin wentg länger als ber Ropf, jiemlidb läng. lich-vierectig.

Fiiblet in ciner Seitengrube des Rüffels cingefęt, etrons länger als der babe fiörper, dünn, gefeult, das 3te und die folgenden Sstieder bis jum 7ten langgeftect, beinabe unter fith gleichlang; Dic feule 4 glicorig, fujammengedrüift, breit, läng, lich, ibre blicder eng aneinander gedrängt, dag 2te und 3te puecrgegogen.

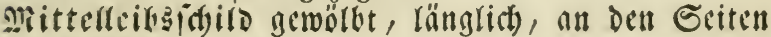
gerundet.

Beine länglich.

Frïgerieffen langgeftreat.

DISCOTENES COELEBS.

(Anthribus [nov. genus.] colebs Mus E. F. Germar, Halensis.) J'iceo-niger corpore subtus, antennarum annulo pedum, thoracisque maculis albido-romentosis, pygidio elytrisque rufescemtibus griso-lomentosis, his macula baseos fasciaque media demudalis nigris, pedi. bus antennisque rulescentibus apice nigris.

Bechbramu-f(f)war; , Der fiörper unten, ciu F̈̈blerring un

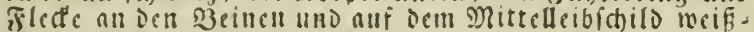

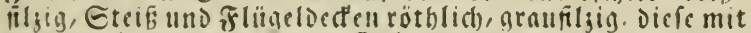

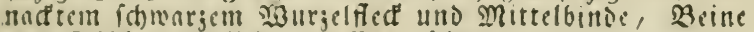
Jino Filfler rotblich, nm Ende fdomars.

$$
\text { Put)ia: Brasilia. }
$$





\section{Fam. ANTHRILIIIES.}

\section{NEMOTRICHIS I)ejean.}

(aput breve, oculis rotundatis, Iateralibus. Rosllum capite ipso adhuc paulo brevus, nec ro angustius.

- fulenne in fovea rotundata, profunda haud procul als oculis inserta, vix dimidium corpus longa, pilosie, clavatie, ante clavain filiformes, tenues; articulis duobus primis crassiusculis, tertio quartoque elongatis, reliquis brevioribus, eque inter se Inngis, nono, decimo \& undecimo clavam constituentibus tongatam, compressam, cujus articuli remoti.

Thorax conicus, ad basin aliquantum angustatus, medio dorso depressus.

Filyera elongata, linearia, postice paulo angustata. Pygidium mucrone apicali instructum.

Solf fur;, mit abgerumbeten, feitlidfoll Pugen.

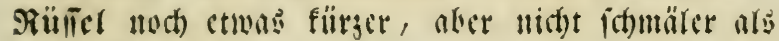
der fiopf.

Fiiblet in eince rundrchell, tiefen (5) rabe muveit den Alugen cingefelat, faum von balber siörpel. länge, baaris, feulenförmig, vor der feule faden. förmig, dïn! dic 2 criten sslicder ctwas did, Day 3 te und 4te geftreft, dic librigen fürjer, unter inch gleich rang, das 9 te, lote und 11 te eine läng. liche, gufammengedriifte Renle bildend, deren (slieder deutlict) von cimander abgefęt find.

mittelleibsfoild feglig, nu der Sisurgel ctmas ver. engt, mittenaui niedergetrïct.

šlügeldeden langgejoyen, gleichbreit, binten

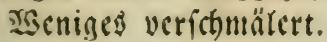

Stcis mit cinem Enoftifte berfehen. 
NEMOTRICIUS INDISTIXCTUS,

(Dejean Catalogue des Coléopt. Sc. 3e Edit, p. 25b.)

Patria: Cayenna.

Subsericeo-pubescens, incanus, maculis punctisque dispersis nigricantibus variegatus.

Etmas feibenglänjent flaumbanrig, greisfarbig, mit gers freuten fduärglichen Flecten und 

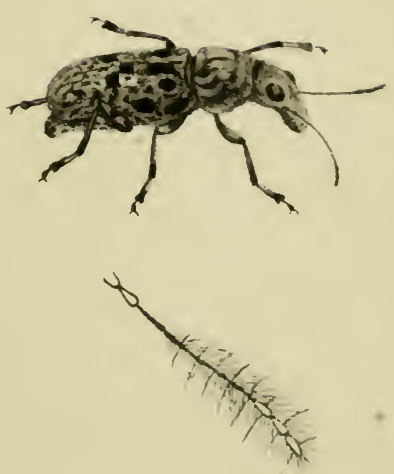

No motrichus indastinctuo 




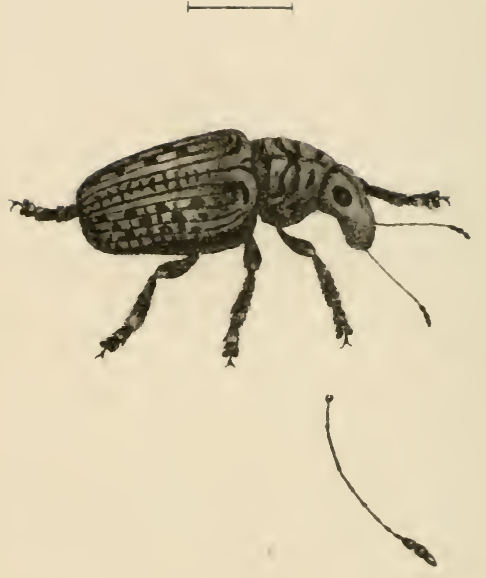

Lagopezus Cencuicorneis 


\section{Fam, ANTHRIBIDES.}

\section{I.AGOPEZLS Dejèan, Schönh.}

Capul aque longum ac rostrum, oculis ovatis.

Rostrum breve, deplanatum.

Ancmnce in medio rostri latere insertie, circiter

dimidium corpus logiludine equantes, clavata; ante clavam tenues, filiformes, articulis elongatis, apice incrassatis, primo et octavo brevioribus, latioribus; clava articulum tertium longitudine haud superante, oblonga, compressa, triarticulata, articulis parum inter se remotis.

Thorax antice angustatus.

Pedes robusti, tibia et tarso hirsutis, tarsi articulo tertio libero et secundo dilatatis.

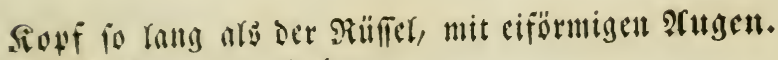
Siiiliel furs, afigefindt.

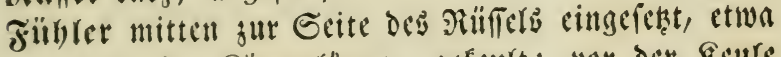

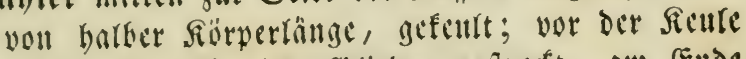
silnit, frocuförmig, Giticder geftreaft, am Ende verdidt, das erite und achte furz, breit; dic Reule micht lämber als bas orttte (slicd, länglich), furam= mengedrïat, oreigliebrig, die Blieder wenig von einander entfernt.

Mittelleigzidjilo vorn verengt.

Sicine frältig, Echiene und F゙แ rauhbarig, orittes freifigendes und jucites $F$

LAGOPEZUS TENUICORNIS.

(Schünl. Gen. \& Sp. Curc. T. V. P. 1. p. 190.)

Jatria: America meridionalis. 
transversim ante basin ducta \& latera versus antrorsum flexa instructus.

Elylra dorso depressa.

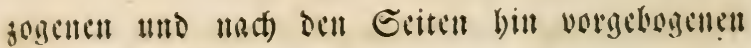
Ficle verifben. Friitgersedfen shentuf cingedritet.

STENOCERUS FULVITARSIS.

(schönh Gen. se sp. Curc. T. I. P. 1. p. 168.)

Patria: Brasiliat. 

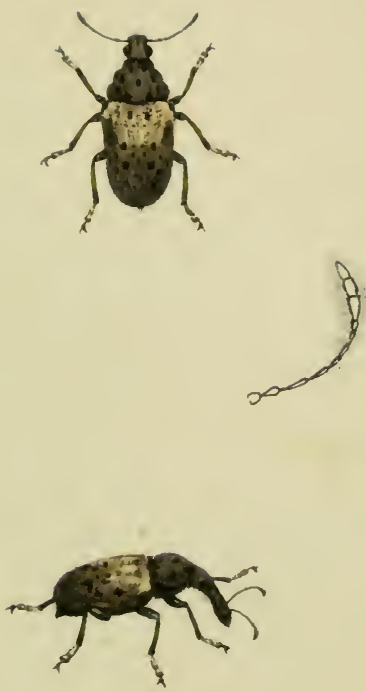

Stenoceres fulvetarois 



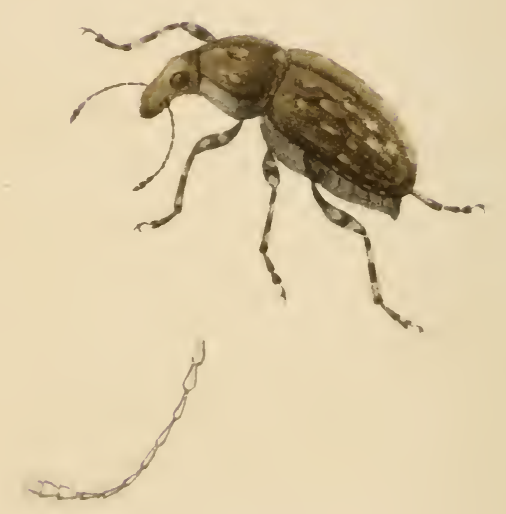

Zetrersomins verreecosees 


\section{Fam, ANTHRIBIDES.}

L'TEROSOMUS Chevrolat.

Capul aeque longum ac latum, oculis sub-oblongis. Rostrum capiti subaeque longum, antrorsum paulum dilitatum.

Antchnae in scrobe rostri subtus flexa insertae, vix dimidium corpus longae, tennes, parcius pilosae, clavatae; clava triarticulata, vix compressa, articulis clavae remotis, reliquis elongato obconicis, pruno \& secundo baseos incrassatis, sub-clavatis. Thorax convexus, lateribus a medio ad apicem usque subito angustatis.

Pedes longiusculi, tibia sub-curvata.

Elytra convexa.

Sopf fo lang alb breit, mit etwas länglichen Atugen. 2iilliel ungefäbr von Jopflänge, nach vorn ein lvenig criveitert.

Jiibler in einer ablvärts gebogenen (Srube des Rëf, fels cingefețt, fnum von balber Fiörpertänge, Dänm, fparfam bebanrt, gefeult, bie fienle 3gliedig, faum jufammengedrüdt, die (s)ieder der Fenle von eitl. ander entfernt, bie übrigen geftrefteverfebrtfeglig,

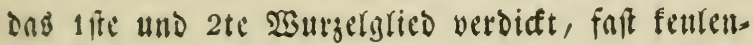
förmig.

Ditterleigatrirs gewölbt, an ben Geiten won ber Ditte unab Dem 3orderende bin pröblich verfachälert. šcine etwas länglich mit fohwnd)gefrümmter Sd)iene. şriigeriecten gewölbt.

L'TEROSOMCS VERRCCOSES.

1h. hon. cien. \& Sp. Curc. T. v. P. 1. p 20 i.1

Palria: Madagascal. 



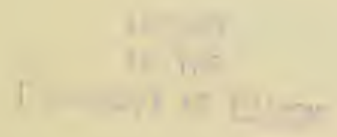





\section{FaIn. ANTHRIBIIES.}

\section{PL.A'TYRRHINLS Clairville.}

fiput transversum, vertice clevato, fronte inclinata, oculis globosis.

Rostrum capiti fere aeque longum, deplanatum, oblongo-quadratum, antice paulum dilatatum.

Antennae in rostri fovea inferiore lata insertae, thorace vix longiores, clavatae; clava Iriarticulata clongata, clavae articulis discretis, primo, secundoque: baseos incrassatis, sequentibus tenuioribus, obconicis sensim brevioribus.

Thork.x medo impressus, laterc ampliato angulatus. Pedci mediocres, robusti.

Lilytril supra depressa.

Folf in die sucere nugioditu, mit crbobenem

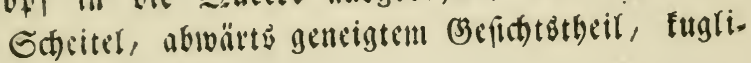
geil ?rugen.

शiïller ungefäbr von sopränge, abgefinct, länglich. vicrefig, vorn ein wentg erwecitert.

sïblet in einct untern, weiten (s)rube des Rüfrels

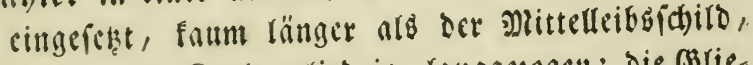
gefeult; die Reule 3glicorig, langgegogen; die Brlie.

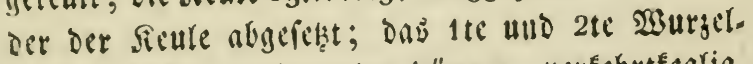
glied verdiat, die folgenden dïnner, verfebrtfeglig, allmäblig fürger.

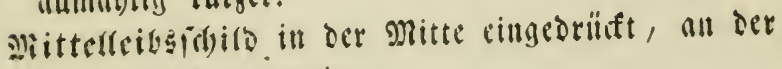
Seiti winflig erweitert.

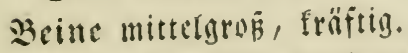

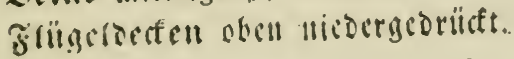





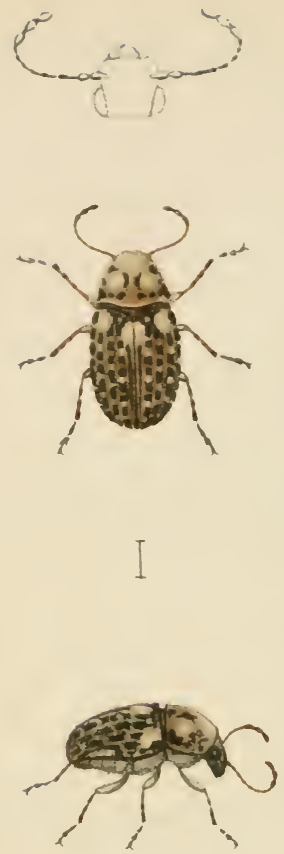

Aracoverus Coffene 


\section{Fam. ANTHRIBIDES.}

\section{ARAOCERUS Schönh.}

Capuc breve, oculis lateralibus, rotundatis, leviter emarginatis.

Rostrum capite ipso fere brevius, apice truncatum. Antennce in pagina superiore rostri apici scrobis subtus flexe inserta, dimidium corpus longæ, graciles, clavate; articulis baseos duobus incrassatis, sequentibus ad clavam usque elongatis, tenuibus; clava triarticulata, articulis discretis, ohovatis.

Thorax latior quam longior, antrorsum angustatus. Pedes sub - elongati.

Sopf furg, mit feitlidben, rumblid)en, reicht ausgeralldetell scugen.

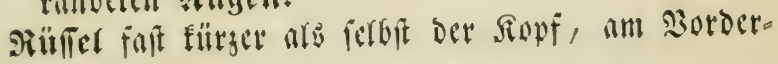
ctide abgeftutat.

Fübler anf Der obern Fräche deb Rüfels in bem sberende eitter nad) unten gefogenth (5rube eill

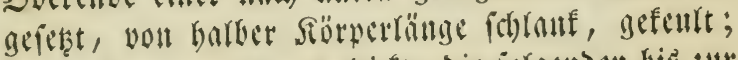

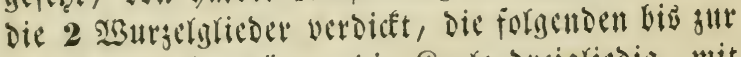

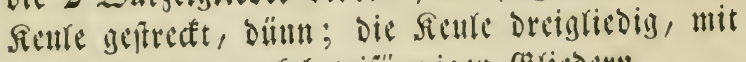
abgejonderten, verfebrteiförmigen Bstiedern.

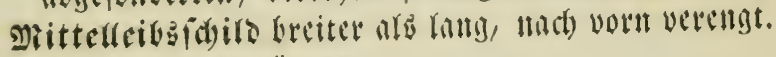
šeine ettwas verfängert.

AR.FOCERLS COFFE.

(Schünh. Geı. \& Sp. Curc. T. I. P.1. p.175. \& T. V. P. 1. p. 27.3.) Patria: India urientalis, Promontorium Bonae Spei Africae, America meridionalis. 



\section{Fam. ANTHRIBIDES.}

CRATOPARIS Dejean, Schön.

Caput rostro haud brevius, oculis lateralibus.

Rosirum crassinsculum, fere latius quam longius, mandibulis validis.

Antennce vix rostro simul cum capite longiores, in rostri fovea laterali, propius oculos inserta, clavatx; clava compressa triarticulata, articulis discretis, ante claram inde a tertio articulo tenues, filiformes, articulis duobus baseos crassiusculis.

Thorax latitudine bascos haud longior, antice angustatus.

Pcdes mediocres, tarsi articulo primo quam secundus saltem haud breviore.

Elytra oblonga.

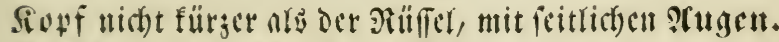
Diiilfer etwas didf, beinnbe freiter als lang, mit fröftige sterficferl.

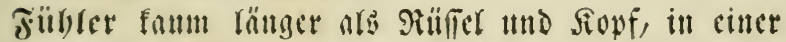

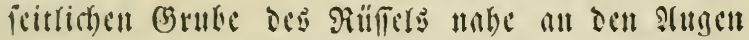

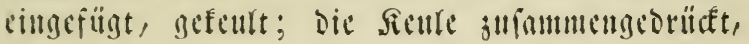

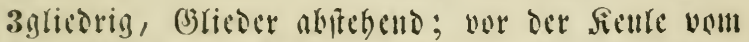
3tull (5licos an Dïnn, fadenfïrmig; dic beiden Bricder der sisurgel etwas diff.

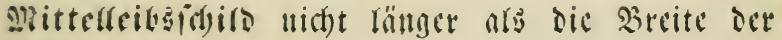
sistrjed, borth berengt.

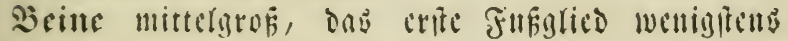
tididt fürger als ing jiweite.

Niiigersecten lämglidt). 


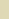




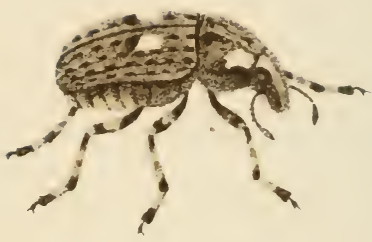

$.0 x^{2 x^{2}+2}$

Cratoparios henatus 


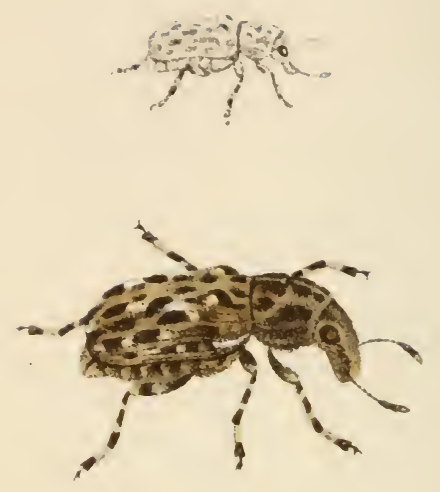

Cratopares Tapenees 
Fam. ANTHRIBIDES.

CRATOPARIS Dejean, Schönh.

STIRPS 1. Schönh.

Elyera sub-convexa.

Friigerseffen beinnbe gewölst.

CR.ITOPARIS LUNATES.

(schüh. Gen. \& Sp. Curc. T. I. P. 1. p. 1.10. s. T. V. P. 1. 1) 221.)

Patria: Georgia, Carolima.

S'TIRI'S 11. Schönh.

Elytra ad suturam latius impressa.

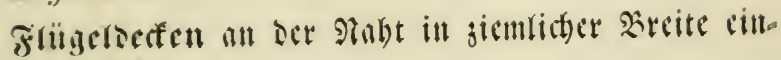
georüit.

\section{CRATOPARIS TAPIRCS.}

(Dejean Catal. d. Coleopt. 3. me édit. ?. 25i.)

Patria: Brasilı.

Elytris tuberculo ad angulum interiorem bascos instructis, niger, pube sericea tectus dilute fusca, maculatim obscuriore, elgtris insuper maculis atbicantibus tessellatis.

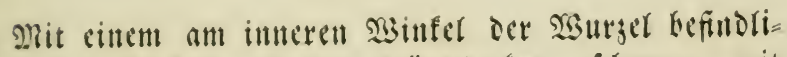
(ben 5öler auf ben. Frügerdecten, fd)war;, mit bellbramer, fiefembeifi Dunflern Gedocmbehantmis

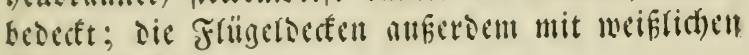
siirferfecten. 


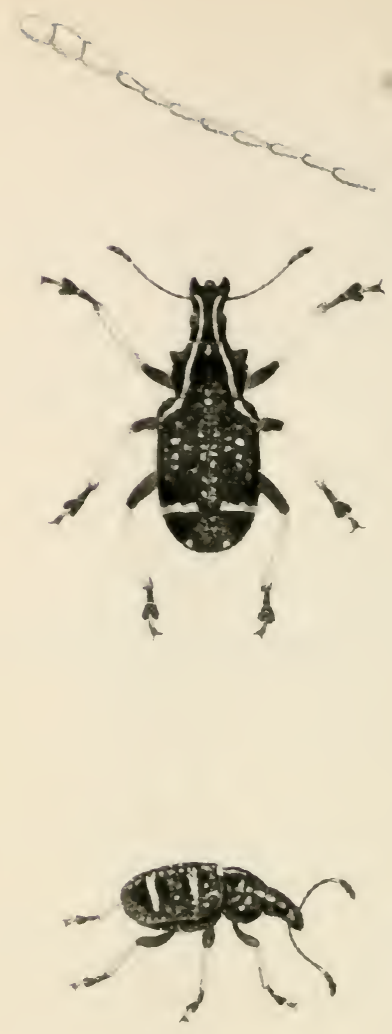

Topherderes frenatus 


\section{Fam. ANTIRIBHDES.}

'TOPHODERES Dojean.

C'iput pone oculos elongatum, oculis rotundatis. hostrum capite vix longius, antice dilatatum. -Antennce versus apicem rostri in fovea laterali elongata, subtus flexa inserta, basin thoracis, cum reclinantur, apice attingentes, clavatie; clava compressa, elongato-obconica, triarticulata, articulis paulum distantibus; ante clavam filiformes, articulis elongatis, obconicıs.

Thorax pro sexu diversus, in uno lateribus rotundatis, muticis, in altero subrectis \& tuberculo armatis, in utroque antice angustatus.

l'odes validiusculi, satis longi.

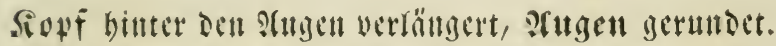
Piillier faum länger als Der Stopf, vorn irweitert.

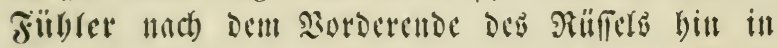
eitter feitlichen, abwäts gefogenten (5) rube cinge-

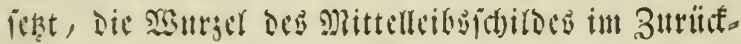
legen mit dor Epise arreid)end, gefult; die siente jufanmengebrilct, geftect verfehrt ciförmig, orei=

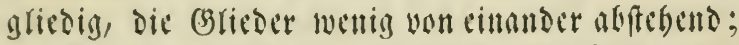
wor ber siule fodenförmig, mit geffecteten, ver. febrt fentigen (STlidern.

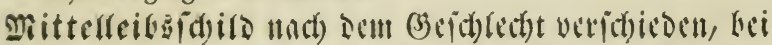
sent cittel mit getuttoeten webrlofen, bei bem all. Dern mit fajt gernden mo mit einem söber bewaff. metell Eeitell; fei beiden vorn verengt.

seinc etwas fräftig, jicmlich lang.

TOPHODERES FREAIIES.

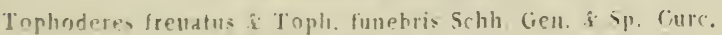

T. I. P I. p. 1.j' i: 153.

Jatria: Mardagascar. 


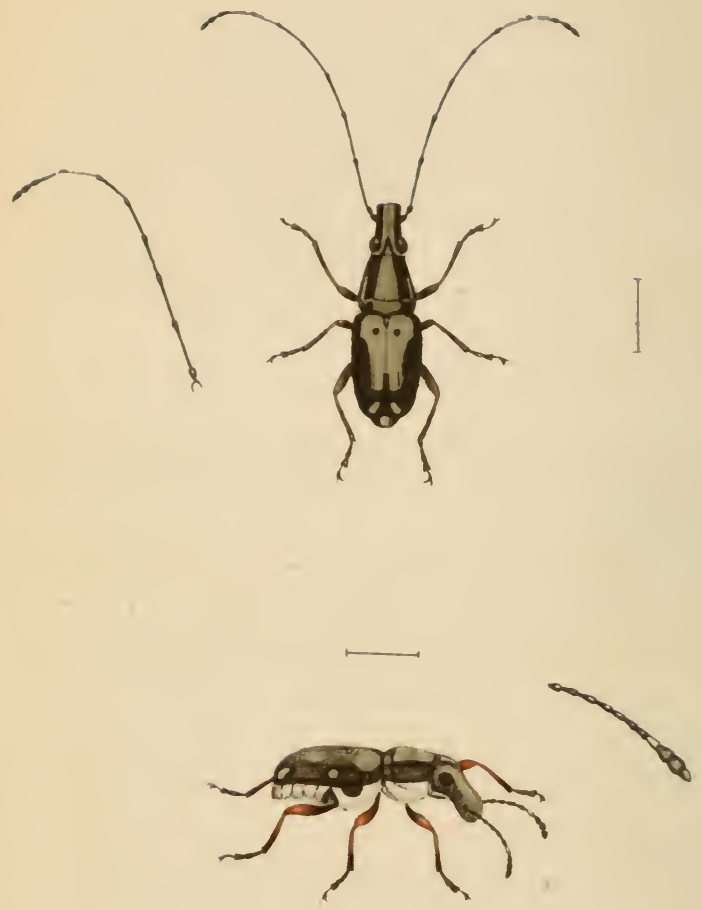

Planeletes disecideres 


\section{FaแI. A.NIHRIBIIIES.}

AN.MLOTES Schh.

Ciput aeque latum ac longum, uculis rotundatis. Roslsum capite longius, deplanatum antice paulum dilatatum.

Antemece in rostri fovea laterali lita insertac pro sexu diversac, in mare corpore sesquilongiores, sub-filiformes, articulis tortio \& sequentibus, ad nonum usque elongatis, decimo \& undecimo crassiuculis conjuntim aeque longis ac nono, simul cum hujus apice clavam valde tcnmem efformantibus, in feminc dimidio corpore vix longiores, clavatae, articulis quarto \& sequentibus subaeque longis, nono, decimo \& undecimo arctius connexis, clavam elongatam, compressam constituentibus.

Thorax antrorsum sensim paulo angustatus.

Pede's mediocres.

Elyı ce dorsi disco deplanata.

Sowf io brcit ald lang, mit gerundeten :rugen. Rïliel länger ald der fiopf, abgeflacht, vorn wenis criveitirt.

Fübler in einer weiten Scitengrubedes Rüfrlg cin. gefejt, nach dem (sefdhlechte veridjeden, beim

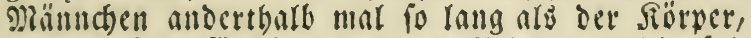
bcimabe fadenförmig, das 3te silico und die fol. genden bis zun 9 ten langgegogen, das lote und 11te etmas dite, zufammen fanm fo lang alb das 9te, und mit deffen Epike vercinigt eine febr dïnne feule fildend, beim sacibd)en famm länger alb cer balbe fiörpir, gefeult, das ste und dic folgen. Den Blieder fait gleichlang unter einnuder, day 9te, sote und lite genaner mit cimander verbunden, cine geptrecte, fulanmengedrüite fienle bildend.

mitterfeitsidnirs mad vorn allmäblig mäfig verid)mälert.

Beine mittilgrob

Friigrísectell obit finct)gedrüct.

A.ILOTLS NISCODEIS.

() hl. (ient. i . sp. ('ure. T. V. P. 1. p. I'?

Nore I:. I. Germa r. Halen-is.

['atriat: Brasilia. 




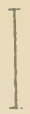

4
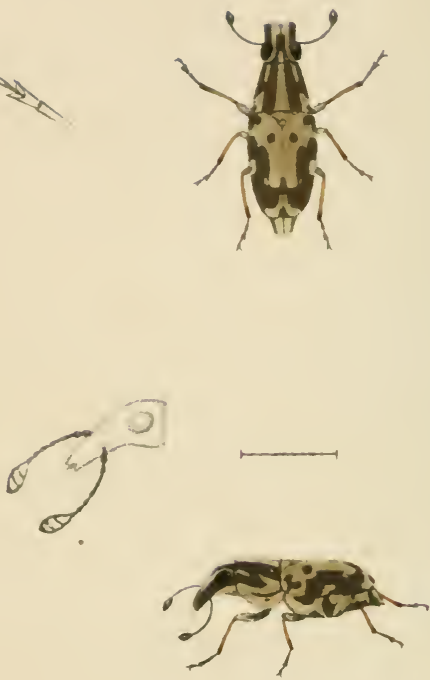

Ciymmognathes Ancora. 


\section{GYMNOGNTHUS Schinh.}

Croput vix longius quam latius, oculis magnis, ob longis, integris.

Rostrum capite aliquanto longius, paulo elongatum, deflexum.

Ancenne medio rostro inferne in fovea oblonga insertie, eque longæe ac caput cum rostro, clavata; clava triarticulata, compressa, oblonga, articulis parum discernendis; ante clavam filiformes, articulis tertio \& reliquis ad clavam usque obconicis, sensim brevioribus.

Thorax sub-conicus.

Elytra medio dorso deplanata.

Pedes mediocres, tibia \& tarso satis gracili.

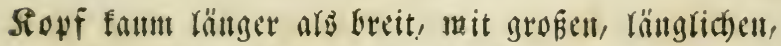
gangrandigen $\mathfrak{P}$ tugen.

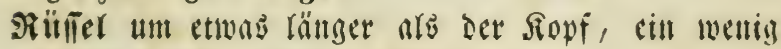
langgeftrecte, abwärts gefogen.

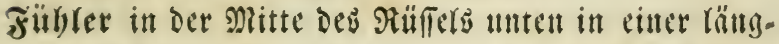

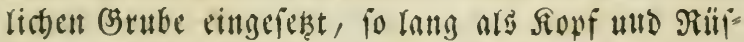
fel, gefeult; die feute dreigliedig, zufammenges sriict, länglich; bie Brieder wenig untericheibbar; vor ber feule fadenförmig, das britte und bie übri. gen SGlieder bis jut feule verfebrtfeglig, altmälig fürzer.

mittelfeigzaddirs falt fegrig.

Frtitgeroeffen oben auf der Mitte flachgedrüdt.

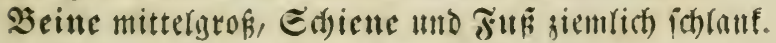



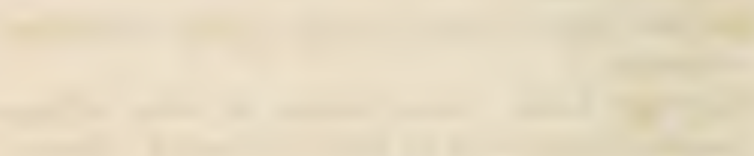

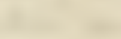
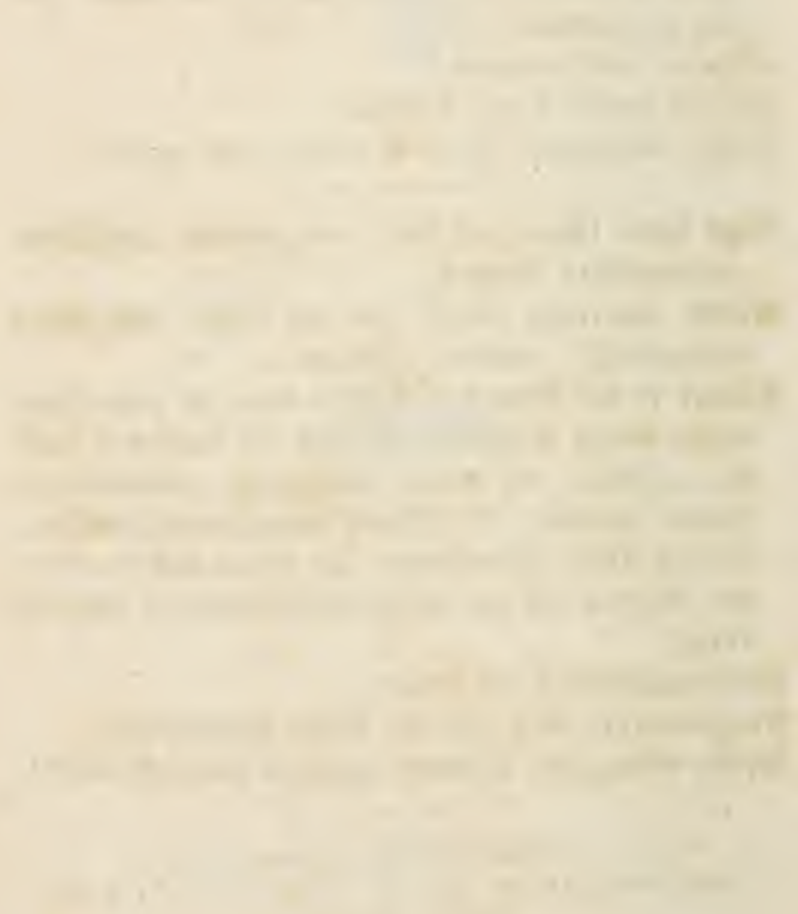


\section{Fam. ANTIIRIBIDES}

\section{PHANITHON Schönh.}

Ciaput aque latum ac longum, oculis magnis, lateralibus, sub-rotundatis, emarginatis.

Rostrum capite haud longus, eique aque latum. Antennce capite vix duplo longiores, sub margine prominente rostri prope oculos in fovea oblonga inserta, clavata; clava fere dimiliam antenna longitudinem requante, triarticulata, compressa, elongatosubrhombica, articulis arcte inter se junctis; ante clavam tiliformes, articulis tertio \& sequentibus ad octavum usque sub-obconicis, sensim brevioribus.

Thorax sub-conicus

Pedes mediocres, tibia \& tarso satis gracili, hujus articulo primo saltem aeque longo ac secundus.

Sionf io breit als lang, mit grofen, feitlicten, folt

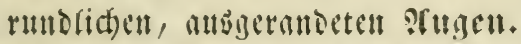

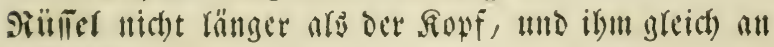
Britte.

Föilgler fanm doppelt fo lang als der Sopf, unter einter Sinte des Rälfily, nabe an den stugen in cinter länglict)en (S) rube eingefïgt, gefenlt; Dic Siute beinahe die barbe sänge der Güblers betragend, oreigliedig, jufammengedrïdt, jicmlict) in (Bseftalt

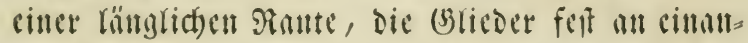
Der georïngt; vor Der Sieule fadenförmig, das ortte

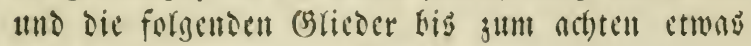
verfebrt cifürmig, allmälig fürzer.

mittelfeigziduirs beimate fegelförmign.

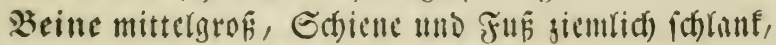
an biefent das erite (s)lice wenigitens ebenio lan!s

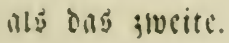




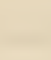

$+$

$+$
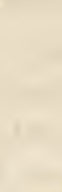

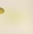




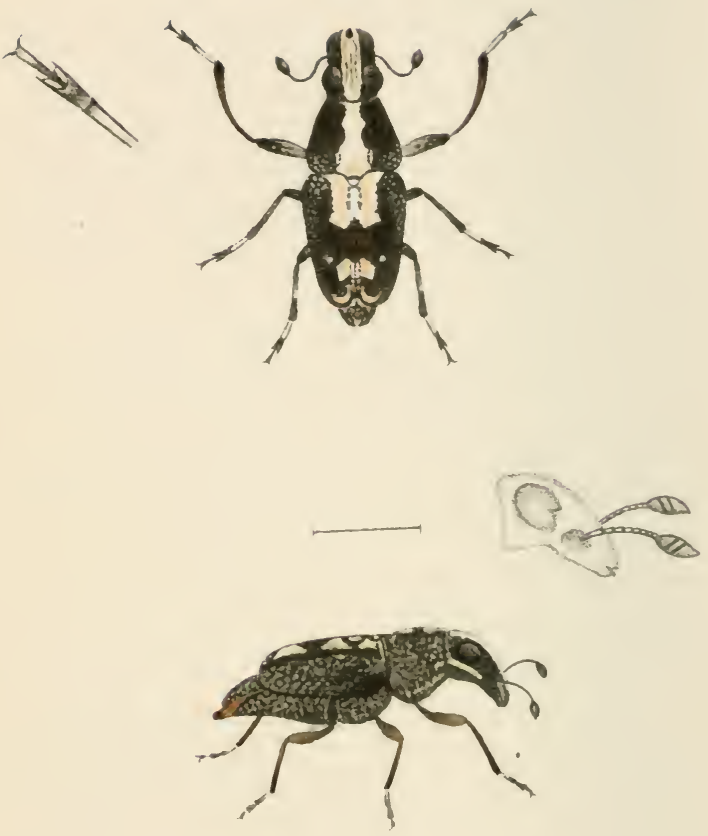

Thanithon costatuo 


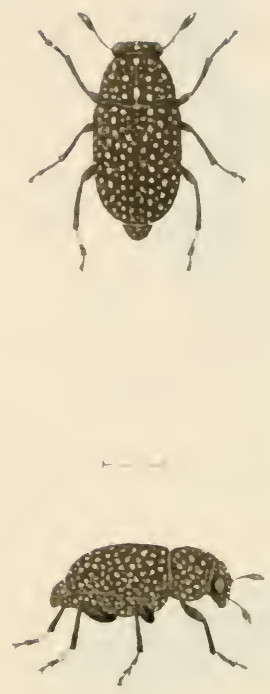

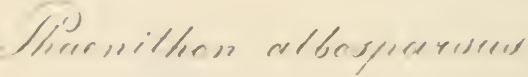




\section{Fan. ANTHRIBIDES.}

PHAENITHON Schönl.

STIRPS I. Schónh.

Corpus sub-elongatum. P'ygidium magnum, oblongum, sub-porrectum. Pedes satisgraciles, anticorum tibia \& tarso, præcijue in mare, elongatis.

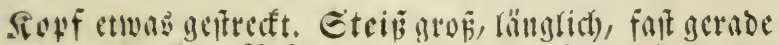

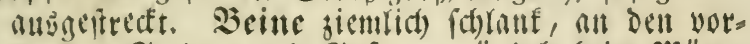

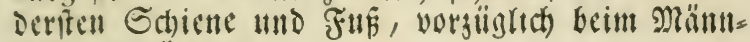
d)en, verthingert.

\section{PILENITHON COSTATUS.}

(Schüul, Gen. Se Sp. Curc. 'T. I. P. 1. p. 15S.)

Patria: Cayenna \& Brasilia.

STIRPS II. Schönh.

Corpus breviter sub-ovatum. Pygidium mediocre, semi-rotundatum, sub-deflexum.

Störper jienlid) won furser Eiform. Eteif̈ mittels grof, balkrundida, ctwas niedergetogen.

PII.NITHON ALBOSPARSES.

PHAENITHOY AI.BOSPARSLS BUQUET

MUS. MAX.SPINOI,A GENUENSIS.)

Patria: Cayenna.

Niger fusco - , subtus cinereo- holosericeo pubescens, punctis villosis plurimis superne \& latere di spersis \&] tarsorum posticorum macula basali albidis.

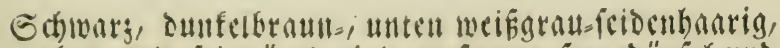
oben und feitmärts viele zerftreute Saardinfer and

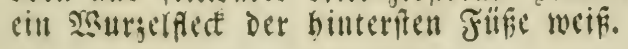




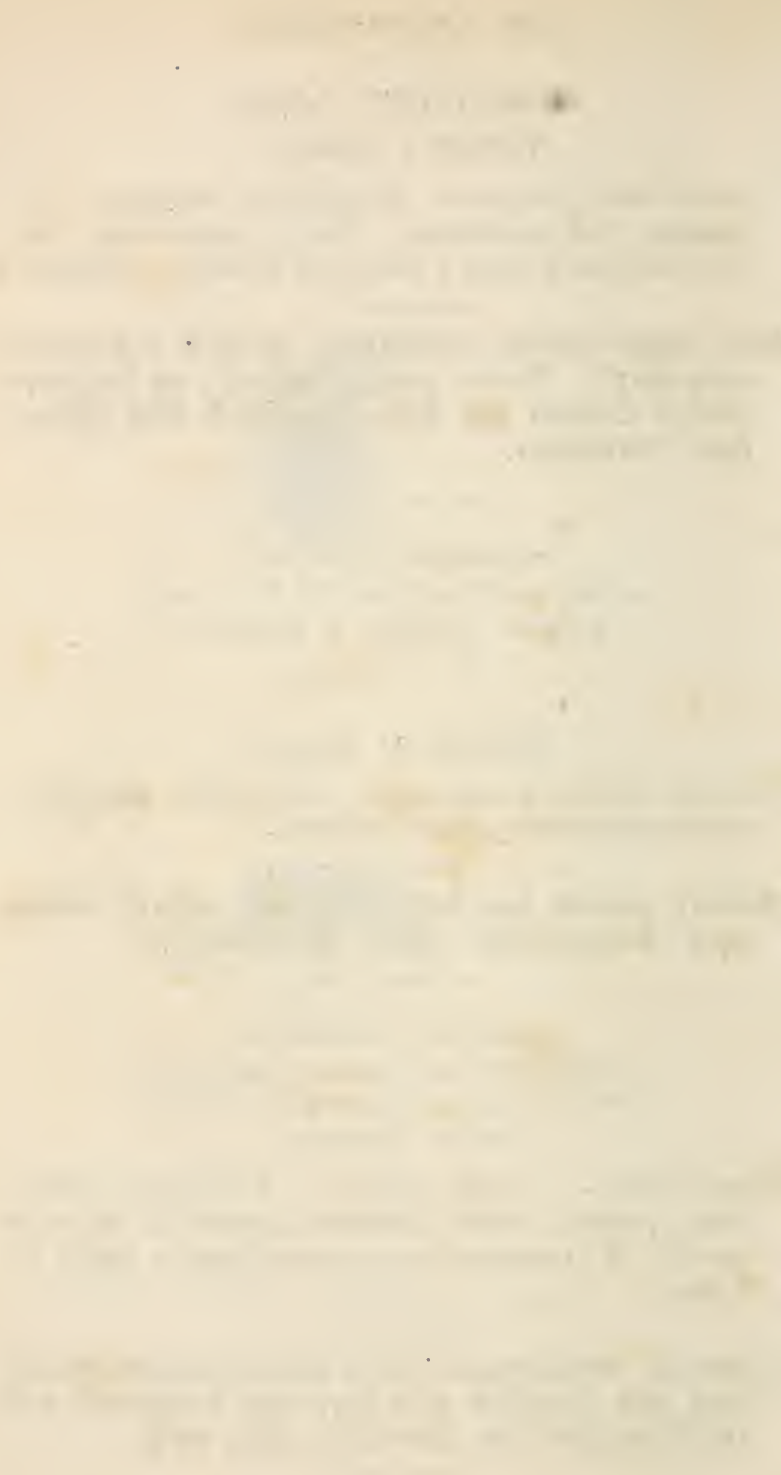




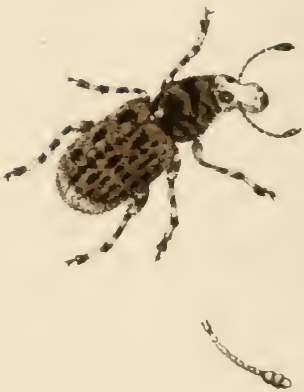

Tropideren niveirootrios 


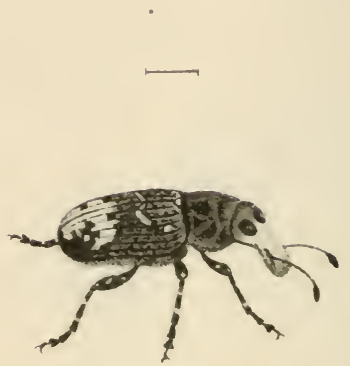

Trepiderees albirentries 


\section{Fam. ANTHRIBIDES.}

\section{TROPIDERES Schönh. STIRPS I.}

Oculi frontales, antrorsum convergentes.

Pugen pirntândig, nach vorn gegeneinander ftebend.

TROPIDERES ALBIROSTRIS.

(Schönh. Gen. \& Sp. Curc. T. I. P. 1. p. 147. \& T. V. P. 1. p. 206.) Patria: Europa borealls \& intermedia.

STIRPS II.

Oculi laterales.

2ugen feitenftändig.

TROPIDERES NIVEIROSTRIS.

(Schonh. Gell. \& Sp. Curc. T. I. P. 1. p. 155. \& T. V. P. 1. p. 213.)

Patria: Europa temperata, Suecia. 


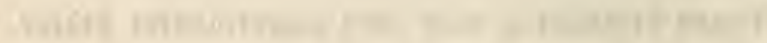

$-$

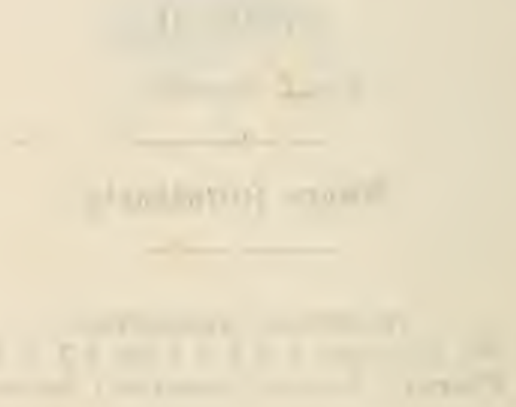




\section{Fam, ANTHRIBIDES.}

TROPIDERES Schönh.

Caput rostro haud longius, oculis sub-rotundatis. Rostrum breve aut sub-elongatum, deplanatum. Antennce capite simul cum thorace vix longiores, medio rostri latere insertx, clavatx; clava elongata, compressa, 3-articulata, articulis inter se approximatis; ante clavam filiformes, articulis sensim brevioribus.

Thorax subconicus.

Pedes mediocres.

Elytra oblonga, apice conjunctim rotundata.

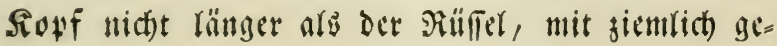
rundeten sagen.

Railiel furg oder etwas langgejogen, afgeflact)t. Fiibler foum länger alg Der fopf mit Dem Mittel =

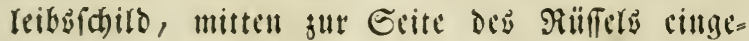
fügt, gefeult; Reule langgejogen, zujammenge= orïat, 3gliedrig, ihre Bstieder cinntuer genäbert; vor ber Jieule fadenfürmin, mit allmälig fïrzern Bsticdert.

Miittelfeigzidails faft feglig.

Beine mittelgrof.

Friigelseffen länglich, am Endoc gemeinfaraftlich gerundet. 


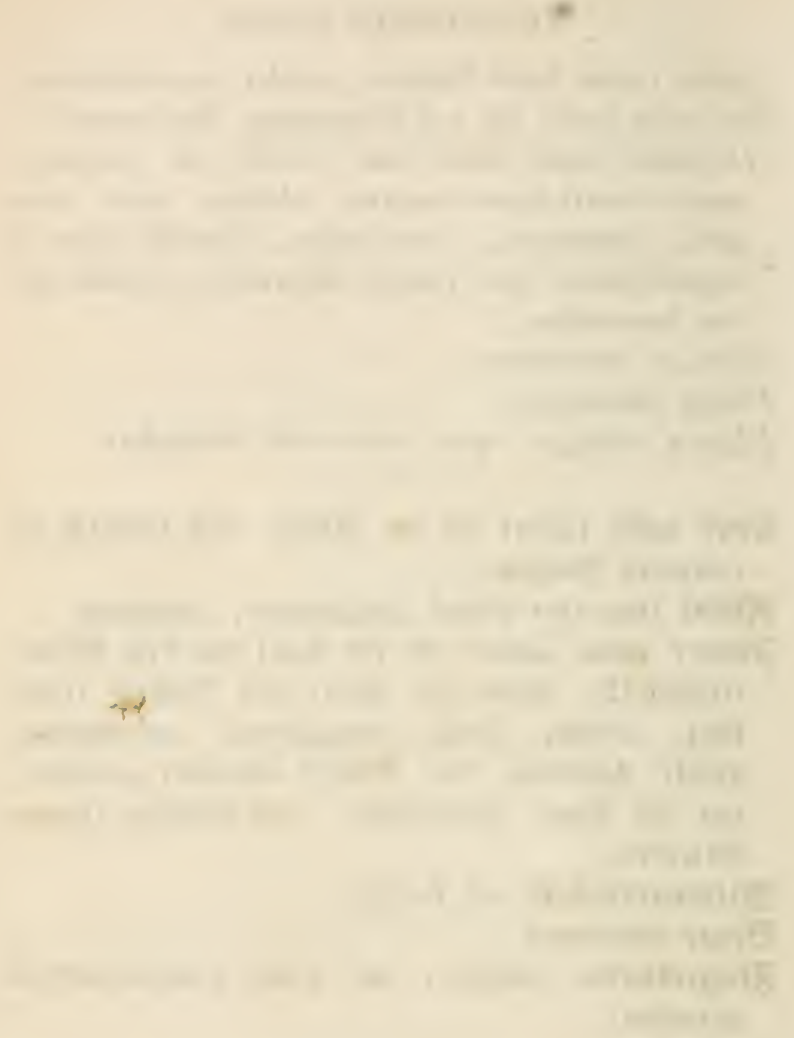




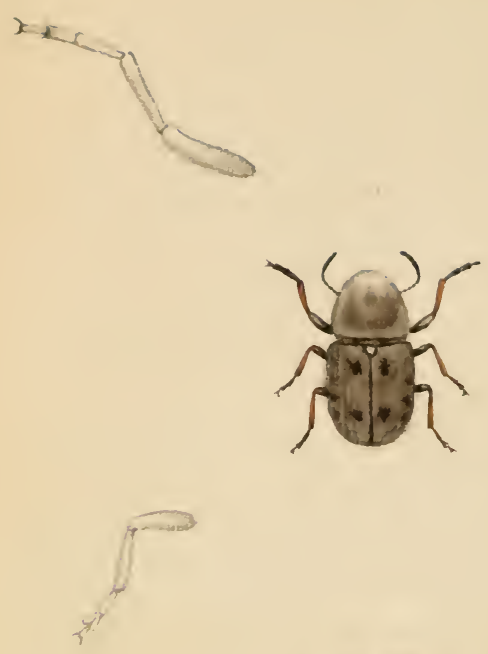

I
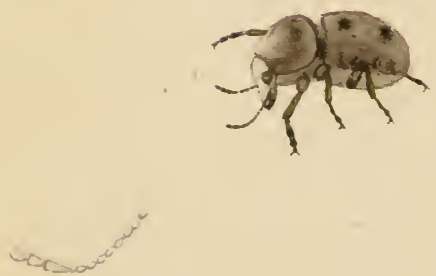

Blecberwes felleror 


\section{Fain. AN'THRIBIDES.}

\section{BI.ABERI'S Schh.}

Caput ad oculos usque thoraci intrusum, supra convexum, oculis lateralibus, antice emarginatis.

Rostrum breve, paulo latius quam longius, deplanatum. Antennce in fovea laterali rostri profunda insertæ, longitudine thoracem æquantes, tenues, clavalæ, clava dimidiam antennæ longitudinem fere æquante, tri-articulata; articulis distinctius sejunctis.

Thorax fere xque longus ac latus, convexus, antice angustatus.

Pedes validiusculi, femore tibiaque inermibus, tarso saltem xque longo ac tibia, articulis primo \& secundo elongato-sub-quadratis, primo quam secundo longiore; pedes antici in sexu depicto (verosimiliter masculino) elongati, tarso præcipue longo, latius culo pubescente.

Elytra conjunctim subquadrata, apice sub-rotundata.

Sopf bis an die $\mathscr{U}$ ugen in den Mittelleibsfdild eingefenft, oben gemölbt, bie $\mathfrak{A}$ ugen feitlich, vorn nusgerandet.

Rüñel furs, etrons breiter als lnng, nbactindit.

Füblex in einer tiefen Geitengrube beg $\Re$ üliels eingefest, an \&änge dem Mittelleibsfoilde gleid), oünn, gefenlt, die Reule die balbe Füblerlänge beinabe betragend, 3glie: Dia, bie (slieder beutlia) gefondert.

Mrittelleibsichillo beinnbe fo lang als breit, gemölbt, vorn verfamälert.

Beine fiemlid fröftig, Sanenfel uno Sdiene unbemebrt, Fue wenigfteng to lang als bie Echiene, fein 1ftes und ztes (slied Innggezogen, fatt vieredtig, bas erife länger als bns 2te; die vorberfen Beine beim abgebildeten (Ge. f(d)led)t (rohbrid)einlth) Dem männlichen) verlängert, vore züglid ihr Fuf langgeffedt , fiemlich breit, flaumbnarig. Flügeloecfen gufammen beinabe qundrntiff), am Ende beinabe gerundet.

BLABERUS FALLAX.

(Schh, Gen. \& Sp. Curc. T. V. P. 1 p. 249.

Patria: Caffria. 



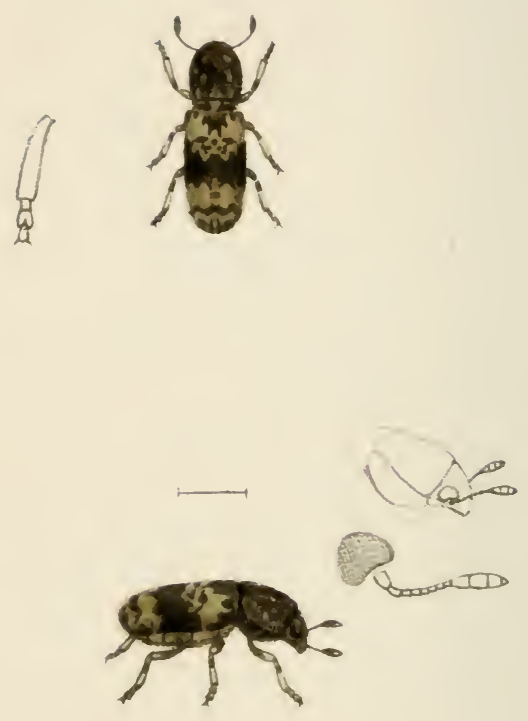

Cugoneer subrytindricuer 


\section{BLGONIS Sehh.}

(i1) ut breve, oculis lateralibus, emarginatis.

hostrum deflexum, eapite ipso fere brevius, apiee profunde emarginatum.

- fintennce prope sinum oculorum in fovea elongata, subtus flexa inserta, vix thorace longiores, clavata; clava compressa, oblonga, triarticulata, articulis distantibus; ante clavam filiformes.

'Thoral sul, quadratus, eonvexus, antice rotundatoproductus, lateribus \& basi acute inarginatus, angulis anticis prominulis, callosis.

l'crles breves, validi, tibia angulata, tarsi articulo primo quam secundus breviore.

Solf furj, mit feitlichen, nusgerandeten Rugen. skiillel niedergebogen, noch fïrger nle jelbit der fopf, an Der Evike tief ausgerandet.

Filf) rer nabe am stusichnitt der s(ugen in einer ber. längerten, nboürts gebogenct Bstube cingetïgt,

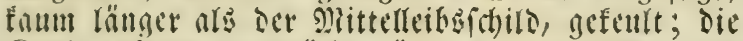
Sittle jufammengedrüdt, länglich, Ireiglichig, mit auscinanderitebenden Blicoern; vor der sicule fa. cenförmig.

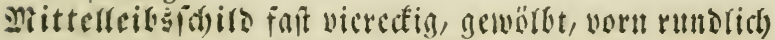
nubgrgogen, nu Eeiten und SBurjel fantf gernabet, mit ctwas wortibendell, fhovieligen Sorderefta.

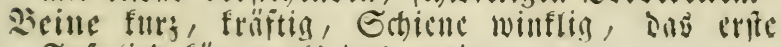
Fubnlie fïrger als das jweite.

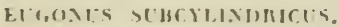

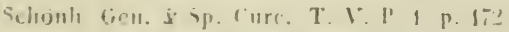

Prll-ius: Mf xicn. 


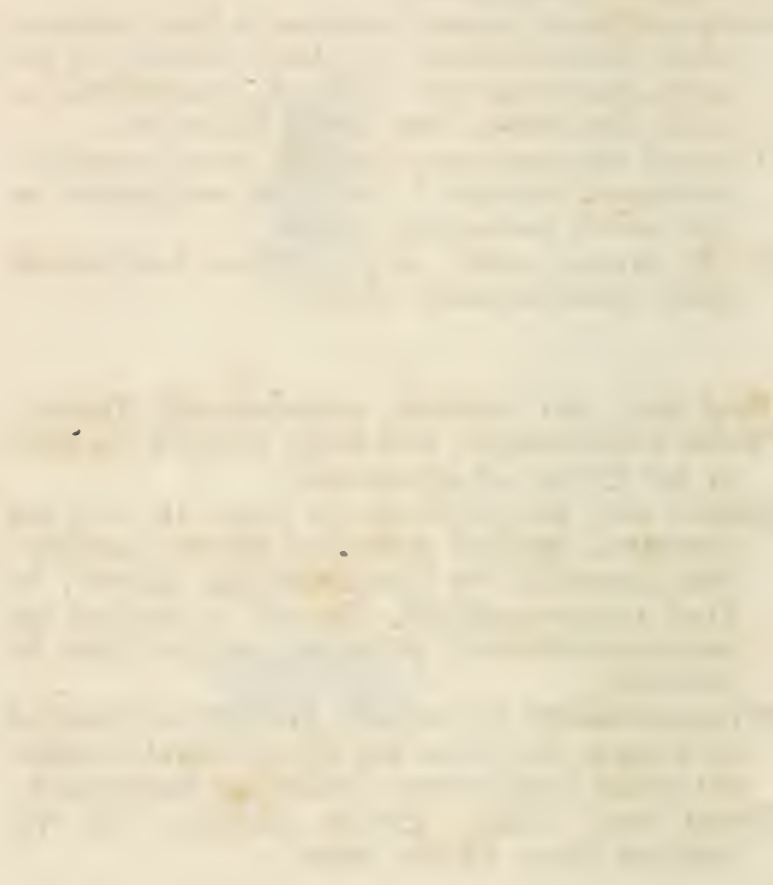






\section{FaM. ANTHRIBIIESS}

\section{BRACHITARSUS Schh.}

Coput breve, latius quam longius, oculis lateralibus, rotundatis.

liostrum deflexum, capite haud longius.

-lmemne sub margine prominente rostri in fovea inserta, longiudine thoracis, clavata; clava oblonga, compressa, triarticulata, articulis paulum distantibus; ante clavam filıformes, articulis tertio \& sequentibus ad octavum usque sub-tmrbinatis.

I'lorax: aliquanto latius quam longius, antrorsum angustior.

l'celcs breviusculi, validiusculi, artıculo primo tarsi quam secundus breviore.

Sioff furg, breiter als lang, mit fittidben, germu. deten : ougen.

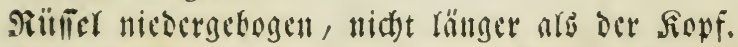

Fïbrer unter dem voripringenden Rande des Rüffel in ciner (Sruke eingefügt, wou ber sänge des slit. telleibsfobildes, geftult: die sicule länglich, jufum. mengedrilct, oreiglicoig, mit wenig won cinander abitehenden Shlicdern; wor det Sieule fadenförmig,

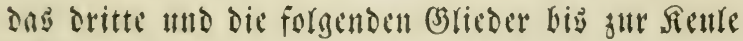
fait freifichörmitg.

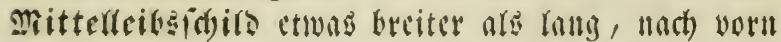
ict)mäler.

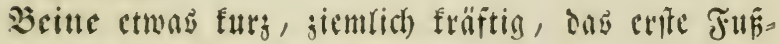
glies fürget als ons. juete.

BR.ACHYTARSES SCABROSLS.

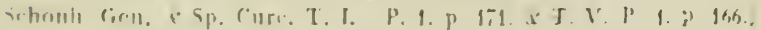

J'at)ia: Furupal. 



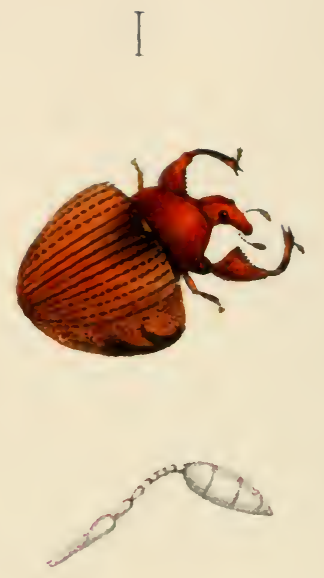

Camarcter marginatios 


\section{Fam. A'T'TELABIDES.}

\section{CAMAROTUS Germ Schh.}

Caput \& rostrum deflexa, deplanata, thorace vix longiora, aque inter se lata.

Capul porrectum, oculis lateralibus, in frontem assurgentibus, prominulis.

Rostrum capite paulo brevius, latius quam Iongius, antcmllis in fovea rostri laterali insertis, capite duplo longioribus, 11 articulatis, clavatis, clava reliquam antennam fere longitudine expuante, elongata, tri-vel subquadri-articulata; ante clavam tenuibus, articulo basali elongato, clavato, secundo subrotundato, sequentibus brevissimis, coarctatis.

Thorax duplo latior quam longior, antice subito constrictus.

Pedes inæquales, omnium tibia ad apicem unco armata, posteriores breviusculi, antici illis robustiores, duplo longiores, femore in medio valde incrassato, intus angulato-dilatato, latere antico serrato-dentato, tibia incurra, apice bidentata.

Elytra marginato - dilatata, margine a humero ad apicem usque sensim angustato.

CAMAROTUS MARGINALIS.

(Patria: America meridionalis. Mus. Escher-

Zollikofer, Turicensis.)

Antennis tarsisque flavo-lestaceis, rufus, elytris circa scutellum \& ad marginem lateralem infuscatis, sul_ catis, sulcis punctatis, suturalibus ultra medium sim. plicibus, margine ipso punctis majusculis crebrius impresso. 

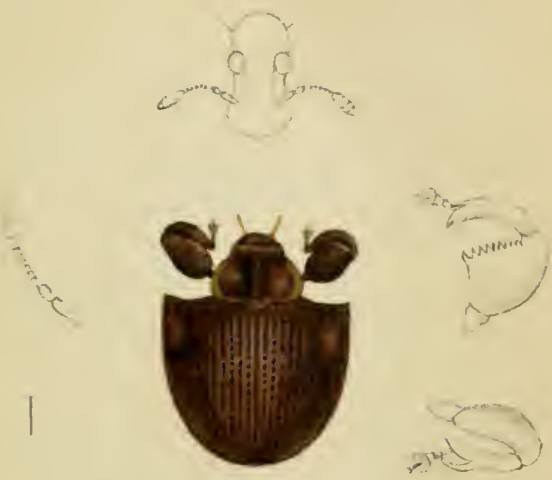

Camereralies eresenelleides 

(1)

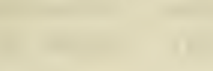

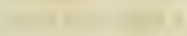

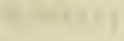


Fam. AT'TEI.ABIDES.

PTEROCOLUS Schh.

Luput ierque latum ac longum, pone oculos paulo elongatum, oculis lateralibus, rotundatis.

Rostrum capite dimidio latıus, eoque vix longius, lineare.

Antemnce in fovea laterali baseos rostru inserta, rostro plus duplo longiores, 11 articulatæ, clavatie; clava reliquam antennam loncitudine pene aquante, elongato-ovali, sub-perfoliata, 3articulata, articulis clavam antecedentibus a tertio ad octavum usque sensim brevioribus, primo \& secundo baseos crassiusculis, longiusculis.

Thorax latior quam longior, antice angustior, postice dilatatus, subtus utrinque fovea profunda excavatus.

Pedes validiusculi.

Elyira lata, ultra thoracis angulos posticos extensa, basi emarginata, postice late dehiscentia, singulatim postice angustata, apice rotundata.

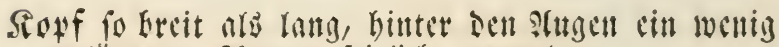
verlängert, Fitugen feitlict), gernttoet.

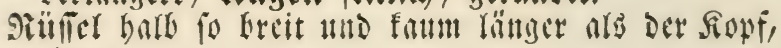
limint.

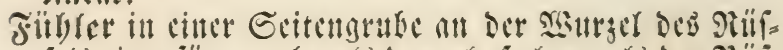

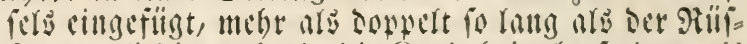

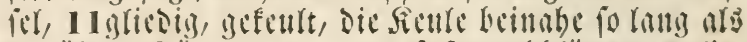

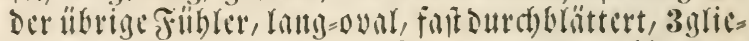

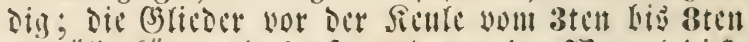

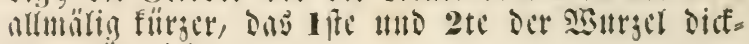
lich), lïnglict).

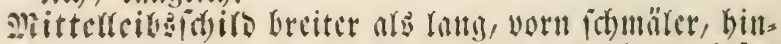

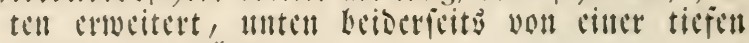
(5rube nusgiböblt.

Sicine jiomtid) fribftig.

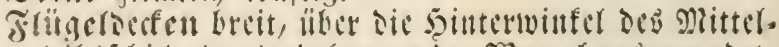

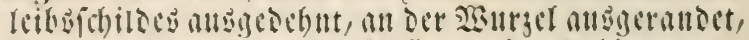
binten weit von cintander flaffent, cingeln binten wer. id)mïlert, an Dor Eppize germlloct. 

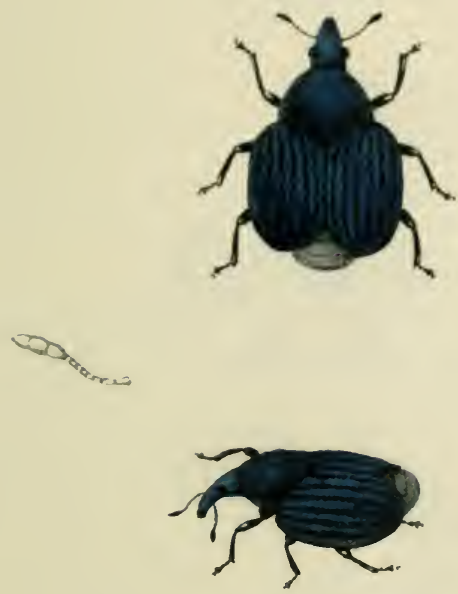

Sterocoles maters 



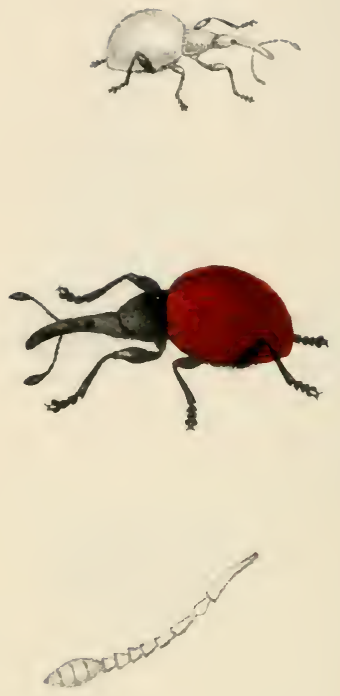

Cybebees reefipeños 
CYBEBUS Schh.

Caput sub-cylindricum, pone oculos elongatum, oculis prominulis lateralibus.

Rostrum capiti aque latum, eoque duplo longius, modice arquatum, teres, fovea in medio latere incipiente \& inferne ad basin usque percurrente impressum.

Antennce medio rostro in fover laterali inserta, rostro vix longiores, validiusculæ, 12 articulata, clavata:, clava oblongo-ovata, acuminata 4articulata, articulis arcte connexis.

Thorax conicus.

Pcdes mediocres, antici paulo elongati, omnium fe-more pone medium clavato, tibia apice paulo dilatata, tarso dilatato, articulis, ultimo excepto, subtus spongiosis, secundo tranverso, tertio bilobo. Elytra fornicata, ovata.

Sowf zienlid) walgig, Ginter Den Flugen verlïngert, mit vorfthenden, feitlichen sagen.

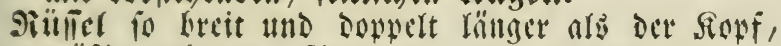
mâñig gebogen, fitelrund, mit cintr mitten jut

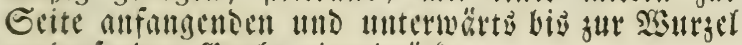
verfaufinten 3 ratbe cingedrïct.

Fiibler mitten an Rilifil in ber Geitengrube cin. gefïgt, faum ränger als ber Ritifel, ziemlich fräf= tig, 12 gliedig, gefeult; bic fieule länglich)=ciförmig,

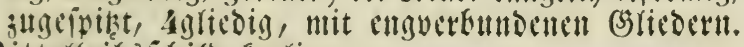
Mitterleigafdirs figlig.

Ṡcine mittelgrof , Die vorderifen cin wenig verläln, giert, an arlen ber Ed)enfel nach Der Mlitte gefenlt, die Edbiene an Dem Ende ein wentig erweitert,

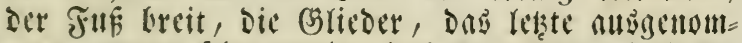
men, unten fowammig, bas 2 te ancer, bais 3te 2lappig.

Friigerocfen boctgewölst, ciförmig.

CYBEBLS RUFIPENNIS.

(Schïnh. Gen \& spec. Curc. T. V P 1. p 4is.)

Patria: Madagascar. 



\section{ATTELABUS L. Sehh.}

Caput longius quam latius, pone oculos elongatum, oculis prominentibus, lateralibus.

Rostrum vel capite brevius, crassum, basi constrictum.

Antennce approximate, ante oculos in summa fovea rostri laterali lata inserta, caput longitudine saltem æquantes, sub-12articulate, clavate; clava sub-quadriarticulata.

Thorcax sub-quadratus, antice angustior, supra convexus.

Pedes in quibusdam speciebus inæquales; posteriores in omnibus mediocres, antici in nonnullis illis subaquales, in aliis longiores.

Elycra sub-quadrata, postice dehiscentia, singulatim basi truncata, apice rotundata.

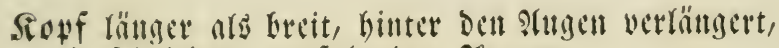
mit feitlichen, wortithenden sofugen.

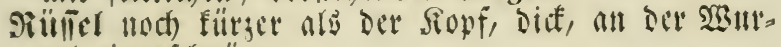
jel cingeictutiurt.

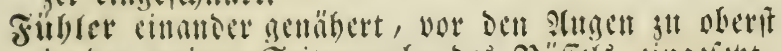
in Der weiten Esitengrube des Bitillelg cingeleșt, bem fopf wentglteng an sänge gleidg, faft 12 glicoig, gefenlt: sic Fittle folt Anlicsig.

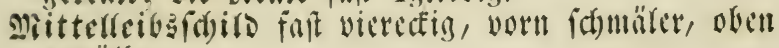
gewölct.

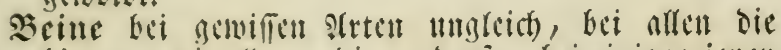
binteren mittellang, sie vorderiten bei cinigen fenten aleich, bei andern länger.

Frïgeroeffen beinnbe vierectig, binten flaffend, cint=

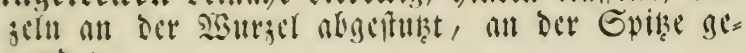
ruttert. 


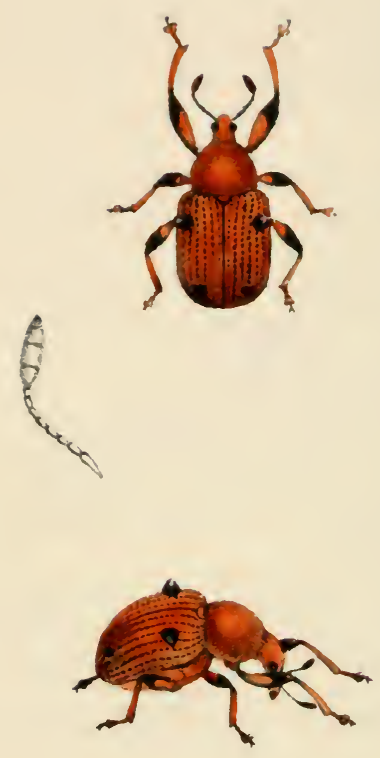

Attekebes bispinosus 



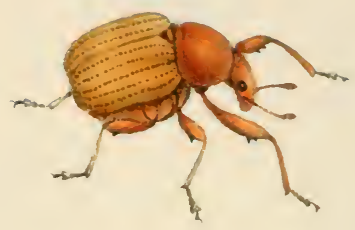

dellelabers metancorygehes var. 


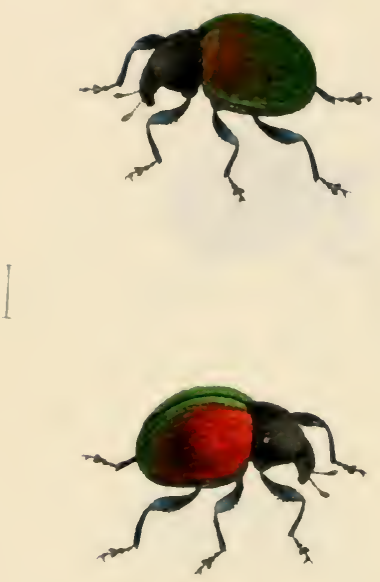

alkelabus variabilis 
Fam. ATTELABIIES.

AT'TEL.ABUS L. Schh.

COHORS I. GENUINI.

C'aput modice elongatum

Erfti sichant.

II e d) $t$ e.

Solf mäping lanis.

MANIPULUS I.

Finora mutica.
Erite 9rotte.

Earenfer mbinert.

attelabes bispixoses Gyll.

(Schïnh. Gen. \& Sp. Curc. T. I. P. 1. p. 20\%. T. V. P. 1. p 300.) Patria: Insula Java.

MANIPULCS II. 3weite Mrotte.

Femork subtus dentata. Erbenfer untell gijnhnt.

ATTELABCS MELANOCORYPIIS var.

Patria: Brasilia.

Dilute rufus, elytris, tibiis tarsique flavotestaceis. bell röthlid) mit jiegelgelben Flügelbeden, Echienen und Flügelocatent.

MANIPULUS III.

ficmorce Subtus crenatodenticulata.
Dritte Motte.

Ed)enfer unten ferbig gejübilitt.

ATtelabes variabilis Schh.

ahiinh, Gen, \& Sp. Curc. T. I. P. 1 p. 201. T. V. P. 1 p. 311.)

Patria: Brasilia, Cayenna. 


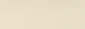




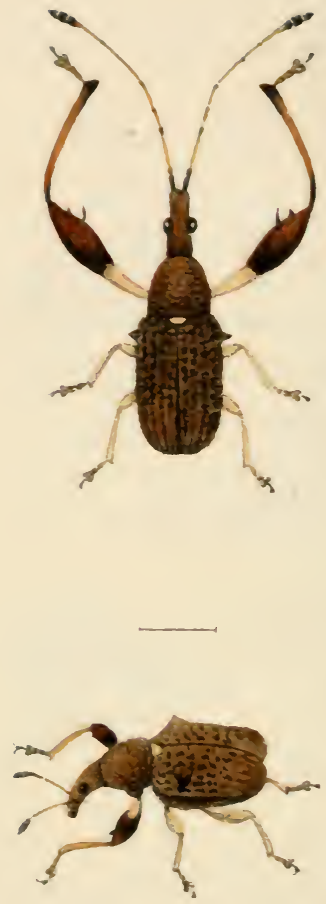

deltetediens sortelleris 
Fam ATTELABIDES,

ATIELABUS L. Schh.

\section{COHORS II.}

Spurii (Euscelus Germar).

Cuput valde elongatum

3write Schane.

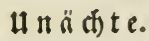

Sopf fibe vertängert.

attelaeus scuteliates Schh.

(Schün)、 Gen, \& Sp. Curc. T. I. P. 1. p. 205. T. V. P. 11. p. 314.)

Patria: Insula Cuba. 
APOIDERLS OI. Schh.

Copuc pone oculos elongatum, postice in modum colli constrictum, oculis lateralıbus, prominentibus.

Rostrum capitc brevius, crassum, basi constrictum. Antcunce basi approximata, in rostri fovea lateralis fastigio inserta, thorace paulo longiores, 12 articulala clavata; clava dimidian vel tertian partem antenna æquante, elongata, quadriarticulata, articulo apicali pracedenti sub-intruso.

Thorax sub-conicus, antrorsum valde angustatus. Pedes mediocres vel longiusculi.

Elytra oblongo-quadrata, apice singulatim rotundata.

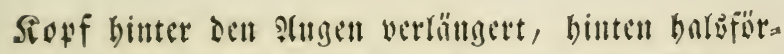
mis cingefonnirt, mit feitliof vorifebenden ?atugen.

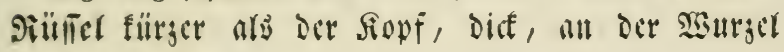
cingcidnnürt.

Fïbler an Der Santrel cinander genäbert, in Der

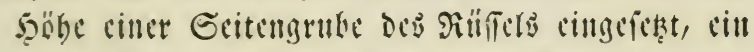

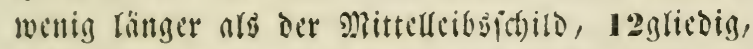
gefeult; Sienle die Sälfte oder sen Drittbit der sänge ocg füblers bilocnd, rangggogen, 4glicdig, Das Endgrico in bay vorbergebende fatt cingejobobal.

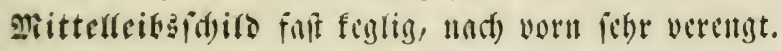
Beine mittellany oder läinglidf).

Flitgerseffen länglid)=victectig, ant cante cingeln gertubet. 
a
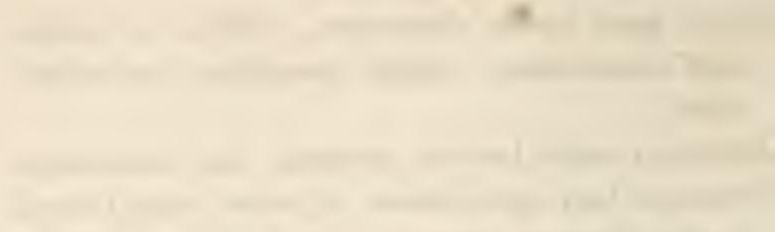


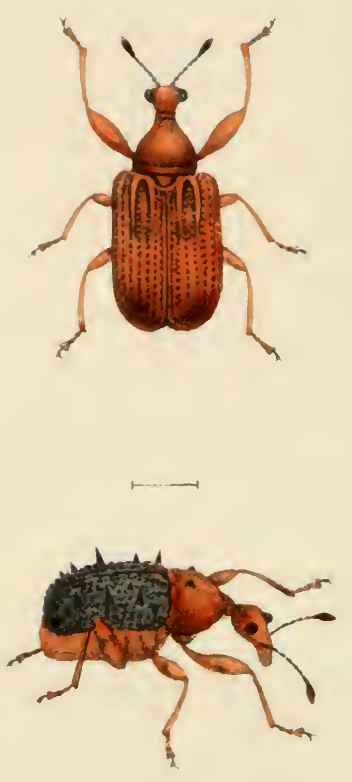

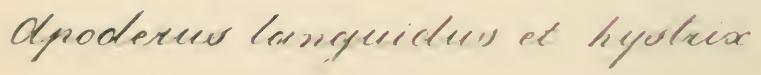




\section{Fam. ATTELABIDES.}

\section{APODERUS OI. Schh.}

\section{COHORS I.}

Capul pone oculos modice elongatum, obconicum.

\section{Erfte Soljarar.}

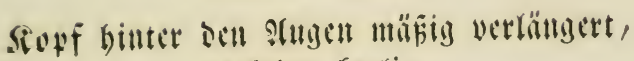
verfebrt = fegrig.

MANIPULUS 1.

Elytra mutica.

\section{Erite Miotte.} Frïgerberfen unbewehrt.

apodentes havguidus Schh.

(Schünh. Gen \& Sp. Curc. T. V. P. 1. p. 2SO)

Patria: Guinea.

MANIPULUS II.

Elyera spinosa.
Bucite Motte. Fiitgerseffen Dornig.

$$
\text { APoderts hystrix F. }
$$

(Schünh. Gen. \& Spec Curc. T. I. P.1. p. 196. T. V. P. 1. p. 2ss.) Patria: Insulæ Sumatra \& Java. 



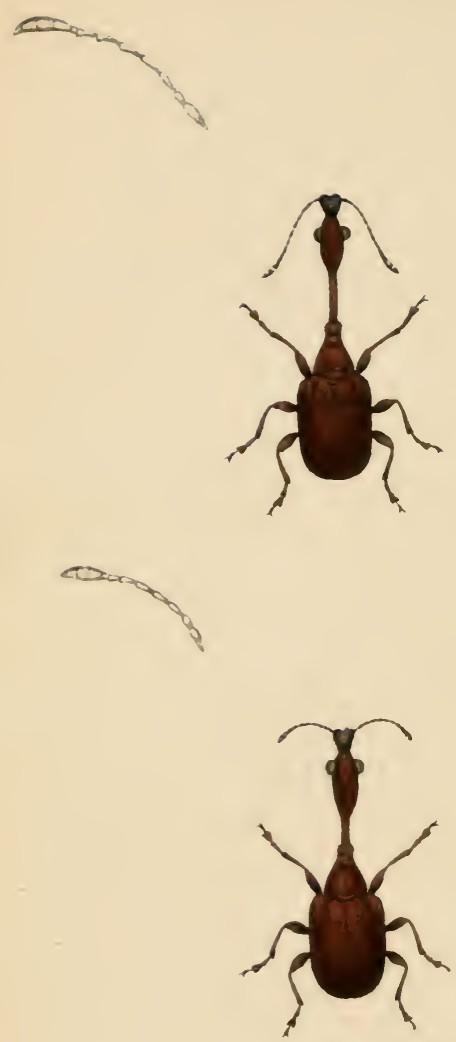

Cyenderees Prosedus 


\section{Fam. ATTELABIDES.}

\section{APODERUS OI. Schh.}

\section{COHORS II.}

aput pone oculos valde elongatum, cylindricum quasi collum formans.

3weite Srhaar.

Copf binter ben Iugen febr verlängert, gleidfam einen walgigen Şals birbend.

APODERUS CAMELUS OI.

(5chönh. Gen. \& Sp. Curc. T. V. P. 1. p. 291.)

Patria: Insula Madagascar. 




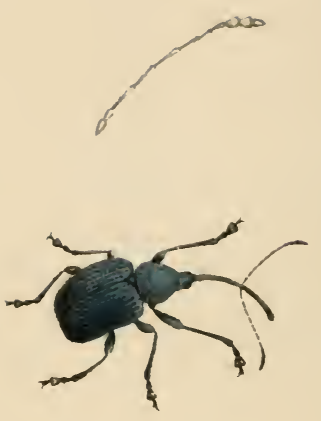

Siluynehetes gerendie 
RHYXCHI'ES Herbst. Schh.

C'aput rostro latius subquadratum, oculis rotundatis, lateralibus.

Rostrum apice plus minusve ampliatum, seu filiforme elongatum, seu breve deplanatum.

Antennae medio rostro in canali laterali usque ad ocu. los deducto insertæ, 11 -articulatæ, articulis mediis aut elongatis, aut sub-obconicis, aut subrotundatis, ultimis tribus crassis, inter se remotis, clavam ovalem, sub. perfoliat am constituentibus.

Thorax sub-conicus, antice constrictus.

Pedes satis valıdi, femore clavato, tibiaque tereti inermibus, tarso quam tibia nunquam longiore, articulo penultimo lato bilobo subtus spongioso, in nonnullis speciebus membranula marginali (arolia) insuper instructo.

Elytra lata, apice singulatim rotundata.

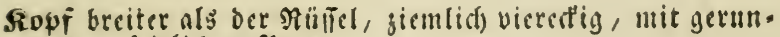
Deten, feitlidien 2 ugen.

Rüfiel am Ende mebr ober weniger erweitert, entweder fadenförmig, langgegogell, ooer furg, Hact) gedrüdtt.

Füblex mitten nm Rüllel in einer feitlicben, bis zu ben 2ugen nusgedebnten Rinte eingefebt, 11=gliedig, die mittlern Glicoer cutmeder langgejogen, noer fiemlia verfefortfeglig, ober jiemlid) rundich, Die 3 Enoglieder diä, von cinnnoer entfernt, cine obnle, beinabe ourd). blïterte fieule bildeno.

grittcllcibsidhilo giemlidi feglis, vorn cingef(hnürt.

Beiue jienlich fraftin, Der feulförmige Sdincnfel uno die fiiclrunde Edsiene mebrlos, Der Fus niemals länger als Die Estiene, fein vorlelstes (slico breit, gmeilappig, unten f(b)wammig, bei cintgen Arten nufierdem mit einem rnnobrutaen (Softläpyden) verfeben.

Flügclocefen breit, nm Ende cinjeln gerundet.

\section{RHYNCHITES GRANDIS}

(A rostri apice ad anum 10 $\frac{1 / 2}{2}$ lineas longus.)

Cœruleus, albo-pubescens, rostro pane dimidiam corporis longitudinem xquante, filiformi, arcuato, subnudo, supra hasi tri-carinato, antennarum clava plantisque nigris, elytris punctatonstriatis, interstitiis cre. berrime punctulatis.

(Von oer Rülfelipize bis sum 2ffter $10 \frac{1}{2}$ Rinien Inng.) Blnu, weifsbefinumt, ber beimabe sie halbe Rörperlinge bildende, fnoenförmige, gebogene, faft madte, oben an ber $23 u r g e l$ oreifielige Riinel, die Füblerfeule uno oie ז5uEfoblen fdwwars; Die Flügeldeden punftirt geftrict), Die 3 mifdentrume febr Didbt fein punftirt.

Patria: Insulae Plilippinae. 

Addenda hic sunt quxdam Deuterocratem nebu= losum spectintia, ut haecce species \& genus, cui illam inseruimus, melius illustretur.

Corporis longitudo variat a pollice ad dimidium pollicem. Oculi antice emarginati. Antenno maris (A. m.) in individuis maximis 3 pollices longæ, ariiculo secundo subflexuoso quam primus ter longiore, tertio quam secundus plus duplo longiore, quarto omnium longissimo, tertium \& secundum simul sumtos longitudine pœne rquante, quinto duplo quam quartus breviore reliquisque longitudine inter se subrqualibus; antennee femina (A. f.) in indi. viduis maximis 11 lineas longæ, articulis inter secundum \& ultimum intermediis inter se longitu. dine subxqualibus, secundo \& ultimo crteris non. nihil longioribus. Elytra striato-punctata, interstitiis alternis elevatoribus, basi callis duobus, altero humerali, altero interiore instructa. Labrum (I.) mandibulis triplo brevius, harumque apicem si clausæ sunt attingens, transversum, lateribus rotundatum, antice ciliatum, nonnihil emargiuatum. Mandibula (m.) validx, facie inferiore inæquali, superiore fasciculo setarum medio instructa, arcuatæ, intus dente inter partem apicalem sensim acuminatam \& basalem, subquadratam, latam intermedio armatæ. Maxillee malis elongatis, xque fere inter se longis, interiore apice acuminata, facie inferiore hirsuta, exteriore apice rotundata, facie superiore hirsuta, palpo malis sesquilongiore filiformi, quadriarticulato, articulo ul. timo secundo tertinque simulsumtis æque longo, lan. ceolato, tertio quam secundus duplo breviore, hoc basi altenuato, primo minimo. Ligula subquadrata, apice utrinque dilatata, paraglossis $(\mathrm{pr}$.$) \& palpis (p.)$ illius margini antico insertis, oblique distantibus, illis mediis angustis, linearibus facic exteriore, i. e. inferiore hirtis, his triarticulatis, articulo primo paraglossis parum longiore cylindrico, apice vixclavato, secundo tertioque simulsumtis primo vix longioribus obconicis, secundo apice, tertioque toto e facie inferiore pilis intus directis hirtis. Mentum (mt.) corneum durissimum, trinsversum, basi medio inciso, margine apicali, i. e. antico emarginato, in emarginatura callo scmiannulari, ad ligulam fulciendam instructo.

()ris partes in Tabulac sinistro latere delineatx si. cuta superiorc facie, in dextro latere sicut ab inferiore lacic conspiciuntur. 

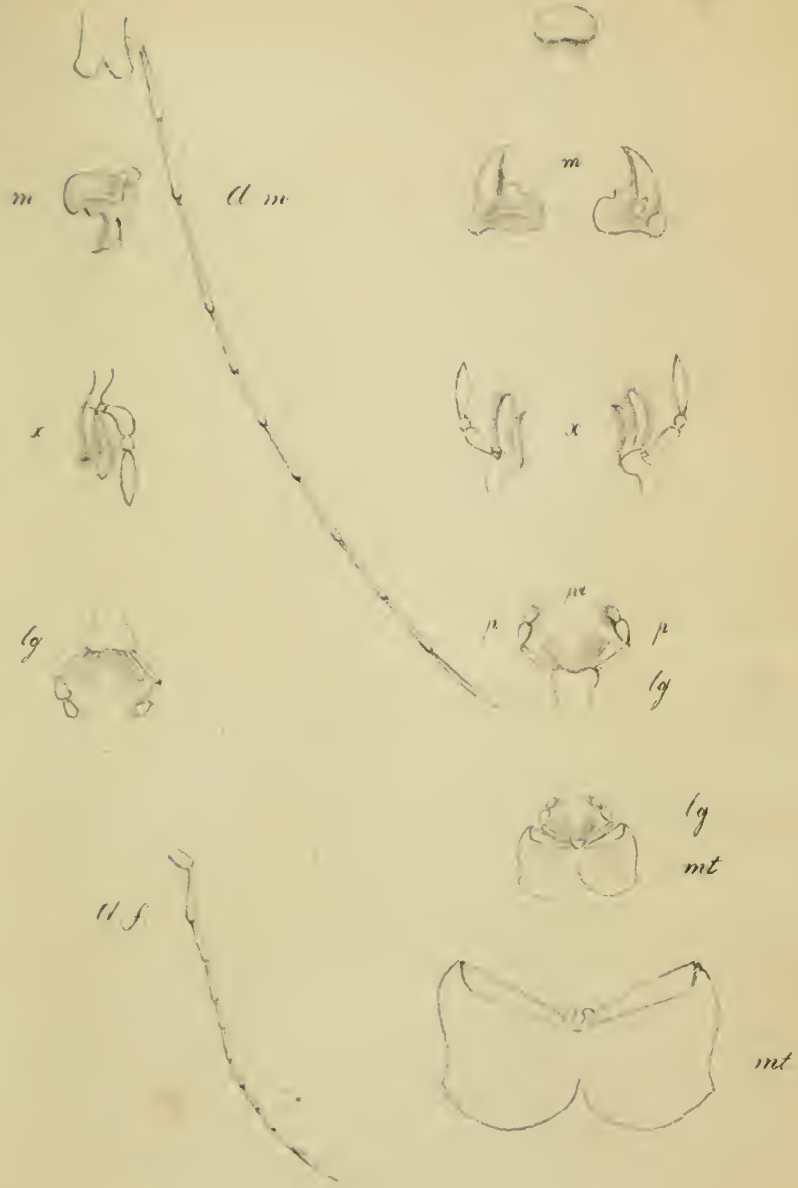

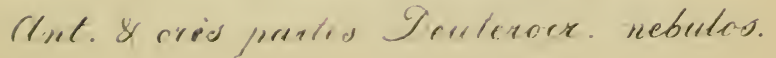



1) absolvenda opusculi nostri parte prima quae decem fasciculos complecti posse videbatur, non pos. sumus quin ante omnia viris aestimatissimis qui nos. trum inceptum variis subsidiis benevolentissime adju. verunt, maximas gratias agamus. Rogamus obsecrimus eos, ut etiam in posterum indulgentia \& libera. litate sua nos prosequantur. Praeterea hacc monell. da sunt :

Inter species depictas atque descriptas una reperitu. quain fasciculo primo pro Platymero Germari ha. buimus, a Cl. Germario vero litteris edocti sumus, hanc speciem esse Antliarhinum Dregei Schh. (Gen. \& Sp. Curc. T. V. P. 2. p. 535.) In errorem istum illduxit nos Drège ipse, qui illam speciem huc transmissam illo nomine appellavit. It aque erroris corrigendi causa visum est verum quoque Platymerum Germari describere \& depingere, \& ut commorlius intelligi possit in utra tabula vere Germarianus depictus sit, nomini literas ,Schh" adjecimus,

Gratum etiam entomologis facere crevidimus exhibenda figura Camaroti coccinelloidis Germ. quam expressimus e pictura post confectum fasciculum nonum, in quo inest Camarotus marginalis noster, a $\mathrm{Cl}$. Ger= mario benignissime nobis permissa. Addidimus postremo specierum, quae parte ista prima continentur, indicem, eo quidem ordine, quo optime collocari posse existimabamus.

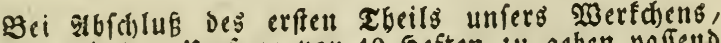
welchem wir Den llming von 10 Seften gu geben paffento hielte" fömen wir nidbt umbin, vor gllem ben bochges efrten Männern unfern innigften Danf nbzuftenten, welde

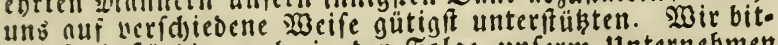
ten fie infindig nud) in ber Folge unferm unternebmen

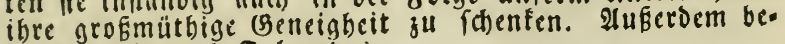
merfen nir noch frolgendes:

Unter den befaricbenen uno nbgebildeten arten findet (if) cille, weld)e wir im liten Seft für Platymerus Gers mari biclten, wir find nber von $\mathfrak{B r o f .}$ Germar brieflich

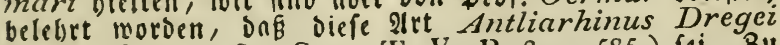
(Schh. Gen. \& Sp. Curc. T. V. P. 2 p. 585.) fei. Bu unferm frrtbum bat uns Drege felber verlettet, melder unter jenem $\mathfrak{R a m e n}$. Diefe 2 ret bieber gefandt hat. um die. fen Srrtbum gu berid)tigen, foien es unts baber bas befte, auch Den wabrell Platymerus Germari zu befdreiben uno nbjubilben, und mir baben bemnach nud, um angu. seigett, nuf meld)em Blätt(d)en wirflict) bie Germar'sche Aft nbgebiloet fei, Dem Darunterfebenoen Namen die Buchitnben "Schh." beigefekt. 2 ir glauben ferner ben Entomologen cinen Befallen gethan zu baben Durch die Darfiellung Des C'am arotus coccinelloides Germ., weld)e von einer abbiloung copiert iff, dic un\& Germar gütigft sugeifellt bat, nachoem bereits ons 9te beft, in weldiem (iid) unicr Camarotus inarginalis befindet, volfendet war.

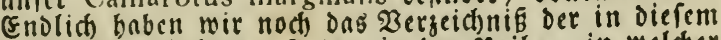
erfen Theile entbultenen 2 reten in oer Reibe, in weldser fie uns nin beften nuf einanber zn folgen fócinen, beigefügt.

Balel, 21. Juni 1812 . 
lis, qux jam in pagella quadam superiore de Platymero Germari \& Camaroto coccinelloide monuimus, aliquid adhuc in nonuullas alias species adnotare nobis restat

Ischyromerus madagascariensis eadem est species" ac Rhyticephalus brezicornis Schönherri (Gen. \& Sp. Curc. T. V. p. 521.) Nomen genericum istud characte. rem talem denotat, qualem sexus modo masculinus prabet, nostrum vero nomen a signo! depromptum est, quod tam in masculino quam feminino sexu reperitur. 1schyromerus erythroderes, cujus sexum modo mascu. linum descripsimus \& depiximus, nomine Teramocerus erythroderes secundum utrumque sexum in Schön. herriopere (libr. cit T. V. p. 56\%.) descriplum invenies. Taphroderem striolatum monet Erichson (Archiv f. Naturg. Anno octavo. 'Tom. II. p. 240. ) propriam spe. ciem fortasse non constituere, sed modo varietatem esse Taphrod. laevipedis Schh. Nullum judicium hac de re proferre audemus, cum ista species nobis non ante oculos fuerit nec adhuc sit.

Ulocerus tetraurus nobis eadem species ac UI. pannosus Schh. (Gen. \& Sp. Curc. T. V. p. 585.) esse videtur.

Xenocerus saperdoidesvar. tamquam propria species nomine X flagellatus a Schönherrio (libr. cit. T. V. p. 239.) describitur.

Phlcotragum illum, quem Heros apellavimus, speciem esse, cui nomen Phl. gigas Schh. sit, Germar in literis ad nos datis declaravit.

Cum Meconemo tuberculato perfecte quadrat Ischnoce.

Den Bemerfungen, meld)e wir nuf einem frübern Blätthen über Platymerus Germariuno Camarotus coccinelloides mitactheilt haben, fügen wir hier nod) Dicieniget über einige nubere arten bei:

Ischyromerus madagascariensis ift ber Schönherrfche Rhyticephalus hrevicornis. (Gen. \& Sp. Curc. T. V. p. 521.) Der lektere Gattungsname begieft (ith nuf ein Merfmal, velches nur bem männlichen (Befdhlechte Diefes Rĭfers zufommt, mäbrend unfer Name volt einer Eigen. (d)aft entnomment ift, welde fowohl ber männlicbe nls meiblide Räfer Darbieten.

Ischnomerus erythroderes, von bem wir nur ons männs lide (serdiled)t befdricben und abgebildet haben, findet fid in Echönberr's Merf (a. a. D. p. 564) als Teramocerus erythroderes nad) beiden (Sef(hlect)tern befdrieben.

ueber Taphroderes striolalus bemerft Ericlison (Archiv f. Naturacf(h. Ster Safrg 2 ter Bo. p. 240), Dase er viel= leid)t nur cine Ibänderung Des 'Taphrod lavipes Schh. fei Da mir bicfe art nicht vor uns baben, fo fömnen wir felbit uns bicriber fein llrtheil erlnuben.

Ulocerus tetraurus fobeint uns diefelbe Irt mit Dem UI. pannosus Schh. (Geli. \& Sp.Curc. T. V. p.589) zu fenn.

Xenocerus saperdoides var. wirb als befondere art unter Dem PtamenX. flagellatus von Schönherr (n a. D.p. 239) befchrieben.

Die als Phløotragus Heros beicidnete $\mathscr{A}$ rt bat Germar in cinem Briefe an ung als Phl. gizas Schh. erflärt.

Mit Meconemus tuberculatus fifimmt völig Ischnocerus 

rus infuscatus secundum descriptionem a Schönherrio (libr. cit. 'T. I'. p. 192) exhibitam.

Eucorymus crassicornis sexu modo masculino nobis antea notus, clavam antemnarmm non 4-articulatam, ut perperam attulimus, sed 5. atticulatam habct; iden' valet de femini, cujus antemse tertiam modo partem corporis longx sunt.

Polycorymus pantherinus in sexu feminino, quem admodum nuper cognoscere licuit, in eo discrepat a masculino sexu, yuod clava modo quartam totius an $(\in n)=$ na partem constituat nec nisi articulis 4 sit composita.

Nemourichus indistinctus generi Corrhecerus a Schön. herrio dicto adnumerandus, maxime Corrh. pilicorni (Schönh. libr. cit 'I'. $Y$. P. 255.) propinquus est.

Secundum adnotationem Erichsoni (libr. cit. Anno 6. Г. II. p. 256.) errorem commisimus, cum Tophode. rem frenatum \& funebrem utrumque sexum unius ejusdemque specici crediderimus; unumquemque pro. priam constituere speciem \& quidem ambos feminei sexus esse, autor ille affirmat.

Eodem autore Rhynchites grandis a Rhynch. calestino Sclıönh. non differt. (libr. cit. Anno 9. 'T. II. p. 206.) Nosmet ipsi huic opinioni accessissemus nisi insectum nostrum toto corpore pube tectum esset nec solum. modo lateribus $\&$ subtus, ut diagnosis Schönherri præfert $\&$ proterea uisi vestimentum plantarum at rum conspe. xissemus, dum Schönherrius in descriptione sua ('T. I. p. 211 l. ult.) tarsos subtus brunneo.spongiosos exhibel.

infuscatus nach oer von Schönherr (libr. cit. T. V. p. 192.) gegebeuctl Befdrcibung überein.

Eucorynus crassicornis tone uns früber nur und bem mănns liden (Bsefdsled)te befnnnt, deflen Früblerfeule toir irrig als 4 gliedig itatt 5 gliedig nngegeben bnbent ons oleicfe findet für Dns meibliche Befdledt fintt, Deffen Fribler übrigens tur Den Drittheil Der förperlänge beträgt.

Polycorynus pantherinus fetgt fich im weiblidien (Sefdiledite : meldes uns erft vor nicht lnnger Seit befannt gevorben iff, Durch Den Frübler vom männliden infofern verfoieden

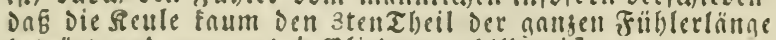
betrïgt uno nur nus 4 Glicbern gebildet i|f.

Nemotrichus indistinctus gebört Der Bnttuna Corrhecerus Schönh. nn und näbert fich am meiffen Dem Corrh. pilicornis (Schbonh. libr. cit. 'T. V. p. $25 \%$ )

Pac) Der Bemerfung Erichson's (A. A. D. Gter Sabrg. 2 ter 3D. p. 256.) baben wir Den 'lophoderes frematus u. funebris irrig als bie beisen (sefdilechter ciner art nngefeben, fie follen jeder ins meibilin einet befors. Dern Sit fern

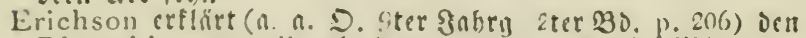
Rhynchites grandis nlg Den crestinus Schh. Dir wür= Den uns ju berfelben Infict befannt gnoen, wenll nid)t unfer fiffer ïber Den ganjen Sïrwer bebanet fids geigte, mäbrend er mad) Schönherrs Dingnofe diefe $\mathfrak{B c h a n c u n a}$ nur unteu u. an Den Eeiten bat und menn ferner die tne tere Befleidung der Füfe fid) ung nicht nls gani fdomar's bargefiellt bätte, mäbrens lie Schönlerr in oer Befdereis bung als braun.fonnmmig nnaibt. 


II. 1.
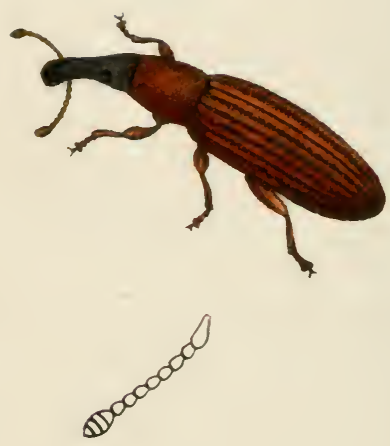

Tanarus sanguineus 
TANAOS, Schönh.

Corpus elongatum, alatum.

Caput rostro paulo latius, pone oculos elongatum, ocu= lis rotundatis.

Rostrum porrectum longitudine capitis, cylindricum crassiusculum.

Antemce medio rostrilateri inserix, crassiuscula, caput longitudine vix superantes, vel recti, vel subarcuatx, 12 - articulat $x$, clavata, clava ovala, acuminata, f-articulati, articulis eam antecedentilus brevi. bus, primo paulum elongato, basi attenuato; scrobe antennali infera, profunda, curvata, una cum altera ad basin rostri fere conjuncta.

Thorax fere longior quam latior, subconicus, antice posticeque truncatus.

$p$ edes validi, breves, femore ad medium incrassato, tibia apice mutica, tarso lato, articulis subtus spongiosis, tertio bilobo, articulis præcedentihus latiore, ungue paulum elongato, unguiculis basidente obtuso munitis.

Scutellum minutum.

Elytra elongata, pọne medium paulum dilatata, apice obtuse rotundata, anum excedentia.

Sḯrwer langgejogen, geflügelt.

Rovf ein wenig breiter als Der Rüliel, binter ben Iugen verlängert; 2tugen gerundet.

Rüliel vorgefired't, von ber \&ange bes Ropfes, malgig, fiem= lich) Didt.

Fibblex zur Mitte deg Rüficlo an oer Geite cingefelst,

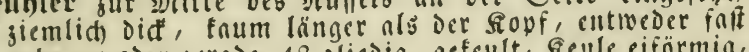
gebogen oder gernde, 12sgliedig, gefeult, Feule eiförmig, $4=$ gliedig, dic ibe vornngehenden (B)licder furg, daserite cin menig verlangert, nn ber 20 urgel verdünnt; Fïl)ler: grube unten befindlich, tief, gefrümmt, eine mit Der andern an Der $\mathfrak{B}$ urgel Des Rüfiels faft vereinigt.

gittelleibsinthilo beinahe länger nlo breit, beinabe feglig, vorn uno binten nbgepitut.

Beiuc fröftig, furg, Der Echenfel in Der Mitte verdid"t, Edicne am Ende wehrlos, Fruf breit; feine Blicber unten foronmmia, das 3te gineilnovia, breiter nls die vorbergebenden (s)icber, Glane ein mentiy Inngaezogen,

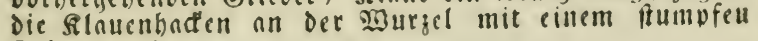
3nfin bemebrten.

Enilodien tlein.

Flïgeloecten langgeliredt, binter oer Mitte ein menig cr. weitert, nm Ende ftumpf gerundet, liber den 2 fter hin= ausereidend.

TANAOS SANGUINELS.

(Schöıh. Gen. \& Sp. Curc. T. II. P. 1, p 170. \& T. V. P. 1, p. 451 )

Mus. Cl. Germar, Halensis.

Patria: Caffria. 


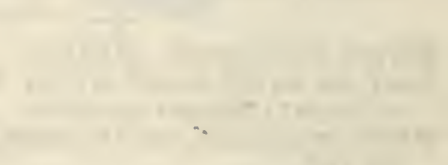

$+2$

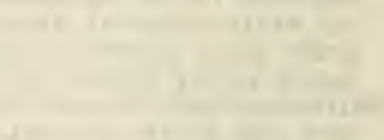


(n)

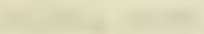




\section{2 Fam. RHINONACERIDES.}

\section{EUGNAMPTUS Shönh .}

Corpus oblongum, molliusculum, alatum.

Caput subquadrat:um, pone oculos elongatum, oculis prominentibus.

Rostrum modice curvatum et deflexum, capite paulo longius, eoque dimidio angustius, apice ampliatum. Antennce medio rostri lateri insertæ, vel rectæ vel curvatæ, dimidium corpus fere longæ, tenues, articulis elongatis, ultimis tribus majoribus, reliquis inter se subæqualibus, scrobe antennali laterali ante oculos desinente.

Thorax capite paulo latior, oblongus.

Scutellum apice rotundatum.

Pedes longinsculi, mutici, tarso angusto, articulo teris bilobo, subtus spongioso.

Elytra oblonga, apice singulatim rotundata.

Sḯrwer länglid, giemlid) meich, geflügelt.

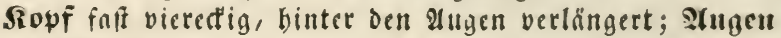
vorrageno.

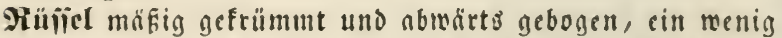

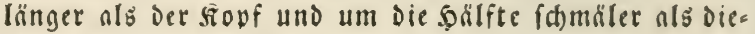
fer, am Ende ermeitert.

Fiihler mitten zur Eeite des Rüfiels cingefatt, entweder gebogen oder gernde, beinabe balb fo lang nla der $\Omega$ ör= fer, dünn, mit gefiredten Bliedern, die 3 lebten gröfer, bie übrigen unter lid) giemlich gleidf); Fühtergrube feit-

- lich, vor Den stugen aufföretto.

Mittelleibsidfilo eit menig breiter nls ber Sovf, länglid) Erhilochen an Der Evike abgerunder.

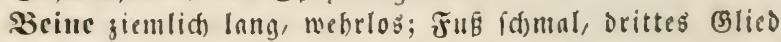
gucilappig, unten formammig.

Stlïgeloecten länglid), nu Der Evißge eingeln gerundet.

\section{EUGNAMPTUS COLLARIS.}

(Schönh. Gen. \& Sp Curc. T. I. P. 1. p. 235 \& P. V. P 1. p. 341.) Nomine Eugu, ruficollis Gr., au collaris Schlı, ? e' Mus. Cl. Germar a Dre. Schaum nobis transmissus.

Patria: America borealis. 

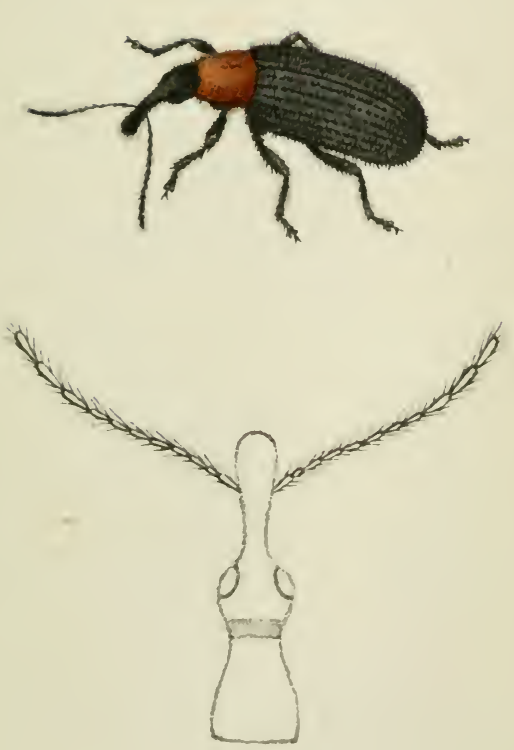

Sugnamples collaris 



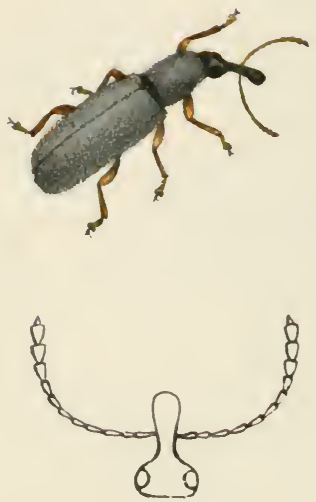

Rhinomacer attelaboideo 


\section{3 Fam, RHINOMACERIDES.}

RHINOMACER F. Schh.

Corpus paulum elongatum et angustatum, molle, alatum.

Caput thorace vix angustius, transversum, oculis pro. minentibus.

Rostrum capite fere duplo longius, deflexum, apice rotundato-dilatatum.

Antennce versus media rostri latera inserta, dimidio corpore breviores, vel rectæ vel curvatæ, 12-articu. latæ, articulis obconicis, nono, decimo \& undecimo majoribus, duodecimo accessorio, mınuto, conico.

Thorax oblongus, angustus, capite haud latior, sub. cylindricus.

Scutellum minutum.

Pedes mediocres, mutici.

Elytra elongata, thorace dimidio latiora; apice singu. latim rotundata.

Sörver ein wenig verlängert und verfámälert, weidh, geflïgelt.

Ropr fnum famäler als ber Mittelleibsfdild, queer, mit vorifebenden alugen.

Kiiliel falt Doppelt länger als Der Ropf, berabgebogen, an Der Enile gerundet uno erweitert.

Fühler gegen die Mitte der Eeiten des Rüflels eingefekt, fürger als ber halbe Rörper, entmeder gerade ober gebo= gen, $12=$ glicoig, dic Blieder verfebrtfeglia, gtes, 10tes und 1 ites gröfer, ons 12 te nls 2lntong gaglied flein, feglig. Mrittelleibeidnilo länglich, f(bmal, nicht breiter als oer Roof, falt malgig.

Ediliduen flein.

Seine mittelgrofi, wehrlos.

Flïgeloecten langgejogen, 1 m die bölfte breiter als ber Mittelleibsfdilo, an Enoe cingeln nbgerundet.

RHINOMACER AT'TELABOIDES.

(Schönh. Gen. \& Sp. Curc. T. I. P. 1. p. 242 . \& T. V. P. 1. p. 344.) Patria: Europa borealis \& intermedia. 


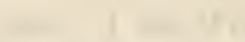
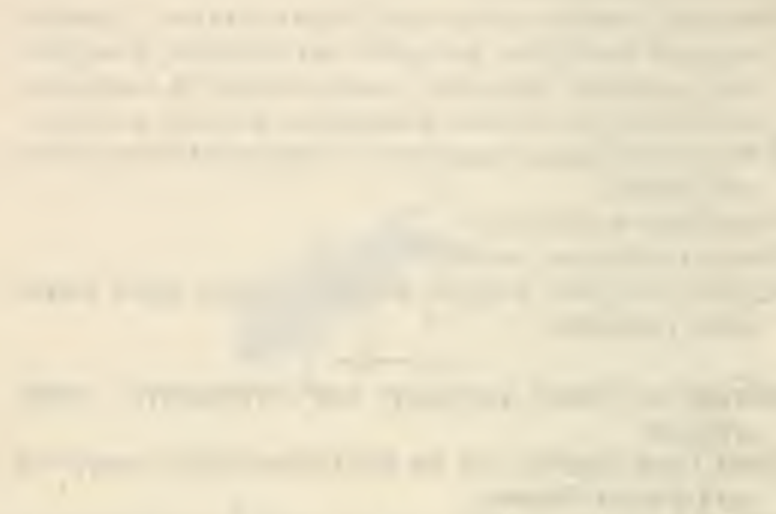

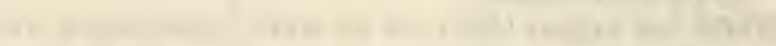
10

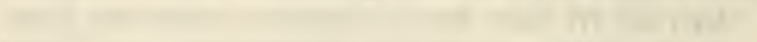

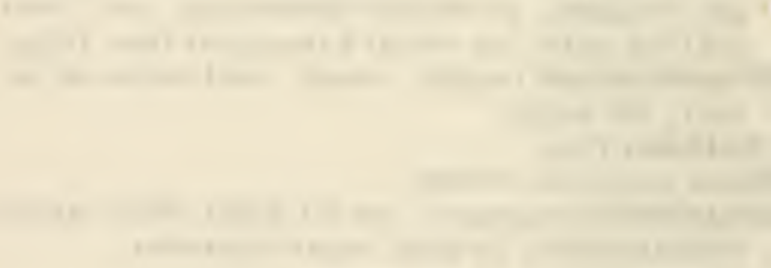

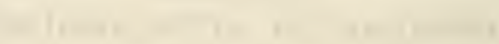



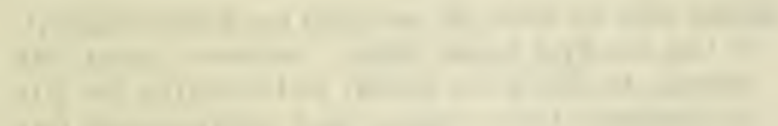

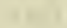

$-$ 
II. \& Fam. RHINOMACERIIESS.

\section{I)OEDYCORHYNCHUS.}

Corpus molliusculum, oblongum, alatum.

Coput transversum, breve, supra convexum, oculis lateralibus, prominulis, rotundatis parvis.

Rostrum capite plus duplo longius \& angustius, teres, deflexum, paulum arcuatım; apice paulum dilatatum.

Antennce prope medium rostri latus insertx, rostrum \& caput simul longitudine xquantes, seu recıx seu curvare, 12-articulate, articulis obconicis, duodecimo hreviore, conico, accessorio, tribus antectentibus clavam constituentubus; scrobe antennali versus oculos spectante lata, minus profunda nec longa versus basin rostri evanescente.

Thorax paulo latior quam lougior, lateribus, postice rotundatus, margine antico elevatus, atque late emarginatus.

Scutellum parvum.

Pedes mediocres, tarso cum articulo tertio secundo appresso.

Elytra thoracis basi latiora.

Sïrper giemlich weid), länglid), gethügelt.

תopi quecr, furg, oben gewölbt, mit feitliden, etwas vor= ragenden, gerundeten, fleinen \$lugeu.

Ruiñal mebr als doppelt länger uno fhmäler als ber fiopf, ftielrund, nbwärtggebogett, wenis gefrïmmt, am Ende ein menig ermeitert.

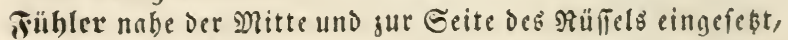
fo lnng als Ropf fammit Rülfel, entweder gernde oder gebogen, 12=gliedig, die (Slicber verfebrtfeglig, ons 12 te als 9 nbanglel fürger, feglig, die 3 vorfergebenden cine Reule bilbeno; Dic Fïl)lergrube gegen die alugen ge= richtet, breit, meder tief nod) lang, gegen die 3 urgel Des Rüllels bin verfdimindend.

Mrittelleibsichild ein wenig breiter als lang, an oen Eei. ten billtell gerundet, Der vordere Rand aufgerietet und meit aแs่gernแbet.

Eshiledsut flein.

Szeine mittelgrofi, ong 2 te Fufiglico an Das 3te nugedrtidt. Flïgelocefen breiter als die sisurgel bes Mhittelleibsfdildes.

DIODYRHYNCHUS AUSTRIACUS var.

ISthouh. Gen. \& Sp. ('urc. T. I. P. 1. p. 2it.\& T V.P. I p. 3i5.)

Palria: Plures Europae partes. 
II. It.

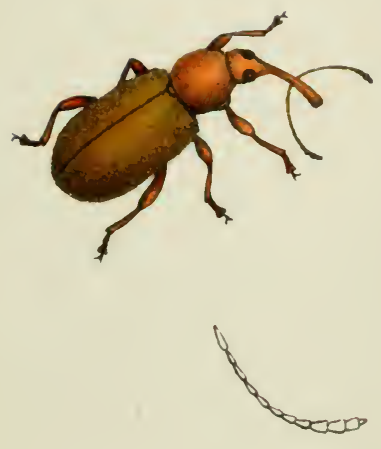

Doedyeorhynchus austrians var. 



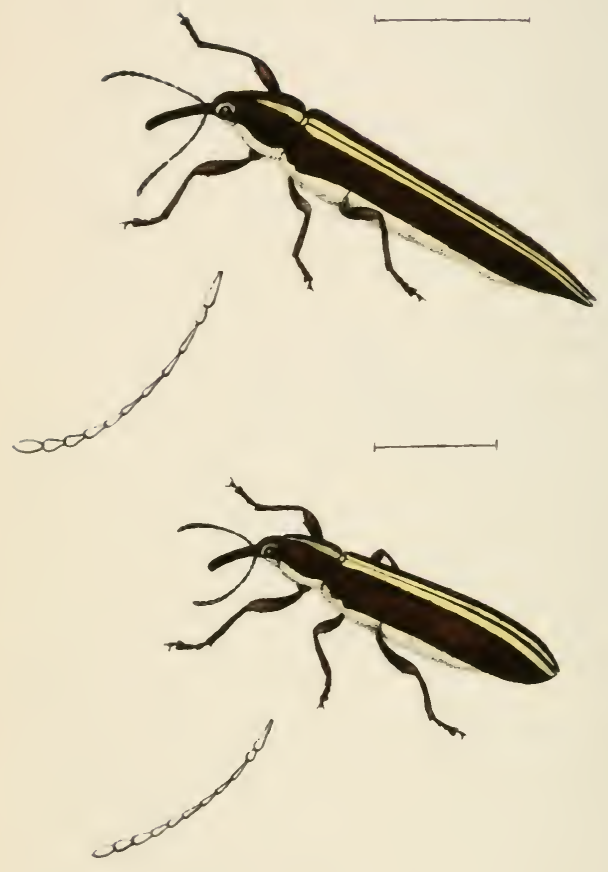

Betur suluratios et melancepthaters 
II. 5 Fam, RHINOMACERIDES.

\section{BEl.US Schh.}

Corpus elongatum, alatum.

Caput paulo latius quam longius, oculis lateralibus, prominentibus.

Rostrum capite dimidio angustils, eoque duplo longius, subdeflexum, subcurvatum, teres.

Antennce medii rostrilaterubus insertæ, dimidium corpus longitudine fere æquantes, vel rectæ vel curvatæ, versus apicem sensim incrassatx, 11 -articulata, arti. culis, ultimo ovato excepto, obconicis ; primo, tertio, quarto quintoque elongatis; scrobe antennali vix articuli basalis antennarum longitudine.

Thorax antrorsum angustatus, basiprofunde bi_sinuatus.

Pedes mediocres, antici paulum elongati, liormni femore satis valido, in nonnullis speciebus denticulis duobus versus apicem instructis, uno externo, altero interno, omnium tibia recta, tarsi articulis discretis.

Scutellum transversum.

Elytra elongata, basi singulatim in lobum rotundatum producta, apice (an pro sexu aut specie?) vel conjunc. tim rotundata vel elongato-acuminata.

\section{Sïrver langgeffect, geflïgelt.}

Siovf ein renig breiter als lang, mit feitliden, vorfeben, oen sugett.

Riiñel balo fo famal und dopvelt länger als Der Ropf, etwns nbmartsogebogen, ziemlich gefrïmmt, fitelruno.

Tühler zur Seite Der Mitte Des Rülielo cingefügt, faft von balber Rörperlänge, entmeder gerade oder gebogen, genen die Evike allmälig verdid"t, 11=gliedin. Die (Slieder, ons lebte eiförmige nusgenommen, verfehrtfenlia, Das 1 ife, 3te, 4te uno 5te verlängert; Die Tüblergrube fnum von ber En̈nge des (5runogliedes der Frïbler.

Mittelleibeffhild nad) vorn verengt, an ber 23 urgel tief jocibuthtig.

Scine mittelgrofi, vorberle cin wenig verlänact, ifr Echens

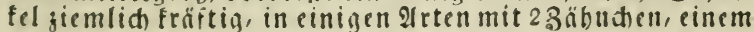
rufer" und einem innern nach Dem Ende hin verfeben, an allen $\mathfrak{B e i n e n}$ die Schiene gernde, Die FuBglieder von cin. ander aefondert.

\section{Edilodien queer.}

Fliigeloefen langgeftredt, an ber 2 urael cinjeln in einen lerundeten Enppen ausiegogen, am Ende (ob nad) Dem (Befchled)t ober nad) Der alt eltweder?) gemeinfd)aftlich gerundet ober berlängert und zugefvibt.

\section{BELUS SU'TURALIS \& MEI,ANOCEPHALUS.}

(Schönh. Gen. \& Spec. Curc. T. V. P. 1. p. 351. )

Nota. Dur istæ $\mathrm{Cl}$ Schönherri species fortasse unum alterumque sexum unicre speriei solumınodo constitmunt B suturalem non sine quodam dubio citavimus; ponimus tamen, in diaguosi a Schönh. allegata pro "canaliculato, albido" legendum essé "albido= calla=licnlate."

Patria: Australasia. 


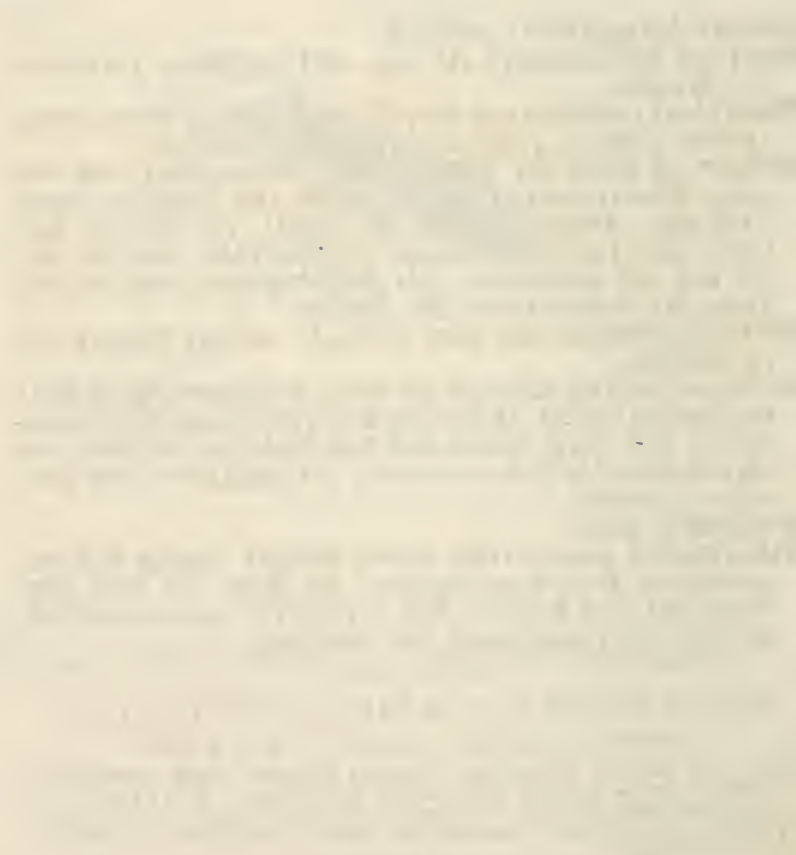



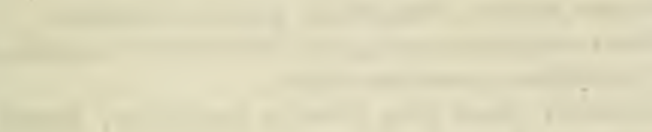

1

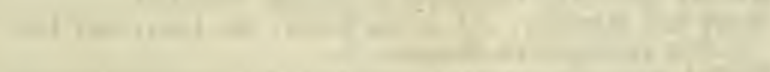

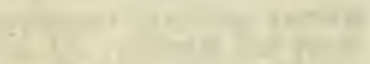

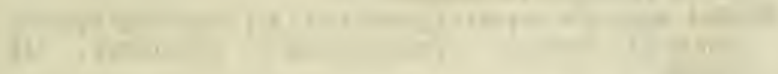

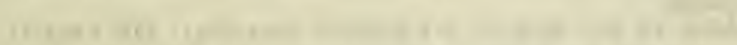

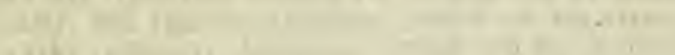
-

4(2)

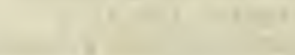
$\ldots$

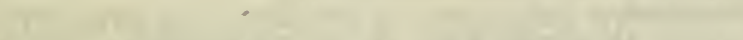
(1)

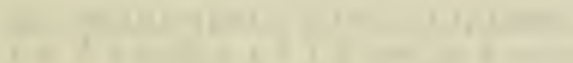




\section{6 Fam. RHINOMAGERIIDES.}

\section{HOMALOCERLS Schh.}

Corpus alatum, elongatum, postice dilatatum.

Caput subquadratum, paulo latius quam longius, oculis latcralibus, prominentibus.

Rostrum capite plus dimidio angustius, eoque duplo longius, deflexum, curvatum, subcylindricum.

Ancennce ad basin rostri insertæ, rostro fere duplo longiores, compresso-subdilatatæ, basi attenuatæ, 12. articulat $x$, articulis primo, secundo \& tertio oliconi. cis, sequenubus subquadratis, duodecimo accessorio minuto, acuminato, scrobe antennali rotundata, ininima.

Thurax fere brevior quam latior, antrorsum angusta. tus, coarctatus.

Scutellum hreve.

Pedes mediocres, antici paulum elongati, omnium femore mutico, medio incrassato, tarsorum articulis inter se discretis.

Elytra elongata, basi thoracis postica parte paulo latiora, dilatata, apice conjunctim rotundata.

Sïrper geflügelt, langgegogen, binten ermeitert.

Sopf faif viereffig, ein loenig breiter als lang, mit feit= lichen vorrngenden slugen.

Riiifel mebr nls Dopyelt fomäler nls ber Rovf und Dopyelt linger als berfelbe, nbrörtögebogen, gefrummt, fait malig.

Fïhler an Der 23 uriel bes Rüliels eingefïgt, faft doppelt länjer nls der Ruljel, jufammengedrüt uno ctmas bers breitert, an der 23 urgel verounnt, 12 alsedig, 1ftes, stes und 3 tes (slied verfebrtfeglia, die folgenden inte vieredtig, Dns 12 te als anbännfel, flein, jugefvilzt; Tühlergrube gerundet, febr tlein.

Mittelleibaid)ilo beinabe fürger nls breit, vorn berfdinä. lert, \&uisefd) nürt.

Edilioden fur;.

Scille mittelgroô, die vorderîten ein menig verlängert, an allen ber Ethenfel mebrlos, in Der Mitte verdiat, bie Fuf́licder von einander.gefondert.

Fliigeloecten lnaggezogen, an Der $23 u r z e l$ ein mentig brei, ter als der bintere Theil bes Mittelleibsfdildes, binten ermcitert, am (Endi gemeinf(haftlid) abgerundet.

HOMALOCERUS LYCIFORMIS var.

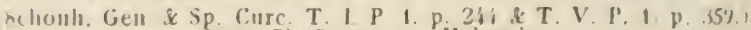
Mus. Cl Germar, Halensis.

Patria: Brasilia. 
II. 0

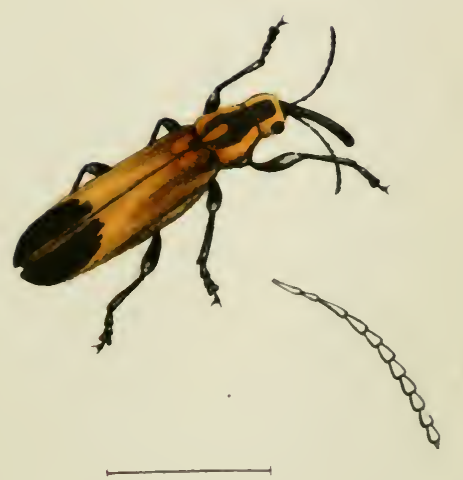

Homalocenes lyciformis var. 



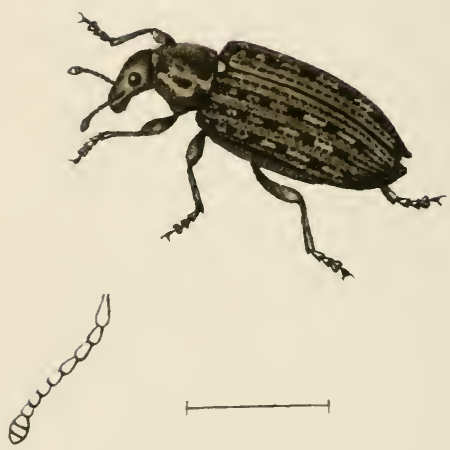

Jthigerent curculionoides 


\section{ITHYCERUS Dalm. Schh.}

Corpus oblongum, alatum.

Caput supra pone oculos convexum, oculis lateralibus, rotundatis.

Rostrum capite vix longius, apice incrassatum. Antennce rostro nonnihil longiores, aut curvatæ aut recıæ, versus apicem rostri insertx, 11.articulatæ, clavatæ, clava 3-articulata, brevi, ovata, ex articulis arcte connexis formata, articulis a secundo ad octarum usque obconicis, sensim brevioribus, articulo basali subclavato.

Thorax oblongus, basi apiceque truncatus.

Scutellum majusculum.

Pedes validi, tarso aeque longo ac tibia: articulo secundo a tertio discreto.

Elytra oblonga, antice thorace duplo latiora, postice declivia, apice singulatim attenuato-rotundata.

Rörper lïnglich, geflügelt.

Siovf oben binter Den Augen gemölbt; Augen feitlid, ge= rundet.

Küifel faum linger nls ber Ropf, nm Enbe verdidet.

Fïhler etmas länger als ber $\Re$ üffel, entweder gebogen oder gernde, nach Dcm Enbe des Rüliels bin eingefügt, 11 : gliedig, gefeult; dic Reule $3=$ gliedig, furg, eiförmig, nus enguerbunonen Sliedern gebildet, Das 2 te Füblerglico bis zum gten verfebrtfeglig, allmälig fürzer, Dns (s)undglied giemlich) feulenförmig.

grittelleibsichild länglich), nIt 23 rgel und Vordcrende nbaclitutst.

Eabilochen giemlid) grofi.

Beine fräftig, FuE cben. To lang alo Echiene, gmeiteb Fusglied vom oritten gefondert.

Flïgcloecfen länglich, vorn Doupelt breiter als ber Mits telleibsfaild, hinten nbfoüfig, nat ber Suize cingeln veríd)mälert und gerundet.

\section{I'THYCERUS CURCULIONOIDES.}

Schönh Gen. \& Sp. Curc. T. 1. P. 1. p. 26. \& T. V.P. 1. p 360 ,

Mus. Cl Germar, Halensis.

Patria: America borealis. 


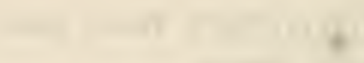



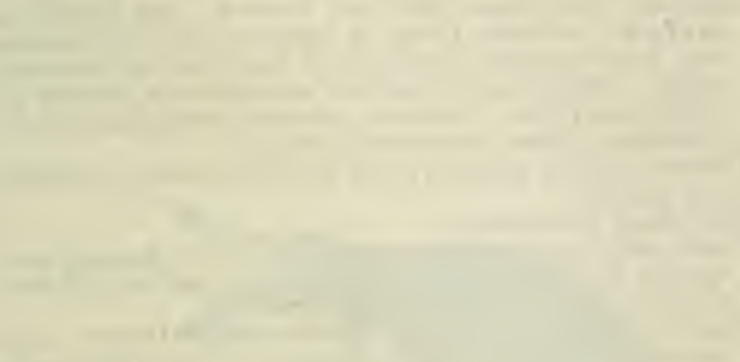

10

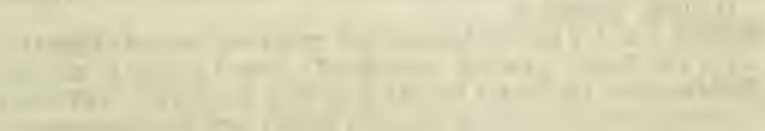

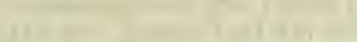

(1)

(1)

(n)

(1)

-

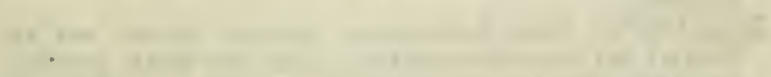
(1)

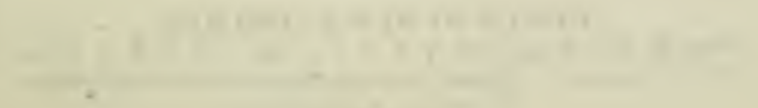




\section{EURHYNCHUS Schl,}

Corpus elongatum.

C'aput pone oculos elongatum, tumidum, oculis latera. libus, rotundatis.

Rostrum capite dimidio longius \& plus duplo angu. stius, sub-porrectum, sub-arcuatum, cylindricum.

Antennce ultra rostri medium insertæ, seu rectæ seu curvatæ, rostrum simul et caput longitudine æquan. tes, 11-articulatæ, articulis 5 basalibus subclavatis, sexto, septimo atque octavo sub-globosis, tribus ul. timis majoribus, remotis, clavam elongatam constituentihus; fovea antemnali minuta.

Thorax capitis postica parte nomnilsil latior, latitudine sua longior.

Scutellum demersum.

Pedes antici elongati, omnes validiusculi, femore ante. apicem incrassato, tarso quam tibia paulo breviore, articulo secundo a tertio discreto.

Elytra oblongo-ovata, thoracis basi duplo latiora, pone medium convexa, apice ultra anume marginato-sub. expansa.

Sörper Innggezogen.

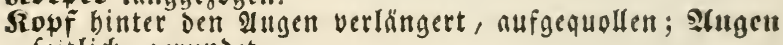
feitlid), gerundet.

Rülifel u nls der Ropf, ziemlid vorgefifredt't, etwas gebogell, wnl gig.

Frihbler über die Mitte Des Rüliels meg cingefełt, entmeder gernde odergebogen, folng alö Rülel und hopf zufammen, 11 =gliedig, die $5 \mathfrak{M u r z e l g l i c o c r}$ falt feuliörmig, Das 6te, ite uno ste beinabe fuglig, Die 3 Endglieder gröfer, von cinander entfernt, eine Innggesogene feule bildend; Fiihlergrube flein.

Mrittelleibsichilo etmas breiter als ber bintere Theil bes Rovfes̀, länger nlá breit.

Echilochen niedergefenft

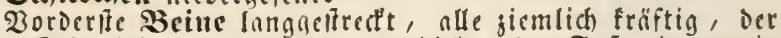

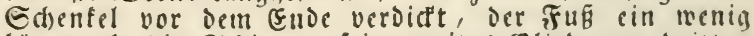
fürzer als dic Ed)iene, fein zneites (Slicb vom Drittell aciondert.

Slügeloecfen lämalich)eiformig, Doppelt breiter als bie Wuriel Des Mittelleibsidsildes, binter der Mitte gemölbt, am Ende über Den Iffer binnus in einen fiemlid) all: gedebuten Rand criveitert.

\section{EURHYNCHUS SCABRIOR.}

Achönh. Gen se Sp. (curc. T. I. P. 1. p. 24S. \& T. V. P. 1 p. 361.) A (l. Germar, Halensi, ex ejus Musaeo nobis transmissus. Patria: Australasia. 
$f$
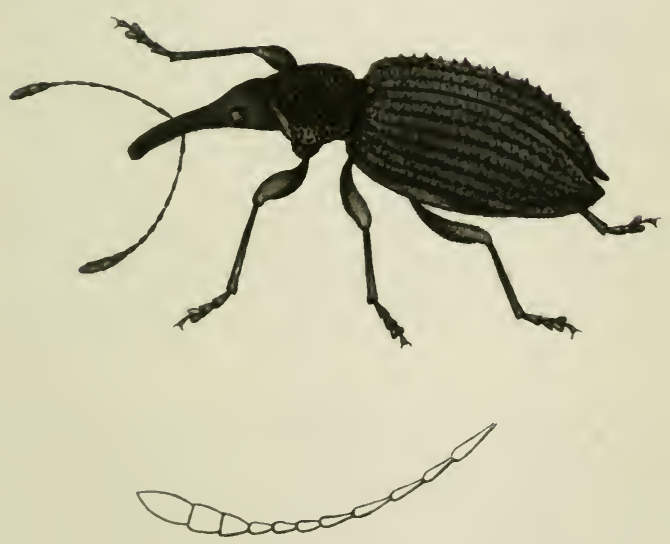

Curhynetwew seabrior 



\section{FaIs BRACHYCERIDFS.}

Corpus durum, pingue, apterum.

IBRACII Y CERUS F'.

Caput transversum, postice tumidum, pæue usque ad oculos thoraci intrusum, oculis lateralibus, oblongis, deplanatis, immersis.

Rostrum capite duplovel triplo longius nec eo angustius, deflexum, arcuatum, crassum, xque altum fere ac latum, basi in pluribus speciebus constrictum.

Antenna in fovea profunda, versus apicem rostriincipiente ad ejus basin curvatim descendente, insertæ, rostro vix æque longæ, crassæ, seu fractæ seu curvalæ, scapo nonnisi tẻrtiam circiter totius antennæ partem constituente, versus basin attenuato, fla gello seusimversus apicem, incrassato, articulis octo arcte connexis composito, articulis ultimum præcedentibus valde brevibus, inter se satis rqualibus, ultimo majore, longiore, articulos duos, decimum scilicet \& undecimum ei intrusis continente, apice obtuso vel brevissime acuminato.

Thorax elytris fere triplo brevior, saltem xque latus ac longus, in plurimis speciebus latior quam longior. Pedes robusti.

Corpus posticum i. e. elytra cum ea corporis parte, cui illa insident, quod brevitatis causa Elytraeum appellabinus, vel ovatum, vel obovatum, vel globoso-ovatum, vel subquadratuns, postice declive.

Elytra connata, anum obtegentia, \& supralatera abdo. minis deflexa.

Sörper bart, plump, unge lügelt.

Ropf in Die Dueere aubgeochnt, binten aufgequollen, falt bis an Die 2ugen in Den Mittelleib eingeffoben, mit feit. lidfen, länglidien, nbgefinditen uns eingefenften sugen.

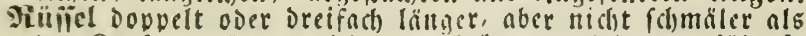
Der fiopf, abmärts gerichtet, geftümmt, didt, ungeföbr fo bod alo breit, bei mebrern Irten am Infang eingefdnürt.

Fibler in einer tiefen, tabe an oer Spibe oes Rüfels ans. fangenden nach Deflen Burgel bin gefrümmt fid berunter. fentenden srube eillbefüat, Eatm fo lang alo oer Rüliel, Did", entweoer gebrodien oder bebogen; Der Genft nur all= mälig verdidt, nus š enguerbunonen (sliedern gebildet, die (s)lieder vor Dem lesten febr furz. cinander giemlich gleid), in: leste gröfer, länger, nod) 2 (Blieber nämlich cin intes und lites, die in onsfelte cingefchoben find, entbaltend,

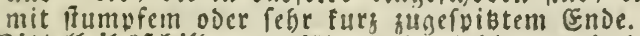

sgittelleiboichils ungefïbr oreimal fürzer als oie frlïgel. Dedten, menigitens eben fo breit als lanis, in Den meiffert arter breiter nls lnmb.

Secine frïftig.

Sinterförqer (D. G. Die Flügelded゙en mit ocm Rörperthille, nuf welchem fie fiken) entmeder eirund oder berfebrt ciruno, ober fualig=eirmno ober faif vieredtia, binten abfdiafiig.

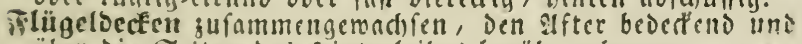

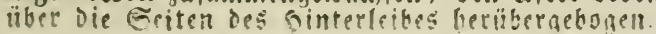





\title{
Fam. BRACHYCERIDES.
}

\section{BRACHYCERUS F.}

\author{
COHORS I.
}

Tibjarum anticarum apex rotundatus. Tarsi subtus spongisi:

\section{Erite Shaar.}

Ende Der vorderfen Schienen nbgerundet. Füfe unten fdivammig.

BRACHYCERUS TUBERCULOSUS Schh. II, 9.

(Schönh. Gen. \& Sp. Curc, T. V. p. 676.)

$$
\text { Patria: Aquapim Guinece. }
$$

Add. Tibiæ apice unco brevi acuto intlis flexo armatæ. 3ufat: Gdienen am Ende mit einem furgen fpilzen nach innen gebogenen backen bewaffnet. 

II. 9
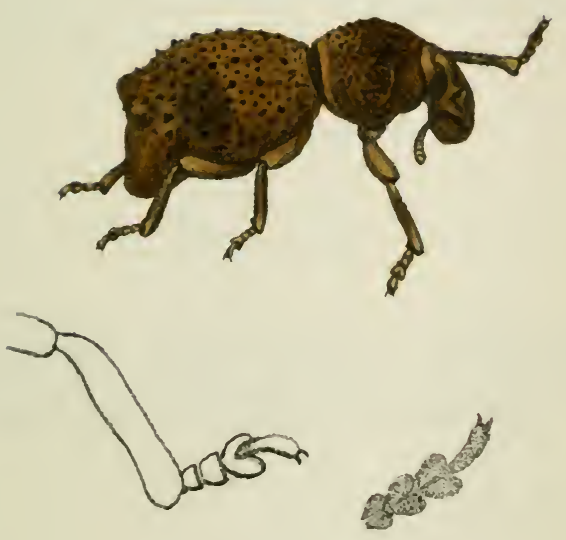

Brnechyerus tuberculoono 



\section{Fam.BRACH Y CERIDES.}

\section{BRACHYCERUS F.}

\section{COHORS II.}

Tibiæ anteriores apice dilatatæ, angulo externo transversim rotundato-extenso. 'Tarsi crassiusculi, subtus pilis spissioribus seu rarioribus instructi.

\section{Bwcite Eahan.}

Dorbere Sdienen am Ende ertweitert; Die n̈ufere Ede in bie Dueere gerundet=augged ebnt. Füfe fiemlid) Did, unten mit bäufigern oder fparfamern banren verfeben. 



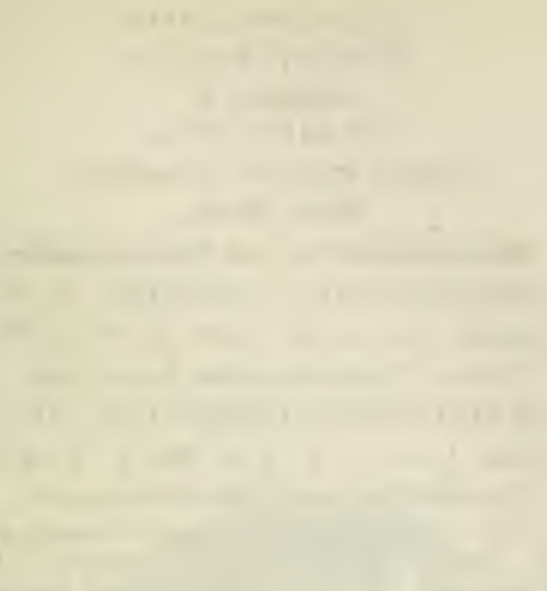


Fam BRACHYCERIDES.

BRACHYCERUS Fै.

COHORS II. MANIPUIUS I.

Thorax lateribus rotundatus.

Erite Mitte.

Inittelleibsfbilo an sen Geiten gerundet.

BRACHYCERUS ALBARIUS II. 10.

(Schönh. Gen. \& Sp. Curc. T. V. p. 653.)

Patria: Promontorium bona spei.

[BRACHYCERUS CORNUTÚS. II. 11.

(Schönh. hbr, cil. T. I. p. 349. T. V. p. 643.)

Patria: Promontorium bonce spei.

Add. In hac \& antecedente specie tarsorum articuli utrinque lobati, lobis deflexis \& margine infero pilis densis funbriatis, nec non unguis subtus tomentosus.

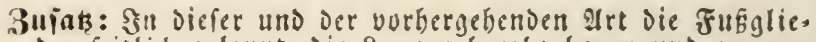
oer feitlich gelappt, die Snppen bernbgebogent und nm un. tern Rande Dicht mit Sanaren befranjt, nuch bas Rlauen. glied unten filgbanrig.

BRACHYCERUS CURRUCA. II. 11.

(Schönh. libr. cit. T. V. p. 6i7.)

Patria: Africa australis.

$A d d$. Tarsi subtus pilis satis rigidis rarioribus instructi.

3uiatz: Die früfe unten mit jiemlid) rauben, fparfomen Saarell verfeben.

BRACHYCERUS TEXATUS. II. 12.

(Schönh. libr. cit. 'I. I. p. 433. T. V. p. 711.)

Patria: Promontorium bonce spei.

13R ACHYCERUS PERTUSUS. II. 12.

(Schönh. libr. cit. 'T. V. p. 713.)

Patria: Promontorium bonce spei et Caffraria.

-1dd. In hac \& præcedente specie elytra foveis seriatis impressa

3ufatz: in sicfer und Der vorbergebenden atrt bie Flügel. ieden mit gereibten Gruben. 
11. 10.
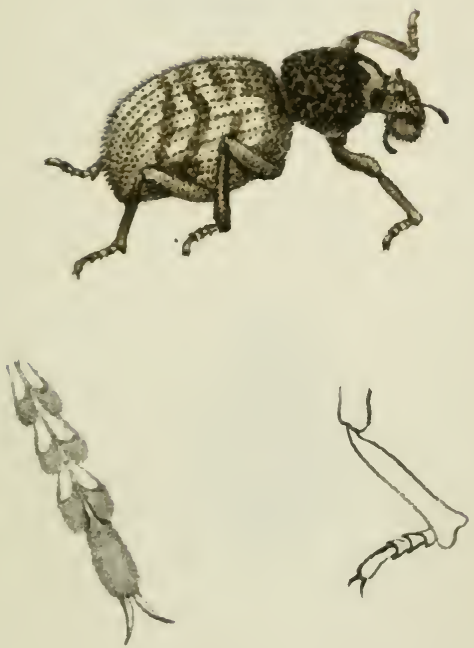

Br albariun 


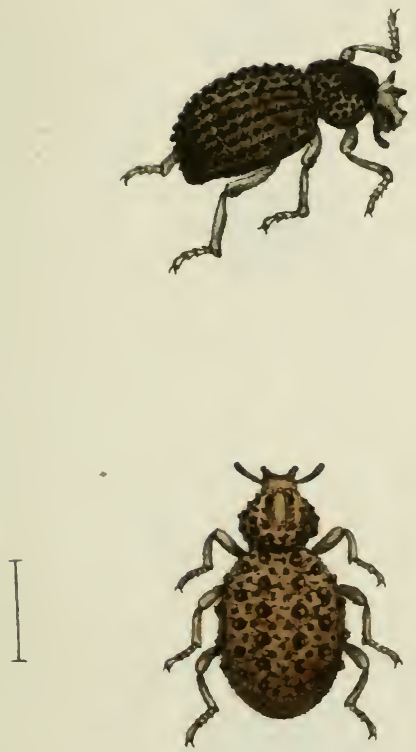

Br. cornietes \& Br. Curruca 



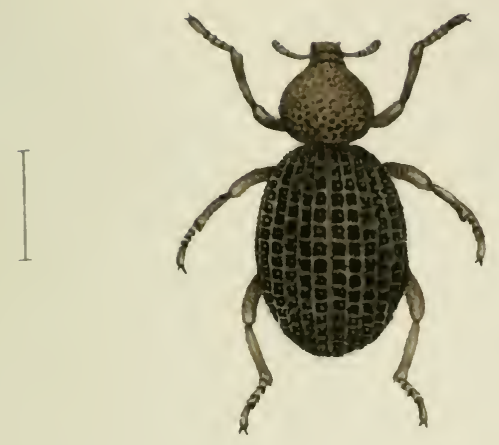

$I$

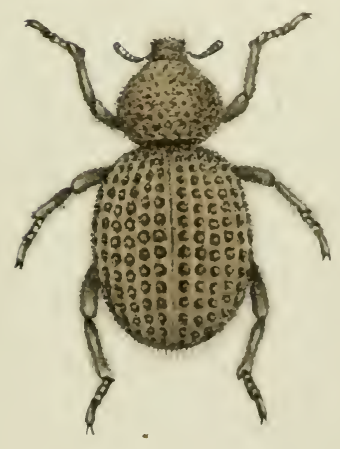

Br. texatus \& Br. portivus 


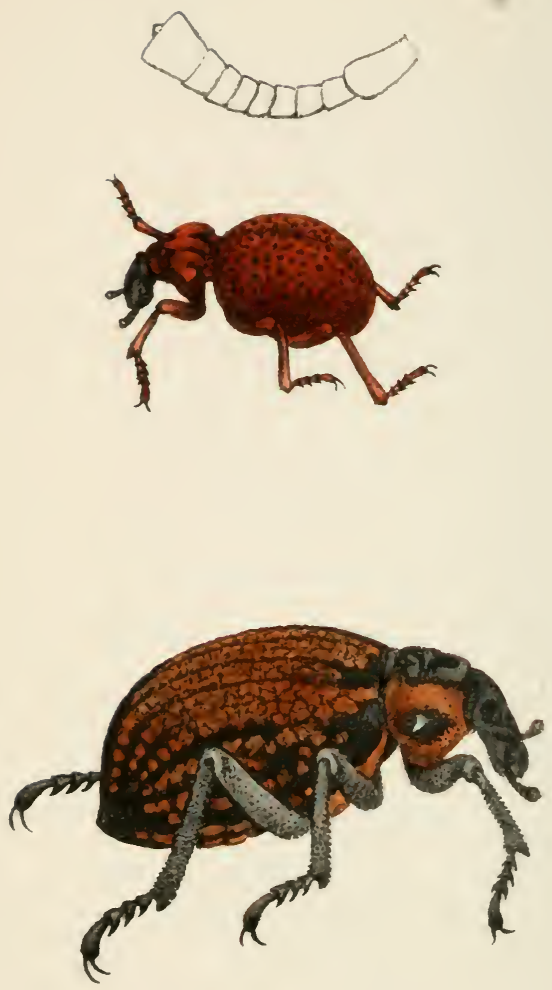

Brobesus ear. \& Br. apilerenv iar. 
. 

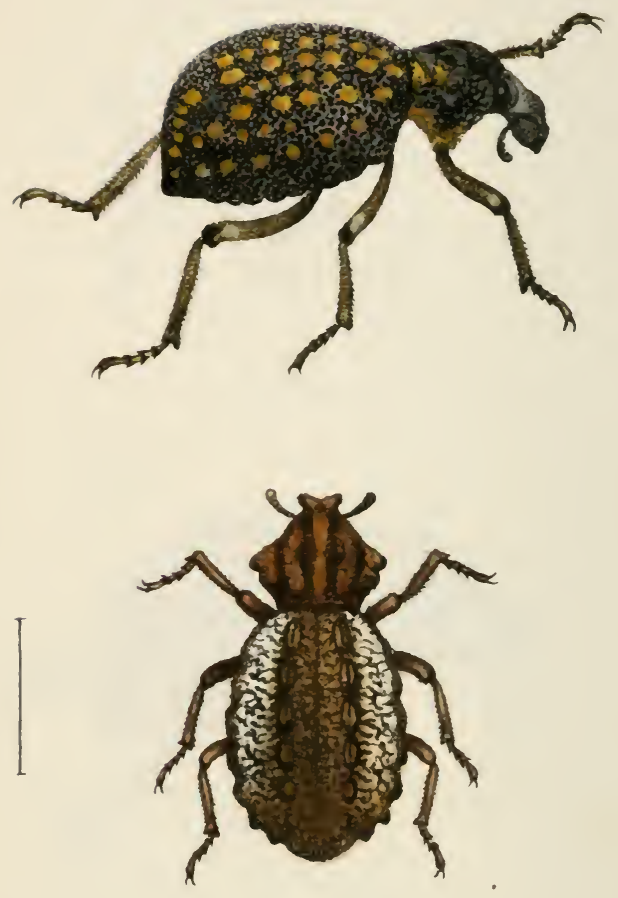

Br. sacer \& Br. duplicatus 
Fam. BRACHYCERIDES.

BRACHYCERUS F.

cOHORS II.

MANIPULUS II.

'Ihorax utrinque spina armatus seu angulatus.

3ucite Potte.

mittelleibsf(bils feitlich mit einem Dorn bewaffet ober ediig

IBRACHYCERUS OBESUS VAR $\delta$. SCHH. II. 13. (Sc!ı̈nh. Gen. \& Sp. Curc. T. I. p. 391. 'I. V. p. 609)

Patria: Promontorium bonce spei.

Add. Thorax sulcis longitudinalibus exaratus; elytra lavia, punctis minimis impressa.

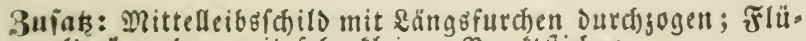
geloedten eben, mit febr fleinen Buntefichen.

BRACHYCERUS APTERUS VAR, $\gamma$. Schh. II. 13. (Schönh. libr. cit. 'I' I. 359. 'T. V. p. 606.

Patria : Promontorium bonce spei.

Add. 'Thorax eminentia cruciformi in fovea profunda instructus; elytra parum scabra. Tibiæ tuberculatoscabrx.

3uiats: Mittelleibsfoild mit cimer freugförmigen Errböhung in einer tiefen Grube; Flingeloeden cin toenig raub. Ed)ie. nen böterig=rnub).

BRACHYCERUS SACER Latr. II. 14.

(Cailliaud Voyage à Méroé etau fleuve blanc 'T. IV. p. 28') \& sq.)

Niger, pedibus dilute fusco-squamosis; maculis tomentosis thoracis, elytrorum et corporis inferioris nec nonsemiannulo femorum ochraceis, maculis elytrormm in series longitudinales dispositis, thorace \& elytris granulosotuberculatoque.scabris; tuberculo thoracis laterali majore spiniformi.

Edmmar; Beime bellbraunichupvig; filibanarige Flecte Des Mittelleibs, Der frlügeldedten uno deg förvero unten, foivie aud ein Salbring an Den Ëchenteln od)ergelb, die flede Der Flügelded" il in Eangseriben georonet; Mittelleibgfails uno Flügeloed"ell törnig: und hoderigornub; cin Eciten. bö̈er Des Mittelleibsfdilloes grö̈er uno dornförmig.

Palria: Regrum Cordofan Africæ interioris. BRACHYCERUS DUPLICA'IUS II. 14.

(Sçönh. libr. cit. 'T. .V. p. 638.)

Patria: Africa alestralis. 




\section{Fam, BRACHYCERIDES.}

\section{BRACHYCERUS F.}

COHORS III.

Tibiæ anteriores apice sinuato_incisæ; angulo externo in dentem producto. Tarsi, præsertim postici, subtenues, subtus pilis raris rigidis instructi. Elytræum globoso. ovatum seu subquadratum.

\section{Dritte Echar.}

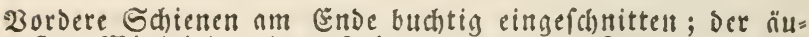
Eere Minfel in eitten $3 a b n$ vorgegogen. Fübe vorgüglich Die binterften fiemlich Dünn, unten init foarfamen, fieifen 5oanen verfeben. Sonterförper fugligeifürmig ober fapt vieredtig.

\section{MANIPULUS I.}

Tibiarum anteriorum dente apicali externo truncato.

\section{Erite Rotte.}

Der äufere Endgahn Der vorbern Shienen abgefukt.

BRACHYCERUS BESSERI. II. 15.

(Schönh Gen. \& Sp. Curc. T. I. p. 413. T. V. p. 656.)

Patria : Russia meridionalis, Volhynia, Podolia, Tauria, Persia.

BRACHYCERUS ALBIDEN'TA'TUS. II. 15. (Schönh. libr. cit. T. V. p. 654.)

Patria: Sicilia \& Lusitania.

\section{MANIPULUS II.}

Tibiarum anteriorum dente apicali externo acuminato.

\section{3iveite Ritte.}

Der äusere Ënognhn Der vordern Sdienen zugefpikt.

BRACHYCERUS SVPERCILIOSUS II. 16.

(Schönh. libr. cit. T. V. p. 662. T I. p. 421 \& 422.)

Patria : Caucasus, Persia occidentalis.

BRACHYCERUS UNDATVS. Il. 16.

(Schönh. libr. cit. T. I. p. 408. T. V. p. 653.)

Patria: Europa meridionalis, Barbaria. 
11. 15.
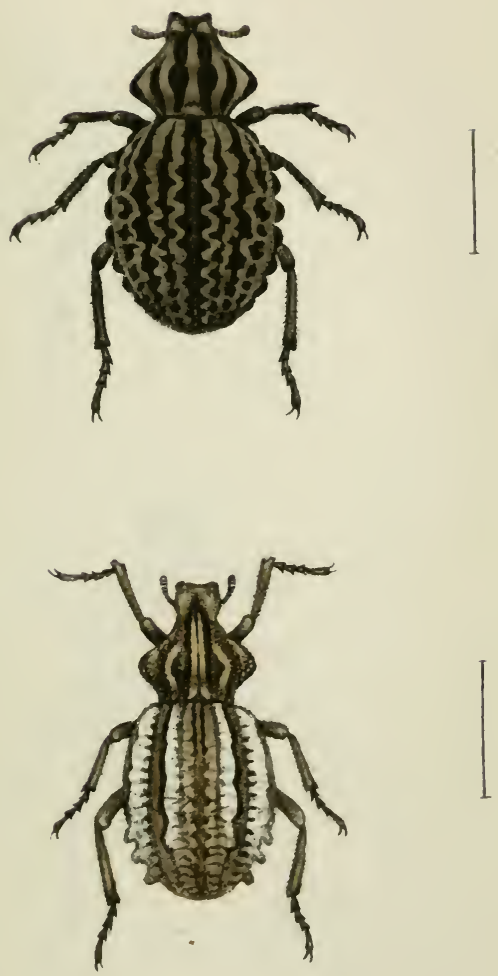

Br. Besseri \& Br. altidentratus 


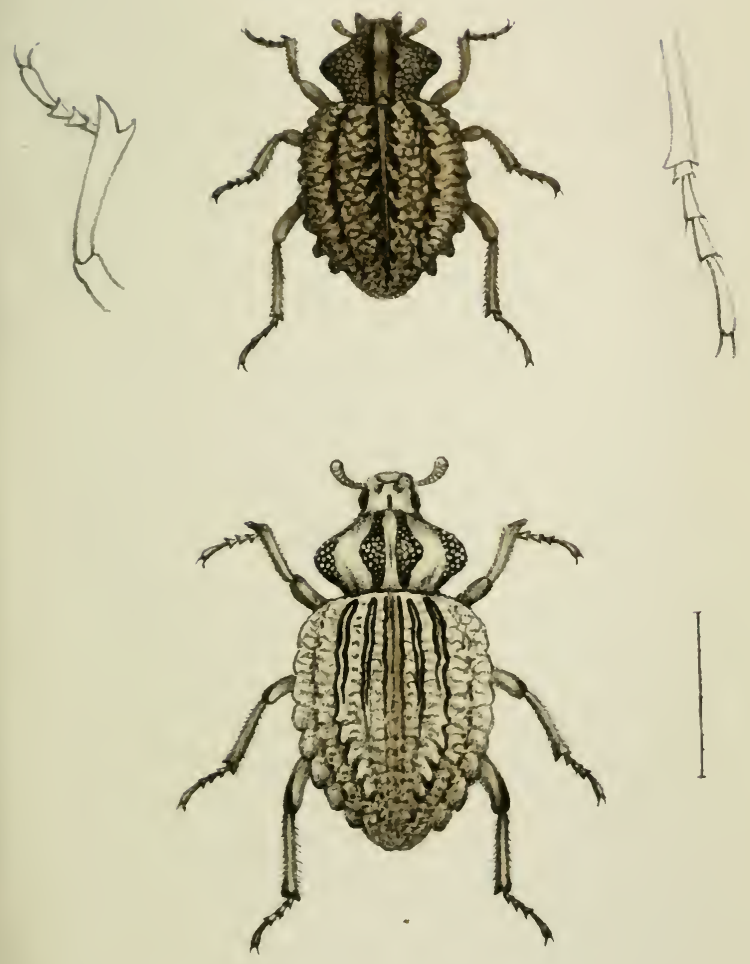

3r. meprercilionew \& Br. undatur 




\section{17}
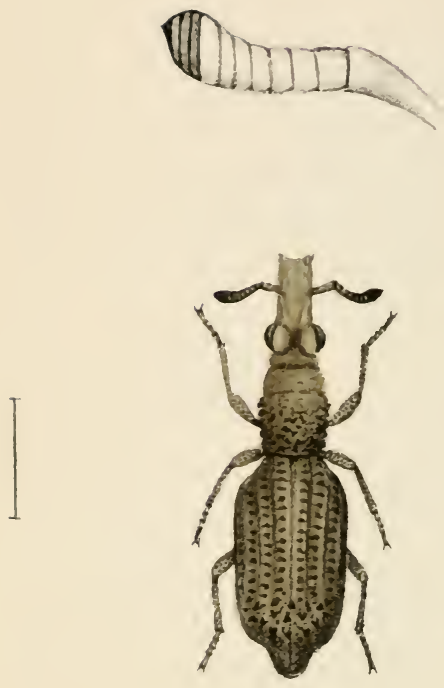

Microcerus grivescens 


\section{MIROCERLS Gyll.}

Corpus squanis obtectum, oblongum, anterius angustatum, apterum.

Caput transversum, oculis lateralibus prominentibus, supereiliis elongatis, appressis.

Rostrum capite contiguum, eo parum longius, apice declive.

Antennce in canali rostri valile profunda, pone apicem rostri incipiente el ad ejus basin oblique descendente, inserta, rostro vix longrores, crassa, seu fractie seu arcuata, 12articulata, scapo sub-obconico, flagello versus apicem sensim incrassato, apice ipso acuminato, articulis arelissime inter se connexis, transversis, quatuor ultimis brevissimis dimidian clava partem constituentibus.

Thorax nonnihil latior quam longior, pone apicem transversim incisus.

Pedes mediocres, tarso cylindrico, subtus setoso, articulo ultimo antecedentibus duobus aeque longo, unguiculis falcatis, acutis,

Elytraeum thorace duplo latius \& plus duplo longius.

Elytra connata, postice abrupte declivia, apice ipso prominulo.

Sörper mit Echuppen bededt, länglicl), vorn verengt, un= getingelt.

Siopfin bie D.uecreallsgedeht, mit feitentändigen vorragen= ben stugen unb verlängerten, nngebrütten, oberen \$lugen= räแอctu.

Piiinel in Den fiopf gennu übergebend, wenig länger nls ierfelbe, ant Ende abflitifig.

Filbler in eitter fehr tiefen, hinter Dem jorberende ant=

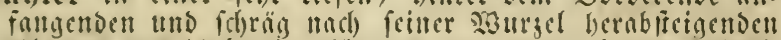

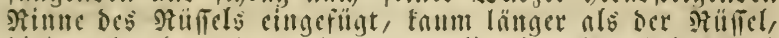
biat, gebrocken oder gebogen, !2glicdrig, ihr Echaft fait verfebrtfeglig, ibre seifiel gegen Dns Ende allmälig ver=

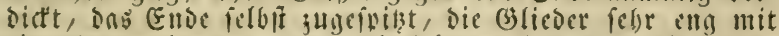

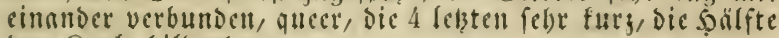
ber fieule billoend.

Szittelleibsidhilo etmas breiter nls lang, binter Dem 23orberende queer cingefdinitten.

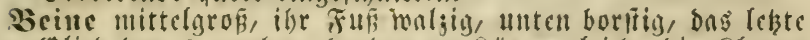
Glied ben 2 vorbergebenden nn Eänge gleich), die. Flauen fichelformig gefrümmt, foils.

Sinterförper Doppelt breiter als Der Mittelleibsfefilo und mebr als sounelt länger.

Fliinclocefen vermaclfen, binten wlöblich nbfdiuffig, an ber Evize felbit micoct ctmas vorrageno.

\section{MICROCERLS GRISESCENS.}

(Schönh. Geu. \& Sp. Curc, T. V. p. 728.)

Patria: Promontorium bona spei. 


\section{Fam. ENTIMIDES.}

\section{RHIGUS Dalm.}

Corpus sub-elongatum, antrorsum angustatum.

Caput pone oculos tumidum, oculis lateralibus, ovatiṣ, subdepressis.

Rostrum capite paulo longius, robustum, apice valde incrassatum.

Antennce in canali angusta value curvala, ad apicem rostri incipiente $\mathcal{d}$ sublus ad ejus hasin desinente inserta, rostrum semel $\&$ caput longitudine aquantes, scapo tertiam totius antenux partem constituente, funiculi articulis sub-obconicis, aeque inter se longis, duobus basalibus vix longioribus, clava oblongo-ovali.

Thorax vix longior quam latior, apice utrinque lobatus.

Scutellum breve, rotundatum, sub-transversum.

Pedes mediocres, intermedii reliquis breviores, anticorum tibia unco apicali, introrsum curvato, acuto, valido instructa.

Elytraeum thorace duplo latius, eoque triplo vel ultra longius.

Röryer etmas [angugejogett, vora verentyt.

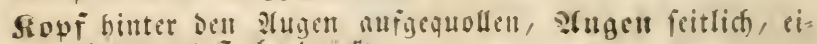
runb, itmas Aad)gebrudt.

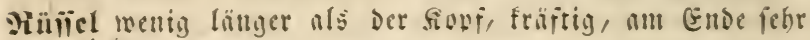
verbidt.

Tïbler in ciner engen febr gefrummten an ber Evike Des

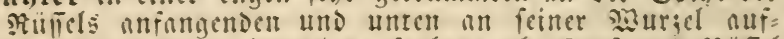

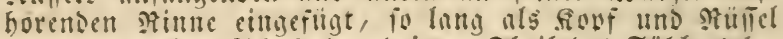
guinmmen, ibr Echaft Den Dritten Ibcil bes Füblers be= tragerts, Die Glicber ifrer Gctilel faft verfebrtfeglig, untercinanber gleich, bie 2 Girumbglieder faum länger; ibre fieule längli(f) oval.

9tittelleibsidnils faum länger als breit, nu 20oderente fu beisen Eciten gelaput.

Ediled)en turg, gerundet, etmas quect.

3eiue mittelgros̄, Dic mittlern türger als sic librigen, nn ben vorberiten die Echiente mit cinem nach intmen ge= trummen, fribigen, traftigen Enobaden verfeben.

sinterförqer Donvelt breiter und oreimal und Darüber länyer nls ser mittelleibsichild. 



\section{18 .}

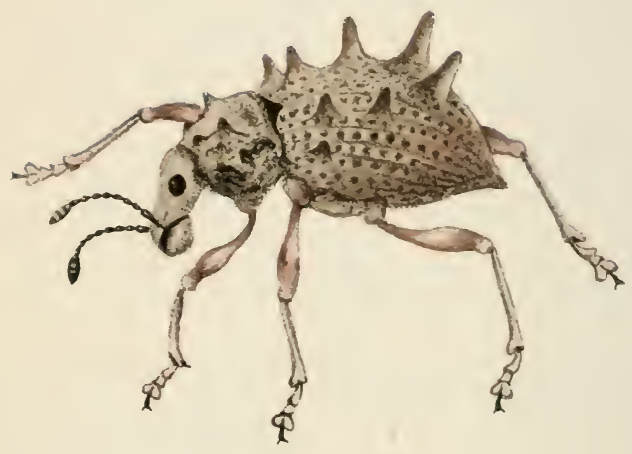

Rhigus hovridus 

II. 19.
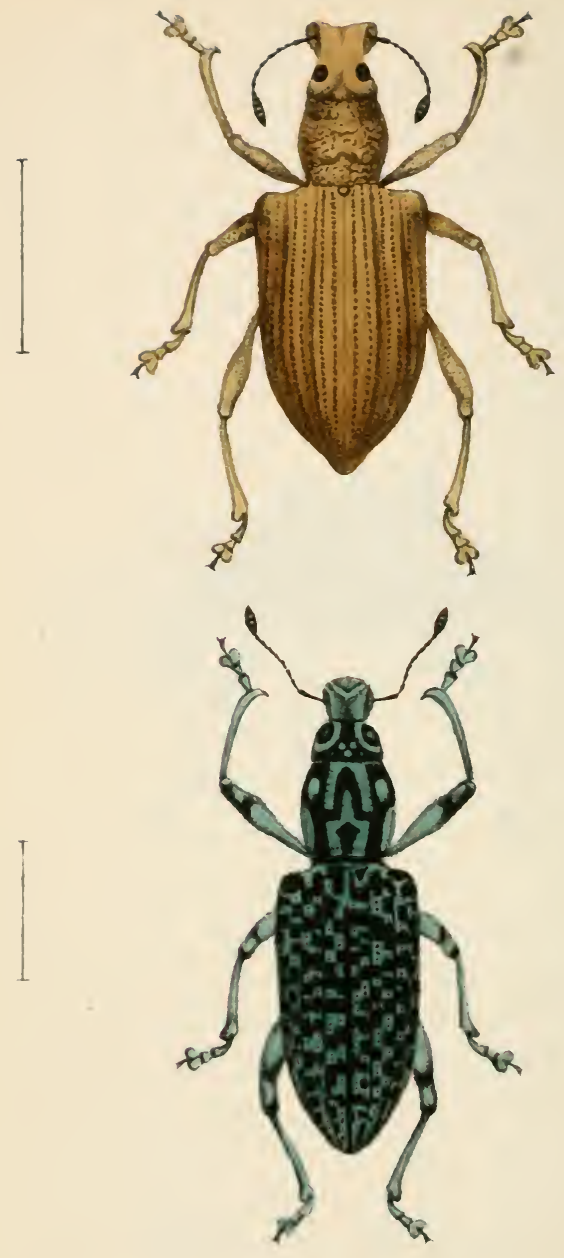

Rehigues Forldermañi \& irerrentur 
Fam. ENTIMIDES.

II. 18. 19.

RHIGUS Dalm.

COHORS I.

Elytra humero in spinam producto.

Erite Eat)ant.

Flïgeloeden mit in cinen Dorn aแğgegogence Echulter.

\section{RHIGUS HORRIDLS.}

(Schöıh. Gen. \& Sp. Curc. Tom. I. p. 475 \& Tom. V. p. 731.) Patria : Brasilia.

COHORS II.

Flyera humero rolundato-angulato.

3weite Erhar.

Flïgeloesen mit gerundet=ettiger Ed)ulter.

\section{RIIGLS FALIERMANNI.}

(Schönh. lib. cil. Tom. V. 1. 733.)

Secundum specimen ab ipso schönher V. Cl. beniguissime donatum.

Patria : Brasilia.

\section{RHIGLS IRRORATUS.}

(Schönh. lib. cit. Tom. V. 1. 735.)

Vatria : Brasilia interior. 


\section{CYDIANERUS Schh.}

Corpus convexum.

Cuput rostro paulo brevius, oculis sub-depressis, ovatis, inferne aeuminatis.

Rostrum robustum, apice incrassato.

Antennæ in canali rostri sub-angusta, subito subtus flexa inserta, scapo circiter quartam totius antennx partem constituente, funiculi articulis sub-obconicis, secundo quam primo duplo longiore, sequentibus sensim brevioribus; clava elongata, sub-fusiformi.

Thorax paulo latior quam longior, basi bi-sinuatus, apice utrinque valde lobatus.

Scutellum oblongum.

Pedes mediocres.

Elytraeum thorace fere triplo latius, ovatum, fere æque altum ac latum.

Elytra humero producto, apice acuminato.

תörper genölbt.

Sopf menig fürger als ber Ralled, mit jimlich) flad)gedrüct= ten, cirunden, unten ;ugépisten singen.

Pliinel fraftig, mit verdidtem $230 r d e r e n d e$.

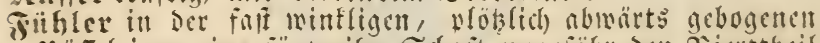

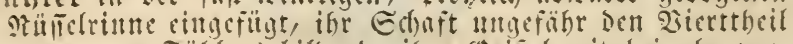

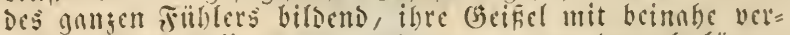
fehrtfegligen Bjlicbern, von benen das 2 te bobyelt länger

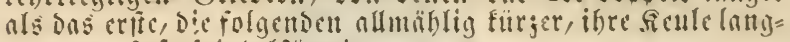
gegogen, folt frindelformig.

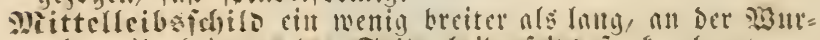

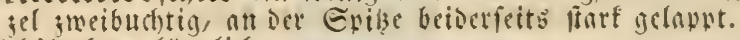

Entodsen lïmglid).

3eine mittelgrof.

Sinterföruer beimahe orcimal becter als ber Mittelleibs: f(hils, efformig, falt fo hodh als breit.

Niliigeloedfen mit vorgezogenter Ed)ulter, jugefpiktem Ende.

\section{CYDIANERLS ARANEIFORMIS.}

(Schönlı. Gen. \& Sp. Curc. T. I. pag. 450 \& T. V. p. 739.)

Secundum specimen a Cl. Germar, Halensi, transmissum.

Patria: Brusilia. 
II. 20 .
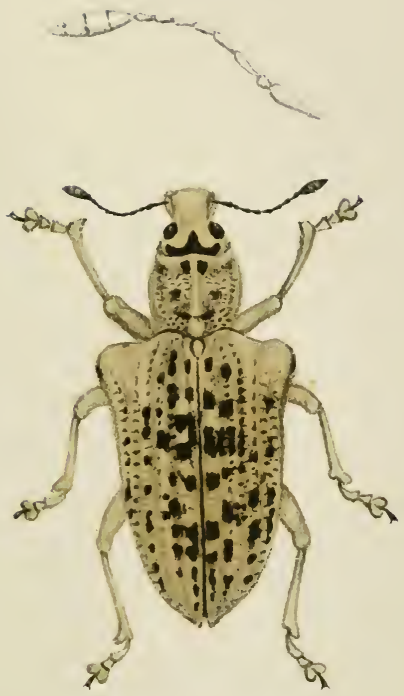

Cydianerus arerseiformis 


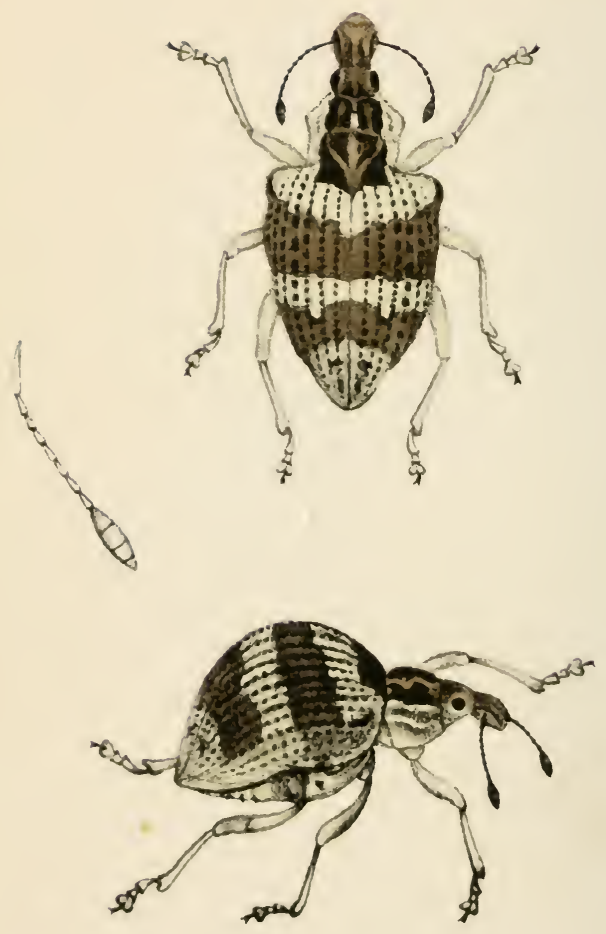

Solyteles Cuerini 


\section{POLYTELES Schh.}

Corpus convexum, autrorsum depressum.

Caput rostro paulo brevius, oculis lateralibus, prominentibus, rotundatis.

Rostrum apice modice incrassalum.

Ancennue in canali rostri iucle ab apice ad basin usque curvatim descendente inserta, scapo terliam fere totius antenna partem constituente, elongato, funiculi articulis obconicis, infer se subaqualibus; clava elongala, acuminata. Thorax latior quam longior, sub-quadratus, apice constrictus. Sculellum intra elvira immersum.

Pedes mediocres.

Elyeraeum thorace duplo latius, breve, valde convexum.

Elytra hasi interiore antrorsum rotundato-producta, humero rotundato-angulata.

Söruer gemolbt, vorn niebergebrildt.

Souf ein twenig tïrger nls ber Rülfel, mit feitlichen, vor= ragenden, gerumbeten stunen.

Yiinîl am EnDe mifin verbiett.

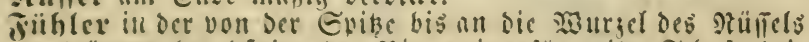
gefrünmt herabiexigenden Rinne cingefügt, ibr Echaft bei= nabe Den Drittbeil Des gungen Fiblers bilsents, verlingert, gefeult, Die Geiffelglieder verfebrteglig, unter fic) jiem= lich nleich; ficule langgegogin, jugefnikt.

Wittelleibsishils breiter nls lnmg, beinnbe vieredtig, am 23orderende juinmmengefornürt.

Edbilodien jmifd)en bie fslïgeldeden cingefent.

शieine mittelgrof.

Binterforwer bopelt breiter nls Der Mittelleibsforbilo, furg, fefir newolbt.

Flïgeloecten am innern surgeltbeil nad) vorn gerundet vorgejogen, nu ber Edulter gerunbet=edig.

\section{POLYTELES GLERINI.}

(Schönh. Gen. \& Sp. Curc. T. V. p. 7ィ3.)

Secundum specimen a Cl. Germar nobiscum anice communicatum.

Patria: Brusilia interior. 
Corpus oblongum.

\section{ENTIMLS Grmr.}

Caput pone oculos tumidum, oculis prominulis, sub-rotundatis.

Rostrum capite nonnihil longius, supra canaliculatum.

Antemno in canali rostri curvala ab ejus apice incipiente o subtus ad basin desinente insertæ, scapo terliam circiter totius antenna partem constituente, elongato, clavato: funiculi articulis sub-obconicis, tribus primis guam sequentibus longioribus; clava elongata, subconica.

Thorax oblougus, supra canaliculatus.

Scutellum sub-elongatum, apice rotundatum.

Pedes longiusculi, robusti, femore \& libia circum circa $\&$ larso superne in uno sexu pilis longiorilus mollibus obsitis, in altero parum \& breviter pilosis, tarso in illo sexu articulis omnibus ante unguem dilatatis.

Elytraeum thorace plus triplo longius, lateribus inde ab humeris compressum.

Elytra humero in angulum producta, apice attenuata, in plurimis speciebus spinoso-acuminata.

Sïนพcน länglich).

Soyi hinter ben stugen nufgequollet, 2 agen ziemlich vors ragend, falt gerunbet.

STijel etmas länge: als ber fonf, oben gerinnt.

Fiible: in cincr gefrummten an Der Enibe Des Rtillels nn= fangenden und unten an feiner cingefügt; ihr Echnft ungeföhr. Den Drittheil Des ganfen Fitiblers betragetto, langgejogen, getult, die Geifelglieder foif vertebrtfeglig, dic 3 erfen linnger als die folgenoen; ficule langgezogen, beinnbe feglig.

Dittelleibofich lianglich), oben gerinnt.

Echilodien jiemlid langgegogen, an ber Evise gerundet.

siscinc länglich, fröftig, Echentel uno Edicne ringsum

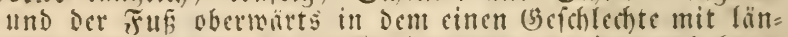
gern, meichen Sonern bebedt, im nnocrn meniger uno furg: banrig, in jenem (sefeldecl)! alle vor bem filattenglied liegende Trusglieder ermetert.

Sinteröbuer mehr als orcifuch länger als ber Plittelleibs= f(l)ild, an ben Eeiten von ben Echultern an zufammen= georiict t.

Tlïneloceft an ber Echulter in cine Eate vorgegogen, am Ende verfomillert, in Den meifien arten finchelfipisig.

\section{ENTIMUS SPI.ENDIIULS.}

(schönh. Gen. de sp. Curc. T. I. P. 15i d T. Y. p. 744.) Patria: Brasilia. 
II. 22

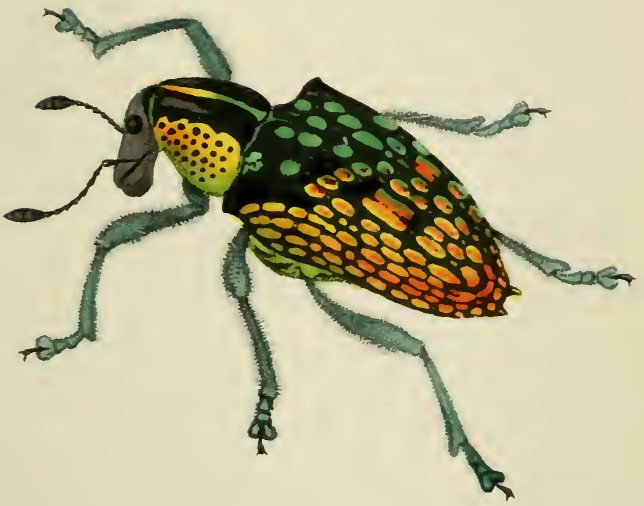

Sntimus uplendidus 



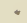


II. 23
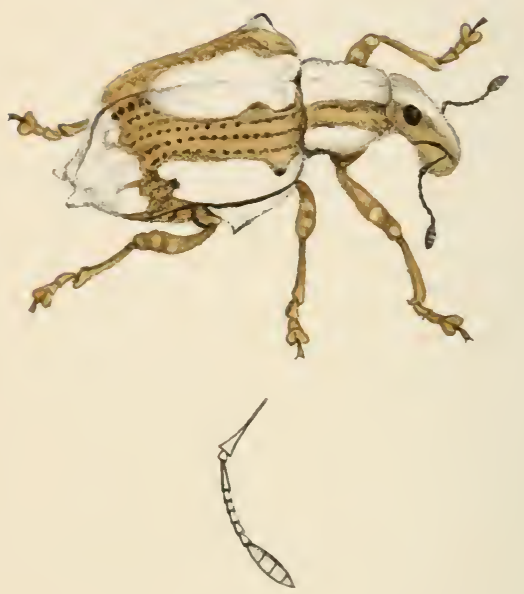

Shasdrepus togates 


\section{PIIADROPLS Schh.}

Corpus elongatum.

Caput rostro brevius, oculis ovatis, infurue acumiualis.

Rostrum apice modice incrassatum.

Antennce in canali rostri angusta arcuata subito subtus flexa iuserta, satis tenues, scapo terliau tolius antennx partem aquante, elongato, clavato, funiculi articulo primo crassiusculo, secundo co duplo longiore, reliquis brevibus, obconicis ; claya ovali.

Thorux longior quam latior, subcylindricus.

Scutellum inter elytra immersum.

Pedes validi, libia subflexuosa.

Elytracum thorace duplo latius.

Elyera humero in spinam extenso, posterius gibba, apice produclo-acuminata.

Sörver langgejogen.

Sovi fïrzer als ber Rilliel, mit cirunden, unten zugefpilzten จุй

Miiīel am Ende mähig verdidt.

Tiigler in ber fommlen gebogenen plöblich nach unten ge= bogenen Riillelrinne cingerügt, ficmlich Diunte; ihr Edhatt Den Drittheil Des ganjen Friblers bildent langegegen,

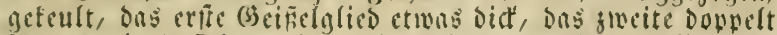
länger als ballelbe, die übrigen furg, verfebrtfeglig; Die Fieule ciförmig.

Syittellcibsidhilo länger als breit, falt malgig.

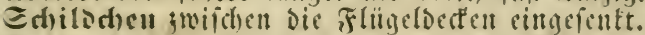
Beiue tröftig, mit etmas gemunbener Echienc. Sinterförver bonyelt breiter als der mittelleibsfoils. Fliineloecten mit in cincu Dorn nusigedihnter Echulter, hinten budtlig, mit nusgegogenem jugefpigtem Enbe.

\section{PHADROPLS TOGATLS.}

(Schönlı. Gen. \& Sp. Curc. T. 1. p. 647 \& T. V. p. 745.)

Patria : Brasilia. 


\section{MESOPTILIUS.}

Corpus oblongo-ovatum, alatum.

Caput sub-conicum, oculis lateralibus, rotundatis.

Rostrum capite duplo anguslius, eoque fere duplo longius, curvatum, deflexum, subcylindricum.

Antennce medio rostri lateri in canali oblique descendente ad basin rostri desinente insertie, dimidium corpus longa, seu rectæ seu sub-fractæ, 12-articulata, interrupte pennatx, articulo primo clavato de clava 4 -articulata elongatis, sub-nudis.

Thorax subquadratus, antice constrictus.

Scutellum rotundatum.

Pedes mediocres, antici paulım elongati, omnium femore subtus ad medium dente acuto armato, tibiis anticis apice uncis duobus acutis, posterioribus altero brevissimo instructis, tarsorum articulis inter se discretis.

Elytra versus apicem nonnihil dilatata.

Röนผcเ länglich)=cirumb, geflügelt.

fiopf jicmlich teglig, mit feitlichen, gerumbeten stugen.

geitifel boppelt fetmäler als ber fiopf und beimabe boppelt länger als dericlbe, getrümmt, herabigbogen, beinabe walzig.

Wibhler mitten an Den Eciten Des foriagen mad feiner sisurgel berabfeigenden rinne cinge= fiigt, von balber siorperlänge, gerabe ober fait gebrochen, 12gliedrig, unterbrochen gefiedert, bas erife gefeulte bjlied uno bie 4gliedrige fieule langgejogen, fatt madt.

grittelleibsithilo beinne vierettig, vorn jufammengejogen. Echilochen gerundet.

Beitte mittelgrofi, bie vorderiten cin menig verlängert, au allen Der Echentel unten nait) ber Mitte bin mit cinem rwizen 3nhn bemaffnet, bie vorderiten Echienen an Ende mit 2 fuiben Sonden, an bent bintern einer berjelben febr furz: Tufiglieber beutlich abgefetzt.

Fliigelocefen mad) Dem Enbe hit etwas erweitert.

\section{MESOP'TILIUS APICALIS.}

(Specimen a Cel. Germar Halensi nobiscum adumbrandum communicatum, qui novum genus constituere declaravit.)

Ater, thorace holosericeo-quadri-viltato, elytris crenato-striatis, macula postica holosericea rufo-testacea antrorsum lineatim incisa ornatis.

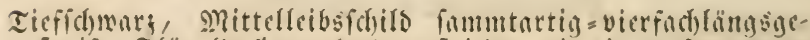

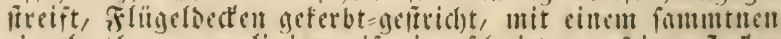

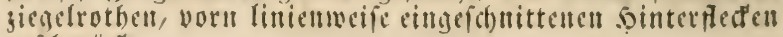
gef́chmü d"t.

Patria: Nova Granada America. 
II. 24 .
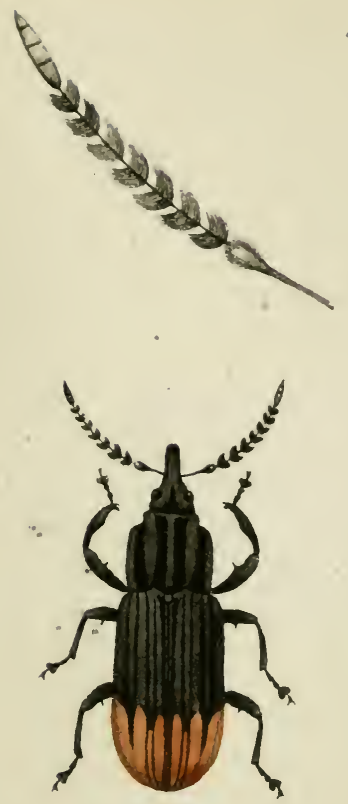

Mesopitilius apicalis 


11. 95.
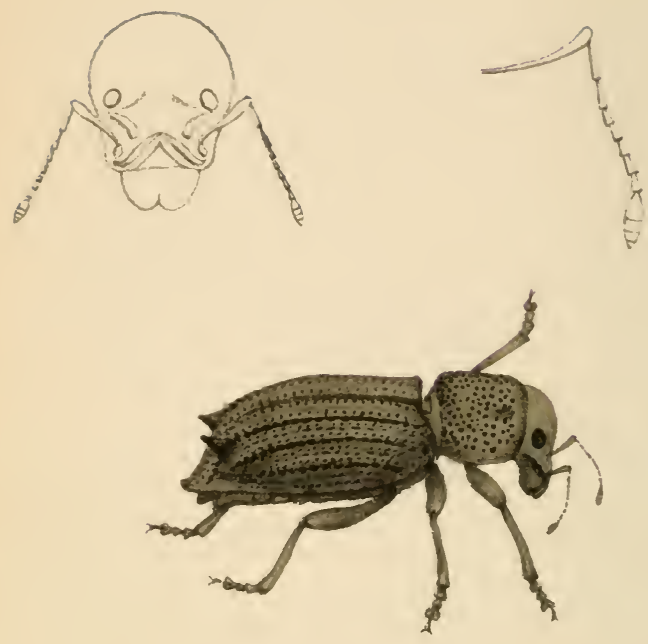

Comatorles misumfmes 


\section{SOMATOI)ES Schh.}

Corpus longiusculum, ellipticum.

Caput deflexum, transversum, supra convexum, rostro longifudine ayuale, oculis oblongis, transversis, prominulis. Rostrum capite contigumu, eo paulo angustius, mandibulis latissinnis.

Antennce in canali rostri valde curvata prope oris aperturan incipiente et in margine interiore oculi desinente inserta, rostro simul cum capile vix lougiores, satis tenues, scapo diundium flagellum longo, modice curvato, versus apicem sensim incrassato, flagelli articulis obconicis, primo et secundo elongalis, reliquis brevibus, inter se aqualibus. clava satis angusta, oblonga.

Thorux capite fere duplo latior, sub-depressus, suborbicularis, apice el basi trumcatus.

Pedes satis robusti, tibia intus serrulata, tarsi articulo tertio bilobo, pracedentibus haud latiore.

Elytram thorace triplo longius.

Elytra ad humeros oblique truncata.

förver lïnglict), elliptifa).

Siopi nbmärs gebogen, queer, oben gewölbt, Dem Rüliel nn sen̈nge gleich), mit lïnglicben, queerifebenden, etwas

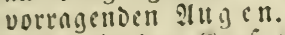

Rüflel in den fiopf gennu überachend, ein wenig ichmiller nls er, mit febr breiten Sbertiefern.

$F_{\text {übler }}$ in cime febr getrimmue, an der Mundöfnung an= fangende and am untern Rande Des शluges aufborende Rinne cingefügt, faum lä̈ger als Der Ruțel fanm Dem foufe, jiemlich dünn, Der Gdinft balb fo lani als die (Scifel, mǟig getrümmt, gegen Das Ende nllmäblia ver= Didt , Die (5eif́lglieder verfehrtfegliu, Das erlie und jweite verlängert, Die ïbriget furg, unter lich gleit), Seule giem: lich enge, lïnglich.

Mittelleibsichild beinnbe dovpelt beeiter als Der fouf, ficmlich flachgedrüdt, faff treistund, am $20 \mathrm{rder}=$ und binterende nbge tülzt.

Beine jiemlict trärtig, die Ectiene inmendin feinfägezähnig, orittes frufglied zmeilapuig, nidht breiter als bee vorber= getbenditl.

binterförver orcimal länger als der Mittelleibsidbilo.

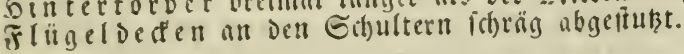

\section{SOMATOIES MIISUMENUS.}

(Schönh. Gen. et Sp. Curc. T. V. P. 2. p. 801.)

Secundum speciueu a. Cl. Germar, Halensi nobis Iransmissum.

Palria: Promontorium bono spei. 


\section{CHERRUS Dalm.}

ferpins pingue.

fapue rostro perparum latius, thorace dimidio angustius, oculis sub-ovatis, sub-depressis.

liostrum capite fere duplo longius, supra camalifulatum.

Antenna in serobe rostri triangulari profunda imacrtir, atd thoracis basin pertingentes, subtenues, scapo flagellum longitudine subxquante, recto, versus apicem sensim incrassạlo, liagelli articulis primo el secundo elongalis, obcoutcis, reliquis brevibus, sublurbinatis, clava oblonga.

Thorax paulo latior quam longior, sub-pulvinatus, lateribus rolundatus, anterins angustior, apice pone orulos lobalus, basi truncatus.

sculellum nullum.

Pedes robusti, antici reliquis longiores, omnim tibia apice inirorsum unco lrevi armata, tarsi articulo forlio bilóloo, allicuis pracedeutibus laliore.

Elytram thorace duplo nec vix ultra longius, elongato-sib)yuadrafum, apice rotundatum.

Elytra basi elevato-marginata.

fï $r$ per plump.

So of lebr menig beciter als der Rüfil, balb fo fomal als

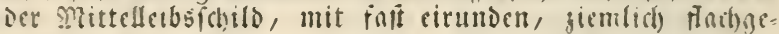
orüften 2 ! $4 \mathrm{~g}: \|$.

Rïffel beinnbe Dowpelt länger nls ber fiow, vorn gerintt.

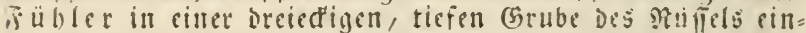
geftigt, an bte Murgel bes Mittelleibsfitilis rechend, etmas Diinu, Der Ed)aft fo lang als die cheifïel, gerude, yegen Dns Enbe bin verdidt, erifes und ;uncites Glico Der (s)eifiel verlängert, verfebrtfeglig, die übriogen furg, etmas treijel. formig, dic fienle länglich.

Mittelleibsfdild cin wenig breiter als lang, etmas volferig, an Den Geiten gerundet, vorn fifmuller, nm Borberende binter ben ?agen gelapht, an ber shurgel ab. gelitukt.

G (l) il disen feins.

3eine fröftio, die vorberfien länger nls bic lubrigen, an allen die Edicte am Ende emmatrs mit eillem furgen Sonten bewaffuct, Drittes Fufiglied jucilapula, breiter nls die vorberocbenden slicber.

Sintertöryer taum mehr als doudele fo lang als der

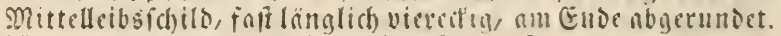

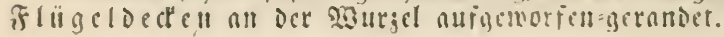

\section{CHERRUS PLEBEILS.}

(Schönh. Gen. et Sp. Curr. T. 1. P. 500.)

secundum specimen a Cl. Schiinherr ipso dono datum.

Palria: Nova Hollundiu. 


11. $2 \%$
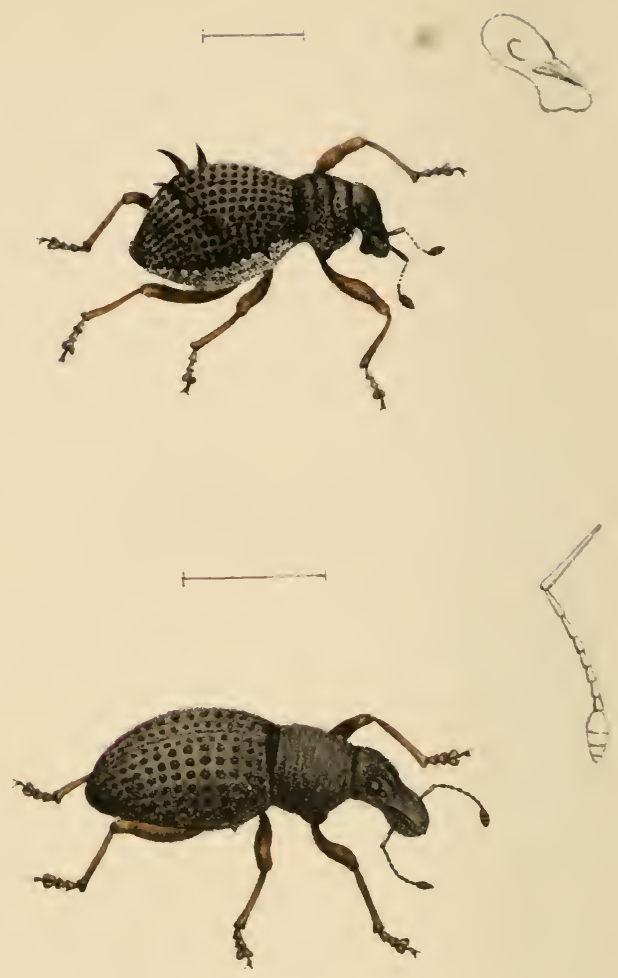

Catcrsarrors upinipeñis \& rufipes 


\section{CA'TASARCLS Schh.}

Corpus ovatum, convexum.

Caput transverse convexum, oculis subdepressis, sub-ovatis.

Rostrum capite paulo longius, supra canaliculatum, versus basin linea transversa impressum.

Antenno in canali ad apicem rostri incipiente el curvatim ad oculi angulum inferiorem descendente inserta, rostro circiler duplo longiores, subtenues, scapo tertiam totius antennx partem constituente, flagelli articulis primo et secundo elongato-obconicis, reliquis breviter-obconicis, clava ovali, acuminata.

Thorax capite duplo latior, transversus, antrorsum angustior, apice pone oculos lobatus.

Pedes satis validi, tibia introrsum erenulata et apice unco brevi armata, tarsi articulo tertio bilobo, articulis pratcedentibus latiore.

Elyeraum supra convexum.

Elytra dente laterali munita.

fiörper cirund, gemolot.

fiovf in Die Dathere gemölbt mit etwas flachgedridten, fiemlich eirunben if ugen.

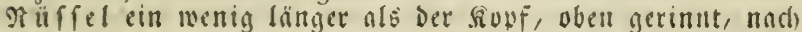
Der sisurgel bin von einer D. Heerlinie dutebfurebt.

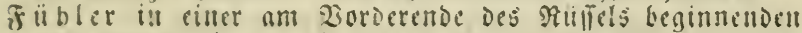
und bosennrtio an bie untere ?fugentante bernbifengenden Piume cingefetst, ungefithe Dopbelt fo lang alo ber stiffel, etmas Dumn, oer Edbaft den oritten Theil Des ganjen

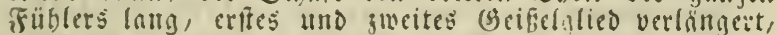

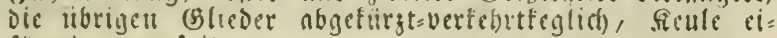
formig, gugefvikt.

Mittelleibsfd)ild Doppelt breiter uls ber fropf, queer,

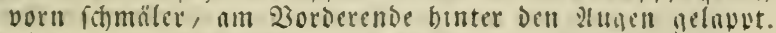

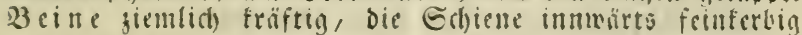
uno am Ende mit einem furgen saten bemafnet, Drittes

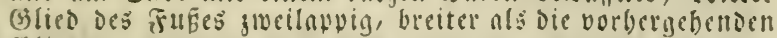
(Slieder.

Sillterforper oben gemölbt.

is lügelde de en mit eincm Eettengubne veriefent.

\section{CATASARCUS SIPINIPENNIS.}

(Schöuh. Gen. el sp. Cure. T. V. P. 2. pag. 817.)

Secundum specimen a Cl. Germar nobis transmissum.

Patria: Reyio circa Swan River Nove Hullandie.

CATASARCES RLFIPLS.

(sichïuh. 1. cil. pair. 81 i.)

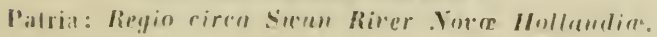




\section{OPHRYASTES Germ.}

Corpus oblongo-ovatum.

Caput transverse convexun, oculis lateralibus, prominulis. ob-ovatis.

Rostrum capile fere duplo longius.

Antenna in canali rostri subito subtus flexa inserta, rostro sinul cum capite vix longiores, crassiusculx, funiculi articulis brevibus, solummodo primo longiusculo, ultimo clava adpresso ef rum ea arctius connexo, clava ovali.

Thorax transversus, ultra basiu lateraliter ampliatus et apice utrinque in formam lobi iuxta oculum productus.

Scutellum nullum.

Pedes Iongiusculi, libia et tarso satis gracilibus, tarso subtus subnudo, arliculo terlio inciso.

Elytroxtm thorace triplo saltem longitıs.

Sörver länglict)=ciruno.

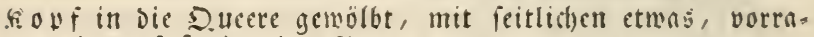
gendell, fait cirunben il ugen.

Pitffel beinabe bowelt fo lang als ber fiopf.

fö über in cinter plöklich abmärts gebogenen Rullielrinne

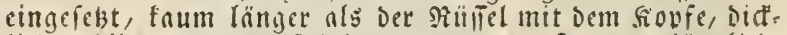
lich), Glicder ber (5eificl furz, mur Das erite etmas länglich, bas lebte alt bie fieule angedridtt und mit ifre eng ver= bunderi; ficule eiformig.

Mittelleibsfibilo queer, ctmas entfernt von ber Murper feitlich erweitert und am 2iorderende beiderfeits in Geifalt ciues Sappent neben dem ?tuge nusgegogen.

E,(d)ild dhe n feins.

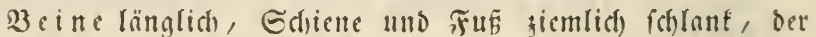

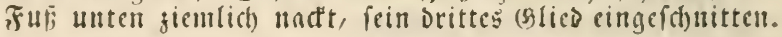

binterförper mentiglens dreimnl länger als ber mitel. leibsfchilo.

\section{OPIIRYASTES VITTATLS.}

(schöuh. Gen. el Sp. Curc. T. I. p. 509.)

serumbum specimen a C.. Germar nobis transmissum.

Natria: Amerion borealis. 


$$
\text { II. } 28 .
$$
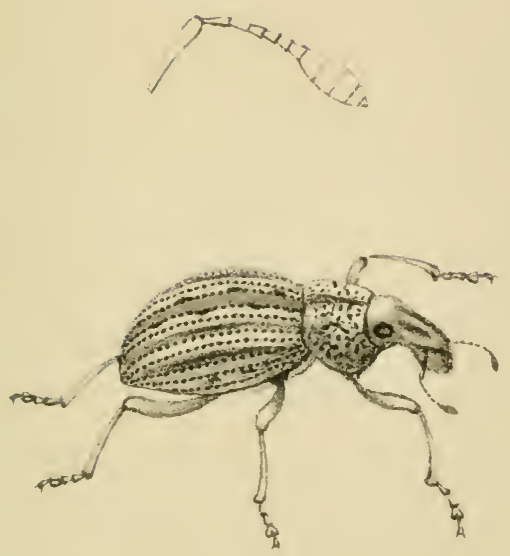

Ophryastes vittaturs 




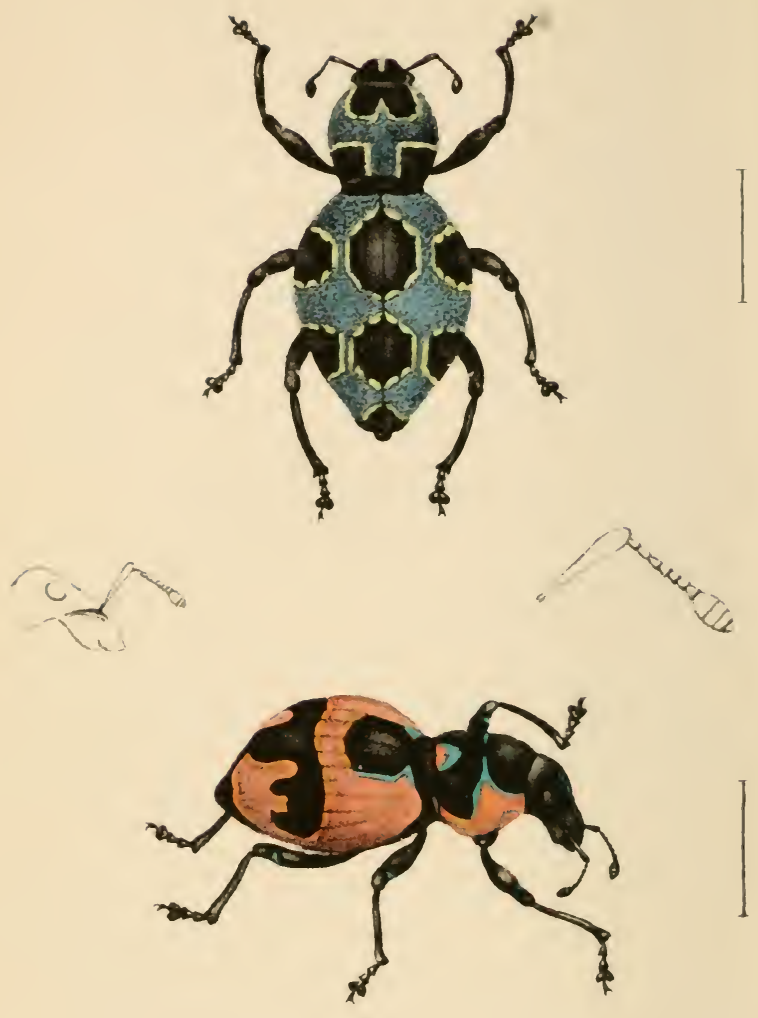

Sunhyrhynshus vebifor s jungifer 


\section{P.ICII) RIIT) V(III S Germ.}

Corpus ovatum.

Caput rostro paulo latius, oculis rotundatis.

Rostrum capile vis longius, supra primum inplessum, func elevalum.

Antenne in canali curvala subilo subtus llexa inserta', rostrum simul cum capite vix longituline aquanles, crassa, funiculi

- apicem versus seusim incrassati articulis brevibus : clava breviter ovata.

Thorax oblongus, laterihus rotundalus, hasi marginalus.

siculellum nullum.

Pedes longiusculi, libia subcompressa, prope apicem modice curvala, apice intus unco mimulo armala, larsi arliculis primo et secundo trigonis, terlio iis duplo latiore, biloluo. Elytraum thorace plus duplo longius of in medio co duplo. latius, supra convexum.

fior o ber cirunto.

ho of ein wenig breiter als ber niillel, mit getundeten It

R lifiel faum länger als ber foyf, vorn juelif eingedrüdt, saun erbaben.

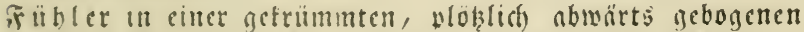
Riane cinnefügt, taum fo lants als Sovf uns Rulfel ;u= fanmengenommen, Dief, bie Glieder Der nllmbltig verdidten (belfiel tury, Dic ficule furg, cirund.

Mitelleibsfillo läuglich, an ben Geiten gerundet, nil Der 23 uriel gernndet.

E(t)ilo (d) en tein:

3et nabe am Ende mäFig cingebogen, am Ende inmendig mit

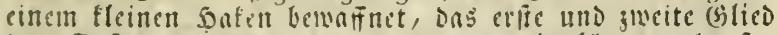
Des $\tilde{5} u f e s$ oreiedig, Dus irtte boppelt länger als fie, jillecilappio.

G interförper metr als Dopuelt fo lang als Der Dhitelleibs: f(bild und it der mitte Dopyelt breiter nls dieler, oben geivolbt.

\section{PACHYRHYNCHUS ORBIFER.}

(Schönh. Fen. et Sp. Curc. T. VIII. P. 2. p. 386.)

Patria: Insula Philippina.

\section{PACHIRIINCHLS IIGIFER.}

«chönh. Vien. pt Sp. Curc. T. VIII. P. 2. p. 38.,

Palria: Insular Ihilimpinar. 


\section{Fam. PACHYRHYN(HI)ES.}

\section{APOCYR'IUS Erichs.}

Coput rostro andue longum, oculis rotulidatis.

Rostrum supra suleo transverso a capite distincto, mandibulis falcatis.

Antemne in canali profunda curvata ad apicen rostri incipiente el in eius facie inferiore basi propius desinente inserta, thoracis basin sub-altingentes, scapo dimidian anleiuan consliluente, parum curvato, versus apiém seusim incrassato, funiculi articulis primo et secundo longiusculis, reliquis brevibus, obconicis, clava elongato-ovali.

Thorax nonnihil longior quam latior, basi fruncalus, eleralumareinatus.

Scutellatm nullum.

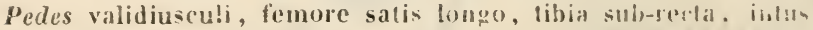
crenulata, apice unco brevi amata, tarsi arficulic primo el secundo trigonis, tertio latiori, hilo!no.

Elytraum thorace duple longius.

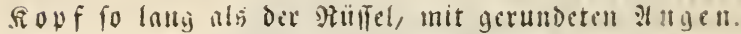

$\Re$ iifel oben ourch cine Dueerfurdie vom fiopfe nogegrent, mit fichelformigin Doerfiefirn.

F üf ler in einer tiefen, getrümmten, am 2iorderende bes Ritifels anfangenden und an feiner untern Fläde nabe nn Der Murgel endigenden Rimlte eingefïgt, fait an Die

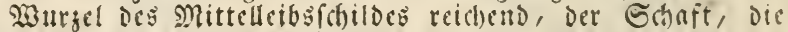
Gerlfte des frublers bildend, menig gebogen, negent bas Ende bin nllmablig verdidte, erfes und zmettes Glicd Det (seifiel länglich, Dic übrigen furq, verfefrtteglig, fienle länglid $=$ cirund.

Mittelleibsfoild etmas länger als breit, an ber 2 surget abgefulat, nufgemorfen gerandet

S(b) il d chenteins

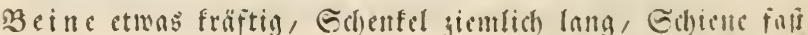
gernde, innmärts fein gefirbt, am Ëlde mit cinem furgen

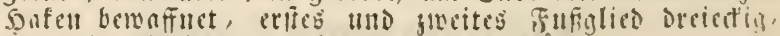
ins britte breiter, zmeilanpio.

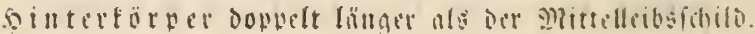




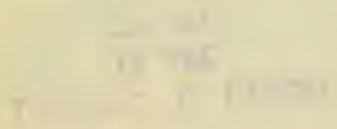

. 
II. 20.

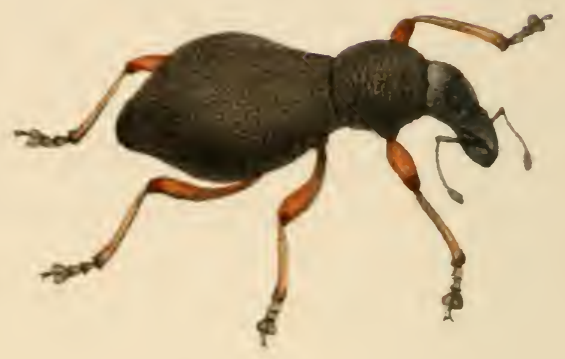

Apereyeters conecess 

11. 31.
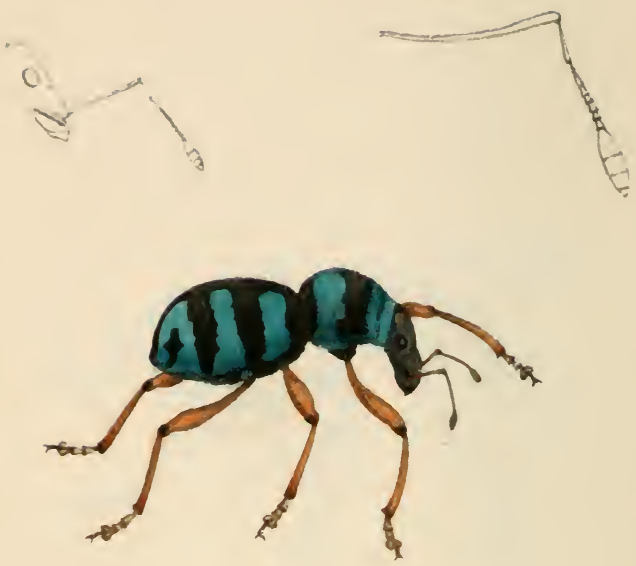

apreyeters sucb-fasciaters 


\section{Fam. PACHYRIINCHIDES. II, 30, 31 \\ APOCIR'TLS Erichs.}

\section{Cohors 1.}

Corpus supra depressiusculum. Elytrapum medio dilatatum, thorace duplo latius.

\section{Erite Ed)anr.}

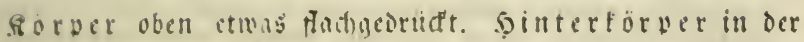

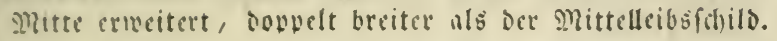

\section{APOCYRTLS CONICLS.}

Schöuh. Gen. et Sp. Curc. T. VIII. P. 2. p. 393.)

Patria: Insulce Philippince.

\section{Cohors II.}

Corpus supra thorace et elytrao convexis. Elytraum thorace xque latum vel eo angustius.

\section{3tweite Edfanr.}

horper oben mit gemolbtem Mittelleibjferilo uno Sinter= forper. binterforver fo breit oder fdumäler nlo ber Mittelleidsidrillo.

\section{APOCYRTUS SUBFASCIATUS.}

Schönh fren. et Sp. Curc. T. VIII. P. 2. p. 39\%.)

Patria: Insula Philippinœ. 


\section{DERACANTHUS Schh.}

Corpus sub-ovatum.

Caput rostro paulo latius, antrorsum angustatium, oculis lateralibus, ublongis depressis.

Rostruin capite haud longins.

Antennce in canali angusta, arcuata in medio rostro subtus evanescente inserta, rostrum simul cum capite longitudine haud superantes, validiuscula, scapo quarlam lotius antennæ partem circiter æquante, clavato, funiculi articulis inter se subequalibus, primo maiore, secundo et terlio subturbinatis, quarto, quinto et sexto rotundatis, transversis, septimo crassiori, clavæ appresso, eiusque basin mentiente, clava ovata.

Thorax transversus, in aliis lateribus rotundatus muticus, in aliis spina armalus.

Scutellum triangulare.

Pedes mediocres, tibia sub-compressa, apice spinulis instructa, tarso sub-gracili, subtus setoso, articulis, terlio excepto, elongatis, hoc apice inciso.

Elytraum ovatum, thorace duplo et paulo ultra longius, supra posterius convexun.

Si oryer ctmas cirund.

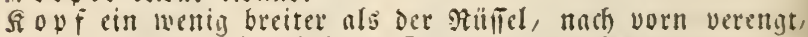
mit feitlichen, länglichen, flachgedrüdten $\mathfrak{A}$ u gen.

Rülfel nicht länger alg ber fiopf.

Fै $i$ b $l$ er in ciner ichmalen gebogenen, unten in ser Matte

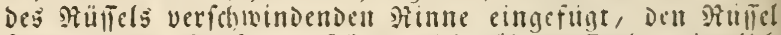

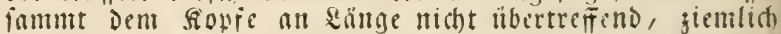
fräftig, Der Ecinat ungefïhr ben V̧iertheil des gonjen Fïblers betragend, geteult, bie Shlteder Der Eseifiel unter fich jlemlid) gleid), Das erife etmas grof̈, Das jueite und Dritte iaft treifelformig, viertes, fiinftes und feclstes ge= rundet, queer, Das liebente bicter, ant Dte fieule anzedrüdt,

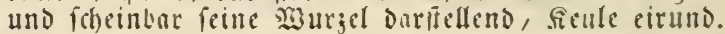

Mittelleibsithild queer, bei Deat cinten an Der Eeite gerundet, webrlos, bei De.l andern mit eittent Dorn bes waffnet.

S ch $i$ i d che en orciedig.

马e it e mittelgrofis, Edbiene etmas jufammenjedrudt, am Ende mit Dormiten verfeben, frub giemlich fithnte, unten

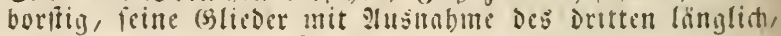
Diefis an Ende cingefiluntten.

Dintertoryer cirund, etn menig mebr als sopvelt fo lang als ber anittelletbsfobild, oben Gintermäts gemolbt.

\section{DERACA VTHUS KARELINI.}

Schöuh. Gen. et sp. Curc. T. V. P. 2. p. 839.

Secundum specimen a. C. Germat nohis transmissum.

Palria: Littus orientale maris Caspici. 
11. $3 \%$
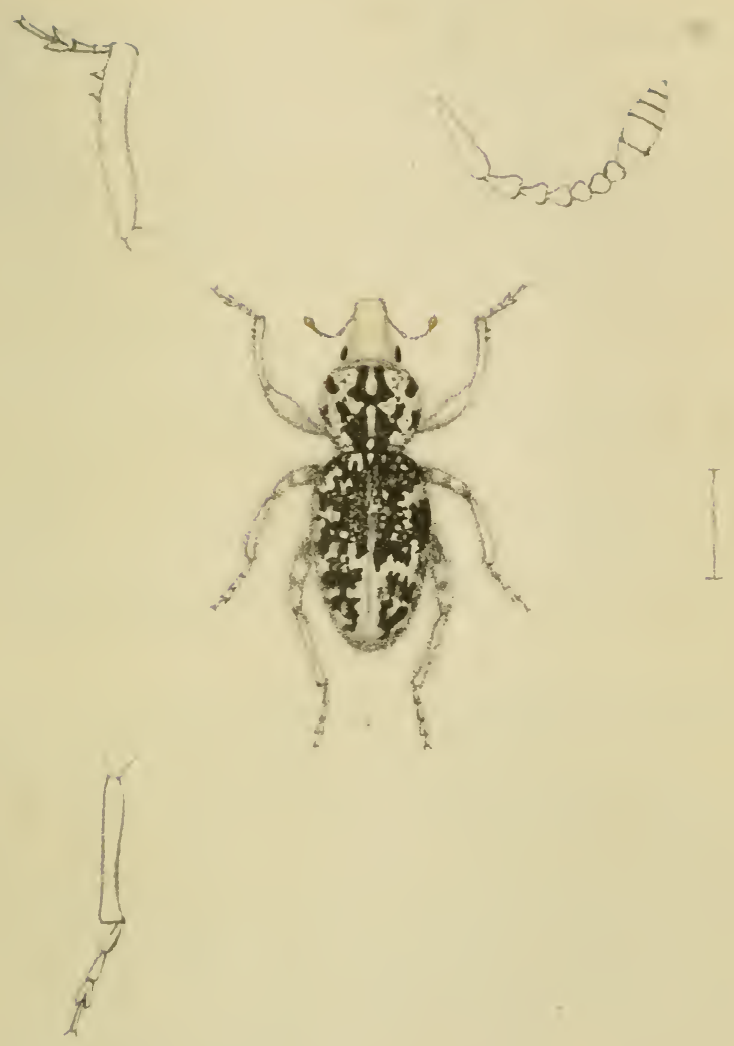



\section{Fam. ENTIMIDES.}

\section{IIIPPORIIINUS Billb.}

Corpus clongatum, apterum, scahrosum, in plerisque speciebus tuberculatum vel spinosum.

Caput transversum, oculis ovatis, depressis.

Rostrum sub-clongatum, apice crassius, aut capiti sub-contigunm aut basi abscissum.

Antenna in canalicula ad apicem rostri incipiente et versus angulum oculi inferum directa inserta, rosirum simul et caput longitudine saltem rquantes, scapo oculum non superante, funiculi satis tenuis arliculis obconicis, primo et secundo elongalis, reliquis brevioribus, inter se aqualibus; clava oblongo-ovali.

Thorax vix longior quam lalior, lalerilums in plerisque rotundatus, in aliis spinosus.

Pedes validi, aut Iongiusculi aut mediocres, tibia tereti, tarso in paucis tibia aque longo, in plurimis ca lireviore, arliculis primo, sccundo et lertio suhtus spongiosis, quarto hirto.

Elytrceum oblongo-ovatum, florace triplo quadruplove Iongius.

Elyeru coadunata, apice in aliis rotundala, in aliis ultra abdomen producla.

Siorper lamigejogen, fitigellos, roul), bei den meipen sir= ten bocterig oder Dornig.

Ropf queer, mit cirmben, fladiged anden Ifugen.

R liffel zicmlich langgejogen, nm Ziorberende dider, mit

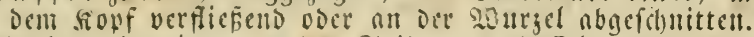

Füble $r$ in einer an Der Evib̧e bes phullels anfangenden und gegen ben untern ?lugentintel gerichteten simne cin= gefügt, wentglfens fo lang als stuffel und fiopf zufom= men; Der E(t)nft niclet liber Dns aluge wegreicl)end, Die Glieder ber mäfig Dunnen (beifel vertebrtteglig, Dns erife und jweite langgejogen, Die tibrigen türger, cinnuber gleich); Reule länglich ciformig.

Mitt elleibsfolito taum länget als breit, an Den Eciten bei ben meifien gerundet, bei cinigen bornig.

cine fräptig, entweder länglict) oder mittelyrofi, Échiene

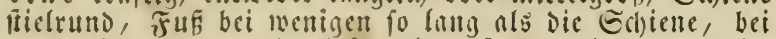
Dell meifien tirzer als bicle, feill erifes, zweites und orit= tes Glicd untell fomnmmig, Das vierte raubhanrig.

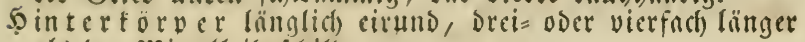
als ber Mittelleibsfidild.

Fliigelded"en aneinnndergefïgt, num Ende bei ben cinen nbgerundet, bei Den andern ibber Den șinterleib binnus verlängert. 
II. 33. 34. 35. Fam. ENTIMIDES.

\section{HIPPORHINUS Billb.}

Rostrum basi supra deplanatum et capiti subcontiguum. $\Re$ üffel an ber sisurgel obermärts cben und faft in gleidfer Flïche mit Dem Ropf verlaufenb.

\section{HIPPORHINUS NIVOSUS.}

(Schönh. Gen. et Sp. Curc. T. I. pag. 470 et T. V. pag. 752.) Patria: Promontor. Bona Spei.

Rostrum supra sulco longitudinali impressum. $\Re$ ü ff mit cincr sängsfurche.

\section{HIPPORHINUS SPECTRCM.}

(Schönh. libr. cit. T. I. pag. 462 et T. V. pag. 748.)

Patria: Promontor. Bonce Spei.

Rostrum supra sub-trisulcatum. Rüffel oben faft orei= furctig.

\section{HIPPORHINUS INFACETUS VAR.}

(Schönh. libr. cit. T. Y. pag. 760.)

Secundum specimen a Cl. Schönherr ipso nobis dono datum.

Patria: Promontor. Bonae Spei.

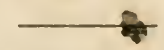

Rostrum basi proprius in tuberculum geminum alte elevatum.

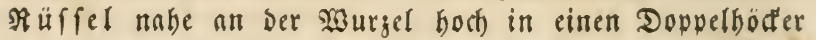
aufiteigend.

\section{HIPPORHINLS DREGEI.}

(Schönh. libr. cit. T. Y. pag. 749.)

Patria: Promontor. Bonae Spei.

Rostrum basi profundius constrictum. Rüffel nn Der $\mathfrak{M} u r=$ zef ticf eingefdürt.

\section{HIPPORHINUS RHAMPHASTOS.}

(Schönh. libr. cit. T. I. pag. 486. et T. V. pag. 780.)

Patria: Promontor. Bonae Spei. 
1/. 33 .
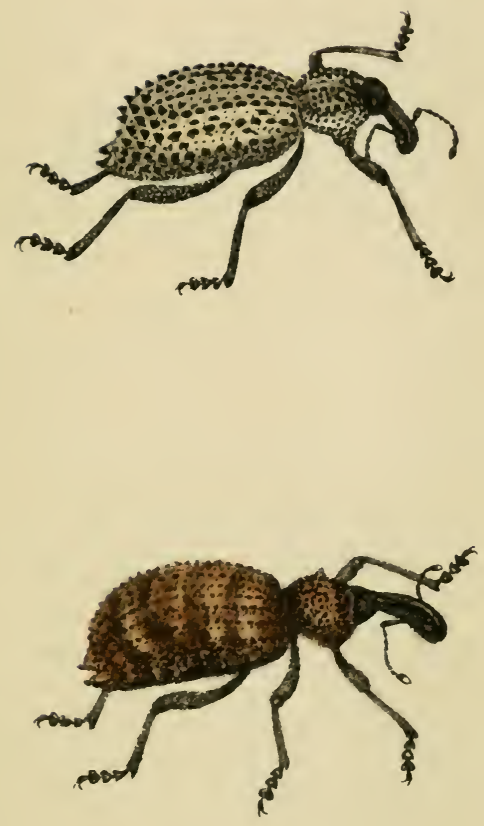

Hipporthinus nivosus \& spectrum 

J1. 34.
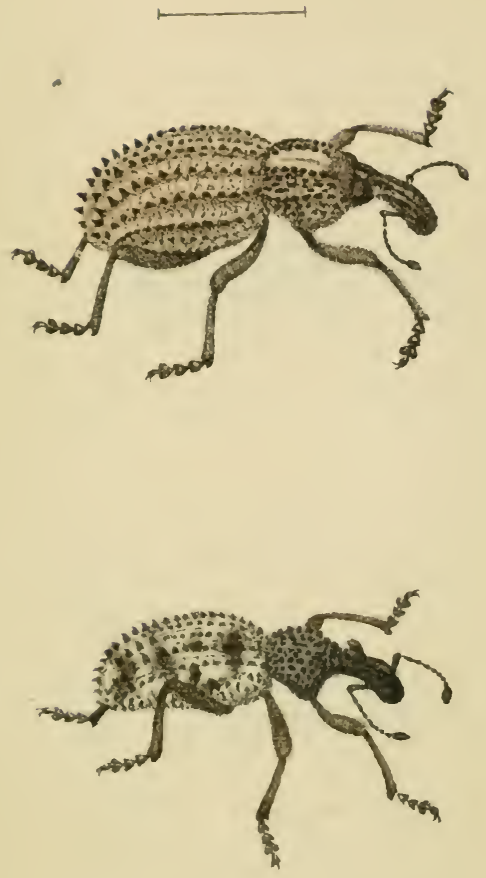

IH. infoustien var. \& Dregei 


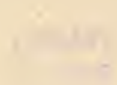


II. 35
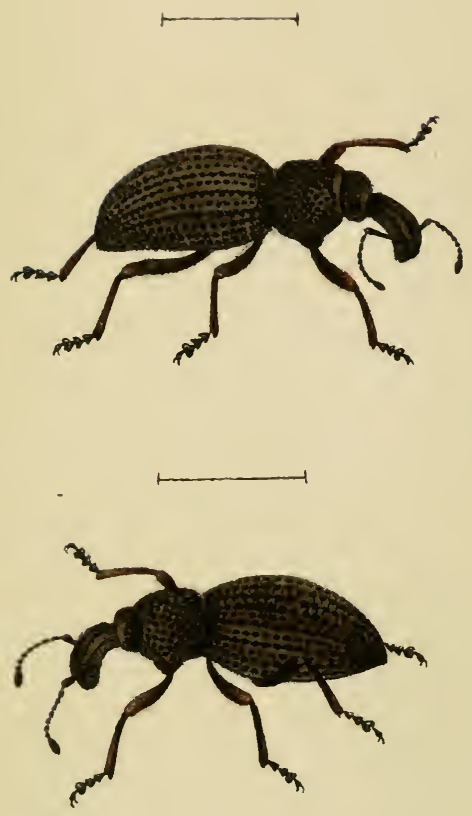

H. Tilumphoutur mas \& fem. 


II. 36 .
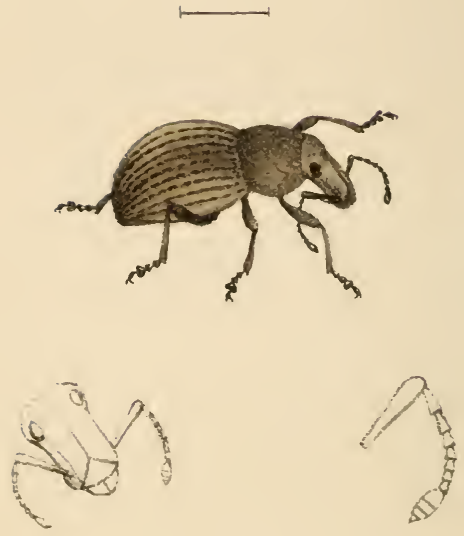

Poluptrades payanus 


\section{POLYPHRADES Schh.}

Corpus sub-ellipticum.

Caput inter oculos planatum, oculis ob-ovatis, sub-depressis.

Rostrum capite nonnihil longius, supra apice lamina triangulari, nitida, mandibularum basin tegente instructum.

Antennae in scrobe rostri profunda, latiuscula, ante oculum desinente insertx, rostro saltem duplo longiores, validiusculx; scapo oculos vix superante, funiculi articulis primis longiusculis, obconicis, reliquis brevibus, turbinatis, clava oblongo-ovata, acuminata.

Thorax haud longior quam latior, perparum convexus, basi, fere recte truncatus, lateribus modice rotundatus.

Pedes mediocres, anticorum tibia intus remote denticulata.

Elytraeum thorace paulum latius.

Elytra apice conjunctim sub-acuminata.

Kërper falt elliptifor).

fe o f gmifthen Den 2 ugen verfndst, mit verfebrteiförmigen, faif finchgeorüdtent slugen.

Rëtffel etmas lättger als ber sepf, oben am 20 orberende

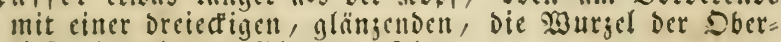
fiejer bededenden \$latte veriefhen.

F ühler in einer tiefen, etmag breiten, vor dem $\mathfrak{T u g e}$ aufs

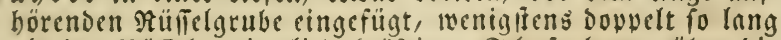
als ber Rüliel, ziemlich fräftig; Echaft faum über bie Ilugen megreichend, Die erfien (j)eiselalieder länglich), ver= fehrt feglig, Die übrigen furg, freifelförmig; Seule läng= lich ciruno, jugefvibt.

Drittelleibsfdils nicht länger als breit, fehr wentg

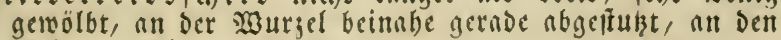
Eeiten mäfig gerundet.

Beine mittelgrof, dic Echiene Der vorderfien intmörts entfernt gegähnelt.

Sinterförper menig breiter als Der Mittelleibsfotho.

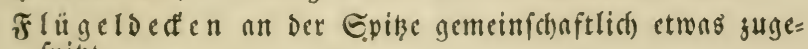
fpikt.

\section{POLYPIRADES PAGANLS.}

(Schönb. Gen. et Sp. Curc. T. V. Pars 2da pag. 377.)

Patria: Nova Hollandia. 


\section{PROSAYLELS Schh.}

Corpus oblongo-ovatum.

Caput paulum convexum, oculis prominulis, rotundatis.

Rostrum capite vix longius.

Antennae in scrobe curvata, ante oculum desinente insertx, validiusculis, rostro saltem duplo longiores; scapo clavato, lumiculi articulis hasalibus duobus breviter obconicis, reliquis brevioribus, lurbinalis; clava ovata, acuminata.

Thorax haud latior quan longior, basi apiceque truncalus, lateribus rotundalus.

Scutellum parvum, apice rolundatum.

Pedes modiocres, anticorum tibia inlus a medio ad apicen crenulata.

Elytracum thorace fere triplo longius.

Elytra convexa, postice compressa, apice altenuata.

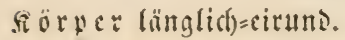

fopf ein wenig gemolbt, mit vorragenden, gerunderen I $u$ ij $\mathbb{C} \|$.

Rüfel faum länger nls der Ropf.

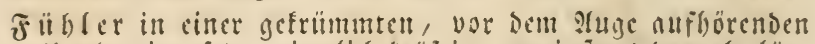

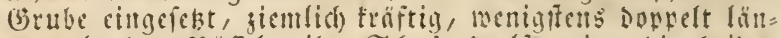

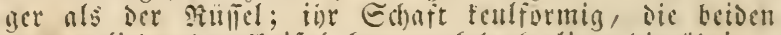
Grundglieder ber Geifel furg verfelgrteglig, dic iibrigen furger, treifelformig; senle cirund, jugefpizt.

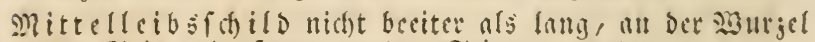

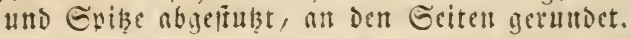

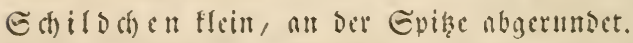

23 eine mittelgrofi, Eethicue Der vorderfien inmmäts von Der slitte bis ants Ende tleingeferb:

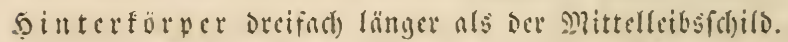
Fै verf(t)mellert.

\section{PROSAYLELS A'HEROP'TERLS.}

(Schünh. Gen. el Sp. Curc. T. V. p. 8\%.)

secundum specimen a C. Germar ad publicaudum nobis transmissum.

Patria: Nova Hollandia, 


\section{II. $3 \%$}
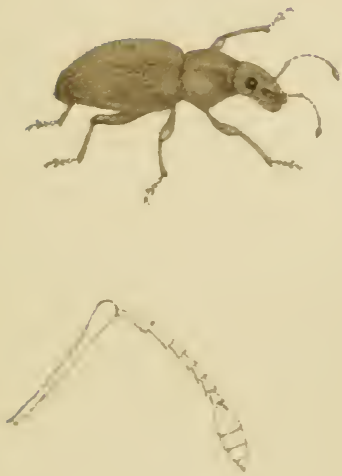

Prosayglous atheropterues 




\section{JI. 38.}
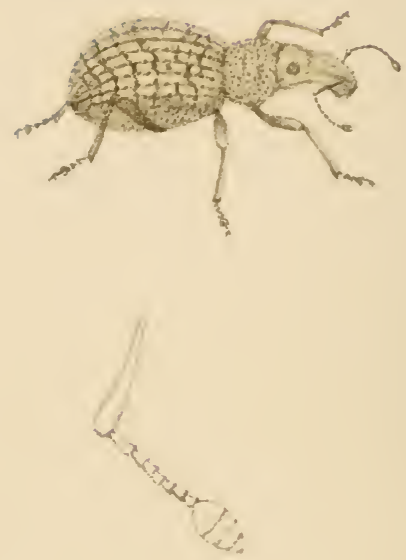

Dernenteded yearnulretios 


\section{JERMATODES. Schh.}

Corpus oblongo-ovatum.

Caput breve, oculis prominulis, rotmudatis.

Rostrum vis capile longius nee eo angustius, apice triangulariter emarẹinatum.

Antenna in canalicula curvala, profumba, ante oculum des. cendente, ad os incipienle inserta, rostro vix duplo longiores, validiuscula ; seapor vlavilo, fusiculi articulis breviler obconicis seu lurbiuatis, secumdo paulo elongato, ullimis subcrassioribus; clava ovala.

Thorax latitudine baseos brevior, supra paulum convexus, antrorsum angustior, lateribus obliquis, subrectis, apice truncalus, basi bi-sinualus.

Scutellum in plerisque distinctum, parum elevalum, in alis indistinclum

Pedes validi, libia apice unco brevi armala.

Elytraum oblongo-ovatum, thorace duplo latius, eoque sal(cu) triplo longius.

Elyera medio convexa.

fï $\mathrm{r}$ ex länglid)=ciförmig.

fiof f fur;, mit vorragenden, gerundeten 9

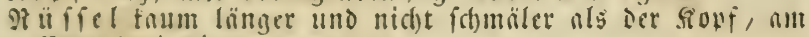
Enoe Dreiefin ausgernmoit.

F ib $l$ e $r$ in cinct getrummen, tiefen, vor oem stuge bernb=

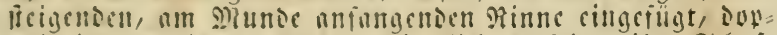
felt langer nls Der Riuliel, jiemlich traftig; ifr Echnot

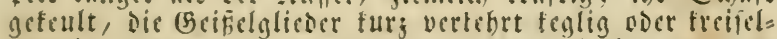
formig, ins jucite cin wenig verlüngett, Die leşten etmas Ditter; Fenle ciruns.

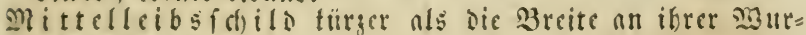
jel, oben eit menig gemolbt, mad) vorn fdmaller, fibicf, jemlich geroblinio, an Dorberente nbgefubt, an Der ais urel jucibuchtiy

E(f) ildo cn bei Den meilien beutlid), cin menig erbuben, bei nusern undentlich.

Be in e tröftio, Dic Echionen nm Ende mit cincm furjen Sonden bemafinct.

Sinterförver länglich ciformig, mefr als Donpelt fo lang als Der mlittelleibsichild, und incnigltens breifacl) länger nls Dieler.

folugelded"en in der mitte gemölbt.

\section{I)ERMATOIES GRANLLATUS.}

Schöul. lieu. et Sp. Curc. T. I. p. 614. T. V. p. 896.)

Secundum specimen a Cl. Germar nobis transmissum.

Patria: Java. 


\section{PLATYCOPES Dalm.}

Corpuns coactum, rotundato-ovatum.

Caput transversum, oculis prominulis.

Rostrum capite vix longius, eique ad basin contiguum, antrorsum nounihil angustalum, supra sulco longitudiuali impressum, apice triangulariter emarginatum, basi per rimam transversan angulatam a capite distinctum.

Intennae in scrobe profunda, versus oculum direcla inserta, rostro fere triplo longiores, scapo dimidiam antenna fere longitudineur constituente, dilatato, complanato, basi attenuato, tlagello satis gracili, articulis duobus hasalibus elongatis, reliquis breviter obconicis; clava oblonga, ovali, acuminala.

Thorax Iranversus, duplo latior quam longior.

Scutellum nullum.

Pedes breviusculi.

Elytrceum amplum, thorace plus triplo longius.

Elytra lata, convesa, postice valde declivia, et nonnihil subtus flexa, inter se connata, in plerisque speciebus pone basil intira humerum tuberculo extenso instructa.

Sörper gedrungen, runblich eiförmig.

of opf queer, mit fiemlich vorragenden $\mathfrak{A} u g e n$.

: $u$ fiel taum länger als Der fiopf, uno an Der Murgel in ibn übergebend, nad) vorn etmas verfontilert, oben mit ciner Enngsfurcbe, am Ende oreiectig nusigerandet, an Der subrgel Durch eine inintlige Duecrime boun sopt abge= grents.

Fubler in einer tiefen gegen Das \$nge geridsteten Grube cingefeßt, beinnbe oreimal länger nls ber stullel, Eechnft beinabe die balbe \&ünge Des Jublers bildend, ermeitert,

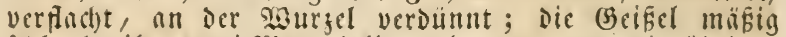
fiblant, ifre guei Murgelglieder langgezogen, Die übrigen (blicoer tur; vertefrtteglig; fieule laimglid), ciformig, zu= gefuitit.

Mittelleibsf fild queer, boppelt breiter als lang.

$\Xi$ (b) il

zeine jicmlich turg.

Sintertörper mebr als boppelt fo lang als oct mittel leibsfoild.

Flugeldeder breit, gemölbt, binten febr abfoüfíg und etmas untermäts gebojen, unter lich verwachfen, bei ien meilien ?rten Habe an Der 3 urgel muterbalb Der Gobulter mit einem ausgeliredten . Doderverfeben.

\section{PLATYCOPES SQUALIDLS.}

(Schönh. Gen. et Sp. Curc. T. V. p. 901.)

Secundum specimen a Cl. Germar nobis Iransmissum.

Patria : Africa australis. 
II. 39.
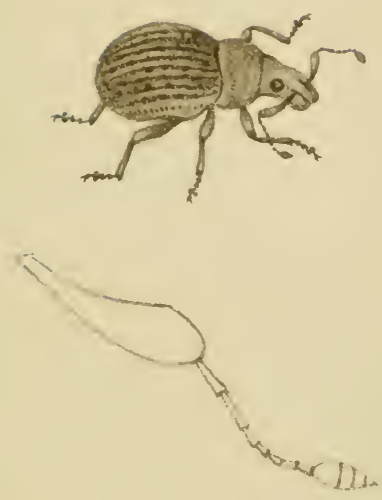

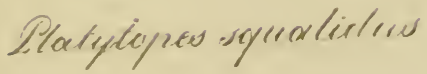





$$
x^{2}+x^{2}=4
$$


II. 40.
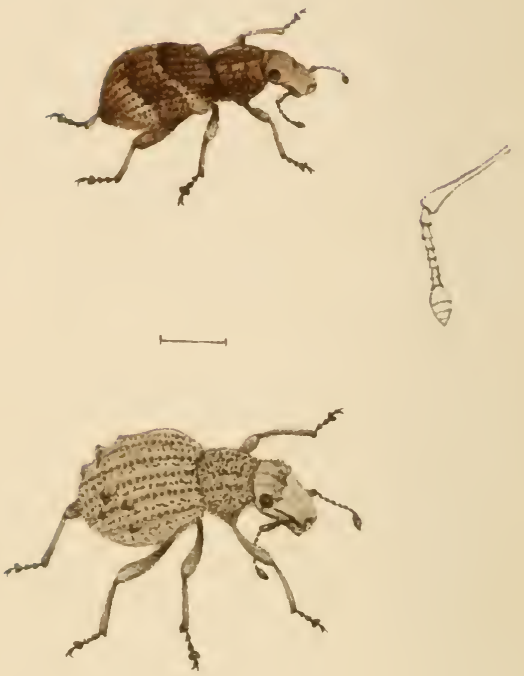

Blcsyous Clsellews \& inacyoulis 


\section{BLOSYRUS Schh.}

Corpus breve seu breviusculum.

Caput depressum, transversum, oculis prominentibus, rotundatis.

Rostrum xque latum et longum ac caput, sub-tetragonum, depressum, apice acute et profunde emarginatum, rima transversa a capite distinctum.

Antennue caput simul cum rostro longitudine vix superantes, scrobi profunda in canaliculo infraoculari continuala inserta, crassiuscula; scapo tertiam totius antenua partem vix aquanie; clavato, flagello articulis coarctatis, breviter sub-obconicis seu sub-rolundatis, primo reliquis majore; clava ovata, acuminata.

Thorax capite paulo latior, aut sub-cylindricus, aut lateribus modice rotundatus.

Scutellum aut parrum, aut nullum.

Pedes mediocres.

Elytraetum aut sub-ovatum aut sub-globosum.

Elytra convexa, postice valde declivia, in plerisque ad humerum retusa, in angulum producta.

Röper furz oder jiculid furg.

fopf fladgeorudt, queer, mit vorragenden, gerundeten I 4 g en.

$\Re$ ü ifel fo breit und lang als Der fopf, beinabe vieredtig,

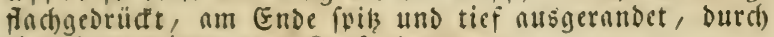
cine Suecrinne vom fopf nbgegrengt.

$\mathfrak{F}$ übler Den fopf mit Dem Rufilel an sin̈ge faum ïbertref= fend, einer tiefen in eine unter Dem stuge meg verlnufen= Den Rinne fid) nusłichenden (srube cingefügt, biatlich); Der Ed) Eit Delt Drittheil Des Fublers betrngend, geteult,

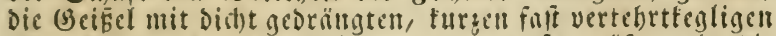
oder falf rumblicten (slicdern, Das erife gröfer als die übrigen; fieule eirund, fugefpizt.

Mittelleibs foild wenig breiter als Der Ropf, entweder falt maljig ober an Den Eeiten mäphig getundet.

$\sigma$ d) ild d) ent entmeder tleint ober teills.

3 cine mittelgrón.

So interförber entmeder falt eirumb oder foit fuglig.

Flügeldeden gewölbt, binten febr abfdlürlig, bei ben meifen an ber Edulter nbgefrubt, in cine Ede vorgezogent.

\section{BLOSYRUS ASELLLS.}

(Schönh. Gen. et Sp. Curc. T. I. p.552. et T. V. p. 909.) Secundum specimen a Cl. Schönherr ipso nobis dono datum.

Patria: Bengalia et Java.

\section{BLOSYRLS INAQUALIS.}

(Schönh. Libr. cit. T. VIII. Pars 2da pag. 402.)

Secundum specimen a Cl. Germar nobis Iransmissum.

Patria: Pondichery Indiae orientalis. 




\section{II. y1}
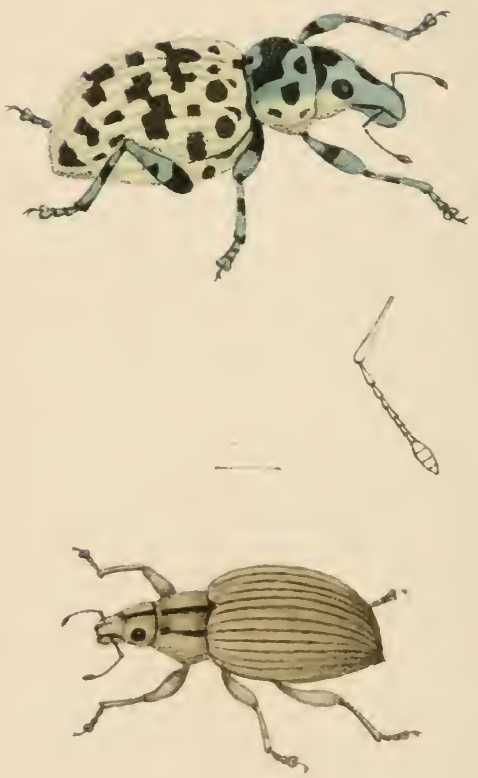

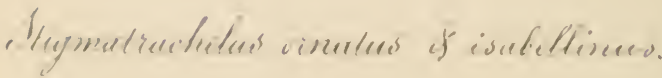




\section{STIGIATRACHELIS Schh.}

Corpus oblongo-ovatum.

Caput latiusculum, canalicula frontali impressum: oculis oblongis.

Rostrum capite vis longius, rima tenui ab eo distincta.

Antennae in canalicula angusta ante oculum deflexa insertae. vix ultra medium thoracis pertingentes, sub-tenues: flagelli articulis primo crassiori et secundo obconicis, reliquis brevioribus, sub-turbinatis: rlava ovali, acuminata.

Thorax fere aque longus ac latus, antice angustior postice basi bi-simuatus.

Pedes satis robusti, antici nonnibil elongati.

Elytraeum sub-ovatum, thorace triplo longius et duplo latius. Elytra convexa, apice declivia el compressa.

forper lanilich eiruns.

Ropf zremlich breit, mit enner Etirnrinne; $\mathfrak{A}$ ug en länglid). Rüffel faum linger als ber fiovf, ourch eine feine Ribe von ifm abgegrenjt.

is übler in einer fomalen vor Dem :age Gernbgeridfteten Rinne eingerügt, faum Den balben Mitteilcibsichild über: ragend, jiemlich dünn; das didtere erife und bas zmeite (s)lied Der Beifel verfebrtfeglig, bie übrigen fürzer, falt freifel= förmig; Reule ciformig, gugefvitzt.

Besne jiemlict) fröftig, bie vorberfen etmas verlängert.

Dedentheil inft cirund, oretmal linger und dopvelt brei= ter als der Mittelleibofd)ild.

Flügeldedfen gemolbt, am Ende abidurifig uno zuram: mengebrüdt.

\section{STIGMATRACHEILS ORNATLS}

Sehömh. Gen. et sp. Cure: T. VI. p. 130.)

Palria: Madagascar.

\section{STIGMATRATHELUS ISABELLINUS.}

schönh. Gen. el Sp. Curc. T. VI. 1, 13!.)

Patria: Madagascar. 


11. 42
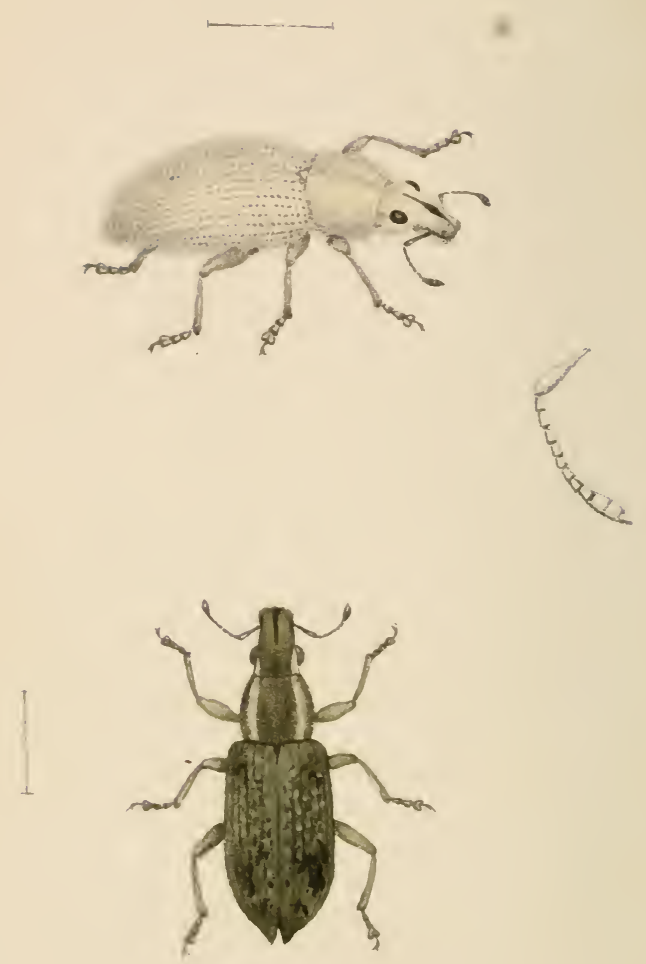

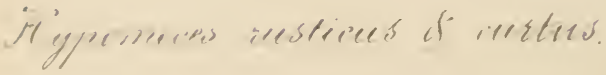




\section{H) POMECES SI'Hh.}

Corpus elongatım

C'aput transversum; uculis sub-globusis.

Rostrum capile vis longius, supra planum, canaliculatum.

Antennue canalicula areuala, infra oculum desinenti, insertae, validiuscula, haud ultra lloracis mediun pertingeutes; scapo vix tertiam antenna tolius partem ronslituente, funiculi arliculis primo ef secuuto longiusculis, sub-obronicis, reliquis lurbinatis, ultimo paulo crassiori; clava satis angusta, elougala, sub-ovala, acuminati

Thorax sub-conicus, basi bisinualus.

Scutellum sub triangulare, apice rotundatum.

Pedes satis robusti, antici nomnihil longiores, omnium tarso sublus spongioso.

Elycrueum lhorace triplo longius, oblongo-subovatum.

Elytra apice sub-acuminata.

forper lnnigejogen.

Rovi un die Dueere: mit falt fugligen ? แ gen.

Biiffel faum länger als Ber foof, oben pinch, mut since Rinne Durchjogen.

f5 it ber in einer gebogenen, unter bem Stuge nufförenden Rinne cingefïgt, fiemlich tröftig, nicht über Den balben Mittelleibsictild megreichend; Echnit faum Den oritten Theil der gangen forblerlänne bildend; erifes und zweites

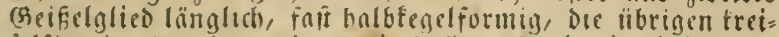
felformig, ons lebte ein wenig buter; fellle jiomlid) enge, verlängers, fiemlich cirunt, zugéptşt.

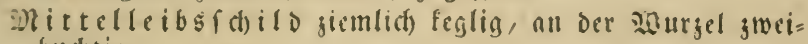
buct)tig

E(t)ild (b)

$B$ i ine giemlisf fräftia, dic vorberten ctwas länger, nn

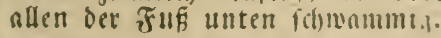

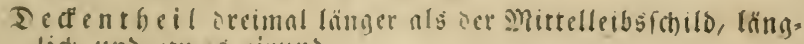
lich und et)

irliggeldeden am Ende ein menig jugerpizt.

\section{HYPOMECES RLSTICLS.}

(Schöuh. Gen. et Sip. Cure. T. VI. p. 20T.)

Palria: Java, India orientalis et Timor.

\section{HYPOMECES CURTLS.}

(Schönh. Gen. el Sp. Cure. T, VI. p. 209.)

Palria: Timor. 

$p^{\prime+1}$ in a f whing

$-$ 
11. 113

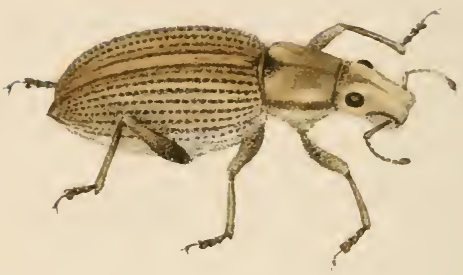

$P^{x}$

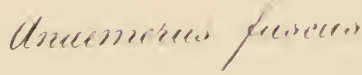




\section{Fam. BRACHYDERIDES. II. 13.}

\section{ANFMERUS Schh.}

Corpus elongatum.

Caput Iransersum, utringue supra oculum productum el elevalum; oculis valde convexis.

Rostrum capite longins, eopue nomnihil angustius, supra deplanalum.

Intennae canali flexusa ab apice al medium rostri infra oculos exeunti inserla, rostro simul cum capite paulo longiores, validiuscular; scapo flagellum longitudine requante, luniculi articulis brevibus lurbinatis, primo reliquis nonmihil longiore, sub-obconico: ultimo clava adpresso; clava ovali, ac'untinata

Thorax fongior quam latior, antrorsum nonniliil anguslatus. Scucellum sub-elevalum.

Pedes longiusculi, lihia apice intus unco brevi armata, tarso anguslato, setis longiusculis instructo.

Elytraeum thorace triplo circiter longius.

Elycraapice attenuata, singulatim in mucronem brevem desinentia

fiorper langgefoijen.

Sopi in bie suere nusgedehnt, betoerfetts iiber dem Aluge nusgegojen uno rebolyt, mit felir getvolbten $\mathfrak{A} u \mathfrak{g}$ en.

Rüffel lïnger und etmas fchmäler als ber sopf, oben nb= getinctit.

Fîbler in einer gemundinen von det Spize bis fur Mitte bes Rtiffels lic) eriftedenden unter bem Auge ausiaufenden Rinne eingefïgt, ein wenig lr̈nger als Fopf fammt Rüf= iel, ficmlich trüftig; ibr Schaft ber Grifel nn \&änge gleich), Beifelglieder fury, freifelformig, das erfte etmis länger als bie übrigen, faft verfebrtfeglig, bas lebte an die ficule angeorüctt; Feule ciformig, fugefpibt.

Mittelleibsfallo länger als breit, mad) vorn etmas verengt

G(t) ild then etmas erboben.

3 eine länglich, die Gobiene an oer Epize inmärts mit

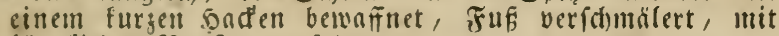
lïnglicben 3 orfien verfeben.

Ded entheil ungefübr oreimal länger als ber Mittelleibs: (d)illo.

F्ञ Enitge endigeno.

\section{AN HELIRUS FISC'TS.}

sihönh. Fren. el sp. Cure. T. il. Th ol T. VI. 11. 211.)

l'alria: Senegallia. 


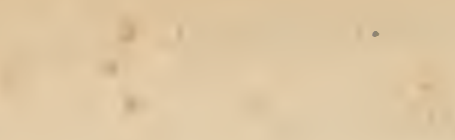

i.

2

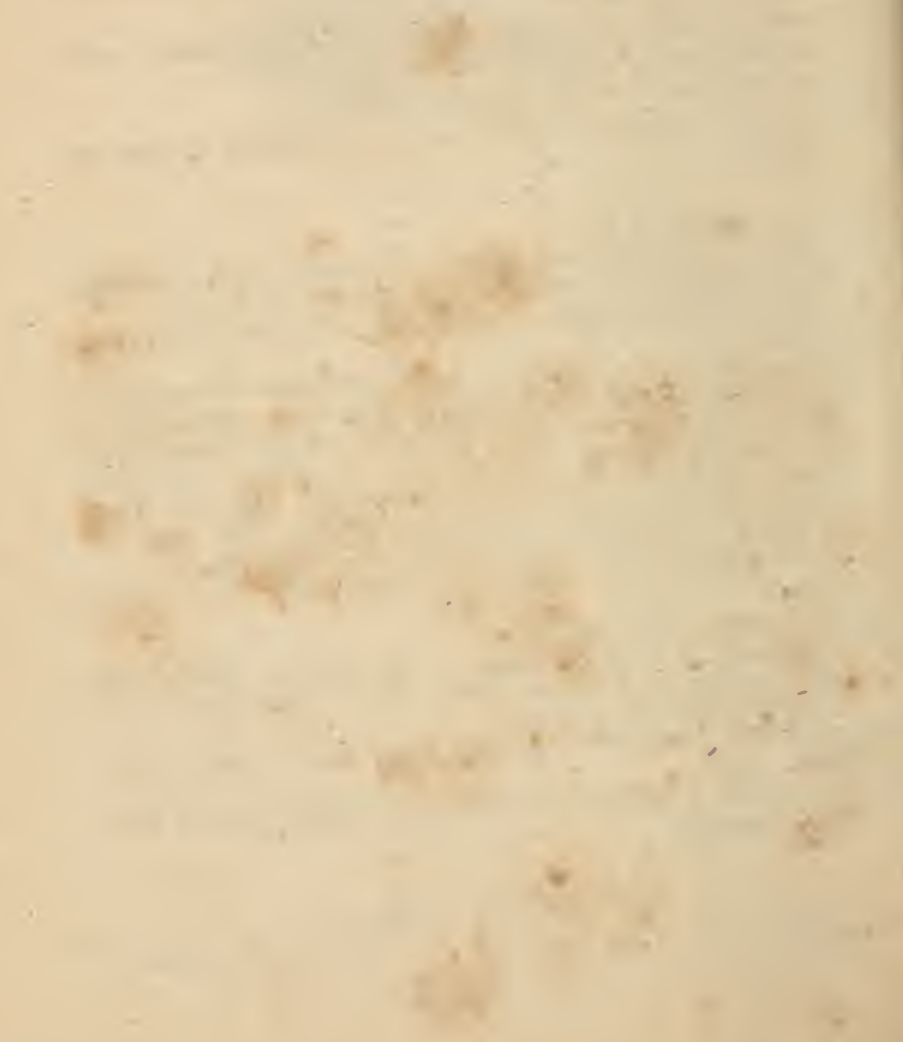


11. 44

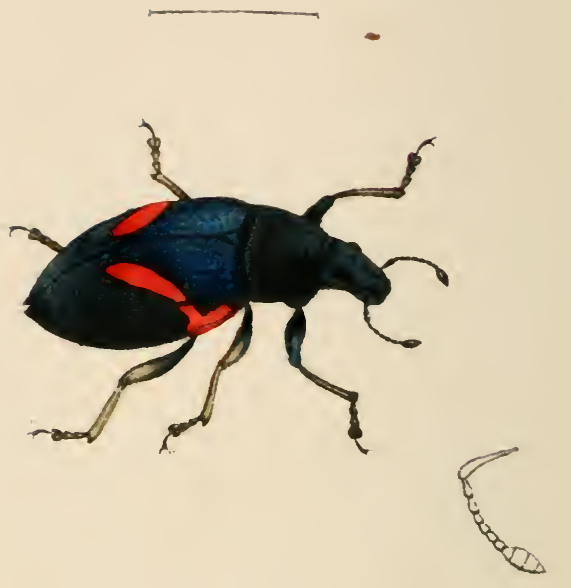

Plyclustis tquestsios. 


\section{POI,ICLAES Schin.}

1 arpess sub-oblongurn.

faput latiusculum, orvelis at magnis, sub-ovatis, parum proininulis

Rostrum rapite nomnihil longius ef augustius, supra planiusculum, canalicula longuludinali impressum.

Antenne in canalicula angusta ante oculum deflexa insertae, ad Horacis medium uon perlingentes, validiusculae: llagelli articulis sub-turbinatis, secundo quam primo dimidio longiore, obconico, septimo praecedentibus crassiori; ciana oblonga, acuminala.

Thorax suld-triangularis, aplee capile vis latior, fruncalus. basi lale ol miums profunde bi-sinualus et ulrimque aculaugulus.

sculellum triangulare.

Pedes salis validi, libata anticorum apicem verws aremata. posteriorum ante apicem exlus angulalo-dentala.

Elytraetm thorace triplo lougius, oblongu-ovatum.

Elytra apice singulatim breviter mucronata

fiorper giemlid) linglid).

fi on fetmas breit, mit jiemlich grofect, fait eirmmin, menis vorragenien $\mathbb{2} u_{\text {if }}$ en.

R if ffel etmas länger uno ichmäler als Der sopf, oben flill lich find), mit einer Eängorimni.

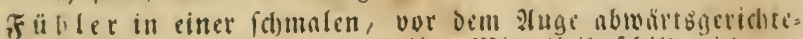

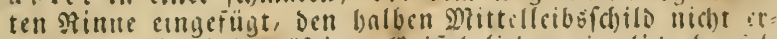

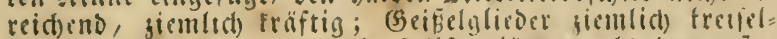
förmig, Dns smeite um oie Solffe länger ols bas itfie, verfebrtfeglisy bas licbente dider als bie vorberaibenden; fieule länglid), §ugcforizt.

Dittelletbofthilo etmas in Dreiedgeralt, am 2ordir.

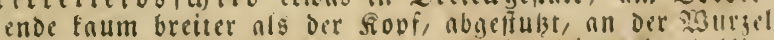
weit und wenig tief fmibuchtig und beiderfeits wibintution.

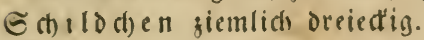

Beine giemlich fraftig, Ethiene ier vorderlin gegin ins Ende bin gebogen die der bintern bor dem Ende ausimats edtig gegatint.

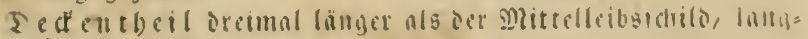
lict)=eiruno.

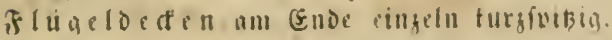

POLICLALIS EQUESTRIS.

Schönh. Virn el sp. I.urc. 1. 11 p. 217

Serundum sperimen ab III. Schönherr ipso molos domo dalum.

$$
\text { Palria: raffria }
$$



II. 45.
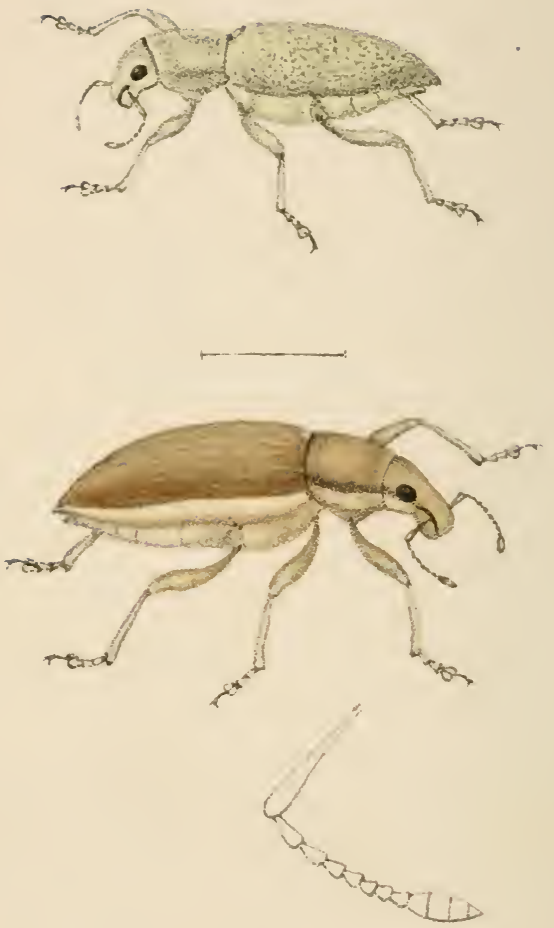

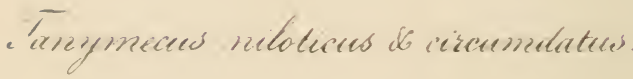




\section{TANYMECUS Grmr.}

Corpus oblougum.

Caput supra satis convexum; oculis sub-rotundatis.

Rostrum longitudine capitis, eoque nonnibil augustius.

Antennae canali curvatæ, brevi, prope oculum desinenti insertæ, thoracem longitudine parum superantes, aut validiusculæ aut subtenues; scapo plus tertia parte totius antennæ longiore, funiculi articulis primo et secundo subobconieis, reliquis brevioribus, ultimo exacte clavæ minus incrassatæ, elongatx, acuminatx adaptato.

Thorax longior quam latior, antice posticeque trancatus.

Scutellum triangulare.

Pedes inter se rquales, mediocres, anteriorum tibia apice intus unco parvo munita, tarsis ungue elongato.

Elytraeum thorace Iriplo longius, antice duplo eo latius.

Elytra apice acuminata.

Siorper lituglicf).

fi opf oben giemlich gemolbt; mit beinabe gerundeten $\mathfrak{A}$ ugen. $\Re$ üffel von der \&änge des fiopfes, und etwas fomäler als Diefer

F Den Rinne cingefügt, ben Mittelleibsfabild an \&änge wes nig übertreffend, entmeder ziemlich frätig oder etmas dünne; E(t)aft länger als der Drittel bes Füblers, erites und zmeis tes Eeifelglied falt verfebrtfeglig, Die ïbrigen fürzer, Das lebte genau ber menig verbiaten, verlängerten, zugefpis: ten sieule angefügt.

Mittelleibsfchilo länger als breit, vorn uno binten ab. geftukt.

Schild chen oreiedtig.

Beine unter lich gleidh, mittelgrofi, bie Gefiene ber vor= bern am Ende innwärts mit einem furgen Saden ver= feben; Fübe mit verlängertem Glauengliede.

Ded゙entheil oreimal länger, vorn boppelt breiter als ber Mittelleibsichild.

Fl ügelded゙en am Ende zugefpißzt.

\section{TANYMECUS NILOTICUS.}

Schönh. Gen. et Sp. Curc. T. IJ. p. 77 et T. VI. p. 226.) Secundum specimen ab III. Schönberr ipso nobis dono datum.

Palria : Aegyptus.

TANYMECLS CIRCUMDATUS.

ISrbönh. Grell. et Sp. Curr. T. VI. p. 234.

Patria: Aegyptus, Senegallia, Zengalia. 



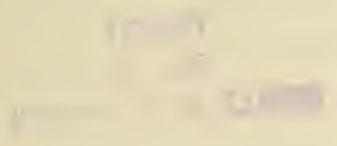




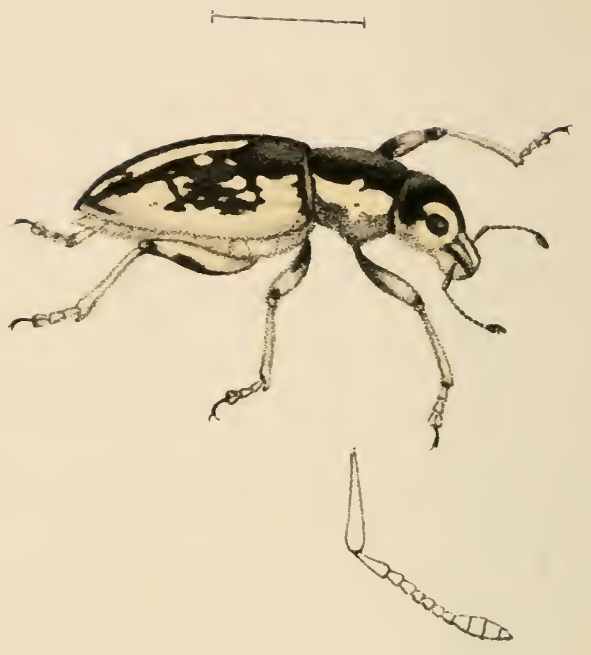

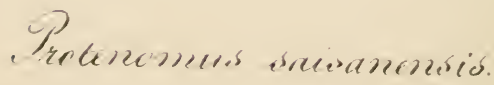




\section{PROTENOMUS Schh.}

Corpus oblougo-ovatum.

Coput vertice et subtus convexum; oculis sub-depressis.

Rostrum capite haud longius, supra concavum.

Anfennae in scrobe longiuscula, ante oculum latius desinente inserta, capite simul cum rostro paulo longiores, validiuscula; funiculi articulo primo sub-clongato, sub-obconico, secundo minore, reliquis ad huc lorevioribus, sub-turbinatis, septimo crassiore, satis arcte juncto cum clava sub-tenui, oblongo-ovata.

Thorax oblongus, sub-cylindricus, postice subtus compressus. Scutellum triangulare.

Pedes satis Iongi, validiusculi, tibia apice intus unco brevi munita, tarso articulis subtus canalicula media uuda.

Elytrueum thorare duplo et nltra longius, ovato-acuminatum.

Elytra humeris antrorsum prominulis, apice singulatim subacuminata.

Siorper länglict)=eirunt).

Rovf nui Dem Scheitel uno unten gewolbt, mit faft nieder: georüctten $\mathscr{A}$ ugen.

$\Re$ üffel nicht länger als ber fiovf, oben Der eänge nach ge= bohlt.

fo b h ler in einer etwas länglichen, vor oem Aluge breiter autborenden (srube eingefügt, ein wenig länger als Ropf fommt Ruliel, fiemlich frätig; erifes (seif́clglied etwas verlängert, faif verfefrtfeglig, bas zweite fleiner, bie übri= gen noch titrger, faft freifelförmig, bas fiebente bider, fiemlich feit verbunben mit ber etras f(f)lanten, länglich). eirunden Reule.

Mittelleibsf d) ilo länglich, faft malzig, binten unten g $^{4}=$ fammenisedrüdt.

Schilo (h) en oreicetig.

Beine fiemlich lanty, etmas fraftig, die Echience an ber Epize innwärts mit einem furzen Sad"en verfeben, der Fus an ben (sliedern unten mit einer mittlern naditen Rinne.

Dedentheil mefr als boupelt fo lana als ber Mittelleibs: ichilo, etruno uno jugeipizt.

iflitgeloedten mit vorn etmas vorrnaenden Schultern, nm Ende einzeln etmas zugefvibt.

\section{PROTENOMIS SAISANENSIS.}

Schönh. Gen. ol Sp. Curr. T. 1I. p. 94 et T. VI. p. 252.

Patria: Mongolin, ad lacum Nor-Saisnn, Sibirin nrcidentalis. 



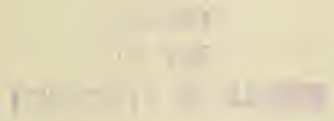


11. 47
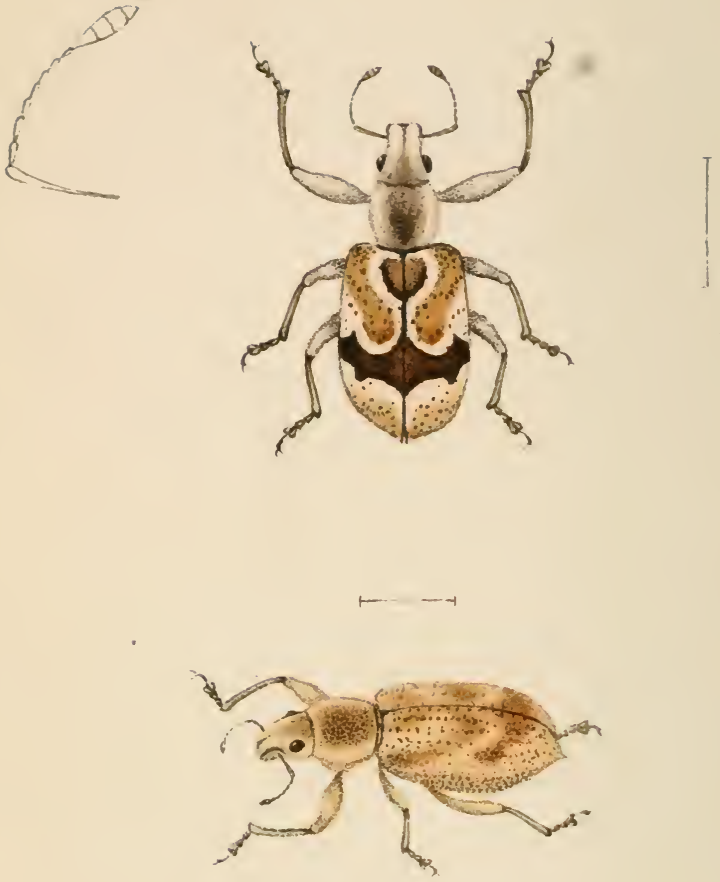

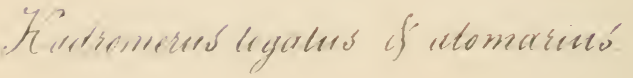




\section{H.IDROMERLS Schh.}

Corpus oblongum

Caput vertice convexum, oculis sub-rotundatis.

liostrum capite haud longius, supra deplanatuu, canalicula longritudinali impressum, apice angulato-emarginatum.

tncennae in camalicula angusta ante oculum curvatim deflexa inserta, ultra thoracis medium vix pertingentes, satis tenues; scapo lertiam totius antennx partem constituente; flagelli articulis obcouicis, primo crassiore et secundo reliquis nonnihil longioribus; clava majuscula, oblongo-ovali.

Thorax autice posticeque truncatus, lateribus rotundatus, ante basin et ante apicem constrictus.

Scutellum triangulare.

Pedes antici reliquis multo majores, femore longo, valde illcrassato, tibia et tarso elongatis, illa subarcuata, intus denticulata; pedes posteriores mediocres, tibia recta, mutica.

Elyeraeum thorace triplo longius, duplo latius, sub-obovatum.

Elytra pone medium convexa, postice declivia adapicem compressa, apice ipso acuminata.

sirper länglich.

SODf nuf Dem Gebitel gewolbt, mit fait gerundeten $\mathscr{A}$ u gen. Ritffel nidft länger nls ber fopf, oben nbgetheft, mit einer lingliden Rinne, an Enbe minflig ausgernndet.

Fi riditeten Rinne eingefügt, faum über ben balben Mittel. leibsfdild wegreidhend, fiemlich dïnn; ifr Sefonft den Drit. tel Der ganzen Füblerlänge betragent; Beifelglieber ver = febrtfeglig, Das bidere erfte uns das gmeite etwas linger als sie übrigen; ficule giemlid) grofi, länglidseiförmig.

Ditecleibsfeit vorn uno binten abgefukt, an dent Eeiten gerundet, bor Dem 2 order, und sinterende einge= f(hnürt.

Sofilo d) en oreiedig.

23 oroctite 3 eine viel grofier als die übrigen; ibr Saenfel lang, febr verdidt, Gabiene und Fruf verlängert, jene etwas gebogen, innmärs gezäbnelt, bintere Bcine mittelgrobi, mit gerabir, metrlofer Ediente.

Dedett beil oreimal länger, soppelt brecter als ber Mit. telleibsifbilo, faft verfebrteiruno.

f5 lügeldedfen binter ber Mitte gemölbt, binten abfoüriiu am Enbe fufammengedruid, ons Ende felbit fugefoitst.

\section{HADROMERLS TOGATUS.}

(Schönh. Gen. ct Sp. Curc. T. VI. p. 290.)

Secundum specimen a $\mathrm{Cl}$. Germar dono datum.

Patria : Brásilia.

\section{HADROMERLS ATOMARIUS.}

(Schönb. Gen. et Sp. Curc. T. VI. p. 292.

Patria: Brasilia meridionalis. 

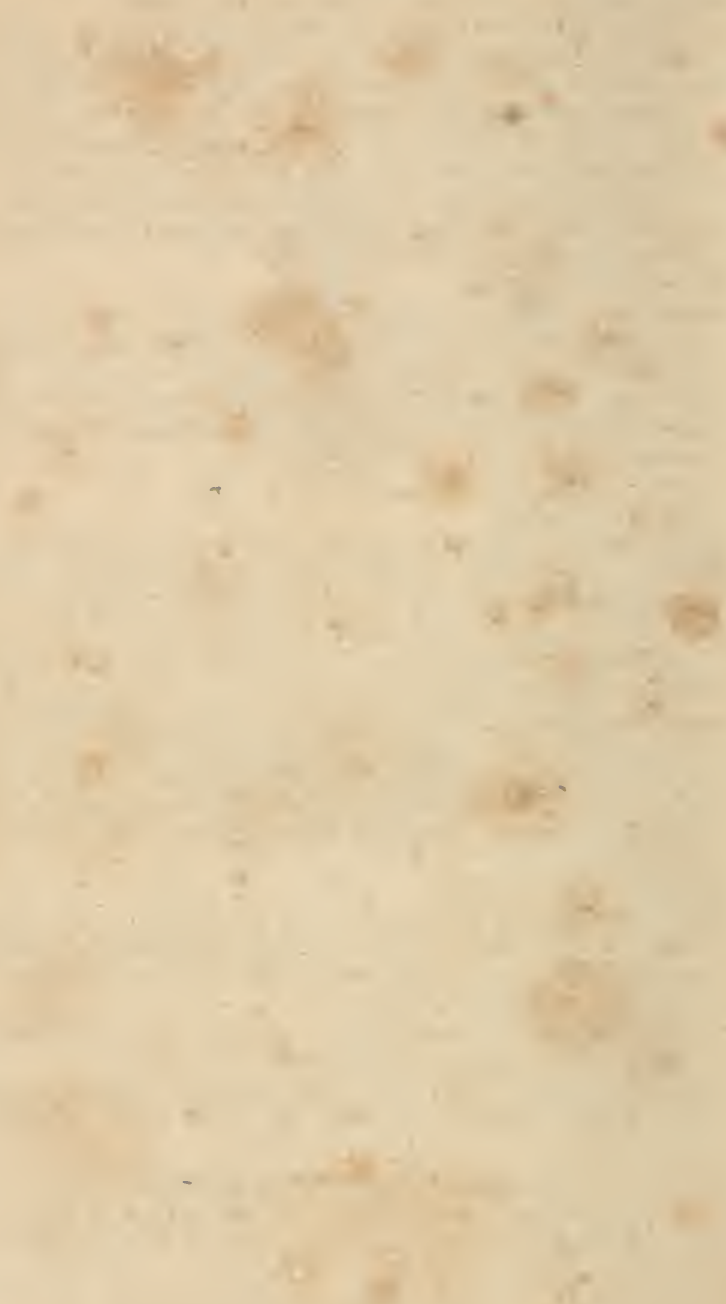

$y=$
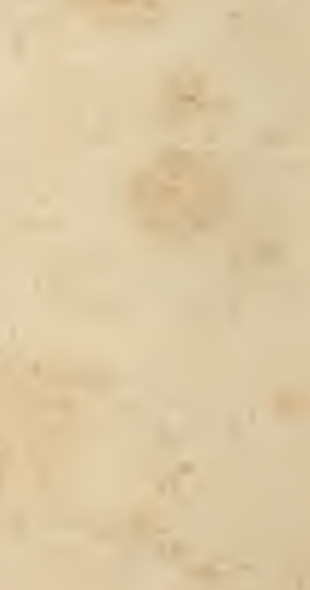
I! 48.

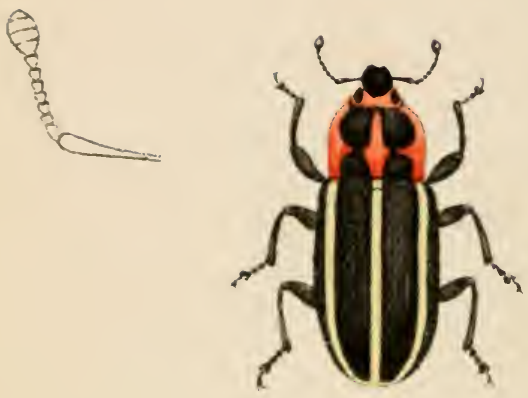

indeayorgus spesiryalis. 


\section{ELDLIROGLS Schh.}

forpus ublongum, sub-elliplicum.

Caput brevissimum. Iransversum; oculis depressis.

Rostrum eapite nomnihil longius, eoque vis angustius, haud longius quam latius, supra sulco longitudinali impressum.

Antennac in canalicula ante oculum deflexa inserta, ad thoracis medium vis pertingentes, validiuseula ; flagelli articulis primo el secundo sub-obconicis, reliquis sub-rotundalis, seusiu crassioribus: clava ovata.

Thorux sub-quadratus, basi angustiore, lateribus anterius rotundatus, apice utrinque in lobum acutum juxta oculos productum.

Scutellum breve, transversum.

Pedes mediocres, tarso latiusculo.

Elytraetem thorace vix Iriplo longius, et basi ejus parum lalius, sub-elongato-quadratum.

Elytra modice convesa, apice conjunctim rotundata.

fiorper linglid), faif elliptif(t).

fovi fibr furg, in ole Duere gitogen, mit niedergedrud" ten $\mathbb{2}$ u g $\mathrm{e} \|$.

Rifiel etmas länger als Der fiovf, uno taum fomäler als Dicfer, nicht länger als bect, oben mit einer \&angofurche.

Fill ler in einer bur bem 2uge nbmärts gerichteten Rinne cillgefügt, faum bis jur Dlitte des Mrittelleibsichildes rei=

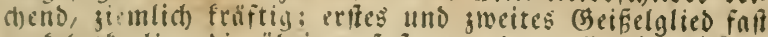
verfectrteglig, die tibrigen fatt gerundet, allmalig bider; fieule eruno.

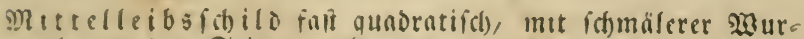
fel, an ben Geiten nact) vorn aerunbet, nm Borderende beiderfite in einen fviken Eappen neben den \&ugen aus. aegoien.

Shilothen furg, queer.

3 eitne mittelgrofi, mit giemlich breitem Fruffe.

De de ntbetl faum dreimal langer als ber Mittelleibsidbild und faum breiter als Defien 3 utrgel, paif lïnglich quabratifd).

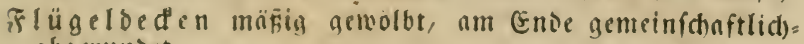
abijerundet.

\section{EUDIAGOGLS EPISCOPALIS.}

Schönh. Gen. el sip. Curc. T. VI. p. 310.)

Patria: Brasilia. 
$-7$

n

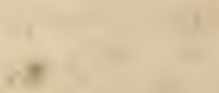

ne

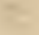

$-2+2+2+20$

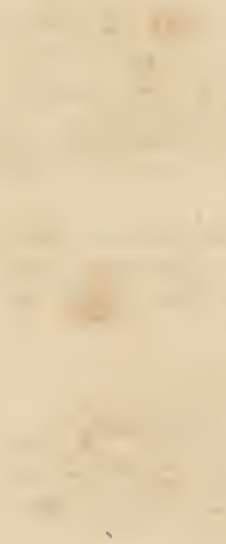

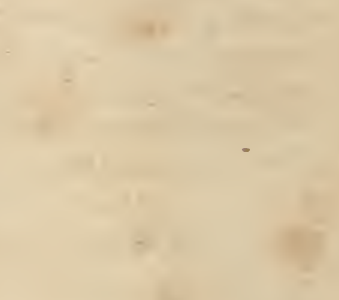

ar

$-1+2$

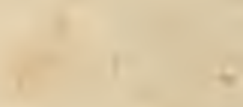




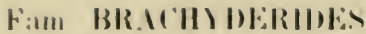

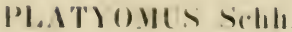

Corpus ublomgo-usallum.

Cupue rostro haud latıs, oculis prominemtibus, rotumdatis.

Rostrum capilis circiter lougiludiue, crassum, supral sulco longitudinali lato exravatum.

Antennae canalicula rurvata, oculum non allingenti insertas, rostri simnl et eapilis longitudinem duplicem in aliis superante, in aliis hand aquante, satis validar, seapo in plurimis apice valide incrassato, funiculi articulis sub-oheonicis, secundo quam primo longiore, meliquis sensim hreviorilous: clava brevi, ovata, acumiuata, i-artıculata

Thorax circiter equer latus ac longus, postice profunde lusimuatus.

Scutellum in alis oblongum, in aliis triangulare.

redes mediocres, antici nomilit elongati.

Eilytroum sub-ovatum.

Elytra basi rotundato-producta, humero in aliis in spinim pxtensa, in aliis obtuse angulata

Sorper lämgltib cirmul.

Rop f nitht breiter als Det niifiel, mut vorragendin, germn= Deten $\mathbb{2}$ u g $\mathrm{e} \|$.

Rüffel ungefebr von Der seange oes hovies, did oben mit linglicher, breiter fiurd)e nusgebolt

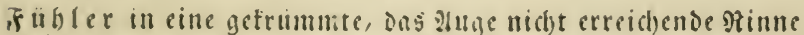
eingefügt, bei oen cinen melbe, bei ben andern meniger al:

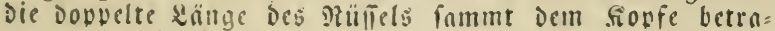
gend, ziemlict) friftig; Der Eenfor bei ben meilien am Ende

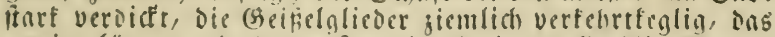
jweite länger nls ons erite, die ribrigen allmälig turger: bie fieule furg, cirund, fugefpilgt, viergliedig.

Mattelleibsfdild ungefebr fo breit als lang, hunten tief zmeibutitig

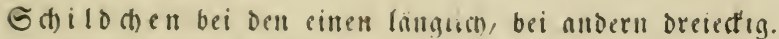

Beine mittelgrofi, de vorderifen etmas verlängert.

De d e nt beil jiemlidi cirund.

Fliigeideden an oer 3 urgel gerundet vorgezogen, die Echulter bei den einen in eillen Torn vornejouen, bei den nudern fiumpifertin. 




\section{49}
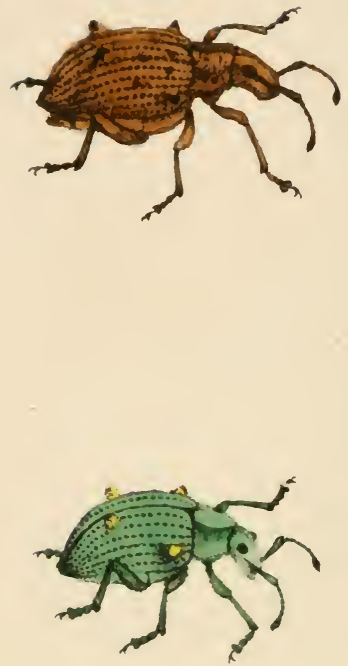

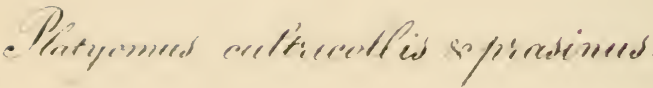



II. 50.

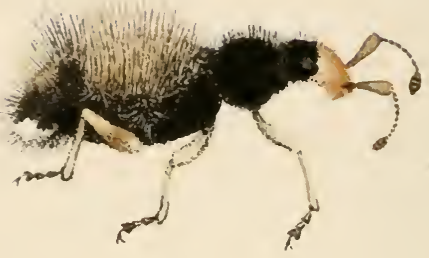

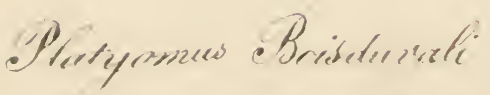



11. 51
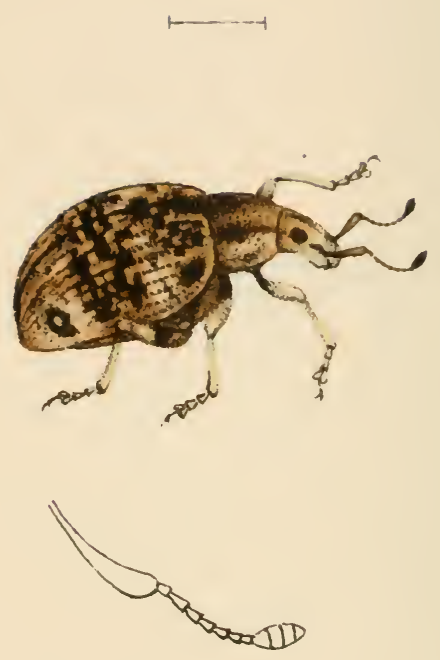

Pfreyomes picilopidus 


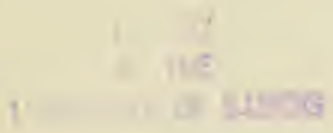




\section{I1. 52.}

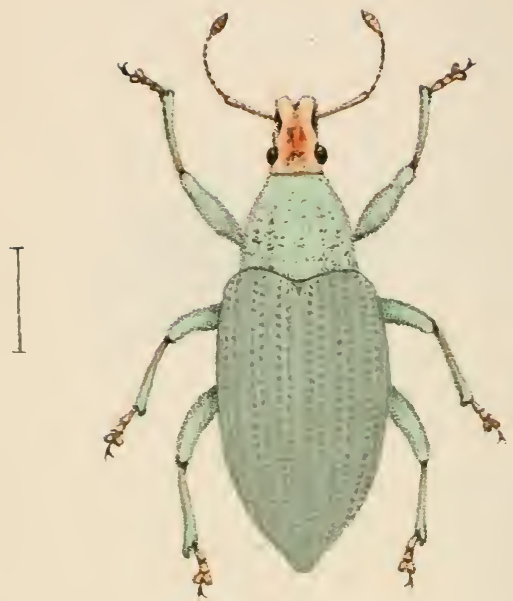

Platyomens areviceps. 
Fam. BR.ACHIIERIIES. II 49.50, 51, 52

PI. T'Yonts Sehh.

GRE.I. I.

Tibia omnes apice intus submuticar.

\section{(Frite Gd)anr.}

Eämmutliche Echiencu am Ende innell joî mebrlos.

MANIPLLLS 1.

Elytra buberculata, antice dorso deplanata, apice disergenlia humeris acuminato-extensis.

Erites Sูäur̆cin.

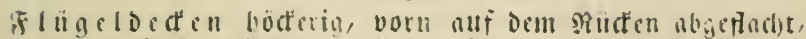

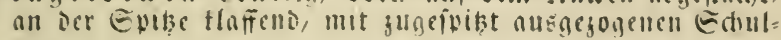
tern.

\section{PLATYOMLS CLLTRICOLIAS.}

(Achönh. Ger. el Sp. Cure. T. VI. p. 155.)

Patria: Brasilia.

\section{PLATYOMLS PRASINUS.}

(schönh. Gien. el Sp. Curc. T. I. p. 634 el T. VI. p. 158.

Patria : Brasilia.

MANIPULUS II.

Elytra aqualia, antice dorso deplanata, humeris obtuse augulatis

Bweites వäuflciu.

T⿱宀 înumpetigen Echultern.

\section{PLATYOMLS BOISIOUVALI.} (Schöıh. libr. cit. T. VI. 1. 163.

Patria: Brasilia interior.

\section{MANIPILLS III.}

Elytra ipqualia, fornicata.

Drittes தäurlein.

is liigeldedten eben, boch gemolbt.

\section{PLATYOMLS PERLEPIDUS.}

Schönh. libr. cit. T. 1. p. 636 et T. VI, p. 1 (is.

Patria: Brasilia.

\section{GREXII.}

Tibia anteriores apice intus unco valide instructal.

\section{3tweite Gdhanr.}

23 ordere Echienen innen an ber Enibe mit rinim han fill soatin verfeben.

\section{PLATYONLS ALRICEPS.}

(Schöuh. libr. cit. T. VI. p. 183.

Palria: Mississipi emerica burealis of Meviro. 




\section{53.}

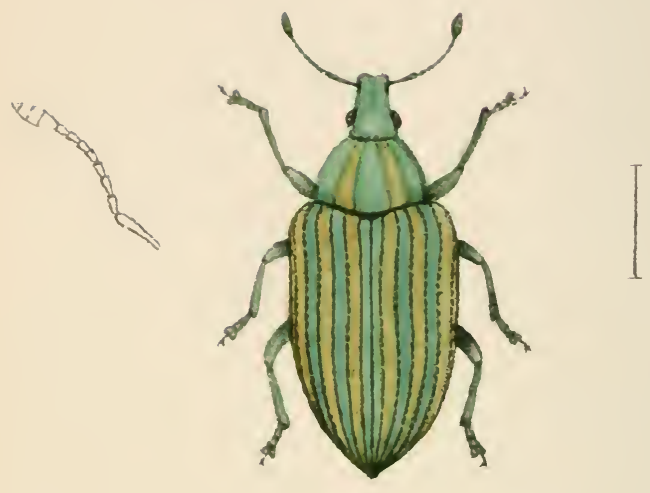

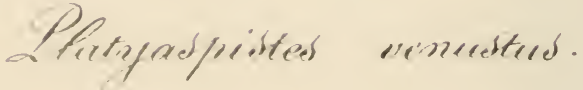




\section{PL.ITY ASPISTES schh.}

Cinrpus oblongo-ovalum.

C'apuc latius yuam longius, oculis rolumbatis.

Rostrum capile longius, lineare.

Antenno canalicula curvata, inlira orulum excurenti insertae, vix ad thoracis hasin pertingentes, validiusculae; scapo quartan solummodo antenna partem aquante, funiculi arliculis duobus basalibus obconic is, reliquis brevioribus, lurbinatis, clava ovali, dislincte -arliculata, acuminata.

Thorax tranversus, basi bisinuatus, anterius angustior.

sicutellum breve.

Pedes mediocres, femore mutico, libia recta,

Elyeraeum satis amplum, sub-ovatum.

Elyera basi rotundato-producta, humeris retusis, apice acuminata.

serper länglids cirund

fiopf linger nls breit, mit gerundeten at ugen.

Ruffel lïnger als ber fiopf, linenr.

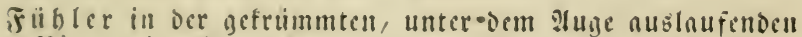

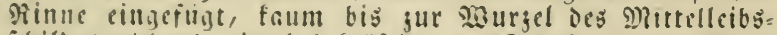

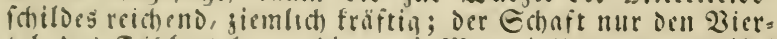

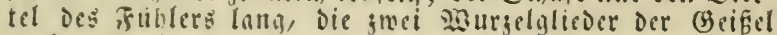
verfebrtfeglig, die übrigen türer, treifelformig; die fieule eiformig, beutlid) vierglledig, zugeipikt.

Mittelleibsfchild in bie Duecre nusgedebnt, an ber 23irgel gmeibudtig, vorn fombler.

Stbild deen furg.

3 eine mittelgrof́, mit mefrlofem Ed)enfel, gerader Edhiene. Ded entbeil ficmlich weit, etwas cirund.

Flïgelded"en an Der 2 Burgel gerundet vorgezogen, mit abgefukten Goultern, am Ende jugeipizt.

\section{PLATYASPISTES VENUSTLS.}

(Schönh. Gen, et Sp. Curc. T. VI. p. 398.)

Patria : Chili. 


II. 54.
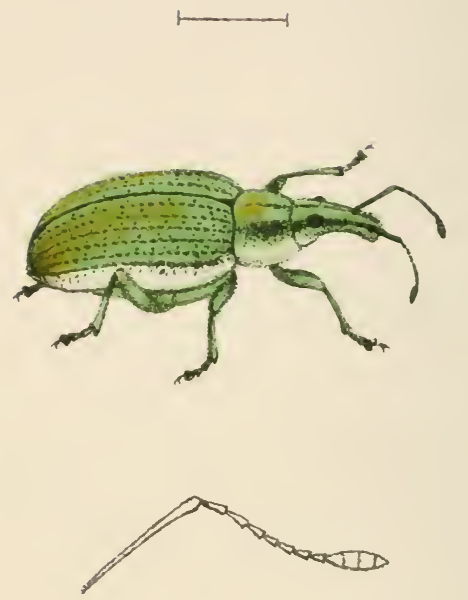

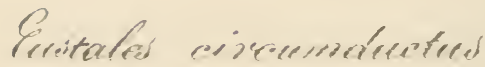




\section{ELS'TALS Schh}

Corpus oblongo-ovatum.

Capet rostro parun latius, oculis oblongis, prominulis.

Rostrum duplo longius quam latius, supra sub-plaumm, apice incrassato.

Antemnae canalicule curvata rostri inserta, capite simul cum rostro duplo longiores, funiculi articulis sub-obconicis, secundo ceteris nommbil longiore, clava elongata, distinctu 4-arlieulata.

Thorax postice lere xque latus at lotus longus, antrorsum angustatus, postice bisinuatus.

Pedes mediocres, anticorum tibia intus denticulis pradita, versus apicem arcuata.

Scutellum imuersum.

Elytraum oblongo-ovatum.

Elytra basi rotundato-producta, lumero angulata, dorso pone medium convexa.

Rörwer lïnglich eirund.

Ropf menig breiter als Der Rüliel, mit länglichen, etwas voritehenden $\mathfrak{A} u g e n$.

$\Re$ iiffel Doppelt länger als breit, oben etwas flach, mit ver= Didtem Endic.

$F$ ï $\mathfrak{b} l$ er in Die gebogene Rüffelrinne eingefügt, Doplelt län= ger als Der frovf fammt Dem Rülifel, Die (SeiËelglieder giemlich verfehrteglig, ins zmeite etmas lïnger als die übrigen; . feule lang gegogen, Deutlid) viergliedig.

Mittelleibs $\{$ d) ilo binten beinabe fo breit als feine gange sanmbe, mach virli verfamilert, binten ziveibudigtig.

Beine mittelgrofi, bie Eniene oex vorberfen innen mit bribnchen rerfeben, gegen das Ende gebolgen.

$\sigma(d) i l d d) e n$ eingefentt.

De de at beil langlich cirund.

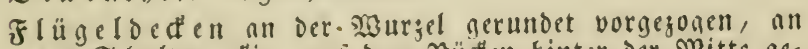
ber Echulter edtig, alti Dem Rüden binter Der Mitte ge= mölbt.

\section{ELSTALES CIRCUMDUC'TS.}

Schöuh. Gen. el Sp. Curc. T. VI. P. 376.

Pibia: Brasilia. 


11. 55.

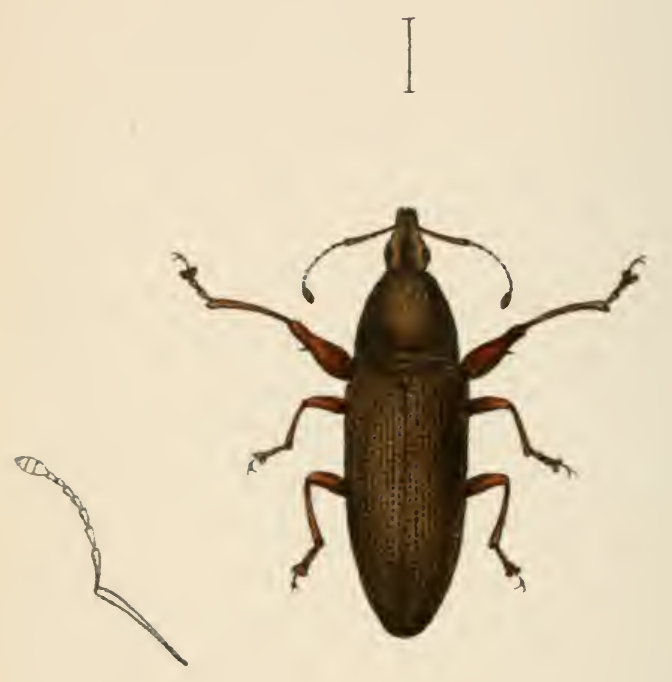

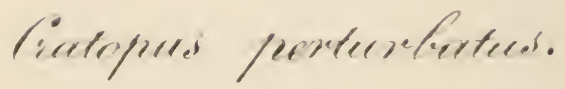




\section{CRATOPLS Dalm.}

Corpus elongatum.

Caput sub-conicum, octlis magnis, satis prominentibus.

kostrum capite haud longius, crassum, lineare.

Antennae canalicula sub oculum flexa inserta, rostro simul cum capite duplo saltem longiores, satis temes; funiculi articulis obconicis, basalibus duobus elongatis, reliquis sensim brevioribus; clava oblonga, acuminata, 4-articulata

Thorax supra convexus, basi apiceque truncatus, antrorsum angustatus.

Scutellum triangulare, apice rotundatum

Pedes antici elongati, femore valde robusto, incrassato, dente valido armato, tibia modice arcuata, intus crenulata: reliqui medioces, validiusculi.

Elytraeum elongatum, thoracis basi vix latius.

Elytra humeris antrorsum prominulis.

Sorper gefiredt

RO of fiemlich. teglig, mit grof̧it, fiemlich vorragenden I 4 ge $n$.

Rüffel niddt lïnger nls Der fiopf, bidf, linear.

Fubler in eine unter ons Huge gebogene stimne eingeftigt, twenightens Doppelt länger nls Der Rüll fammt bem fovf, ziemlich dünn; Die Beif̈elglieder giemlich feglig, die zmei gurgelglieder verlängert; Die ibrigen allmalig türger; fieule länglich, jugépizt, viergliebig.

Mittelleibsf(t)ilo oben gemölbt, an 23urgel uno 23or= derende abgef̂tut, mach) vorn verfdumilert.

$\sigma$ d)

23ordertie 23 in verlängert, mit febr traftigem uno mit

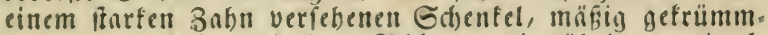
ter, innen flein acferbter Gchienc: Die übrigen mittel. i) rob, giemlich träftig.

Deafentheil lang gejouen, faum breiter als die Murgel Des Mattelleibsthiloes.

Flägeloedfen mit mach vorn etmas vorforingenden Goul. tern.

\section{CRATOPLS PERTURBATLS.}

łschönh. Gen. ef Sp. Cure. T. VI. p. ho9.

Secundum exemplar a liel. Schönherr ipso uomiualum.

Palria: I'romontorium honae spei. 


II. 56.

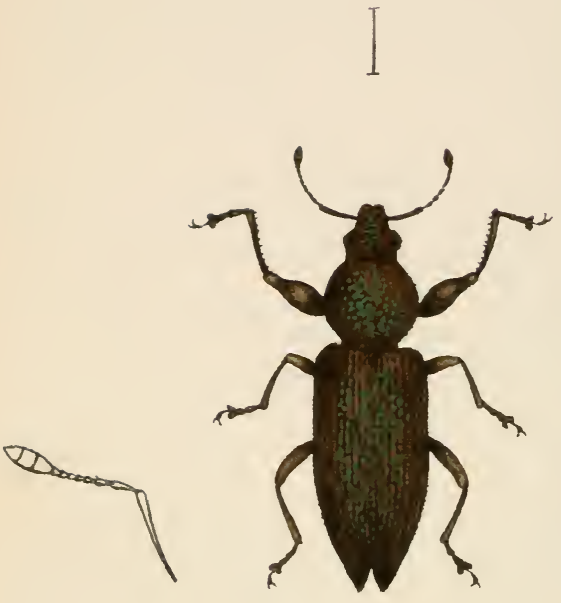

P) Prompterues armminated. 


\section{MACROP'TERLS Boheman.}

Corpus elongatum.

Caput rostro nomihil latius, vix eo brevius, oculis rolundatis.

Rostrum crassum, breve, aque altum af latum.

Ancence canalicula curvala, infra oculum llesa inserta, ad thoracis basin haud pertingentes, satis tenues: scapo funculum longitudine aquante, funiculi articulis primo tougiuseulo, validiusculo, secundoque illo breviore, angustiore obconicis, reliquis brevibus ; clava majuscula, oblongoovali, q-articulata.

Thorax laitudine media vis longior, lateribus rotundaloampliatus, antice posticeque Iruneatus, basi marginatus.

Scutellum apice rotundatum.

Pedes antici elongati, lemore incrassato, libia modice curvata, intus spinulis munita, reliqui mediocres, omnium femore mutico.

Elytraeum thoracis basi duplo latius, eoque plus ter longius.

Elytra posterius attenuata, anum obtegentia, apice mucronala aut rotundata.

fióper gelitredt.

Fopf etwas breiter als ber Ritilel, faum etwas turger als Diefer, mat gerundeten $\mathbb{A}$ ugen

औüfel biat, turg, fo boch als breit.

T) cingefügt, nicht bis nn Dic Sutrgel des Mittelleibsfillides reichend, fienlich Dünn; Der Echait fo lnng als dic (Sciffal, von Den Gerfelgliedern Das erite längliche und etwas frät tige umb ons fürgere, fommälere, gweite verfelortteglig, Die librigen turz; Die Geule giemlich grof́, länglid) ciförmig, viergliedig.

Mittelleibsfal to taum linger als die mittlere Breite, an den Eeiten gerumbet und erweitert, vorn und hinten nbgeltukt, an Der

Gdilochen an ber Enize gerumbet.

Zorderfte 3 eine verlängert, mit verdittem Echentel,

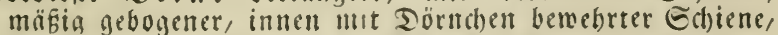
Die übrigen mittelgrof́, oer Echentel nller unbenebrt.

Deatentheil Doppelt briter als die 23 urfel Des Mittel letbsfdildes :illo mebr nls oreifuch länger als diefer.

F lïgeldeden binten verfamälert, den affer bededtend, an Der Gvize mit einer Gtad)elfpize oder gerundet.

\section{MACROP'TERUS ACUMINATUS.}

schönh. Fien. el sil. Curc. T. VI. pag. 421.

Palria: Brusilia. 




\section{57}
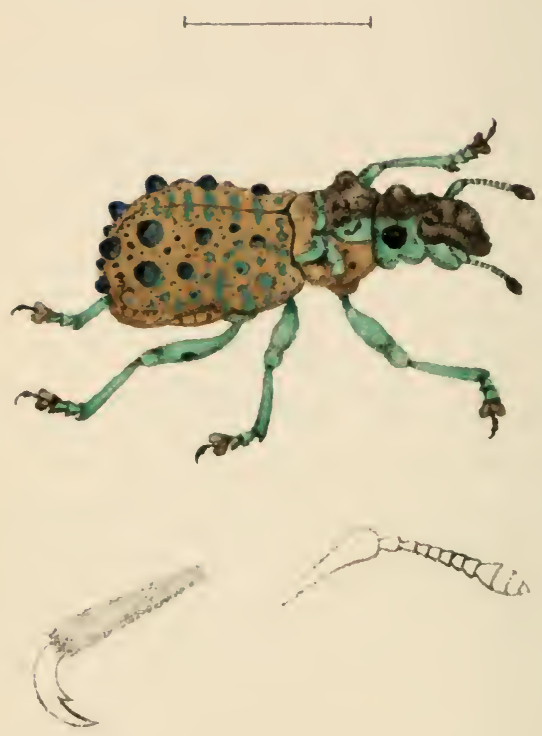

Holmychus acanthopus 


\section{HOLONYCIILS Schh.}

Corpus pingue, rude, tuberculosum, apterum.

Capue rostro brevius, transversmm, oculis prominentibus, semi-globosis.

Rostre mibcubicum, apice crassiori, supra inaquale el linea impersa transversa a rapite discretum.

Antemae caulicula profunda, valde curvata, ad basin rostri sublus liexa inserta, rostro nomnihil longiores, scapo valde clavato, flagelli articulis primo et secundo breviter obconicis, reliquis brevioribus, sublentieularibus, arete inter se connexis, clava oblongo-ovata, minus distincte k-articulata.

Thorax capite simul cum rostro sumto non longior, oblongus, basi apiceque truncatus.

Scutellum vix conspicum, sub-elevatum.

Pedes robusti, satis longi, mutici, larso lato, uni-unguiculato, unguiculo latere versus basiu fisso.

Elytrueum plus duplo lhorace longius, obovatum, postice subretusum.

Elytra margine inllexo, medio sinuato, apice conjumetim rotundata.

forper plump, raub, bödferig, ungetügelt.

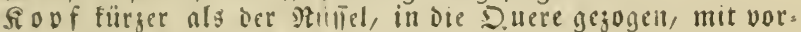
ragenden balbfunligen ?t u ge 11 .

$\Re$ iffel falt murfelformig, mit Diderm 23orberenie, oben uniben und ourd) eine eingedrütte Duerlme vom sopie nbgegrenit.

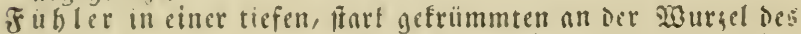
Riijels nad) unten gebouenen Rinne eingefïgt, etions län=

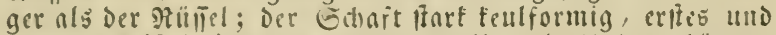

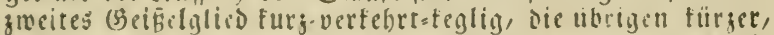
fatt linienformis, ena unter cinnnder verbunden, Sicule länglich cirund, giemlid) undeutlich 4, liebion.

Mitclletbsidild nicht linger als fopf fammt Rülifel, länglich, am Vorber แub Sinterende abicfingt.

$\sigma$ (b) ilo d)en taum bemertbir, etmas erbobelt.

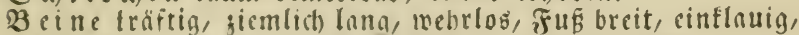
Die filaue jur Eette nach Der 3 surgel biu gefpalten.

Dedentbeil melr als Dopuelt fo lang als Der Mittelleibs: fit)ild, berfebrt ciformig, binten fapt nbigefitubt.

F lügeloe de en mit eingebogenem, in ber Mrite cingebuchte= tem Ecitenrande, am (Ende gencinfit)aftlid) gerumbet.

\section{HOLONYCHUS ACANTHOPLS.}

(Schönh. Gen et Sp. Curc. T. V. p. 835)

Secundum specimen a C.I. Melly, An to, mihi lransmissum.

Palria: Madagascar. 



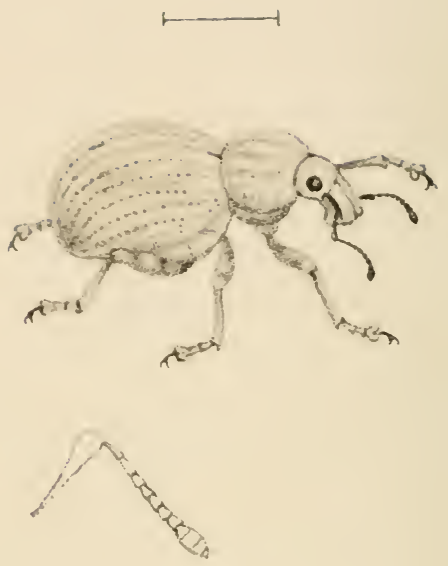

Drosecphalodercos punstiprons 


\section{PROSCEPHALADERES Schh.}

Corpus convexum, aplerum.

Caput transversum, rostro haud longius, oculis rotundatis.

Rostrum fere aque latum ac longum, supra sub-planum, linea transversa impressa a capite discretum, versus apicem nonnihil angustatum.

Anennae canalicula augusta, curvata, ante oculum desinenti inserta, rostro duplo longiores, satis teuurs; articulis funiculi primo et secundo longiusculis, sub-ohconicis, hoc quam illo nomnitil longiore, sequentibus hrevissime obconicis, ultimis glohosis; clava oblongo ovali.

Thorax latior quam longior, lateribus ampliato-rotundalus, supra convexiusculus, basi marginatus, angulis prominulis, ante marginem constrictus.

Scufellum parvum, triaugulare.

Pedes mediocres, tihiis anticis intus subtilius crenatis.

Elytraeum sub-globoso-ovatum, in femina thorace duplo latius.

Elycra hasi truncata, a thorace distinctius sejuncta.

Rorper gemölbt, ungeflïgelt.

Rovf in Dic D.uere nusgedebnt, nicht länger als Der Rüflel, mit gerunderen it uge

Rüffel faft ebenfo breit als lang, oben jicmlich fach, bur(h) cine quere emgebrüdte seinic vom fopfe nbgegrenjt, gegen bng Borderende etmas verfdimallert.

Fs tibler in einet engen, gebogenen, vor den Augen aufbö. renden Rinne eituciugt, Dopyelt länger nls der Ruffil,

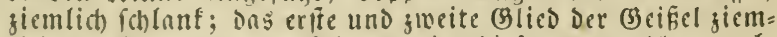
lich länglich, etwas verfehrt:feglig, Diefes ctmas länger als jenes, oie folgenden felse furfuverfebrtefeglig, bie lekgren fuglig; die fieule länglich) oval.

Witt lleibsichild breiter als lang, an ben Eeiten ermei= tert=gerundet, oben ziemlich nemölbt, an ber sisurgel gerandet mit etmas vorforingenden Eden, vor Dem Rande cinaef(t) nürt.

Schilochen fleit, orciedtig.

Beine mittelgrob́, bie vorderiten Edienen inmendig fein geferbt.

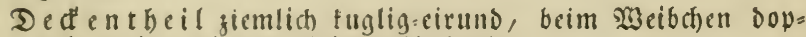
velt breiter alo Der Mlittelleibsichills.

Flügelde afen an Der 23 urgel abgelitutht, vom Mittelleibs: f(t)ild beutlid) nef(t)ieden.

\section{PROSCEPHALADERES PUNCTIFRONS.}

Schönh. Gen. et Sp. Cure. T. V. p. 894.)

Patria: Port-Natal Africa. 


11. 59

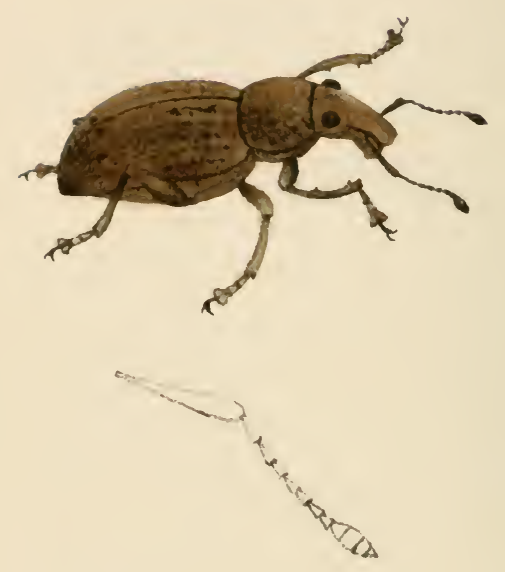

Bhyfsocarpuo squalidno 


\section{RHYSSOCARPUS Schh.}

Corpus oblongum, apterum.

Capue transversum, rostro lalius et saltem duplo brevius, oculis prominulis, rolundatis.

Rostrum angulatum, mandibulis an modo in uno sexu?) exsertis.

Antennae canali satis profunda, curvala, ante oculum latius desinenli insentae, rostro plus duplo longiores, sub-tenues, articulis funiculi sub-obconicis, ullimis quam prioribus brevioribus, clava oblongro-ovali, apice acuminala.

Thorax parum Jongior quam latior, apice et basi truncatus, lateribus ante medium nommihil rotumbato-ampliatus.

Scutellum minutum, rotumalum.

Pedes mediocres, antici elongati, posteriorum tihia recta, apice unco parvo instructa, anticorum libia compressa, llexuosa el (an modo in uno sexu?) intus Iridenlata.

Elytraeum thorace ter longius.

Elytra dorso subdepressa, callo postico iustructa.

fiorver lïnglich, magellügelt.

Rovf in die D.uere nusgedibut, bretter und wenigftens dopdelt furger als Det Rü̈liel, mit etmas vorragenden, gerundeten ?l $\mathrm{lg} \mathrm{g} \mathrm{n}$.

Ruffel fantig, mit (ob nur in cinem (Scfd)lecte? ) vorrn= genden Doortiefern.

F abler in cince tiefen, gebogenen, vor Dem Auge breiter nuslaufinoci Rinne eingefugt, mebr als dovpelt lïnger uls Der Ruilel, etmas íd)lant, Die GeiBelglieder falt vertehrt= feglig, die äuberfin turger als die atn fingsglieder, die fieule länglid)=oval, ant Ende jugefpizt.

Mittelleibsfdilo mentig länger als breit, am 2 order. und Sinterende abiseltubt, nn Den Eetten vor Der Mitte gerundet ermeitelt.

G(t)ild chen flein, gerundet.

Beine mittelgrofi, die vorderfen verlängert, nn den bintern die Echlene gerade, nm Ende mit emem fleinen Sonden verieben, Die $\Xi$ chiene Der vorderiten jufammengeorïdt, ge= f(b) ungen und (ob nur in eitrem (Sefblichte?) inmärts Dreisabnig.

De de $\mathrm{nt}$ beil breimal länger nls oer Mittelletbsfchild. Flïgeldedten nuf Dem Rü̈tell etmas flad)georüd, mit einer bintern Gdurele verfoben.

\section{RHYSSOCARPUS SQL $\triangle L I I) U S$.}

(Schöuh. Gen. et Sp. Curc. T. V. p. 810 et T. I. P. 505.)

latria: Nova Hollandia. 

fint

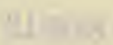




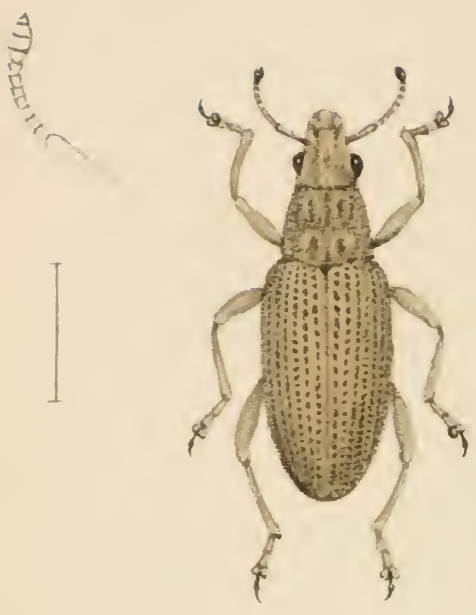

Atmetonychew peregrinus 


\section{ATMETONYCHUS Schh:}

Corpus elongatum.

Caput transversum, oculis semi-globosis, prominentibus. Rostrum nonnihul longius quam latius, capite parmu angustius. Antennat caualicula angusla, curvata, ante oculum sublus flexa inserta, rostro nomnihil longiores, validiuscula ; scapo tertiam fere lotius antenux parlem aquante; flagelli articulis primo el secundo brevissime sub-obconicis, reliquis brevioribus, sub-lurbinatis, satis arcle inter se connexis, ultimo a clava discreto; clava oblongo-ovata, acuminata, 4-articulata, articulis arcte inter se conjunctis.

Thorax latitudine baseos vix longior, antrorsum nonnihil angustatus.

Scutcllum parvum.

Pedes mediocres, tarso satis angusto, parrius setoso, subtus utrinque spongioso, uniunguiculato, unguiculo integro.

Elytraeum thorace triplo circiter longius.

Elytra apice attenuata, singulatim in mucronem brevem desinentia.

fiöper langgezogen.

Sovf in bie D.uere auggedehnt, mit balbtugligen, vorragen= Den $\mathscr{U} u g e n$.

Rüffel etmas länger als breit, wenig fdomäler nls der fiopf.

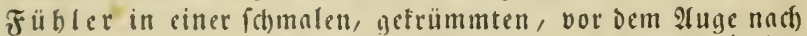
unten gebogenen Rinne cingefigt; etmas länger als Der Riliel, jicmlich fräftia; ihr Gchaft oen ortten 2 beil der ganien Trublerlänge beinabe betragend, erfites uno gneites Seifelglies febr turg, falt verte:rtseglig, die ïbrigen für= zer, faft freifelform:a, jiemlich fatt aneinnmoer georängt, Dns lebte von Der fieule unterficieden; die feule länglich. eiformig, gugefvikt, 4 gliedrig, die slieder enge unterein= ander verbunden.

Mittelleibsfifilo faum länger nls Die wargelbreite, nac) vorn etmas verfinmälert.

G(t) ilo (b)en flein.

Be ine mittelgrof, Der TruÉ siemlich fdomal, fuarfam bor fitnbanria, unten beiderfeits formammig, eintlauig, die filnue unbetbeilt.

Dedtentbeil ungefïbr oreimal länger als Der Mittelleibs= ftill.

Flügel oedten am Ende verfdymälert; eingeln in cine furge Evike endigend.

\section{ATMETONYCHUS PEREGRINUS.}

(Schönh. Gen. et Spec. Curc. T. V1. p. 214.)

Patria: Indiu orientalis. 

$\checkmark$

$41=1 \times 14$ 
II. 61
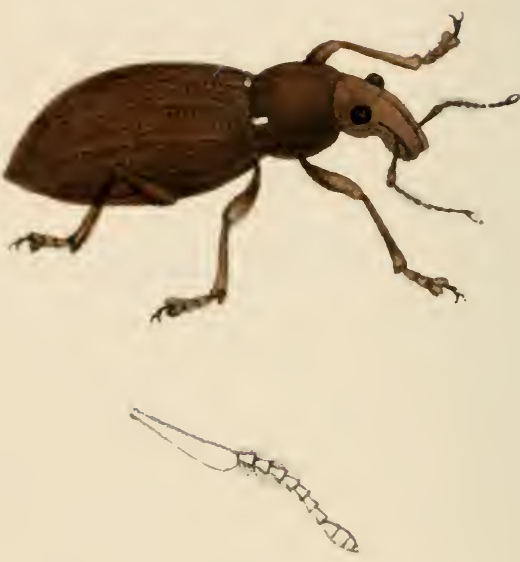

megalortyles Renggeri 


\section{MEGALOSTYYLS Schh.}

Corpus sub-ellipticum, alatum.

Caput rosiro paulo latius, oculis prominentibus, sub-rotundatis.

Rostrum vis longius quam latius.

Antennae canalicula lata, parum profundæe a medio rostro ad oculi uarginem inferum ducta inserta, rostro ter longiores, satis valide; seapo tlagelli longitudinem aquante, clavato, llagelli articulis breviter obconicis, tribus primis ceteris majoribus, clava angusta oblongo-ovata, acuminata, 4-articulata.

Thorax latior quam lougior, antrorsum angustatus, postice bisinuatus et utrinque acute angulatus.

Scutellum triangulare.

Pedes validiusculi.

Elyeraeum oblongo-ovatum.

Elytra basi rotundata, humeris prominentia, apice sensim declivia et conjunctim rotundata.

forver ziemlıch elliptif(d), gefliügelt.

fo v f ein menig breiter als Der Ruifel, mit vorragenden, ziemlich acrundeten $\mathfrak{A}$ u $\mathfrak{g}$ en.

$\Re$ iiffel tium länger als breit.

Fubler in einer breiten, menin ticfen, von Der Mitte des Priliels bis zur untern alugentante laufenden Rinne cinge=

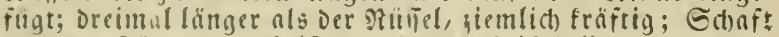
von der \&änge Der Geif́cl, geteult, Geifelglieder fur, ver. febrt=feglia, die orei eriten groser als die tibrigen, fieule fdomal länglids=eiformig, zugefwibt, 4gliedrig.

Mittelleibsfd)ilo länger als breit, nad) vorn verfdamä. lert, binten ; meibudig und betierfeits fpibedtig.

S d) $i$ ( D d) en Dreiedrig.

23) eine jtemlich fräftig.

De á ent beil länglith)=ciforma.

Flïgeldeden an ber 23 urgel gerumbet, nu ben Edultern vorragend, am Ende allmälig abfoüfiig uno gemeinichaft. (ich) gerundet.

\section{MEGALOSTYLUS RENGGERI.}

Antennis medio sub-hirtis, piceo-niger, scutello punctisque duobus basalibus thoracis albo-squamosis, elytris striato-punctatis, striarum interstitiis angustis, planiusculis, tribus convexioribus.

Patria: Paraguuy, provincia lmeris meridionalis. 


$$
1
$$




\section{Fam. BRACHYDERIDES.}

\section{CYPHLS Schh.}

Corpus elongato-ovatum, alatum.

Capuf rostro paulo latius, oculis prominentibus, sub-rotun datis.

Rostrum supra planum.

Incennue canalicula curvata, ad apicem rostri incipienti et latius juxta oculum excurreuti insertie, valida aut validiuscula, tertiam corporis partem fere aquantes, scapo quam flagello breviore, flagelli articulo secundo elongato, sequentibus articulis in aliis speciebus longiusculis, sub-obconicis, il aliis brevissime obconicis; clava oblongo-ovata, acuminata, 4-articulata.

Thorax postice bisinuatus, antice angustior, truncatus.

Scutellum immersum.

Pedes mutici, mediocres, antici in nonnullis speciebus elongati.

Elytraeum oblongo-ovatum.

Elytra basi rotundata, huneris prominentia.

Rörver länglichselförmis, geflugelt.

Ropf menig breiter als der Rülfel, mit vorragenden, ziem= lic) gerundeten 2 u gen.

$\Re$ üffel oben flach.

F्s übler in einer gebogenen, an Der Evike des Rüffels beo ginnenden und breiter neben Dem Iuge auslaufenden Rinne eingefügt, fräftig ober ziemlich träftig, Den oritten Theil Der Forperlänge betragend; Der Echaft fürier als die $(5 e i=$ Ëel, zweites Beifelglied langgezogen, Die folgenden BSlie= Der bei Den einen Arten länglich, fiemlid) verfebrtfeglig, bei andern febr furz verfebrt=teglig; die fieule länglid $=$ et = förmig, zugefpist, 4gliedrig.

Mittelleibafdil o binten zmeibuct)tig, vorn fonmaler, gerade abgefítut.

Sthilod)e n eingefent.

Beine unbemebrt, mittelgrofi, die vorderfen bei einigen Arten verlängert.

Deatentbei ! länglit(b)=eiförmig.

F lügeldeden an ber Murgel gerundet, an ben Gdultern vorragent. 



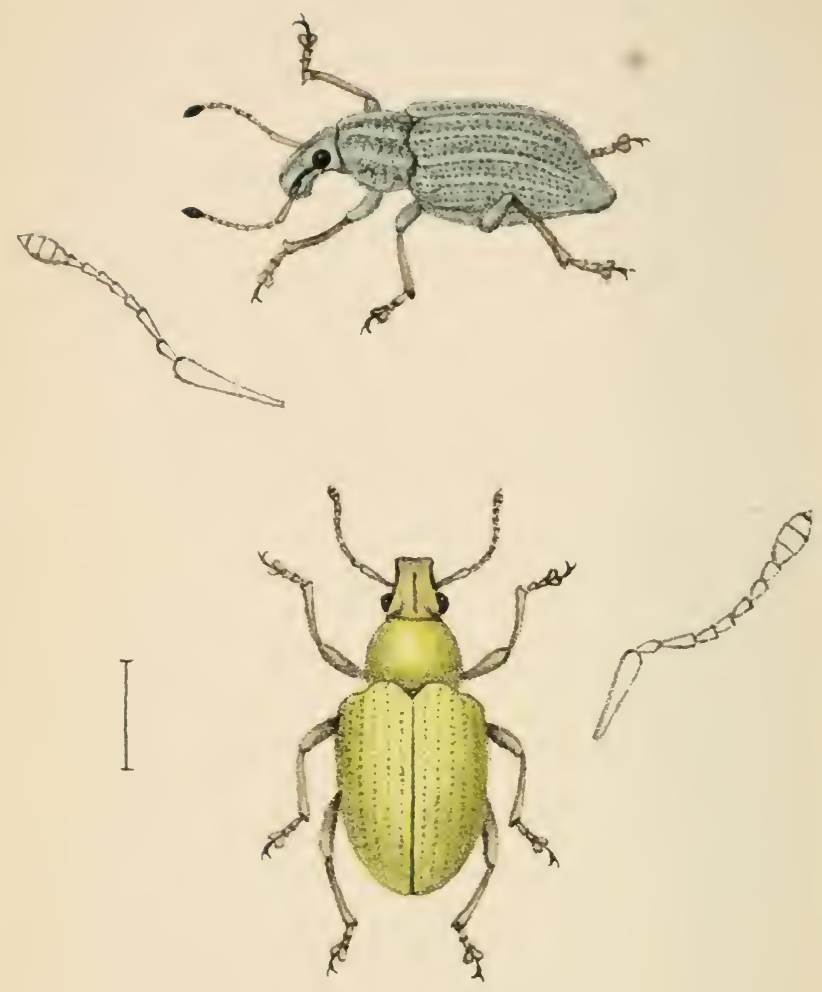

Cyptuer gibber \& C. juvencus 

11. 63
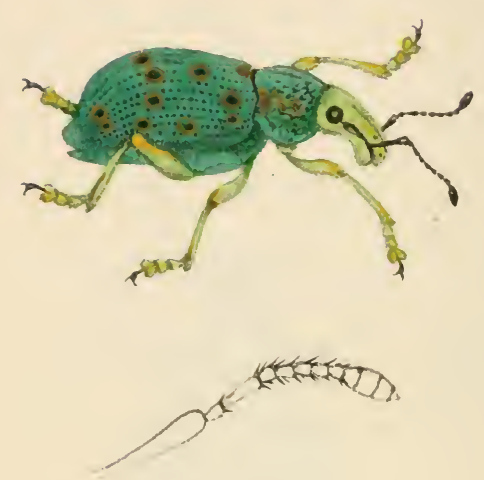

Cyphus Cermari 

11. 64

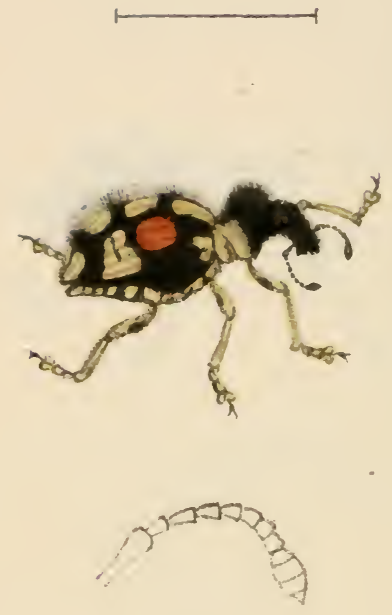

Cyphus Linnei 


\section{Fam. BRACHYDERIDES. II. 62.63.64.}

\section{CYPHES Schh.}

\section{STIRPS I.}

Thorax aut medio longitudinaliter deptanatus vel excavatus, utringue oblique derlivis, aut sub-convexus.

\section{Errte Abtheilung.}

Mittelleibsichild entweder in ber Mitte ber eñnge nach bald abgeflact)t, bald ausigetiolt, nach Der Eeite bin f(t)rigg nbichilfíg, ober etiras geroülbt.

\section{CYPHLS GIBBER.}

(Schönh. Gen et sp. Curc. T. I. 1. 6.2 el T. VI. p. 141.)

Patria: Brasilia.

\section{CYPHUS JUVENCUS.}

(Schönh. libro it. T. I. p. 623 et T. VI. p. 145.)

Patria: Cayenna.

\section{CYPHUS GERMARI.}

(Schönh. libro cit. T. I. p. 627 et T. VI. p. 149.)

Patria: Brasilia.

\section{STIRPS II.}

Thorax transverse valde convexus, postice constrictus.

\section{Bmeite Abthrilung.}

Mittelleibofth 110 in Die Daere fintt gemolbt, binten zufammenicjogen

\section{CYPHUS LINNAEI.}

(Schönh. libr. cit. T. I. p. 629 et T. VI. p. 153.)

\section{Patria: Brasilia.}





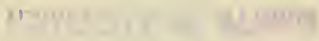


II. 6.5
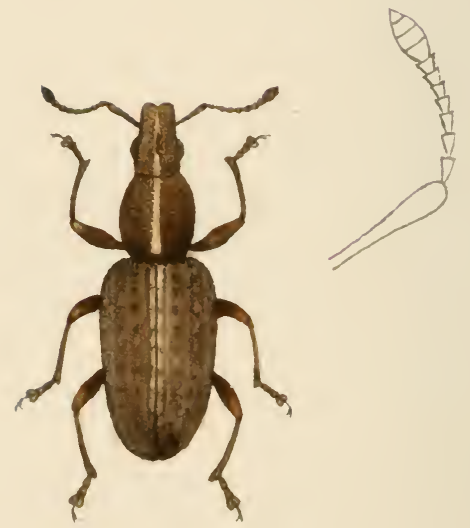

Sitones grivers 


\section{SITONES Schli.}

Corpus elongatum.

Caput haud latius quam longius, oculis aut sub-rotundatis aut oblougis.

Rostrum capite vix angustius nec eo longius, supra apice enıarginalum.

Antennae caualicula curvatx, sub oculum flexa, inserta, capite simul cum rostro paulo longiores, seapo flagelli dimidian longitudinem superante, flagelli articulo primo subelongato el secundo breviore obconicis, reliquis subglobosis, brevibus; clava elongato-ovali, distincte -articulata.

Thorax elytraeo ter brevior, lateribus rotundatus, basi apiceque truncalus.

Scutellum rolundatum.

Pedes inutici.

Elytraeum oblongum.

Elytra apice conjunclim rotuudata.

forper getifedt.

R op i nidit breiter als lang, entmeder mut etwas gerundeten oder länglici)en $\mathbb{Q} \| \mathrm{g}$ e $\|$.

Rüffel taum f(t)mäler nls oer fiovf, und nid)t länger als dicier, oben am Ende nusigernndet.

F Rinne cingefugt, cin menib länger nls Der fiobf mit bem

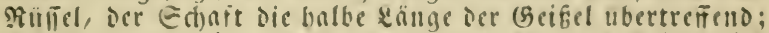

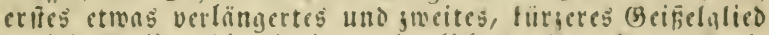
verfebrtieglig, die übrigen gicmlid luglig, turg; sieule geleredt ciformig, Deutlich 4glicoin.

Mittelleibsid) il oreifach furger nls oer Dedfentbeil, an Den Eeiten gerunoet, nn Sinter = und 2 borderende nbgelimbt. Schilo dien gerundet.

3 eine mebrlos.

De atentheil langlith.

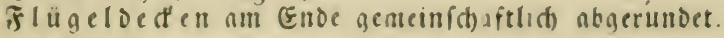

\section{SITONES GRISEUS.}

(Schönh. Gen. el sp. Cure. T. II. p. 98 el T. VI. p. 255.)

Patria: Europa meridionalis el intermedia. 



$$
x^{x}=0
$$

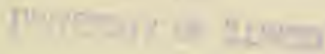




\section{60}
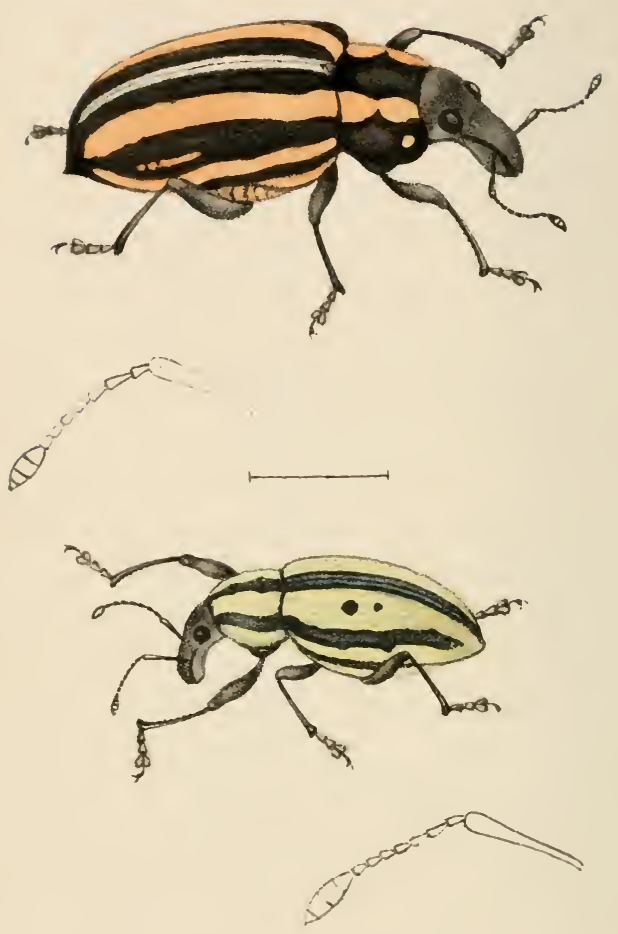

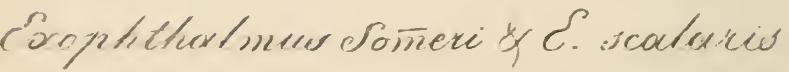




\section{EXOPHTHALMUS Schh.}

Corpus elongatum.

Caput supra planiusculum, oculis sub-rotundatis.

Rostrum capite longius, planiusculum, apice declive lateque emarginatum.

Antemae in canalicula curvata sensim subtus flexa, versus oculi canthum infermm directa inserłæ, mediocres, flagelli articulis prioribus sub-obconicis, reliquis sub-turbinatis, clava oblongo-ovala, acuminata.

Thorax latitudine baseos brevior, a medio latere ad apicem modice angustatus, basi bisinuatus.

Scutellum versus basin thoracis declive.

Pedes longiusculi.

Elytraeum oblongo-ovatum, thoracis basi duplo latins.

Elytra supra modice couvexa, basi rotundato-producta, ad humerum obluse angulata, apice acuminata.

Siorper geffredt.

So vf obea ficmlich fad), mit etmas gerunbeten 2 ugen.

$\mathfrak{R}$ üffel länger hls oer fiolf, etwas fach), am Ende abs fithifig uno breit ausgerander.

F iibler in einer gefrümmten, allmälig abwärts gebogenen, gegen Den untern 2 dugenwintel gerichteten Ninne cinge: fügt, mittrllatty, bie erftern (seiffelalieder ziemlich ver:

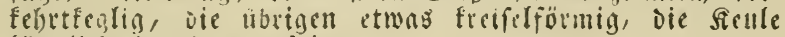
länglich=cirund, zugeipikt.

Ditelletts fhits fürjer als bie Breite Der 3 Burgel, von Der Ecitenmitte bis nats 2 orberende mäbig verfamálert, an Der 23 urgel fweibudtig.

Schild che n gegen bie Murgel Des Mittelleibsfdilloes ab= foürifa.

23 e in e etwas länglich.

Ded ent the il länglicl)=eiruno, Doppelt breiter als bie Burgel des Mittelletbiffeildes.

F lügeldeden oben mäsig gemölbt, an ber 2 surgel ge= ruttoet vorgegogen, an Der Schulter fimpfedig, am Ende fugcipibt.

\section{EXOPHTHALMUS SOMMERI.}

Schönh. Gen. et Sp. Curc. T. VI. p. 339.

Patria: Caba.

\section{PREPODES SCALARIS.}

(Schönh. libr. cit. T. VI. p. 349.)

Patria: Cuba.

Obs. Hanc speciem sub genere Exophthalmo nec sub genere Prepode militare judicamus. 



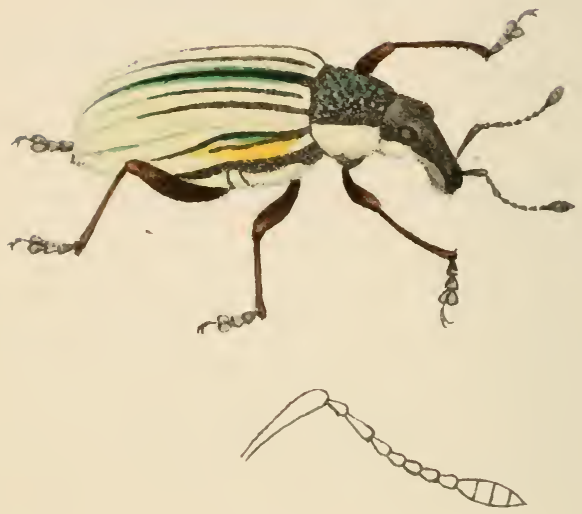

Diaprepes vestivens 


\section{DIAPREPES Schh.}

Corpus elongatum

Caput supra planiusculum, oculis ovatis.

Rostrum caput longitudine saltem requans, supra inaquale, in plerisque tricarinatum.

Antennae canalicula rostri curvata ad oculum pertingenti insertæ, mediocres, llagelli articulis obconicis, excepto secundo, reliquis longiore, subcylindrico; clava oblongo-ovali.

Thorax fere xque longus ac basi latus, antrorsum sensim modice angustatus, basi in aliis truncatus, in aliis subbisinuatus.

Scutellum nonnihil elevatum.

Pedes satis longi.

Elytraeum thoracis basi duplo latius, oblongo-ovatum, supra convexum.

Elytra ad humeros obtuse angulata, nonnihil elevata, apice sub-acuminata.

Sorper gelfredt.

Ropf oben jiemlici) finch), mit etrunden $\mathscr{A}$ ugen.

$\Re$ itfel dem fiopf an Eänge wenigftens gleidf). oben uneben, bei Den meilen arten oreifielig.

Fübler einer gebognen, fum Auge reichenden Rinne ein= gefügt, mittellang, Die Geifelglieder vertebrtfeglig, mit

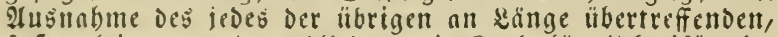
faft walgigen, zmeiten (sliedes ; Die Reule länglich)eciförmig.

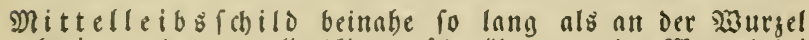
beit, nadt) vorn allmälig verf(t)mälert, an Der 20 urgel bei ben cinen abgelfust, bei den andern etwas giveibuchtig.

Sdil d d en etwas erhöht.

Beine ziemlich lang

Dedentbeil doppelt breiter als de 2 Jurzel bes Mittel= leibfchildes, länglich)=cirund, oben gervölbt.

$\mathfrak{F}$ \ี ge am Ende etmas zugefpibt.

\section{DIAPREPES FESTIVUS.}

(Schönh. Gen. et Sp. Curc. T. II. p. 9 et T. VI. p. 342.)

Patria: America meridionalis. 



$$
y^{2}+x y
$$

we- 


\section{68}
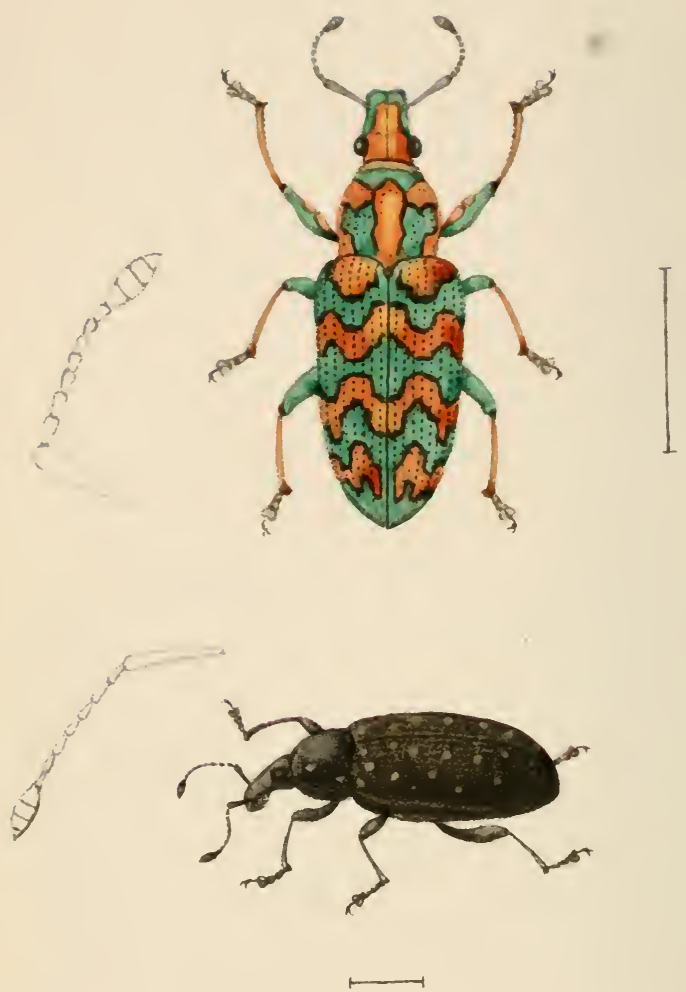

Tetrabothynut spectabilis \&. J.' Auetuouns 


\section{TE'TRABO'THYNUS, Schh.}

Corpus oblongum.

Caput rostro brevius, oculis prominentibus.

Rostrum aque altum ac latum, supra utrinque ante oculos foveola oblonga impressum.

Antennae canalicula curvata, ante oculum latius excurrenti inserta, rostro saltem duplo longiores, flagelli articulis subobconicis, primis duobus quam reliquis nomnihil longioribus, clava oblongo-ovali.

Thorax latitudine baseos saltem non brevior, latere nomnihil amplialo-rotundatus, basin versus minus quam apicem versus angrustatus.

sicutellum rotundatum, elevatum.

l'edes longiusculi.

Elytraeum elongato-ovatum, thoracis basi vix duplo latius.

Elytra ad humerum rotundata, apice acuminata.

So r f per geftredt.

fi opf furger als der Rullel, mit vorragenden $\mathfrak{A}_{\mathfrak{g}}$ en.

औüffel eben fo bod als breit, oben beiberfeits vor den 2lugen mit einem längliden (S)rübeben

F laufenden, rinne eingefugt, mentigfens boppelt fo lang

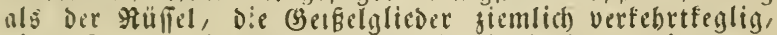
die crifern stoci etmas länger als die übrigen, die fienle länglid)=ciförmig.

Mittelleibof (t)ilo wenigftens nidst fürger als die Breite Der 23 urgel, an ber Seite etmas erweitert gerundet, gegen Die 23 urgel bin weniger als gegen bas 3 orderende bin verfitimälert.

$E$ (h) il (b) ell gerundet, erböbt.

马e ine etmas länalich.

Deat ent beil geltredt cirund, taum ooppelt fo breit als die Murgel des Mittelleibsfdilloes.

Flïgeldedten an ber Gdulter gerundet, am Ende zuge= foibt.

\section{PREPODES SPECTABILIS.}

Schönh. Gen. et Sp. Curc. T. II. p. 25 et T. VI. P. 359.)

Patria: Cuba.

\section{PREPODES LUC'TUOSLS.}

Schönh. libr. cit. T. II. p. 26 et T. VI. P. 360.)

Palria : raba. 


11. 69

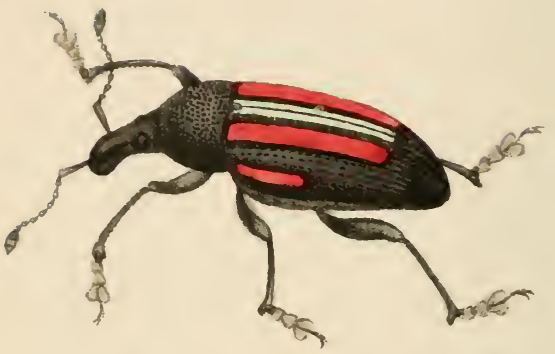

Lrepodes vittatus 


\section{PREPODES Schh. (pro parte.)}

Corpus elongatum.

Caput planiusculum, oculis rotundatis.

Rostrum capile longius, supra sub-planum.

Antennae in canalicula latius ad oculi canthum inferum excurrente inflexæ, mediocres; funiculi articulis primis duobus obconicis, reliquis brevissime obconicis.

Thorax anterius angustior, basi sub-bisinuatus, supra deplanatus. Scutellum apice rotundatum.

Pedes satis validi.

Elytraeum elongato-subquadratum, apice attenuatum, supra parum convexum.

Elytra humeris oblique angulatis.

Rörper geitredt.

Ropf etmas flad), mut gerundeten $\mathfrak{A} u \mathfrak{g e n}$.

Rüfel länger als Der Ropf, oben ziemlidi fact).

Fö üb ler in einer fiemlid) breiten an bem untern 2 tugent= winfel auslaufenden Rinne cingefügt, mittellang; die zmei erfiten (seifielglieder verfehrtfeglig, die übrigen fehr furz. verfebrtfeglig.

Mittelleibsfbild an ber 23 urzel etmas gmeibuchtig, oben abgeflantst.

Sd) illdi) en am Ende gerundet.

Beine ziemlid) fräftig.

Ded"entbeil etwas lainglitb=vieredtig, am Ende verfamä= lert, oben wenig gewölbt.

Flägelded゙en mit fólefwinfligen Schultern.

\section{PREPODES VITTATUS.}

(Schöuh. Gien. et Sp. Curc. T. II. p. 17 et T. VI. p. 348.)

Patria : Jamaica. 



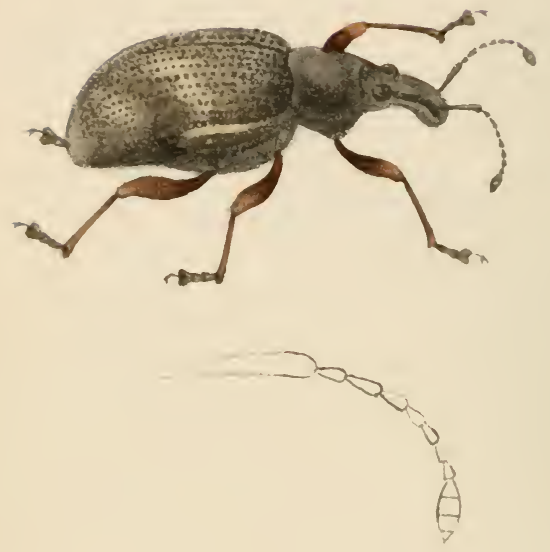

Catamonus mala netrolisuo 


\section{CATAMONUS Schh.}

Corpus oblougo-ovatum.

(apul supra trisulcatum, oculis prominentibus, rotundatis.

Rostrum-capite longius, supra tricarinatum.

Antennae canalicula latæ, parum flexuosæ, oculum attingenti inserta, ad thoracis basin pertingentes, scapo quam rostro nonnihil longiore, flagelli articulis primo, secundo et tertio longiusculis, sequentibus brevioribus, obconicis, clava oblongo-ovali, distincte 4 -articulata.

Thorax brevior quam latior, basi quam ad latera sub-rotundata vix angustiore, bi-sinuata, apice angustatus, supra canaliculatus.

Scutellum minutum.

Pedes mediocres, satis robusti, posticorum femore quam anteriorum validiore.

Elytraeum oblongo-ovatum, basi thorace duplo latius, apice compressum.

Elytra basi rotundato-producta, apice conjunctim sub-rotundata.

Sorper länglid $=$ eirund.

fopf oben Dreifurctig, mit vorragenden, acrundeten 2 a gen.

$\Re$ üffel länger als ber Sevf, oben bretyitielt.

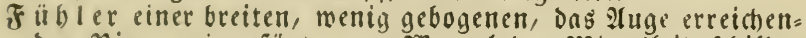

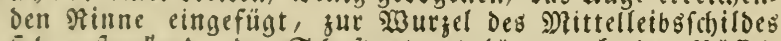

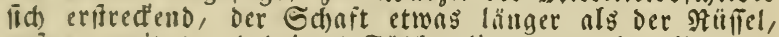
erfes, flocites und orittes fäblerglied etwas länglich), die

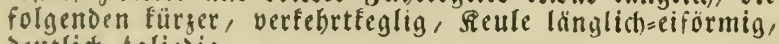
Deutlich 4 gliedig

Mittelleibsfdild fürzer als bret, an Der raurgel faum enger als an ben etmas gerundeten Seiten, zweibuchtig, am 2orberende verengt, oben gerinnt.

S(b) il o d) en flein.

Be ine mittellang, fiemlich fräftig, Sacnfel ber binterifen fraftiger als ber ber vorbern

Dedentbeil länglict)=eirund, an ber $\mathfrak{B}$ urzel boppelt brei. ter als ber Mittelleibsfdrild, am Ende zufanmengedrüdt.

Flügelded"en an der $\mathfrak{B}$ urgel gerundet ermeitert, am Ende gemeinfdaftlich etmas abacruniet.

\section{CATAMONUS MELANCHOLICUS.}

schönh. Gen. ct Sp. Curc. T. VIII. P. II. p. 423.

Patria: Caput bona spei. 



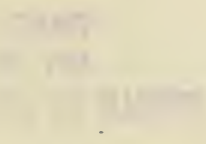



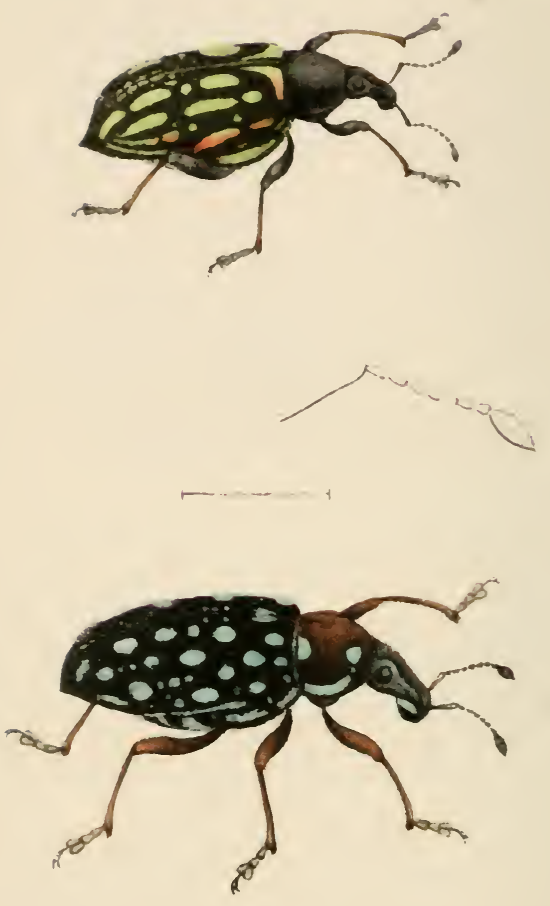

Lachnopus awrifer \& L. argues 


\section{LACHNOPUS Schh. (pro parte.)}

Corpus oblongum.

Caput rostro paulum brevius.

Rostrum sub-teres, oculis prominulis.

Antennae canalicula curvatæ, subtus versus oculum flexæ, insertx, mediocres, funiculi articulis sub-obconicis, apicalibus quam præcedentibus nonnihil brévioribus, clava oblongo-ovali.

Thorax breviter sub-conicus, basi bisinuatus, elytraeo vix vel modo parum angustior, angulis posticis angustis, supra convexus.

Scutellum apice rotundatum.

Pedes elongati.

Elytraeum oblongo-ovatum seu elongatum, supra convexum.

Elytra ad humeros rotundata, apice mucronata; ad suturam in declivie setulosa.

Rörper länglict).

Ropf ein wenig firger als ber Rüffel.

$\Re$ üffel giemlich fiticlrund, mit etwas vorragenden $\{$ ugen. F5 ü b ler einer gefrummten, unten gegen bas 2 uge gebogenen

Rinne eingefügt, mittellang, bie Seif́clglieder etmas ver:

febrtfeglig, Dic endifandigen etmas fürger als bie vorber= gehettden, die feule länglich eiförmig.

Mit telleibafdild etwas furgfeglig, oben gemölbt an ber

Murgel zweibuchtig, faum ober nur wenig enger als ber Dedentheil, die hintern Edten famal.

S(t) $i$ i d (f) en num (Ende gerundet.

3 eine geifredt.

De d" entbe il linglich eirund oder geltredt, oben gemölbt. F⿱ gefvibt; an oer Naht auf Dem abfhuffigen Theil borfen. baarig.

\section{IAACHNOPUS AURIFER.}

Schönh. Gen. et Sp. Curc. T. II. p. 29 et T. VI. p. 380.)

Patria : Jamaica.

\section{LACHNOPUS ARGUS.}

(Schönh. libr. cit. T VIII. P. II. p. 424.)

Patria : Cuba. 



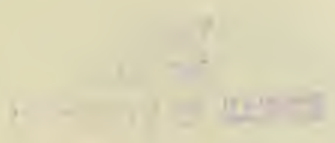

. 
II. $7^{2}$
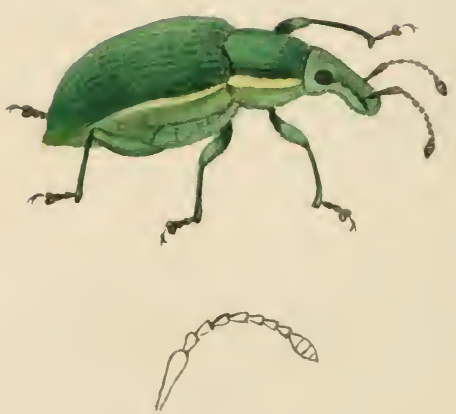

Chlorophanus sibiricus 


\section{Fam. BRACHYDERIDES. II. 72.}

\section{CHLOROPHANUS Dalm.}

Corpus oblongo-ovatum.

Coput latius quan longius, rostro brevius, oculis sub-rotundatis.

Rostrum longius quam latius, supra depressum, carinula media longitudinali instructum, apice emarginatum.

Antennae canalicula parum curvata, ante oculum desinenti, inserta, rostro circiter duplo longiores, scapo vix dimidiam flagelli partem xquante, flagelli articulis obconicis, sensim brevioribus, clava oblongo-ovata, 4-articulata.

Thorax oblongus, basi bi-sinuatus.

Pedes mediocres, antici elongati; tibix anteriores intus curvatæ, apice unco inflexo armatx.

scutellum minutum, triangulare.

Elytraeum thorace ter longius, ovatum, basi thorace duplo fere latius.

Elytra modice convexa, apice mucrone parvo piloso instructa.

Fiorver länglich: etrund.

GODF breiter als lang, fürger als der Ratilel, mit flemlid) gerundeten $1 / \mathrm{g}$ en.

of ulfel länuer als breit, oben niedergeoridet, mit cincm mittlern feinen sängsticl verfeben, am 230 rocrende aus = aerandet.

Jü bler eiller menig gefrümmen, vor Dem stuge aufbörenden Rimne eingefïgt, etma Doppelt fo lang als ber Riuffel; Der Echat faum die balbe entnge der (seifel betragento, die seifelolicder verfefrtfeglig, allmalig fürzer: Die fieule lïnglich)=eirund, 4ulicoig.

Mittelleibsfdilo länglich, an oer Rurgel gucibuctitig. 23 eine mittelgrof, bie vorberifen verlänert; die vorbern Ectienen nad) innen gefrummt, an ber Evißze mit einem eingebogenen Gaden bemaffinet.

Gd) il D(t) en flein, oreiedig.

Dedeutbeil oreimal länger als der Mittelleibsfoild, $c i=$ rund, an oer 23 urgel beinabe dopdelt 10 breit als oet mitrelleibsittilo.

F) lügelocd゙en mn̈fig gemolbt, an der Evize mit einem fleimen barrigen 3 abne verfeben.

\section{CHLOROPHANUS SIBIRICLS.}

(Schönh. Gen. et Sp. Curc. T. II. p. 65 et T. VI. p. 428.) Secundum exemplar a Cel. Schönherr ipso nobis dono datum.

Patria: Sibiria orientalis, Tauria. 


t 



\section{$=t^{2}=8$}

$4-4 x^{2} x-40,00$

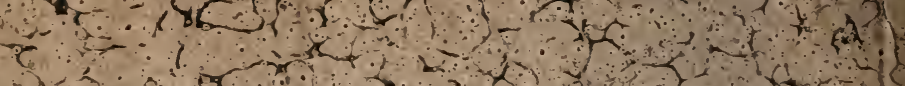

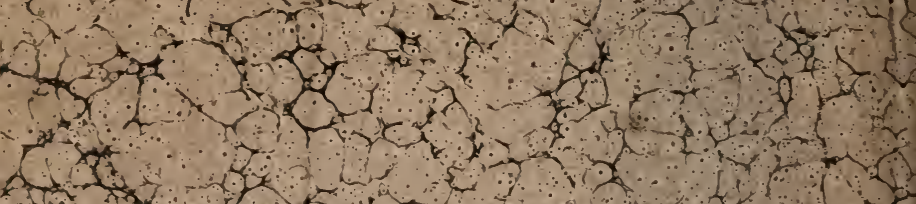

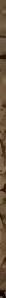
$+x+1+2+2+2$ $4 x+x+2+2 x+1$

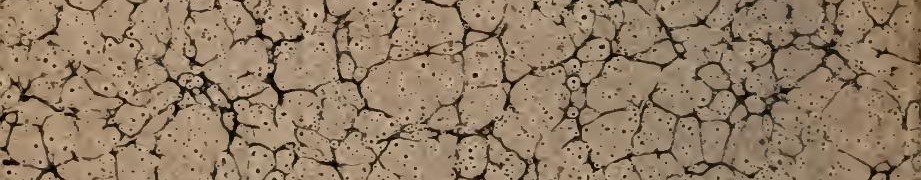

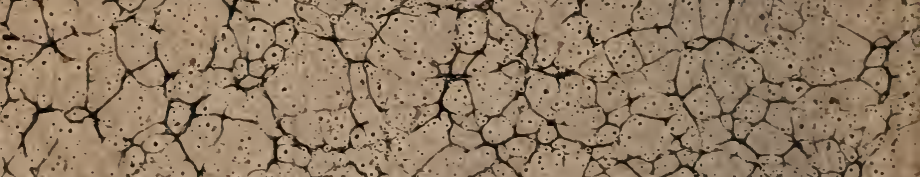

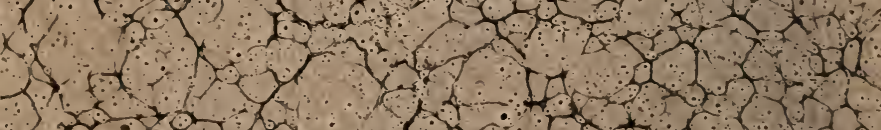

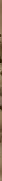
$4 \times-x+40$ $x^{2}+7+1+1$

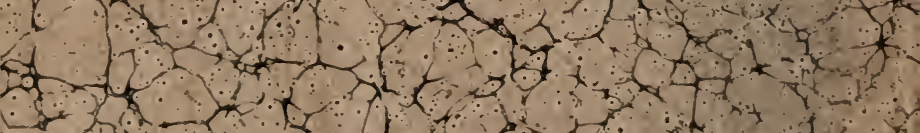
$(x-2-x+2)+x$

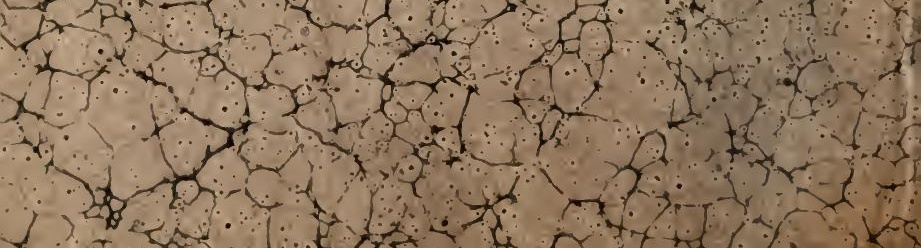


$-200^{2}-2 \times-10$

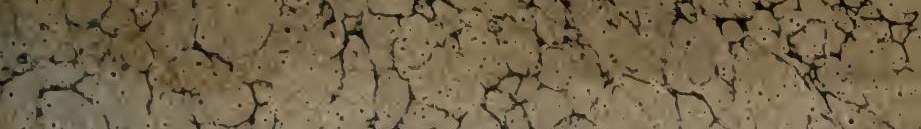
$x+x-2+x+x$

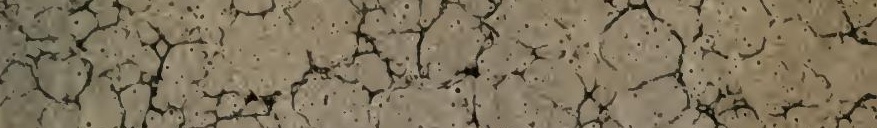
$+4+3 \times+4 x+6$

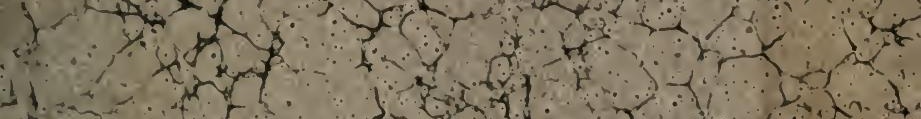

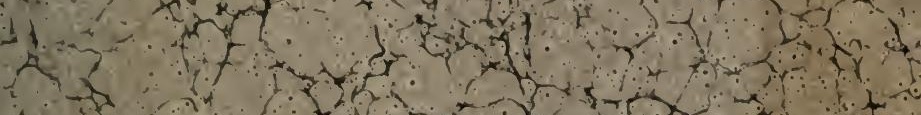
$x+x+x-0,1$

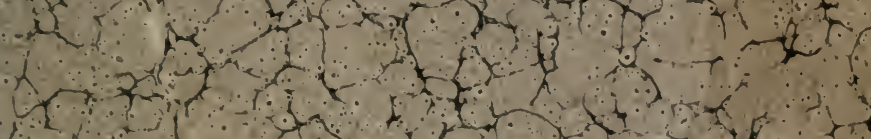
$x-2+4+2 x+4$

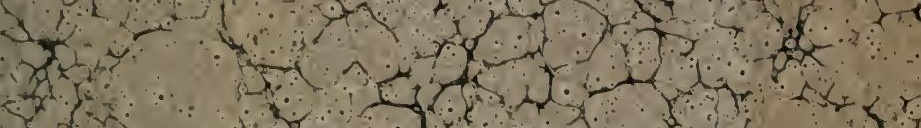

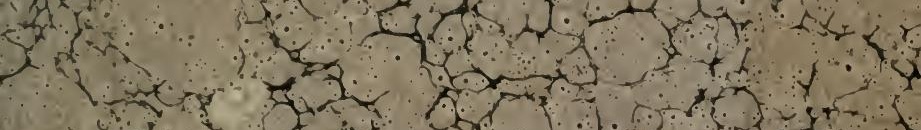

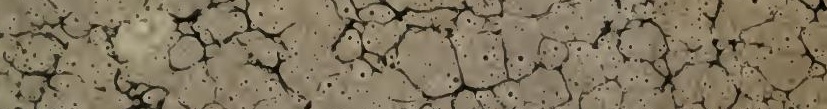
t.

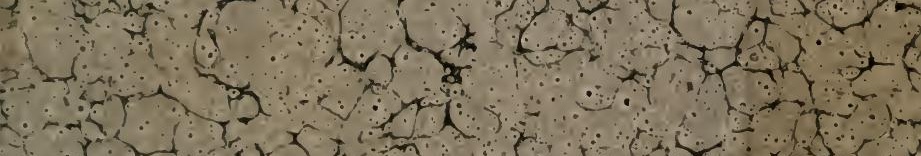
$x-3 x^{2}+2 x+x^{2}$

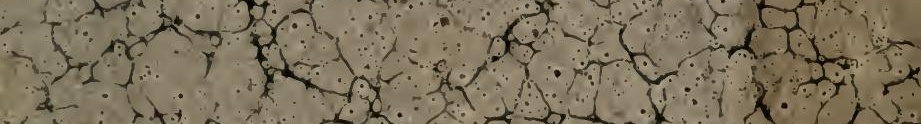

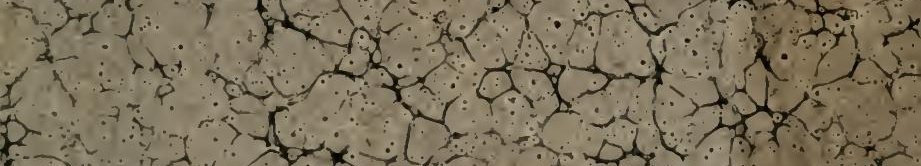
$x^{2}+\mathrm{Nu}-\mathrm{C}=\mathrm{x}$ $(x+2) x+2)=$

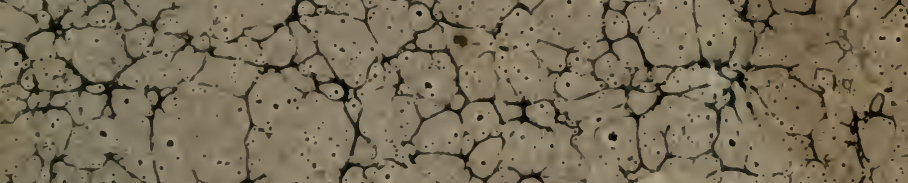

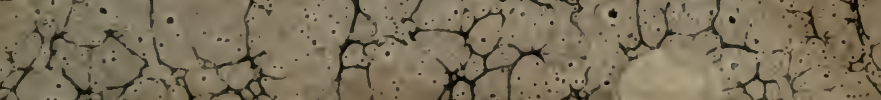

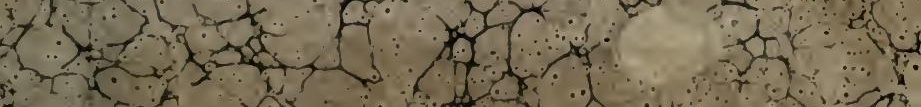

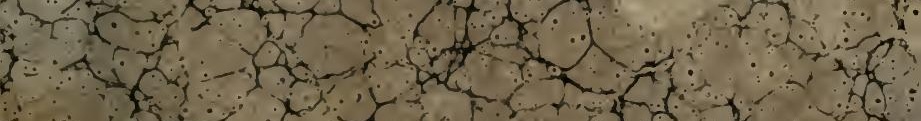

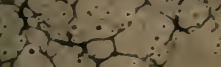
- B.

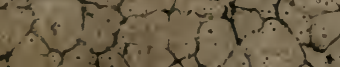


